\title{
Albania: Poverty Reduction Strategy Paper Progress Report
}

Poverty Reduction Strategy Papers (PRSPs) are prepared by member countries in broad consultation with stakeholders and development partners, including the staffs of the World Bank and the IMF. Updated every three years with annual progress reports, they describe the country's macroeconomic, structural, and social policies in support of growth and poverty reduction, as well as associated external financing needs and major sources of financing. This country document for Albania, dated May 8, 2003, is being made available on the IMF website by agreement with the member country as a service to users of the IMF website.

To assist the IMF in evaluating the publication policy, reader comments are invited and may be sent by e-mail to publicationpolicy@imf.org.

Copies of this report are available to the public from

International Monetary Fund $\bullet$ Publication Services

$70019^{\text {th }}$ Street, N.W. • Washington, D.C. 20431

Telephone: (202) 623-7430 • Telefax: (202) 623-7201

E-mail: publications@imf.org・Internet: http://www.imf.org

Price: $\$ 15.00$ a copy

\section{International Monetary Fund \\ Washington, D.C.}



REPUBLIC OF ALBANIA

THE COUNCIL OF MINISTERS

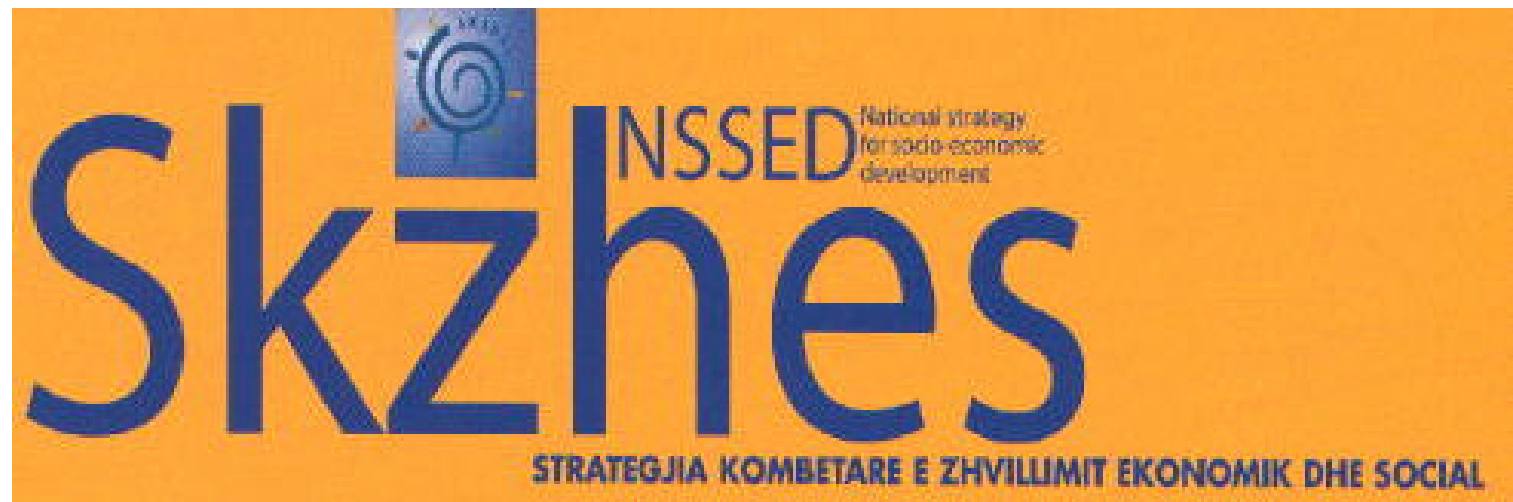

PROGRESS REPORT FOR IMPLEMENTATION 2002, OBJECTIVES AND LONG TERM VISION OF THE NSSED, PRIORITY ACTION PLAN 2003

TIRANA, MAY 8, 2003 


\section{ACKNOWLEDGEMENT}

Considering the dynamic character of the National Strategy for Socio-Economic Development, this document reflects the need to analyze its implementation during 2002, review the mid-term objectives for the period 2003-2006 prepare the priority action plans for this period, and improve the vision and the long-term objectives of the country's development and European integration.

This document is part of a wider effort based on research and analysis, and experiences gained by both state institutions and other interested stakeholders. It was prepared via a transparent process with the participation of interested stakeholders, especially civil society, local communities, the business community, academia, national experts, parliamentarians and at the same was closely followed by the media.

The contents of the document have been discussed with international development partners who support Albania in its efforts to undertake national development and integration reforms.

Considering the overall effort undertaken as difficult and exhaustive, I would like to express my personal and institutional gratitude to all of the stakeholders, public and nonpublic, international development partners and all the experts who contributed with their active participation in the preparation of this document.

Special thanks go to:

- World Bank and DFID, which provided technical and financial support to the preparation of this document;

- Two Albanian Institutions, ISB and ASET, and their team of experts who provided technical assistance in the preparation of this document; and

- The Carter Center and the UNDP for facilitating the organization of the consultations with civil society.

PRIME MINISTER

FATOS NANO 


\section{BACKGROUND TO THE DOCUMENT}

The National Strategy for Socio-Economic Development (NSSED) constitutes the basic document defining the long-term objectives for the socio-economic development of our country as well as the plan of priority public measures to achieve these objectives.

The NSSED has been prepared based on a strengthened analysis of the socio-economic situation and on reforms undertaken over the last 10 years of transition. It is moreover based on the most suitable models for Albanian circumstances including the WB/IMF Poverty Reduction Strategy Paper (PRSP) as well as on a wide and open process of consultations with interested actors from Albanian society, such as civil society, local communities and local government, the business community, the academic community and our international partners.

NSSED implementation is closely connected with the negotiation process of the Stabilization Association Agreement of Albania with the EU. The achievement of the socio-economic objectives defined in the NSSED will constitute a strong base for the gradual and stable achievement of democratic development, the development of a private market and the approximation of Albanian laws with European legislation. Meanwhile, the achievements and medium-term objectives of such a process will be integrated into annual progress reports accompanying the strategy.

The NSSED has also defined some general long-term development objectives in compliance with the Millennium Development Goals.

\section{NSSED - A LIVING DOCUMENT.}

The NSSED is a living document, which will be amended and improved on an ongoing basis. The amendments, improvements and additions are based on:

- Experience gained with the annual implementation process of the priority measures and the concrete analyses of their achievements;

- The increase of monitoring and evaluation capacities;

- In-depth studies and enhanced data collection;

- The reflection and strategic adaptation of fields and sectors targeted by the NSSED;

- Regional integration considerations,

- A wide and open consultative process with interested actors incorporating their concerns.

\section{WHAT DOES THE DOCUMENT PROVIDE}

The document has made possible the analysis of the implementation of public priority measures and the measurement of the degree to which they have been achieved in 2002, the objectives and the program of priority public measures for the medium and long-term periods (2003 to 2006 and over the next 10-15 years) respectively. These have all been developed consistent with European integration requirements and the Millennium Development Goals. 


\section{IMPROVEMENT OF THE LONG-TERM VISION}

The document, by maintaining the basic strategic guidelines, provides an improved long-term outlook based on reliable and realistic analyses. It responds to European integration imperatives and is in accordance with the Millennium Development Goals. It has been based on medium-term economic growthobjectives, on the new poverty profile, and as well as on sectorial strategies already adopted by the NSSED's key sectors. The outlook and long-term objectives have been presented in a special chapter of this document.

\section{PROGRESS ACHIEVED DURING 2002}

2002 was the first year of implementing the NSSED. The implementation process has been oriented towards achieving the annual objectives and in accordance with the program of public priority measures for 2002-2004. The document gives an analytical view of the economic and social developments for the year 2002 and provides in particular detailed and transparent analyses on the implementation of the program of priority public measures for 2002. The progress achieved has been measured according to output, outcome and impact indicators and identifies problems and delays. These analyses have been presented in every chapter of the text of the document, as well as in the matrixes of public priority measures undertaken in 2002 and in the progress indicator tables. Being the first year of NSSED implementation, the effects of the measures and policies undertaken are preliminary. While the monitoring and evaluation systems have been recently established they require further strengthening in order to better asses these effects.

\section{OBJECTIVES AND MEDIUM-TERM PROGRAM OF MEASURES FOR 2003- 2006}

The experience gained in implementing the NSSED in 2002, the implementation of important studies on the factors leading to economic and social development, the improvement of the data bases, the adoption of strategies in key NSSED sectors, as well as the treatment of cross-cutting issues in the NSSED, have made possible the improvement and the extension of some of the objectives for the medium-term period 2003-2006, as well as the program of the public priority measures for 2003-2006, which has been integrated into document. In particular, the document provides:

- A deeper analysis of the factors promoting economic growth, stable macro economic policies and development policies, as well as the medium term objectives of economic growth.

- A deeper analysis, based on international poverty measurements revealed by the 2002 Living Standards Measurement Survey) and on a Study on social problems and the need for Social Services, the document describes the analysis of social problems, social categories at risk and the problems they face, their extent and the underlying factors causing the problems. Based on this, the document provides revised medium-term objectives, improved of poverty-reduction policies and the treatment of social problems.

- Better harmonization as well as a clearer connection with the Medium-Term Expenditure Framework.

The medium-term objectives, policy directions and priority public measures have been presented in the document, as well as in the 2003-2006 priority public measures and in the tables with performance indicators for 2003-2006. 


\section{THE CURRENT STATUS OF THE DOCUMENT}

The preparation of the document has been based on the achievements reported by line ministry monitoring and evaluation unit, the findings of strategic studies and documents drafted by ministries academic and specialized institutions and by civil society and international organizations.

This document was approved by the Council of Ministers on May 8, 2003. 
LIST OF ABBREVIATIONS

\begin{tabular}{|c|c|}
\hline $\begin{array}{l}\text { ABBREVIATIO } \\
\mathbf{N}\end{array}$ & FULL NAME \\
\hline $2 \mathrm{KR}$ & Agricultural Production Growth Project \\
\hline AAATA & Assistance for Albanian Associations of Trade and Agro-Business \\
\hline AAC & Albanian Agro-Business Council \\
\hline $\mathrm{ADF}$ & Albanian Development Fund \\
\hline $\mathrm{AMC}$ & Albanian Mobile Coommunication \\
\hline ANEP & Agricultural National Extension Project \\
\hline ASP & Agricultural Services Project \\
\hline BA & Bank of Albania \\
\hline $\mathrm{CM}$ & Council of Ministers \\
\hline $\mathrm{CSC}$ & Civil Service Committee \\
\hline FDI & Foreign Direct Investment \\
\hline DFID & Department For International Development \\
\hline DoNSSED & Department of National Strategy for Socio-Economic Development \\
\hline DoPA & Department of Public Administration \\
\hline EBRD & European Bank for Reconstruction and Development \\
\hline ERP & Economic Reform Program \\
\hline ESAF 1 & Enhanced Structural Adjustment Facility 1 \\
\hline ESAF 2 & Enhanced Structural Adjustment Facility 2 \\
\hline EU & European Union \\
\hline FYROM & The Former Yugoslav Republic of Macedonia \\
\hline GASS & General Administration of Assistance and Social Services \\
\hline GDP & Gross Domestic Product \\
\hline GFPD & General Forest and Pasture Department \\
\hline GTZ & German Technical Cooperation \\
\hline $\mathrm{HC}$ & Health Center \\
\hline HII & Health Insurance Institute \\
\hline IDA & International Development Agency \\
\hline
\end{tabular}




\begin{tabular}{|c|c|}
\hline IFAD & International Fund for Agricultural Development \\
\hline IFC & International Finance Corporation \\
\hline IFDC & International Fertilizers Development Center \\
\hline IMF & International Monetary Fund \\
\hline INSIG & Insurance Institute \\
\hline INSTAT & Institute of Statistics \\
\hline IPRS & Immovable Property Registration System \\
\hline IPRSP & Interim Poverty Reduction Strategy Paper \\
\hline IT & Information Technology \\
\hline LM & Line Ministries \\
\hline LSMS & Living Standard Measurement Survey \\
\hline MADA & Mountain Area Development Agency \\
\hline MAF & Ministry of Agriculture and Food \\
\hline MAFF & Mountain Area Financing Fund \\
\hline MEn & Ministry of Environment \\
\hline ME & Ministry of Economy \\
\hline MES & Ministry of Education and Science \\
\hline MEU & Monitoring and Evaluation Unit \\
\hline MF & Ministry of Finance \\
\hline MI\&E & Ministry of Industry and Energy \\
\hline MICS & Multiple Indicators Cluster Survey \\
\hline MLGD & Ministry of Local Government and Decentralization \\
\hline MLSA & Ministry of Labor and Social Affairs \\
\hline MTEF & Medium-Term Expenditure Framework \\
\hline NACSG & National Civil Society Advisory Group \\
\hline NCCDR & National Center of Child Rearing, Development and Rehabilitation \\
\hline NFRE & Non-farm Rural Economy \\
\hline NGO & Non-Governmental Organizations \\
\hline NPRC & National Property Restitution Commission \\
\hline
\end{tabular}




\begin{tabular}{|l|l|}
\hline NSSED & National Strategy for Socio-Economic Development \\
\hline PATI & Public Administration Training Institute \\
\hline PHI & Public Health Institute \\
\hline RFF & Rural Finance Fund \\
\hline RTGS & Real Time Gross Settlement \\
\hline SAA & Stabilization Association Agreement \\
\hline SIDA & Swedish International Development Agency \\
\hline SME & Small and Medium Enterprise \\
\hline STD & Sexually Transmitted Diseases \\
\hline TAU & Tirana Agricultural University \\
\hline TRHA & Tirana Regional Health Authority \\
\hline TUHC & Tirana University HospitalCenter \\
\hline UNDP & United Nations Development Program \\
\hline UNICEF & United Nations Children's Fund \\
\hline UPI & Urban Planning Institute \\
\hline USA & United States of America \\
\hline USD & United States Dollar \\
\hline VAT & Value Added Tax \\
\hline VRI & Weterinary Research Institute \\
\hline WB & World Bank \\
\hline WHO & WTO \\
\hline
\end{tabular}




\section{CONTENTS}

A.

A.1 NSSED VISION AND LONG-TERM OBJECTIVES

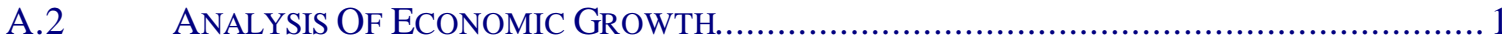

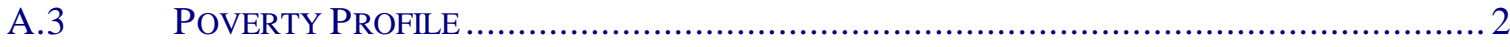

A.4 The IMPLEMENTATION Of PRIORITY PUbliC MEASURES ........................................ 3

A.4.1 INSTITUTIONAL AND GOVERNANCE REFORMS............................................... 3

A.4.2 FinANCIAL AND PRIVATE SECTOR DEVELOPMENT .......................................... 4

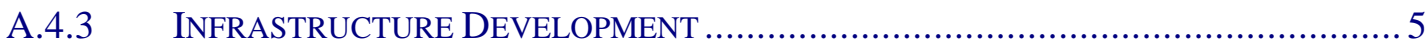

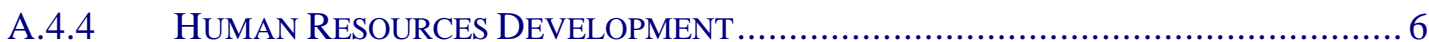

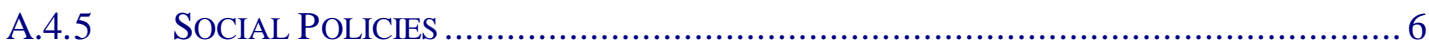

A.4.6 RURAL AND URBAN DEVELOPMENT AND ENVIRONMENTAL PROTECTION .......... 7

A.5 ESTABLISHMENT OF MONITORING AND EVALUATION SYSTEMS............................... 8

A.6 CONSUltation Of THE PROGRESS REPORT ....................................................... 8

B. NSSED vision and longterm objectives......................................................1

C. ANALysis of economic growth.....................................................................1

C.1 2003-2006 MEDIUM TERM OBJECTIVES FOR ECONOMIC GROWTH AND

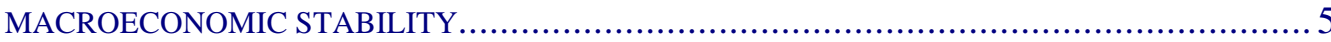

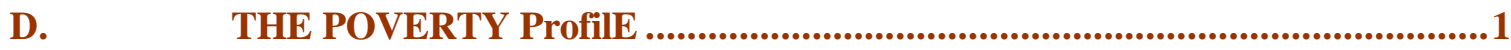

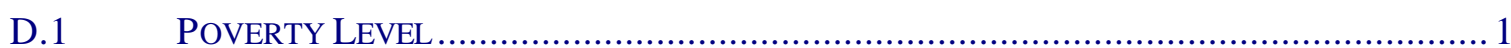

D.1.1 POVERTY AS MEASURED BY INCOME LEVEL AND INEQUALITY ......................... 1

D.1.2 THE EXTENT OF NON-INCOME POVERTY ................................................. 1

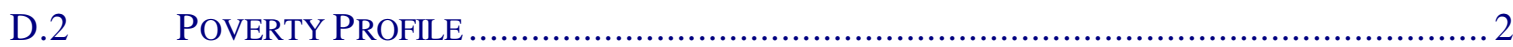

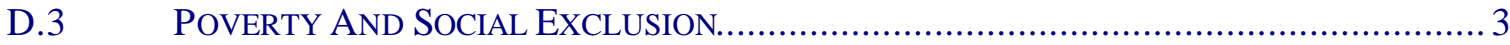

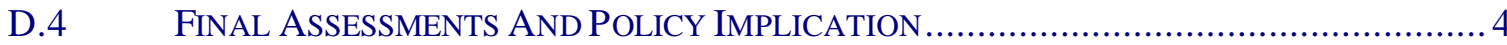

E. IMPLEMENTATION OF POLICIES AND PRIORITY PUBLIC

\section{MEASURES 1}

E.1 INSTITUTIONAL AND THE GOVERNANCE REFORMS ...........................................

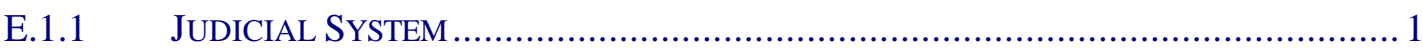

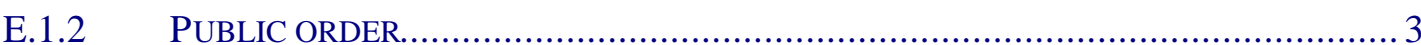

E.1.3 PUBLIC ADMINISTRATION REFORM

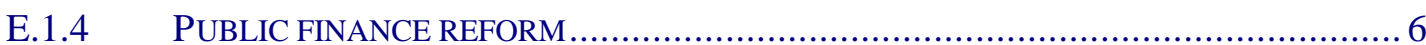

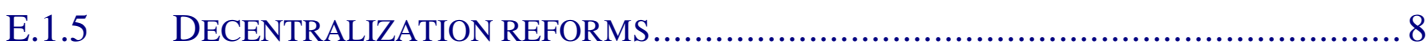

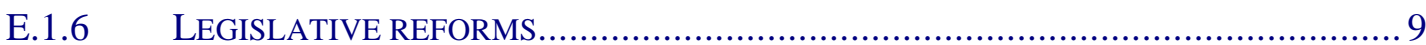

E.1.7 IMPLEMENTATION OF ANTI-CORRUPTION MEASURES .................................... 9

E.2 PRIVATE AND FINANCIAL SECTOR DEVELOPMENT............................................... 10

E.2.1 INSTITUTION CONSOLIDATION AND MARKET FORM ALIZATION........................ 10

E.2.2 PRIVATE ENTREPRENEURSHIP PROMOTION................................................ 11

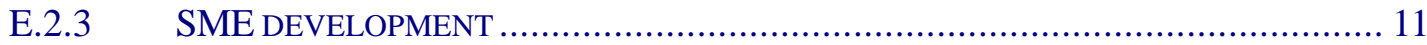

E.2.4 FOREIGN DIRECT INVESTMENT PROMOTION .......................................... 11

E.2.5 TRADE LIBERALIZATION AND EXPORT PROMOTION .................................. 12

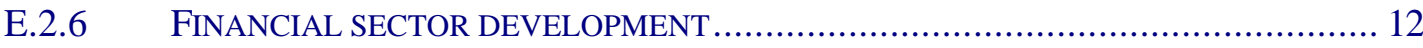

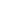

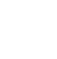
3

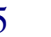

?
8 8 1 1 5

\section{.} 1 2

3

4


E.2.7 THE MEDIUM -TERM PROGRAM FOR FINANCIAL AND PRIVATE SECTOR DEVELOPMENT ...... 14

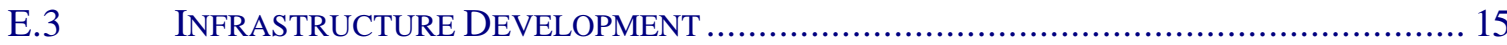

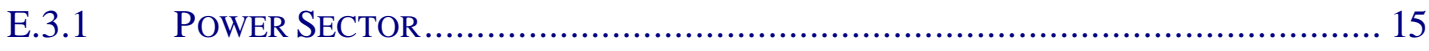

E.3.2 TRANSPORTATION AND TELECOMMUNICATIONS..................................... 17

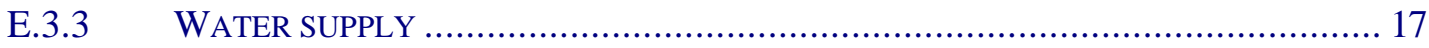

E.4 HUMAN RESOURCES DEVELOPMENT ..................................................... 18

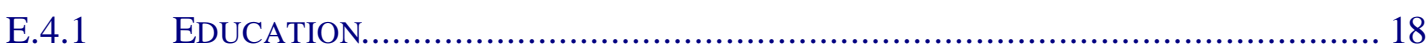

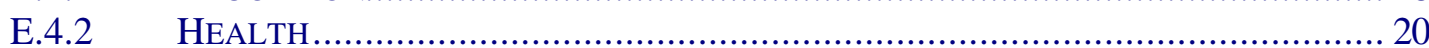

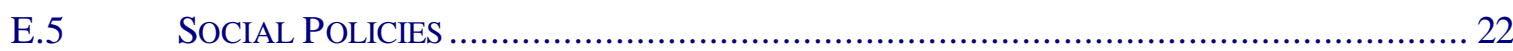

E.5.1 PREVENTIVE AND CURATIVE SOCIAL POLICIES …........................................ 23

E.5.2 FACILITATING AND ALLEVIATING SOCIAL POLICIES .................................... 24

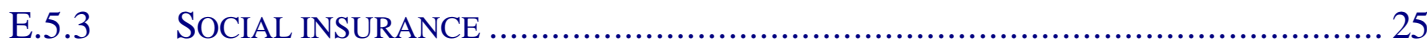

E.6 ENVIRONMENTALPROTECTION AND SUSTAINABLENATURAL RESCOURCES MANAGEMENT.............................................................. 26

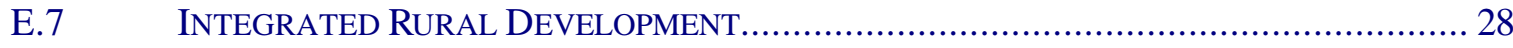

E.7.1 ACHIEVEMENT OF PRIORITY OBJECTIVES AND MEASURES TAKEN IN 2002 ........ 28

E.7.2 SUSTAINABLE NATURAL RESOURCES MANAGEMENT ................................... 29

E.7.3 2003-2006 MEDIUM-TERM PROGRAM FOR RURAL DEVELOPMENT ..................... 31

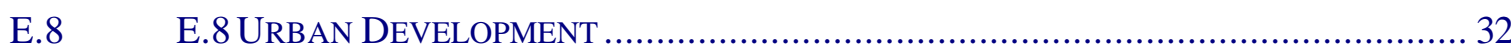

F. ESTABLISHMENT OF MONITORING AND EVALUATION SYSTEM......1

F.1 ESTABLISHMENT OF THE MONITORING AND EVALUATION SYSTEM …...................... 1

F.2 ENCOUNTERED PROBLEMS AND PROPOSED SOLUTIONS...................................... 2

G. PROGRESS REPORT CONSULTATIONS...............................................1

H. $\quad$ ANEKS 1: MATRIX OF REALIZATION OF PRIORITARY PUBLIC MEASURES 2002..............................................................................1

I. ANEX 2: PROGRAM OF PRIORITY ACTION PLAN 2003.........................1

J. ANNEX 3: MONITORING INDICATORS IDENTIFIED BY THE MINISTRIES............................................................................................ 

A. EXECUTIVE SUMMARY

A.1 NSSED VISION AND LONG-TERM OBJECTIVES

A.2 ANALYSIS OF ECONOMIC GROWTH

A.3 POVERTY PROFILE

A.4 THE IMPLEMENTATION OF THE PRIORITY PUBLIC MEASURES

A.4.1 INSTITUTIONAL AND GOVERNANCE REFORMS

A.4.2 FINANCIAL AND PRIVATE SECTOR DEVELOPMENT

A.4.3 INFRASTRUCTURE DEVELOPMENT

A.4.4 HUMAN RESOURCES DEVELOPMENT

A.4.5 SOCIAL POLICIES

A.4.6 RURAL AND URBAN DEVELOPMENT AND ENVIRONMENTAL PROTECTION

A.5 ESTABLISHMENT OF MONITORING AND EVALUATION SYSTEMS

A.6 PROGRESS REPORT CONSULTATIONS 


\section{A. EXECUTIVE SUMMARY}

1 The NSSED has constituted the main document on which the program and activities of the Government during 2002 have been based. The priority public measures have aimed at achieving the one-year objectives of the NSSED and establishing the bases for the achievement of the NSSED's three-year objectives. It has served as a leading document for the activities of state institutions, Albanian stakeholders and cooperation with international partners.

\section{A.1 NSSED VISION AND LONG-TERM OBJECTIVES}

2 The experience gained in NSSED implementation, the definition and improvements to objectives and medium-term NSSED measures the Millennium Development Goals and Albania's European integration objectives have all contributed to further improvements of the vision and medium and long-term NSSED objectives.

3 Long-term improved objectives of the Strategy until 2015 are:

- At a minimum the doubling of per capita GDP growth throughout Albania at all levels of society.

- Reducing by one-half the current absolute poverty rate and the elimination of extreme poverty.

- Total enrollment (100\%) in basic education, $90 \%$ in secondary education and not less than of 13.5 years of education completed

- Reducing by more than one-half the current infant mortality rate and diarrheal diseases.

4 Other long-term objectives determining economic and social development and modernization will be gradually defined with the ongoing improvements to the evaluation and, monitoring of progress made in implementing the Strategy and will be undertaken within the context of Albania's European Integration and the achievement of the Millennium Development Goals.

\section{A.2 ANALYSIS OF ECONOMIC GROWTH}

5 Due to the difficulties linked with the political instability at the beginning of the year, the energy crisis, the liquidity crisis (as a result of the massive withdrawal of deposits during the April-May period) and the floods last fall, economic growth did not exceed 4.7 per cent as compared to the 6 per cent forecasted. The experience of 2002, showed first of all the vulnerability of economic growth to endogenous and exogenous shocks. It also demonstrated the need for the forecasting of economic growth to be based on a more extensive analysis of risk factors. On the other hand, the experience of 2002 has shown considerable potential for economic growth through stronger development policies.

6 Despite lower growth rates among all sectors of the economy compared to forecasted growth, the positive trend in structural changes to GDP continued during 2002. There was a further growth of the service, construction and transportation sectors as a share of GDP, while the downward trend of agricultural production continued. Industry, having been particularly negatively affected by the energy crisis, nevertheless recorded a growth rate of 2 per cent. After a decade of strong growth, some modest but sustained trends indicate that growth is permeating all segments of its all society throughout the country including the less developed regions. 
7 A macro-economic stabilization policy framework has supported economic growth, which has been oriented towards reducing the impact of endogenous and exogenous shocks that the economy suffered during 2002. Year-end inflation was maintained at the 2.1 per cent target although the average annual inflation rate was 5.4 percent. The budget deficit was 6.2 percent against the projection of 8.5 percent. Despite growth of 11.4 percent as compared to 2001, general budget revenues remained under the forecasted level. Among the factors limiting budget revenues, was the failure to privatize some of Albania's strategic enterprises and the current account deficit. However, remittances from abroad remained high. Exports as compared to 2001 grew to 8 percent. The growth of imports was accompanied by a modest improvement in machinery, equipment and industrial inputs.

8 Through a more detailed analysis of the factors fostering economic growth, including the impact of strengthened structural and institutional reforms, measures taken to mitigate the energy crisis and the impact of macro-economic stability, economic growth is forecasted to be 6 per cent in 2003 and beyond. While assessing the rates of economic growth, it is forecasted that in the mid-term period 2003-2006 growth will reach more than 6\%.

9 With the further consolidation of macroeconomic stability forecast for the future years, including an annual average inflation rate not exceeding 3\%, a reduction in the budget deficit up to $5.4 \%$ by 2006 , a substantial increase in revenues and expenditures as a percentage GDP), a declining public debt and with continued emigrant remittances, a favourable climate is expected to achieve objectives for economic growth.

\section{A.3 POVERTY PROFILE}

10 The 2002 LSMS has enabled greater accuracy and a more robust assessment of poverty in all of its depth and scope. According to the base poverty line, one-fourth of the Albanian population is poor. Extreme poverty- as defined by the food lineage of poverty is low at less than 5 percent of the population. The inequality as estimated according to the consumption level is not high and it is almost at the same level with the other countries of the region, with a Gini co-efficient of 0.28 percent. The non-monetary dimensions of poverty are high. Access to infrastructure and services is very low in the rural areas; however, even in urban areas the low quality of services reduces accessibility to them.

11 Poverty is higher in the rural areas. It is 66 percent higher than in Tirana and 50 per cent higher than in other urban zones. Poverty has a specific geographic character whereby the northeast is extremely poor. Poverty is also more prevalent among young families. It is clearly correlated with unemployment and underemployment and the gender gap in the labor market, which penalizes women. The low level of education is also an important determinant of poverty.

12 According to a study on Social Categories at Risk, child, young ages, women and the elderly who are most at risk. The study defined the typology of the social problems that these categories are facing, the depth and range of the social problems and the adequate policies and social services that are needed. Poverty and the social categories at risk are combined with each other to increase social problems.

13 Poverty is not overly deep and many families live close to the poverty line. In these circumstances, effective social policies would give significant results in reducing it. For the mid-term period 2003-2006, the purpose is to reduce the existing level of poverty of $25 \%$ to $20 \%$ and reducing the level of extreme poverty. Poverty policies require an 
appropriate combination with other social policies. An economic growth remains the main factor to reducing poverty and mitigates social problems.

\section{A.4 THE IMPLEMENTATION OF PRIORITY PUBLIC MEASURES}

14 According to the NSSED, "the improvement of a) health and educational services and (b) of infrastructure and life services for the population, constitute priority fields which need special attention;(c) institutional reforms and (d) economic growth constitute the pillars; and (e) macroeconomic sustainability (f) the social support are conditions" to achieve the Strategy's objectives

\section{A.4.1 INSTITUTIONAL AND GOVERNANCE REFORMS}

The deepening of institutional reforms has aimed at strengthening the rule of law and improving the democratic features of institutions.

While the independence of the judiciary has increased, its efficiency and fairness remain problematic. Continued reforms have aimed at strengthening the institutions of judicial autonomy, building capacity, increasing transparency and enhancing access to justice by vulnerable social groups. The initial results of these reform measures are yielding encouraging results such as the reduction in number of the returned and overturned decisions of the Appeal Court brought to the Supreme Court. Judicial reform will continue with the priority towards capacity building, the development of the career system for judges and the strengthening of judicial transparency and impartiality.

The re-organization, capacity building, increase in transparency, democratic education and the extension of cooperation with international institutions, have all been some of the priority measures in the area of public order. The reduction of serious crime, increased crime detection and public order in general are being strengthened through reforms to prosecuting institutions. This includes some initial success in the fight against illegal trafficking and organized crime. The strengthening of public order and the fight against the international organized crime and money laundering in particular needs more international support.

18 The implementation of public administration reforms has enabled some structural improvements, which harmonize better the mission with the competencies of the institutions whereas the deepening of the implementation of the status of the civil servant legislation as well as compensation reform have increased the administration's sustainability and the quality of human resources. Administrative reform will continue both towards the further strengthening but in particular towards the motivation and increase in administrative performance.

Public finance reforms have enabled a marginal improvement to tariff administration performance where revenues greatly increased over 2001. The same is not true in the customs administration. Even the process of the budget drafting, monitoring and implementation has improved. This process has become more analytical and more transparent. The strengthening of the Public Procurement Agency, the reduction of the direct procurement as well as other improvements is establishing the foundations for the growth of efficiency and transparency in the public expenditure management system. The reforms will continue by increasing the effectiveness, efficiency and transparency of the system. 
20 Decentralization reforms have continued through a process of functional and fiscal autonomy and harmonization, strengthened governance, an increase in transparency and the strengthening of local institutions. The results of decentralization are judged to be positive and the reforms will be deepened in the future.

21 During 2002, the efficiency and democratic nature of the Albanian Parliament's legislative processes improved, as did its capacity to monitor the implementation of laws. The strengthening of the technical capacities, transparency and increase in participation in the legislative process and in the electoral reforms will be the priorities of the reform measures of the legislative body in the coming period.

22 The fight against corruption is a cross-cutting issue of all reforms. It has been waged both towards narrowing the spaces for corruption through increased transparency as well as through the adoption of anti-corruption incentives which have mainly medium-term and long-term impacts. Measures have also been taken towards enhancing control and prosecuting corruption cases. As a result, the index of perceived corruption has fallen. The fight against corruption will continue to be a priority and it will be fought according to these two aforementioned approaches.

\section{A.4.2 FINANCIAL AND PRIVATE SECTOR DEVELOPMENT}

23 The development of the private sector has been considered as the main factor of economic growth. The priority public measures, which have been implemented, have aimed at strengthening market institutions, improving the business climate and strengthening fairness and transparent competition. The expansion of economic opportunities has been facilitated through free trade agreements with the countries of the region as well as with the EU. Support to micro-credit schemes for SME's as well as measures dealing with the strengthening of the financial and banking system are transforming these sectors into an increasingly important factor for supporting private initiative. The reduction of administrative barriers and improved access to public services through transportation and tele-communication infrastructure, as well as the extension and improvement of information are also important measures to promote private sector growth. The fight against informal and illegal economies and fiscal evasion, be it through control and punitive measures or through positive incentives, have also had a positive impact on private sector development.

24 Policies and measures are being implemented, and monitored in increasingly close cooperation with the business community, and their impact, although initial and modest are judged to be producing results. The result has been an increase in the number of the businesses; particularly in some less developed regions of the country, an increase in the modernization of capital stock and other investments by local businesses themselves. There is a growing demand for credit as well as increased credit support schemes. It is premature to be able to measure the impact of some of these changes given the nascent monitoring capacity; yet tangible improvements are being made despite the difficult conditions of the energy crisis in 2002.

25 Mid-term measures for supporting private and financial sector development will continue to focus on strengthening market institutions, increasing the financial support by consolidating the banking and financial sectors and adopting incentives that increase the competitive capacities of the private sector in line with a more open economy. Reducing the informal economy, the battle against fiscal evasion and trafficking are also components that will contribute in institutionalizing the market and the development of the private sector. 


\section{A.4.3 INFRASTRUCTURE DEVELOPMENT}

26 Infrastructure development is a key priority for the country's economic and social development given its very fragile state.

Although not at the required level, public investments in the national, regional, urban and rural roads systems have seen improvements over the last few years which are judged to have greatly contributed to economic growth. Important investments have taken place at the port of Durres and at Mother Theresa Airport by increasing their capacities to process goods and passengers. While respecting norms for private sector participation and the maintenance of transportation infrastructure, investments in infrastructure will continue to constitute a public priority by strengthening the operations and maintenance capacities and by using concessions to attract private capital.

Telecommunications have rapidly increased the rate of distribution and penetration of information even in some of the more remote regions of the country. Investment growth in the fixed-line telephone system, the restructuring and the pre-preparation for the privatization of Alb-telecom, the opening of the cellular phone market and the promotion of private investments in the rural telephone system have been important measures that have yielded such positive results. The development of telecommunications technology is paving the way for information technology as one of the most effective instruments of socio-economic development in Albania. The development of this sector is a priority for the medium term. Albtelekom privatization, expanding the mobile phone market, supporting the rural telephone network, institutional strengthening of the Telecommunication Regulatory Board are the priorities of this period. The design and implementation of the Information \& Technology Strategy will be a priority in this sector.

29 The problems of the energy sector remain daunting and severely inhibit economic growth. During 2002, several measures were taken to address this situation. Through imports a significant improvement has been made to the supply of electrical energy and considerable reserves have been created for energy production. Investments have been undertaken in the interconnection, transmission and distribution networks. Moreover, steps have been taken to impose discipline in the sector by disconnecting and penalizing illegal connections and reducing the non-payment of the energy bills. As a consequence, the rate of losses has been reduced to $35 \%$ and there is a corresponding increase in collections of around $90 \%$. For the medium term, reforms to the sector are based on measures that consist of KESH's restructuring andcreating conditions for involving the private sector in the production and distribution of energy, and also in stimulating the use of alternative energy sources. For the medium term the objective is to reduce network losses to below $30 \%$ and increase the level of collections to over $96 \%$. Within this period, among other measures, the completion of the Vlora Power-Plant, the rehabilitation of the Drin River cascade and other large-scale investments in the transmission and distribution system including the complete installation of meters for the consumers are priorities. Tariff reforms will continue to contribute to cost recovery and decreased state subsidies.

30 The potable water supply is also a sector facing severe challenges evident in its quality, quantity, and distribution and in the sector's inefficiencies. During 2002, some important measures were undertaken such as the transformation of water enterprises into shareholding companies and the strengthening of the financial discipline and management capacities, a package of reforms which is ongoing in coordination with their transfer to local authorities. As a consequence, there is a reduction of the speculation rate and there is an increase of over 60 percent in the collection rate although the rate at which water bills are issued is low relative to that supplied. Price increases have enabled the enterprises to cover their costs. While investments in infrastructure have continued, the 
participation of the private sector through concessionary contracts is expanding in some areas. As a result there has been an improvement in the drinking water supply for about 1 million inhabitants in some urban and rural areas as well as in the service quality. Reforms in this sector will continue according to the areas identified above. In particular, reforms will be deepened in the companies' administration by decentralization, commercialization and tariff maximisation strengthening discipline and increasing the scale of revenue collection. Public investment will be increased in this sector consisting also of water quality and treatment. The use of concessions and privatization will be expanded at the same time and the regulatory regime will be strengthened.

\section{A.4.4 HUMAN RESOURCES DEVELOPMENT.}

31 The reforms and priority measures taken in the educational system have consisted of enhancing access to educational services, in building the teaching capacities and improving staff motivation. Policy-making capacities have also been strengthened. While the increased costs to the public have been important, the needs remain great. It is estimated that there is an increase in the school registration rate and a reduction in the drop out rate, which was 2.4 per cent in 2002. There is an increase in registrations in secondary and vocational education and improvements have been made to teaching facilities in a series of the schools across the country. Improvements have been made to the preparation and distribution of textbooks. The restructuring of the institutional roles in the educational system, initiated with the Ministry of Education, will continue at all levels. The problems of the sector remain great but the reforms, which have begun, are expected to yield positive impacts in the medium term. Medium -term objectives aim at increasing elementary enrollment rates to $98.5 \%$ in 2006 and secondary rates to $72 \%$ while vocational secondary education will share $60 \%$ of all secondary education. During this period the complete reform in pre-university education will be extended [in addition to the autonomy of the universities and the quality of instruction based on the European models and orientations of the Bologna's Process.]

32 The health care service continues to face serious structural, managerial and financial challenges. Consequently, the quality and quantity of health care services, including accessibility remain at problematic levels. Nevertheless, during 2002, some important measures were undertaken to improve emergency, ambulatory and hospital services followed by the implementation of national programs for the prevention of infectious diseases. Likewise, several pilot projects are ongoing in general health care reform, which are based on the 10-year health care strategy. The main areas of reform remain the strengthening the sector's effectiveness and efficiency including its financial stability by expanding the health insurance scheme. This will be combined with an increase in public investments in the sector to improve infrastructure and medical supply. In general, the interventions aim to increase access to services, in particular for the poor. For the midterm, the aim is to reduce infant mortality at 14 per thousand births.

\section{A.4.5 SOCIAL POLICIES}

33 The high level of poverty, unemployment and other social problems have required that cash payments for the poor and for other social cases continue to be used as the main social policy instrument at considerable public expenditures. Nevertheless, during 2002, some measures were undertaken in order to strengthen institutions, conduct in-depth studies on poverty and social problems, improve benefit criteria, increase the level of control and transparency, etc. which have increased the number of the poor included in support schemes, increased benefits per claimant, as well as a reduction in abuse. 
34 Evolving from facilitating into integration, social and recovery policies constitute nowadays the main approach to reforms in this field. The increasing rate of employment policies through training, information services and mediation in the labor market, are yielding positive results. Projects to establish community social service centers, including increasingly civil society, the business community, $t$ local authorities and the beneficiaries themselves, are creating a new model, which is the basis for sector reform, and which will in the medium-term be further expanded.

35 For the mid-term period 2003-2006 it is projected an increase in the scale of employment with 18000 employees plus for each year, including also all the poor people in the support scheme, duplicating the amount of financial help and increasing the scale of involvement in social services of the social categories at risk.

36 Social insurance system reform is proceeding according to a long-term program already adopted. During 2002, some important measures were undertaken such as increase of the pension age, extending the coverage of the participation of the rural population in the pensions schemes, lower contribution rates and institutional strengthening. This has all contributed to increasing the efficiency and effectiveness of the system to enable a reduction of state subsidies. For the mid-term period, a reduction in the difference between expenditures and revenues with around 3-4\% per year will be the aim, as well as increasing the number of contributors, increasing urban pensions by $10 \%$ and the rural ones by $20 \%$ and further maximization of social insurance liabilities.

\section{A.4.6 RURAL AND URBAN DEVELOPMENT AND ENVIRONMENTAL PROTECTION}

37 Agriculture and agro-industry development constituted the main priority of rural development. To this end, investment programs in agricultural infrastructure have continued. Support programs and related services, the promotion of farmers' associations, and credit support to overcome barriers to market access etc, have become very important. However, despite the still moderate growth of the sector, it has entered a phase of structural changes and accumulated investments, which offer significant growth potential for the sector. Moreover, public investments in the rural areas, especially roads and water supply collectors, schools or health centers have contributed to the improvement of life in some parts of the country. The challenges however, faced by rural residents remain large. The concept of rural integrated development is being gradually implemented and expanded on an ongoing basis and will be the basis of a long-term vision of its development and mid-term program. Developments in the agriculture sector and in the rural non-agricultural economy, developments in infrastructure and services, human resources development, protecting and harnessing environmental resources are some of the main areas of the mid-term rural integrated development program.

38 The exercise of control over the territory, the demolition of illegal construction and the rehabilitation of the public spaces, as well as investments in infrastructure and public services have continued to constitute the main priority measures in urban areas. Investments and the rehabilitation of infrastructure have been harmonized in all areas of the towns while some urban development projects have begun to be implemented under the guidance of the communities in the peri-urban regions of Tirana, Kamza, etc. Urban development consists of integrating medium and long-term policies and measures with cross-cutting reforms such as: economic development, public order, social policies, education, environment better suited to economical and demographic trends. Halting urban degradation, rehabilitation, the creation of the basis for sustatinable development are some of main priorities for the medium term. 
39 The prevention of environmental degradation has constituted the main priority of sector policies. The public measures taken have served to strengthen the monitoring and control instruments and establish incentives to change the behavior of individuals which will result in a reduction in the rate at which forests, land, water, flora and fauna are being damaged. Measures have begun to be implemented to remediate some of the hot spots despite the high cost of rehabilitation, these interventions are contributing to the resolution the problem of hot spots, which has a disproportionately adverse impact on the poorest segments of the population. Some studies have been undertaken and the recommendations implemented which, in the medium-term period will gradually lead the country towards the road of sustainable development. The key areas of the medium-term measures for the sector remain the same: deepening institutional reform, regulating resource ownership rights, rehabilitation especially those areas where the poor people are most exposed or where considerable environment values are at risk.

\section{A.5 ESTABLISHMENT OF MONITORING AND EVALUATION SYSTEMS}

40 The establishment of the monitoring and evaluation systems has faced challenges that have resulted in delays and a low rate of the systems' efficiency.

41 Nevertheless, during 2002, monitoring and evaluation units in 12 ministries were set up and the creation of initial performance indicators and monitoring and evaluation methods have been adopted. Moreover, the 2002 LSMS was undertaken, a new method of the GDP calculation was used, and many studies, which are creating the basis for an improved monitoring system to evaluate mid-term outcomes, were carried out.

42 The preparation process of the 2002 NSSED Progress Report, as well as the updating being carried out on the Strategy and the drafting of a plan of public priority measures for the 2003-2006 period have been important for the training of personnel charged with the new monitoring and evaluation structure of the NSSED. These documents have been prepared under the guidance of the structure set up by the Government, based on the methodology and leadership provided by the NSSED Department in the Ministry of Finance

43 Strengthening the system through increasing its capacities, updating the indicators and methods, improving the information exchange, reporting and providing feedback, will become a very important area in the priority public measures in the monitoring and evaluation system in the future.

\section{A.6 CONSULTATION OF THE PROGRESS REPORT}

44 Public consultations held in relation to the preparation of the 2002 NSSED Progress Report, the preparation of the medium-term program 2003-2006 and reviewing the longterm strategic objectives with external actors was fundamental. Consultations also were carried out during 2002 related to the preparation of this Progress Report. The suggestions and recommendations of the consultations have been included here. Consultations were undertaken at the national and regional levels with civil society, the business community, and local governments, Parliament as well as with the international partners. However, these consultations were undertaken within very tight time constraints and so their effectiveness was somewhat compromised. Improvements to the consultation process will be one of the priority measures linked with the preparation of this document in the future. 
B. NSSED VISION AND LONGTERM OBJECTIVES 


\section{B. NSSED vision and longterm objectives}

1. Experience gained through the first year of NSSED implementation has shown that the ongoing revision on its objectives is critical.

2. The NSSED has been aligned to the MDGs and SAA process.

3. Successful achievement of the NSSED, MDGs and the SAA require a deepening of the reform process as Albania progress to a more mature and stable stage of transition emphasizing the importance of governance and institutional reform including the creation of a more attractive investment climate

- The acceleration of the privatization process in strategic sectors and the enhancement of the public service;

- The further strengthening of the rule of law and resolution of property rights, administrative reform, the consolidation of the fight against corruption and the increased Governance efficiency,

- Improvements to infrastructure, especially the electricity supply,

- The consolidation of financial sector reforms, and

- The deepening of market reforms;

4. The transition process is incomplete. Its further deepening can only be achieved if tackled head on.

5. The achievement of Albania's long-term objectives including better standards of living and European integration require the consolidation and further consolidation of macroeconomic stability, a more open economy and high rates of economic growth.

6. The high rates of broadly-based sustainable economic growth constitutes the main pillar of the entire range of policy measures and consequently is the main guarantor of achieving poverty reduction objectives. The improvement of the business environment has been one of the basic factors ensuring sustainable economic growth.

7. The analyses of 2001 and 2002 achievements and the methodological improvements linked with the National Account made possible the revision of economic growth objectives. Although, the revised targets of $6 \%$ of GDP annual economic growth for 2003-2006 are slightly lower than initially forecasted, they still remain ambitious. The achievement of these targets would guarantee high rates of economic growth and consequently the fulfillment of the other objectives of the Strategy.

8. NSSED objectives have been presented and quantified through the indicators, which have been divided into final indicators and intermediate ones (input, process and output). Final or impact indicators have taken into consideration the long-term objectives of country's development. The following are some of the main, final indicators:

- Real GDP growth of 24-26\% over the three-year period (2003-2006) and doubling over 15 years ${ }^{1}$.

- Percentage of the population living in poverty according to the absolute poverty line (under \$2/day will be reduced from 25\% in 2002, to $20 \%$ in 2006 and to $13 \%$ in 2015 . The percentage of the population in extreme poverty (under $\$ 1 /$ day) from $5 \%$ in 2002 will be reduced to $3-4 \%$ in the medium term period and will be completely eradicated by 2015 .

\footnotetext{
${ }^{1}$ The main macroeconomic indicators are presented in Appendix 3 of NSSED 2001.
} 
- Reduction of infant-natal mortality from $17.5 / 1000$ births in 2002 , to $15 / 1000$ in 2006, and to $10 / 1000$ in 2015. Incidents of diarrhea diseases have been foreseen to be reduced from 1,400 per 100,000 inhabitants in 2000, to 600 per 100,000 in 2006 and a further reduction for the year 20015.

- The enrollment rate of basic education will be increased from $97 \%$ in $2002,98.5 \%$ in 2006 and to $100 \%$ in 2015 . The enrolment rate for secondary education will increase from $64 \%$ in 2002 to $72 \%$ in 2006 and to $90 \%$ in 2015 while the expected years of education at birth with increase from 9.7 in 2002 to 10.8 in 2006 and higher than 13,5 in 2015

9. The above-mentioned objectives are consistent with the MDGs. The Government's international partners and civil society are currently examining the role of gender in the NSSED. The recommendations will strengthen the NSSED and contribute to the achievement of the Strategy's the long-term objectives.

10. The NSSED medium and long-term objectives will continue being completed from the analysis and conclusions derived from the process of SAA project agreement. 
C. ANALYSIS OF ECONOMIC GROWTH

C.1 2003-2006 MEDIUM TERM OBJECTIVES FOR ECONOMIC GROWTH AND MACROECONOMIC STABILITY 


\section{ANALysis of economic growth}

11. Economic development during 2002 generally followed the projected trends in the NSSED and 2002-2004 Medium Term Expenditure Framework. Maintenance of the high rate of the economic growth has brought about a GDP level of $114.3 \%$, as compared to the level of 1989 (considered $100 \%{ }^{2}$ ).

\section{Graph 1: GDP Trends in Albania}

Fig. 1 : GDP evolution in Albania

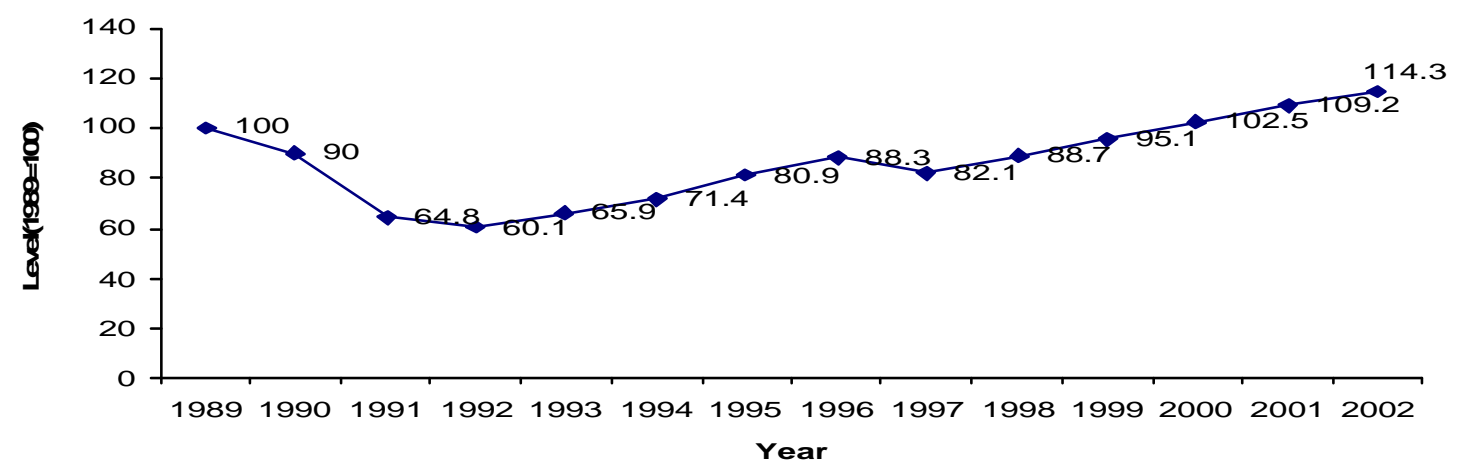

12. GDP growth during 2002 was also accompanied by an increase in per capita GDP, which reached $\$ 1499$, as compared to $\$ 1333$ in 2001 . Nevertheless, per capita GDP remains very low as compared to the countries of the region. Increasing per capita GDP remains one of the most significant challenges to be faced.

\section{Graph 2: Per Capita GDP in Albania}

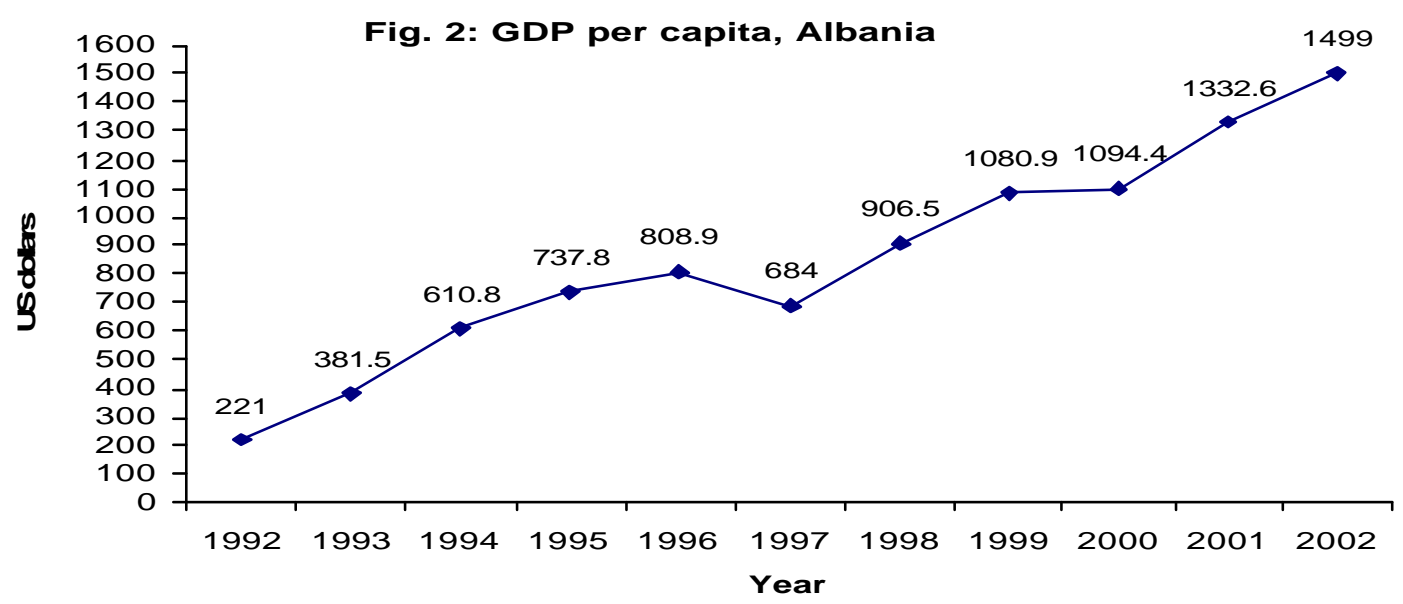

13. The economic growth of 4.7 percent for 2002 is lower than both the first projection in the NSSED (7\%) and the revised government estimation for 2002 of 6 percent.

\footnotetext{
${ }^{2}$ According to the Ministry of Finance, to maintain the consistency of the data, the changes due to the reassessment of the economic growth for the period 96-2000, have not been reflected. According to this assessment, the growth per year of this period as compared to the previous year have been respectively 9.1 per cent, 10.3 per cent, 12.7 per cent, 8.9 per cent and 7.7 per cent.
} 
14. The failure to attain the projected growth rates is the result of a combination of internal and external factors, including the energy crisis, political instability, the failure of the privatization of Alb-telecom and the Savings Bank, the liquidity crisis as a result of the massive withdrawal of the deposits, from the Savings Bank and the National Commercial Bank, in March-April 2002 and the floods in September 2002. These factors speak to the need for an even more objective and rigorous analysis of growth factors and risks in the economic forecasting. Nevertheless, the actual level of economic growth may be considered satisfactory considering the above-mentioned difficulties. Improvements to the methodology used to calculate GDP will increase the accuracy of forecasting prediction.

\section{Graph 3: GDP Growth Rate}

Fig. 3: GDP growth rate

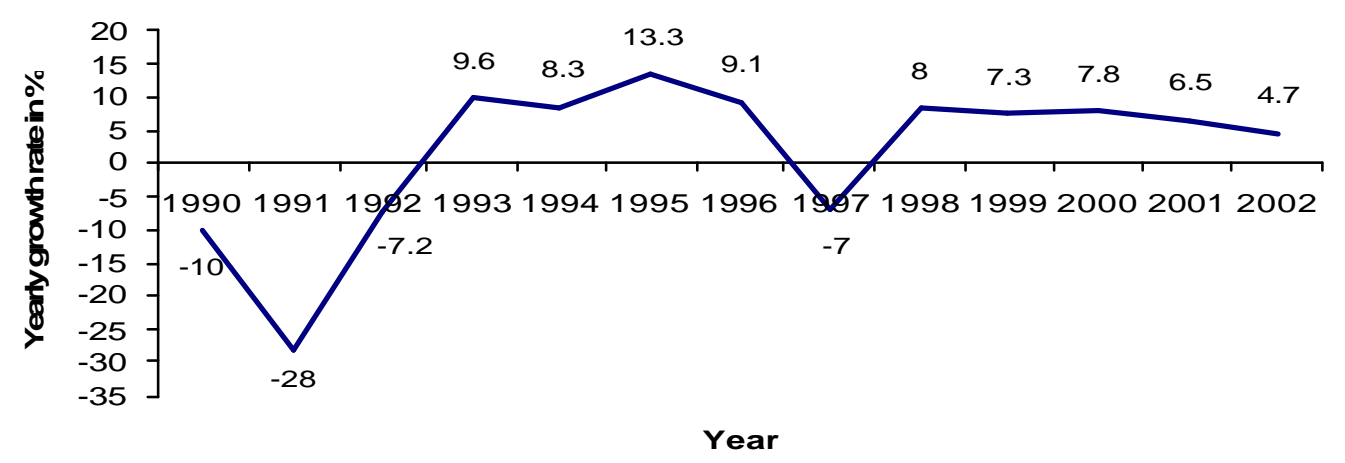

15. Capital investments, including private and public domestic investment, as well as foreign direct investment, represented $20.4 \%$ of GDP in 2002. Public investments for 2002, were 37296 million lek, as compared to planned investments of 50817 million lek. This represents a reduction of $14.5 \%$ over 2001 . Out of $6.5 \%$ and $6.9 \%$ for 2000 and 2001 respectively, public investments fell to $5.6 \%$ of GDP in 2002. Among the factors that influenced the decrease of the public investments were the political changes in the first half of the year and the energy crisis.

16. The private domestic investment increased considerably in 2002, compensating for the reduction in public investment and in foreign direct investment. Private domestic investment amounted 11.7 percent of GDP, an increase over $8.2 \%$ in 2001 . What follows is a direct explanation of improvements to the business climate:

- Increase of credit available in 2002, which was 62.6-billion lek, over 40.6-billion lek in 2001.The surplus of credit at the end of 2002 was 38.7 billion lek as compared to 27.9 billion lek for the 2001 .

- Extension of the micro-credit schemes, which according to their particular target areas and markets ${ }^{3}$, are expanded geographically and are better able to mobilize community resources and, as a consequence, mitigate poverty.

- The increase, although slight, in the imports of machinery and equipments, recorded at 45.095 million lek in 2002 as compared to 45.067 million lek in 2001.

\section{Table 1: The nominal investment trend}

\footnotetext{
${ }^{3}$ In 2002, from only 3 micro credit schemes, the Mountain Areas Development, the Rural Finance Fund and the Besa Foundation, resulted a surplus of credit in the amount of $\$ 19.9$ million, or $\$ 7.6$ million more than in 2001. The geographic coverage includes the remote and the less developed regions of the country. The number of the clients increased to 23 per cent; as well as the average value of each loan.
} 


\begin{tabular}{|c|c|c|c|c|c|c|}
\hline & \multicolumn{2}{|c|}{2000} & \multicolumn{2}{|c|}{2001} & \multicolumn{2}{|c|}{2002} \\
\hline & Amount & $\begin{array}{l}\text { Annual } \\
\text { growth }\end{array}$ & Amount & $\begin{array}{l}\text { Annual } \\
\text { growth }\end{array}$ & Amount & $\begin{array}{l}\text { Annual } \\
\text { growth }\end{array}$ \\
\hline Non-public Investment & 65244 & $0.00 \%$ & 75241 & $15.32 \%$ & 96949 & $28.85 \%$ \\
\hline As $\%$ of GDP & $12.10 \%$ & & $12.75 \%$ & & $14.73 \%$ & \\
\hline Public Investments & 35049 & $0.00 \%$ & 43397 & $23.82 \%$ & 37296 & $-14.06 \%$ \\
\hline As $\%$ of GDP & $6.5 \%$ & & $7.4 \%$ & & $5.7 \%$ & \\
\hline Total Investments & 100293 & $0.00 \%$ & 118638 & $18.29 \%$ & 134245 & $13.16 \%$ \\
\hline As $\%$ of GDP & $18.60 \%$ & & $20.10 \%$ & & $20.40 \%$ & \\
\hline GDP (nominal) & 539210 & & 590237 & & 658062 & \\
\hline
\end{tabular}

Source: Bank of Albania and the Ministry of Finance

17. Foreign direct investment is estimated to be \$143 US million, as compared to \$203.7 US million in 2001. However, if one extracts from the value of 2001 privatization procedures, the amount of foreign direct investment recorded in 2002 is greater.

18. During 2002, the positive trend in GDP structural changes continued. There was further growth in the services, construction, and transport, while the downward trend in the agricultural products weighting continued as a reflection in general in the positive trend in the efficient allocation of the productive resources.

Table 2: Change in the Economy's Structure as a Percentage of GDP in PBB

\begin{tabular}{|l|r|r|r|r|l|}
\hline \multicolumn{1}{|c|}{$\begin{array}{c}\text { Economy } \\
\text { sectors }\end{array}$} & 1992 & 2001 & $2001^{4}$ & 2002 & $2002^{3}$ \\
\hline Agriculture & $54,2 \%$ & $34,2 \%$ & & $33,3 \%$ & \\
\hline Industry & $16,9 \%$ & $13,2 \%$ & & $12,8 \%$ & \\
\hline Construction & $7,6 \%$ & $10,3 \%$ & & $10,8 \%$ & \\
\hline Transport & $3,0 \%$ & $10,1 \%$ & & $10,6 \%$ & \\
\hline Other & $18,3 \%$ & $32,2 \%$ & & $32,5 \%$ & \\
\hline
\end{tabular}

Source: Bank of Albania

19. Throughout 2002, agriculture continued being the single most important contributor to GDP at 33 per cent and has a an annual growth rate of 2.1 per cent as compared to 5 per cent forecasted in the NSSED ${ }^{5}$, Table 2, as compared to the growth rate of 1.4 per cent in 2001.Both endogenous and exogenous factors, such as the flooding in 2002, have resulted in the low level of the annual agricultural growth. Nevertheless, from the studies and different projections it is considered that the agricultural sector's structural changes that are occurring and investments are being made which are expected to yield positive results during the next two to three years.

Table 3: Growth By Economic sectors in 2002.

\footnotetext{
${ }^{4}$ According to the calculations by INSTAT, by using the new method of calculating GDP (implemented for the years 1996-2000) and for the years 2001 and 2002.

${ }^{5}$ The $5 \%$ increase refers to the agro-food and fishing sectors, excluding agriculture/animal husbandry, whereas the increase of $2.1 \%$ and $1.4 \%$ reported above, refers only to agriculture and animal husbandry. Meanwhile, the increase in the agro-food sector in the year 2002 is $13 \%$ more than in 2001, whereas fishing increased by $18.7 \%$.
} 


\begin{tabular}{|l|r|r|r|}
\hline & NSSED Projection & $\begin{array}{c}\text { Projection at the } \\
\text { beginning of the year }\end{array}$ & Actual \\
\hline $\begin{array}{l}\text { Real growth( in } \\
\text { percentage) }\end{array}$ & 7 & 6.0 & 4.7 \\
Out of these: & & 5.0 & 2.0 \\
$-\quad$ Industry & 5 & 3.0 & 2.1 \\
$-\quad$ Agriculture & & 11.5 & 9.1 \\
$-\quad$ Construction & & 11.0 & 10.1 \\
$-\quad$ Transport & & 6.5 & 5.5 \\
\hline
\end{tabular}

Source: Ministry of Finance.

20. Construction and transport reached relatively high rates of growth as compared to the other sectors but lower than those projected. For the construction sector, the strengthening of the regulatory process has had a preventive short-term impact, which is expected to be reduced in the future. Industry recorded the lowest growth in 2002 with only 2 per cent as compared to the 5 per cent forecasted as this is in part due to the energy crisis. The attenuation of the energy crisis is expected to have a positive impact on all sectors of the economy especially industry. The service sector recorded a moderate increase (table 1). There was considerable growth in the tourism sector, which is a sign of significant longterm potential in the sector. However, investments in energy and infrastructure will have a critical impact on tourism receipts.

21. For 2002, the state budget deficit was 40941 million lek or 6.2 per cent of the GDP, as compared with the forecasted 8.5 per cent in 2001. There was an improvement in the indicators of deficit financing. The Government was able to limit its deficit within the limits forecasted in the Budget.

22. As compared to the year 2001, the total Revenues in 2002 increased by 12.6 per cent.

23. Total budget expenditures in 2002 were 191.8 billion lek out of the 212.3 billion lek planned which is 3 percent higher than in 2001.The expenditures for the Strategy's priority sectors, such as education and health, have been greatly increased relative to 2001.The expenditure for education in 2002 covered 11 per cent of the total sector expenditure as compared with 9 percent in 2001. As a percentage of GDP, the indicators are respectively 2.7 percent and 2 percent for 2000 and 2001. Economic support as well has increased as compared to 2001 but this was not at the level of the above-mentioned sectors and unemployment insurance payments were reduced. For these social schemes, the priority for the year 2002 was to increase the programs' efficiency.

24. The year-end inflation rate (as measured by the consumer price index ${ }^{6}$,) was 2.1 per cent in 2002 , whereas the average annual rate was 5.4 per cent. The energy crisis and the temporary shocks in the banking system resulting from the considerable withdrawal of deposits in the spring of last year had a negative impact on the relatively high annual rate of inflation during 2002.

25. During 2002, the Bank of Albania continued to use monetary policies to fix the interest rate target [for the agreements of the REPO]. The use of these indirect instruments increased, particularly during the period of the liquidity crisis and it has given more flexibility to the second-tier banks beeing accompanied by an increase of credit.

\footnotetext{
${ }^{6}$ According to INSTAT, the producer price index for 2002, increased by 1.1 percent as compared to 2001 which recorded, a 3.8 percent growth rate in 2001 over 2000. Nevertheless, according to INSTAT, the indicator for the processing industry was 9.59 percent in 2002, as compared to 2001.
} 
26. The current account balance indicators worsened in 2002. Despite an 8 per cent growth rate of exports as compared to 2001, the trade deficit continued to grow resulting in deficit of $\$ 5$ million. The negative developments ${ }^{7}$ in the trade balance and in the service balance have increased the current account deficit from \$218.2 million in 2001, in \$447.6 US million in the year 2002. However, Remitances transfers were increased essentially, from $\$ 542.7$ US million in 2001 to $\$ 606.8$ million in 2002, or an increase of 11.8 per cent.

27. During 2002, a series of free trade agreements were signed with the countries of the region. It is expected that these agreements will yield positive results in the coming years.

\section{C.1 2003-2006 MEDIUM TERM OBJECTIVES FOR ECONOMIC GROWTH AND MACROECONOMIC STABILITY}

28. Economic growth for 2003 and for the next three years to come is expected 6 per cent. The growth rate will be maintained through such factors as increased institutional reform and strengthening, the attenuation of the energy crisis as well as maintaining macroeconomic stability.

29. The deepening of structural reforms is expected to be accompanied by improvements to the business climate; greater private entrepreneurship supported by a more sound banking and financial sector and by increases in the levels of foreign direct investment. The resolution of property rights is expected to have a positive effect on the economy, particularly in agriculture. The deepening of structural changes in those sectors of the economy with the highest potential for growth, is expected. The restructuring and privatization of the strategic enterprises is expected to have considerable positive effects. The growth of the economic space, the deepening of the regional integration processes, the participation of Albania in the Stabilization and Association Process along with the improvement of the business climate in general are all factors which will result in stronger competitiveness and the exploitation of the economy's full potential.

30. Despite political instability, which is percieved during local and legislative election campaigns, a political consensus between the governing coalition and the opposition is expected to yield positive results in the areas of institutional reform and improved governance which will have a positive effect on economic development.

31. The further consolidation of macroeconomic stabilization as projected for the coming years, an average annual inflation rate not to exceed 3 percent, a declining budget deficit to 5.4 percent in 2006 , with a modest growth in revenues and expenditures relative to GDP, a declining public debt and corresponding declining debt and at least a constant flow of remittances from abroad over the medium term will all contibute to create the necessary environment to achieve an annual economic growth rate of about 6 percent.

32. In the coming years economic growth will be extended to reach the poorest strata of society and the economically disadvantaged areas of the country. Further improvements to the business climate, an upward trend in private investment and the expansion of the micro-credit schemes and other development programs will further broaden and deepen

\footnotetext{
${ }^{7}$ The tendency of the structural changes of import in the favor of goods destined for production, especially machinery and equipment that go to the most dynamic sectors of economy, is an indicator of the positive and restructuring role of import.
} 
economic gains and reduce unemployment, particularly in those regions experiencing already low levels of employment, particularly in the less developed areas of the country.

33. The objectives for broadened and more inclusive economic growth for the medium-term period 2003-2006 have necessitated the review of government programmes and the improvement of priority measures in those sectors closely linked with economic growth over the medium term such as: (1) private and financial sector development, (2) improvements to the business enabling environment, attracting the foreign investments and promoting exports, (3) improvements to the electrical energy supply and infrastructure in general, (4) legislative improvements, the strengthening of institutions and governance etc.(refer to the relevant chapters of the documents).

Table 4: The Main Macro-Economic Indicators

\begin{tabular}{|c|c|c|c|c|c|c|c|c|c|c|}
\hline Indicators & 1997 & 1998 & 1999 & 2000 & 2001 & 2002 & 2003 & 2004 & 2005 & 2006 \\
\hline \multicolumn{11}{|c|}{ In percentage change } \\
\hline Real growth of GDP & $(7.0)$ & 8.0 & 7.3 & 7.8 & 6.5 & 4.7 & 6.0 & 6.0 & 6.0 & 6.0 \\
\hline Inflation (annual average) & 32.1 & 20.9 & 0.4 & 0.0 & 3.1 & 5.6 & 3.0 & 3.0 & 3.0 & 3.0 \\
\hline Inflation (end of year) & 42.1 & 8.7 & $(1.0)$ & 4.2 & 3.5 & 2.1 & 3.0 & 3.0 & 3.0 & 3.0 \\
\hline Fiscal indicators & \multicolumn{10}{|c|}{ In percent of GDP } \\
\hline Budget revenues & 16.7 & 20.3 & 21.3 & 22.4 & 23.0 & 22.9 & 24.5 & 25.3 & 26.0 & 26.6 \\
\hline Budget expenditures & 29.4 & 30.7 & 32.7 & 31.4 & 31.5 & 29.1 & 31.1 & 31.3 & 31.8 & 32.0 \\
\hline Deficit / Suficit & $(12.8)$ & $(10.4)$ & $(11.4)$ & $(9.1)$ & $(8.5)$ & $(6.2)$ & $(6.6)$ & $(6.0)$ & $(5.8)$ & $(5.4)$ \\
\hline Domestic financing of deficit & 10.7 & 6.4 & 5.2 & 3.2 & 3.1 & 3.1 & 2.8 & 2.1 & 1.8 & 1.6 \\
\hline Public debt & 69.0 & 64.3 & 64.1 & 72.1 & 69.0 & 64.6 & 62.8 & 62.1 & 61.2 & 61.3 \\
\hline -Domestic debt & 35.8 & 32.4 & 35.1 & 41.9 & 40.9 & 39.6 & 39.1 & 37.8 & 36.4 & 36.1 \\
\hline -External debt & 33.2 & 31.8 & 29.1 & 30.2 & 28.2 & 24.9 & 23.7 & 24.2 & 24.9 & 25.2 \\
\hline \multicolumn{11}{|l|}{ Monetary indicators } \\
\hline Money growth (in percent) & 28.5 & 20.7 & 22.3 & 12.0 & 19.9 & 7.6 & 8.9 & 8.9 & 8.9 & 8.9 \\
\hline \multicolumn{11}{|c|}{ (Treasury bonds 3 months end of period) } \\
\hline External sector & \multicolumn{10}{|c|}{ In million US\$ } \\
\hline Trade balance & $(519)$ & $(621)$ & $(663)$ & $(821)$ & $(1,027)$ & $(1,096)$ & $(1,129)$ & $(1,208)$ & $(1,276)$ & \\
\hline (In percent of GDP) & (22.7) & $(20.4)$ & $(18.0)$ & (21.9) & $(25.0)$ & $(23.7)$ & $(22.8)$ & $(22.3)$ & $(21.5)$ & \\
\hline Curent account balance & $(276)$ & $(187)$ & $(270)$ & $(271)$ & $(259)$ & $(405)$ & $(379)$ & $(404)$ & $(411)$ & \\
\hline International reserve & 306 & 384 & 485 & 608 & 737 & 809 & 819 & 839 & 889 & \\
\hline (In months of import of goods \& se & 3.8 & 3.7 & 3.8 & 4.1 & 4.6 & 4.9 & 4.6 & 4.4 & 4.4 & \\
\hline
\end{tabular}


D. THE POVERTY PROFILE

D.1 POVERTY LEVEL

D.1.1 POVERTY AS MEASURED BY INCOME LEVEL AND INEQUALITY

D.1.2 THE EXTENT OF NON-INCOME POVERTY

D.2 POVERTY PROFILE

D.3 POVERTY AND SOCIAL EXCLUSION

D.4 FINAL ASSESSMENTS AND POLICY IMPLICATION 


\section{THE POVERTY PROFILE}

34. Despite its limitations, the data of the poverty study conducted in 1998 (LCS) and two other studies completed in 2000 (MICS) and 2001 (the Qualitative Study of poverty) were used for the preparation of the NSSED.

35. The Living Standard Measurement Survey (LSMS 2002) is the first sample observation on inequality at the family level. The information collected from this study permits intensive and multi-dimensional analyses on poverty based on a well-known international methodology. Another LSMS will be carried out again in 2005.

\section{D.1 POVERTY LEVEL}

\section{D.1.1 POVERTY AS MEASURED BY INCOME LEVEL AND INEQUALITY}

36. To serve the aim of this study, an absolute line of poverty based on the cost of the basic needs $(\mathrm{CBN})$, was calculated. According to the absolute line of poverty, one fourth of the Albanian population is poor. Extreme poverty- as defined by the food line of poverty, is low. Less than $5 \%$ of the population does not meet the basic needs for food. Poverty is higher in the rural zones, with 66 percent more poor people than in Tirana and $50 \%$ more than in the other urban areas.

Table 5: Poverty and inequality in Albania

\begin{tabular}{|c|c|c|c|c|c|c|c|c|}
\hline & \multicolumn{2}{|c|}{ Tirana } & \multicolumn{2}{|c|}{ Others Urban } & \multicolumn{2}{|l|}{ Rural } & \multicolumn{2}{|l|}{ Total } \\
\hline & poor & $\begin{array}{l}\text { Very } \\
\text { poor }\end{array}$ & Poor & $\begin{array}{l}\text { Very } \\
\text { poor }\end{array}$ & poor & $\begin{array}{l}\text { Very } \\
\text { poor }\end{array}$ & poor & $\begin{array}{l}\text { Very } \\
\text { poor }\end{array}$ \\
\hline Poverty co-efficient & 17.8 & 2,3 & 20.1 & 4.8 & 29.6 & 5.2 & 25.4 & 4.7 \\
\hline Poverty gap & 3.8 & 0.6 & 4.7 & 0.9 & 6.6 & 0.7 & 5.7 & 0.8 \\
\hline $\begin{array}{l}\text { Average consumption/capita } \\
\text { (lek) }\end{array}$ & & 9,043 & & 8,468 & & 7,212 & & 7,801 \\
\hline Gini & & 0.30 & & 0.28 & & 0.27 & & 0.2 \\
\hline
\end{tabular}

37. Inequality as estimated according to the level of consumption is not very evident and it is almost at the same level with the other countries of the region as can be seen from the Gini co-efficient of 0.28 .

\section{D.1.2 THE EXTENT OF NON-INCOME POVERTY}

38. Inequalities, particularly when considering non-income poverty are much more obvious than when looking at income alone. The availability of basic infrastructure services is almost universal in the urban zones, yet much less so in rural areas. This does not mean that urban areas do not experience severe infrastructure deficiencies. The quality of infrastructure services in rural areas largely is a question of access.

39. Education Albania has high levels of literacy especially among the youth in urban areas. The ruraturban school attendance rates differences are clear. The primary school registration co-efficiet is high at 93 percent There is a modest difference between highschool registration in urban versus rural areas.

40. Participation in the labor market and unemployment. There is a strong correlation between poverty and unemployment in Albania, especially in rural areas. According to the standard definition of unemployment by the International Labour Organisation (ILO), 
the unemployment rate is approximately 10 per cent. However, this number masks the wide unemployment in the rural areas. ${ }^{8}$.

41. Participation and gender Gender inequality is present in the labor market. The participation rate of women in the labor market is approximately two thirds that of men.

42. Property and capital ownership. Landand livestock ownership does not constitute a sufficient condition to escape poverty. Obvious differences in the ownership of equipment exist between rural and urban areas.

Table 6: Indicators of Unfulfilled Basic Needs. (UBN) ${ }^{9}$

\begin{tabular}{|l|c|c|c|c|}
\hline & Tirana & Urban & Rural & Total \\
\hline 1. Unsuitable water and hygiene $(*)$ & 0.5 & 2.6 & 28.6 & 17.5 \\
\hline 2. Unsuitable dwelling facilities (**) & 8.5 & 6.3 & 16.5 & 12.5 \\
\hline 3. Insufficient energy supplies. (**) & 1.7 & 9.0 & 18.1 & 13.5 \\
\hline $\begin{array}{l}\text { 4. Overpopulation (more than 3 persons per } \\
\text { room) }\end{array}$ & 10.3 & 15.6 & 18.6 & 16.7 \\
\hline $\begin{array}{l}\text { 5.Educational level (head of family with 8 } \\
\text { year education or less.) }\end{array}$ & 34.7 & 47.0 & 74.8 & 61.2 \\
\hline Poor (two or more, UBN) & 11.5 & 16.6 & 47.2 & 33.8 \\
\hline Very poor (three or more UBN) & 2.3 & 3.2 & 18.3 & 11.9 \\
\hline Not poor (one or none UBN) & 88.5 & 83.4 & 52.9 & 66.2 \\
\hline
\end{tabular}

\section{D.2 POVERTY PROFILE}

43. 2002 LSMS has managed to create a poverty profile, whose main features are:

- Poor individuals live in large families and in young families which represent about 40 percent of the poor.The incidence of poverty among the young is above the national average. Almost half of the poor in Albania are under 21 years of age. The elderly in Tirana have one of the lowest rates of poverty, about 12 percent.

- The nothernmost and north eastern regions are among the poorest in the country. Almost half of the inhabitants in these regions are poor and more than one-fifth in this group live in extreme poverty ${ }^{10}$.

- The poor and the extremely poor have a low coefficient of school registration, particularly high school registration.The poor benefit less from the health service.

\footnotetext{
${ }^{8}$ The definition of unemployment according to ILO that is used in the 2002 LSMS means: adults older than 15 years old, that didn't work during the last four weeks and are willing to begin working within two weeks. But according to a second definition of LSMS the definition of unemployment also includes the helpless, the seasonally unemployed and the fired people. This unemployment rate is $15.4 \%$. According to a third definition, which includes persons who have worked less than 25 hours per week in the agricultural sector, the unemployment rate is $19.1 \%$. LSMS provides detailed data for the distribution of unemployment by city and village based on each above-mentioned definition. According to the Ministry of Labor and Social Affairs' definition of unemployment which refers to: adults older than 16 years of age, the unemployed and job seekers who have registered in employment offices, the unemployment rate is $13 \%$.

${ }^{9}$ (*) When the family does not have drinking water connection or WC with sewage system.

(**) Subjective assessment for the cases when the house is not suitable for accommodation, or it is under construction.

$(* * *)$ There is no energy interruption for more than 6 hours a day.

${ }^{10}$ According to LSMS results, the poverty level in the following cities: Kukes, Has, Tropoje, Diber, Malesi e Madhe, Bulqiza and Gramsh accounts for $46 \%$ of the nation's poor.
} 
Malnutrition is more addressed among poor children under 5 years of age as compared to the non-poor,yet, this is not obvious.

- The unemployment rate among the poor is about twice as high as that of the nonpoor. The incidence and severity of poverty is more frequent in the families where the head of the family is unemployed. Among poor families, the main source of income is agricultural activity and salaried employment.

- The poor spend more than half of their budget on food (67\%) and less on non-food products.(17\%).

\section{D.3 POVERTY AND SOCIAL EXCLUSION}

44. At the current stage of the country's development towards the market economy as a result of the quick and encompassing socialeconomic changes, and under the pressure of other phenomena that accompany transition like high structural unemployment, poverty, high rates of migration, the rise of crime and the erosion of traditional values, the social vulnerability of different layers and groups of the population has increased. The social vulnerability is entwined and fed by the poverty.

45. According to the study carried out by the Ministry of Labor and Social Affairs, "Assessment of the social situation and service needs for the marginalized groups", realized in the Social Service Delivery Project (supported by the WB) result some vulnerable groups of society.

- Children in danger-Children from (0-14 years old), social and biological affront that live only with one of the parents, those that work and do not attend the school e.g. accounts for $5.72 \%$ of all the children. It is estimated that children in danger specially are encountered in the regions of Kukes, Shkoder and Lezhe, and they respectively account for $16.95 \%, 11.82 \%$ and $10.2 \%$.

- Youth in danger-Youth from (14-25 years old), unemployed, drug and alchol users, with criminal precedent e.g accounts for $22.8 \%$ of the youth. It is estimated that youth in danger is considered a great problem in the regions of Kukes $55 \%)$, Shkoder $(33 \%)$ and Lezhe $(31,7 \%)$ due to uneployment reason while it is strongly viewed even in the regions of Berat (58\%), Tirane (in the other municipalities and not in the municipalities of Tirana and Kavaja) (33.2\%) and Gjirokaster (28\%) also due to unemployment reasons. Drug users seem to be very problematic in Berat, Tirane, Kukes and Shkoder

- Women in danger-divorced, single mothers, abused women as well as victims of prostitution account for $5.16 \%$ of all the women. In all the regions the highest percentage corresponds to the single mother and divorced women. Women in danger due to force and prostitution are strongly encountered in the region of Berat and in the region of Fier and Elbasan at lower level.

- Mentality and physically disabilities accounts for $1.35 \%$ of the population with approximately equal distribution in all the regions. Paraplegics and tetraplegics are encounter more in the regions of Berat, Diber and Fier

- The elders in danger- that live alone, abandoned, with insufficient revenue, handicaps, e.g. accounts for $12.7 \%$ of the elders and are more encountered in Berat, Gjirokaster, Shkoder and Kukes with over $20 \%$ of the elders in total.

46. Based on this study it is prepared the map of social need delivery and also the reforming of social service and support system.

47. Poverty as multidimensional phenomena is at the root of many social problems that have occurred during transition. Poverty produces social exclusion and creates an environment 
prone to increase the risk, marginalization and social isolation of different groups of society. The marginalized groups of society and poverty represent two flexible categories that are interlinked and feed each other. Poverty is reflected in social problems at the elders, street children, handicaped, the unemployed youth, victims of drugs, single mothers, and exploit kids face.

48. Through the combination of LSMS data with the social problems can be considered that poverty and social problems overlapped and strengthened each other especially in North, Northeast areas as well as in rural areas. According to the estimation of integrated indicators of social exclusion (that include indicators of poverty and marginalized groups) it results that cities of Kukes, Diber and Bulqize are those with the highest indicator of social exclusion continuing with the other cities of North and Northeast area. The situation is even problematic in the cities of the central area.

\section{D.4 FINAL ASSESSMENTS AND POLICY IMPLICATION}

49. As a consequence, policies must respond to the level of poverty and its profile (monetary versus non-monetary policies) as well as to its correlation with the social problems:

- Poverty has a regional and geographic dimension. Based on all definitions, villages in general and mountaneous areas in particular are poor ${ }^{11}$. This must influence the programs and the future policies for the poverty reduction in these regions.

- Poverty disproportionately affects the young. This phenomenon must be taken into consideration to better target poverty and social programs.

- Equal consideration in decision-making must be paid to monetary and non-monetary dimension of poverty.

- According to the analysis, many families are very near the poverty line, however, their poverty is not deep and severe.Well targeted transfers will bring about a noticeable achievement in poverty reduction in these cases.

- Poverty, unemployment and under-employment are closely linked with each other. Under-employment is spread among rural regions. This is linked with the structural problems of agriculture in Albania. In order to ensure stable employment in the nonagricultural sector in the rural regions, policies with employment impact are necessary.

- Education indicators are reasonably satisfactory. The challenges in this sector are linked to the increase in the number of students registered in high school and vocational training courses. Secondary education should be part of the government strategy for poverty reduction.

- Labor market studies expose the gender gap which must be taken into account in labour market policy development and program implementation ${ }^{12}$.

\footnotetext{
${ }^{11}$ Also according to MoLSA the economic assistance to the communes in the cities of Kukes, Has, Tropoje, Diber, Malesi e Madhe, Librazhd and Gramsh covers approximately about $80 \%$ of all families receiving economis assistance in such districts and the number of families receiving assistance varies from 40-95\% of the total families of such communes. This shows that economic assistance in rural areas has been concentrated in such zones where the quantity of land per capita is low, while in flat rural area economic assistance is lower. This is due to the fact that economic assistance in rural areas depends on the quantity of land, while in urban areas it depends more on family incomes.

12 According to the information given from MLSI, the unequality between men and women is not related to the wages. The wages are equal for same jobs. This inequality is related to the access that women have in different sectors of labor market. It can be explained from the fact that the labor market is full of activities that ease the male employment.
} 
50. The country's development and modernization, influenced by transition reforms, and lately by continuous economic growth, is contributing to the improvement of the general living standards. Nevertheless the benefits are more noticeable in the urban areas particularly in Tirana whereas the rural ones especially the most remote mountainous regions, are almost forgotten.

51. Based on 2002 LSMS results which are different from those used in the preparation of 2001 NSSED, not only due to the methodology used, but aso due to the fact that for the period 98-2002 progress on the economic and social development fronts have had a positive impact in reducing poverty In this document, the medium-term and long-term objectives of poverty reduction and the alleviation of social problems and policies have been revised and improved in accordance with the MDGs. These have been described in the respective chapters of this document.

52. For the 2003-2006 medium-term period we are aiming at reducing the absolute poverty rate to $20 \%$ and the level of extreme poverty to $34 \%$. We are also aiming at slightly reducing non-monetary dimensions of poverty as well as alleviating the social problems and the poverty dimensions of categories at risk. 
E. IMPLEMENTATION OF POLICIES AND PRIORITY PUBLIC MEASURES

E.1 INSTITUTIONAL AND THE GOVERNANCE REFORMS

E.1.1 JUDICIAL SYSTEM

E.1.2 PUBLIC ORDER

E.1.3 PUBLIC ADMINISTRATION REFORM

E.1.4 PUBLIC FINANCE REFORM

E.1.5 DECENTRALIZATION REFORMS

E.1.6 LEGISLATIVE REFORMS

E.1.7 IMPLEMENTATION OF ANTI-CORRUPTION MEASURES

E.2 PRIVATE AND FINANCIAL SECTOR DEVELOPMENT

E.2.1 INSTITUTION CONSOLIDATION AND MARKET FORMALIZATION

E.2.2 PRIVATE ENTREPRENEURSHIP PROMOTION

E.2.3 SME DEVELOPMENT

E.2.4 FOREIGN DIRECT INVESTMENT PROMOTION

E.2.5 TRADE LIBERALIZATION AND EXPORT PROMOTION

E.2.6 FINANCIAL SECTOR DEVELOPMENT

E.2.7 THE MEDIUM-TERM PROGRAM FOR FINANCIAL AND PRIVATE SECTOR DEVELOPMENT

E.3 INFRASTRUCTURE DEVELOPMENT

E.3.1 POWER SECTOR

E.3.2 TRANSPORTATION AND TELECOMMUNICATIONS

E.3.3 WATER SUPPLY

E.4 HUMAN RESOURCES DEVELOPMENT

E.4.1 EDUCATION

E.4.2 HEALTH

E.5 SOCIAL POLICIES

E.5.1 PREVENTIVE AND CURATIVE SOCIAL POLICIES

E.5.2 FACILITATING AND ALLEVIATING SOCIAL POLICIES

E.5.3 SOCIAL INSURANCE

E.6 ENVIRONMENTAL PROTECTION AND SUSTAINABLE NATURAL RESCOURCES MANAGEMENT

E.7 INTEGRATED RURAL DEVELOPMENT

E.7.1 ACHIEVEMENT OF PRIORITY OBJECTIVES AND MEASURES TAKEN IN 2002

E.7.2 SUSTAINABLE NATURAL RESOURCES MANAGEMENT

E.7.3 2003-2006 MEDIUM-TERM PROGRAM FOR RURAL DEVELOPMENT

E.8 URBAN DEVELOPMENT 


\section{E. IMPLEMENTATION OF POLICIES AND PRIORITY PUBLIC MEASURES}

53. "The improvement of the health and educational services, and (ii) improvement of infrastructure and life services towards the population, constitute priority fields of the Strategy, which need special attention; (iii) he institutional reformation and (iv) the economic growth constitute the pillars of the Strategy; (v) the macroeconomic stability and (vi) the social support are conditions for the realization of the Strategy ${ }^{13}$."

54. Based on this approach, the program of priority public measures has been developed and partially implemented during the reporting period. This chapter analyses progress on the Strategy's priority sectors. The annexes to this document provide more detailed information on this regard.

\section{E.1 INSTITUTIONAL AND THE GOVERNANCE REFORMS}

55. The deepening of institutional and legal reforms was one of the main priorities of NSSED implementation during 2002. These reforms have been drafted and implemented through an stronger analytical process based on more robust information, consultation, and public participation.

56. Institutional reforms have aimed at:

- Increasing the strength of law enforcement bodies and policy development capacities.

- Improving democratic governance and delivery of public services.

- Focusing attention on the poor and the social cases in order to enable their participation in decision making.

\section{E.1.1 JUDICIAL SYSTEM}

57. Judicial independence has increased, albeit not to the desired level. This increase in independence has not been accompanied by a corresponding increase in fairness, effectiveness or efficiency of the judicial system.

58. During 2002, a series of measures were undertaken such as: i) procedural and instructional improvements, ii) institutional enhancements at every level and court (especially in the higher courts such as: the Supreme Court, the Supreme Council of Justice and its inspectorate, the courts of appeal iii) capacity building through training and the expansion of the magistrate's school, iv) improvement of the facilities available.

59. From the judicial statistics in 2002, and as compared to the previous years, a modest reduction of the number of appeals to higher instances of the judiciary was noticed. The reduction of the rate of returned and /or cancelled verdicts of the Courts of Appeal by the Supreme Court, has been observed (32\% in 2002 out of the $41 \%$ in 2001). Meanwhile, there is still a high rate of returns from the lower court cases by the Court of Appeal

60. There have been some improvements in the notary and advocacy services. A series of measures for fundamental changes in these two services has been prepared.

61. The re-organization of the system of clearance offices was finalized during 2002. Some training activities and the recruitment of a new and more qualified staff took place,

\footnotetext{
${ }^{13}$ NSSED-Executive summary, page 14, paragraph 25
} 
control has been enhanced, procedures have become clearer and a more efficient cooperation with the other structures of the state has been achieved. As a consequence, the rate of the judiciary's verdicts as executed by the clearance offices has become $50 \%$ compared to $150-20 \%$ of 2001 , before the reforms began.

62. The setting up of a network of legal aid centers by civil society, is contributing to an increase in the growth of the justice system whereas measures undertaken such as surveys or a PO BOX for public complaints, located at the Supreme Court, are contributing to greater transparency in the judiciary.

63. The justice system is still facing difficult challenges and suffers from a lack of public confidence. For this reason the reform of the justice system is one of the priorities for the 2003-2006 medium term periods. The reform in the judicial system is going to be implemented in accordance with the multi year strategic program, which has been assisted by our international partners.

64. The medium-term reform priorities according to the sectors are i) consolidation of judicial system's independence ii) the increase in confidence in the judicial system iii) the correct implementation of judicial decisions iv) tackling organized crime v) extension of alternative dispute resolution mechanisms vi) increasing the accessibility of disadvantaged social groups to the justice system

65. While the areas of the basic measures still remain the same, the reforms will be deepened and more rigorously monitored. The main set of measures to be undertaken during 20032006 mid term are:

- Institutional restructuring in accordance with the Council of Europe and EU recommendation

- Strengthening of the High Council of Justice and its Inspectorate, regarding the decision-making on the appointment, promotion or castigation of judges, judicial supervision and transparency as well as its independence.

- Improvement of unifying and leading methodological role of the High Court of Justice.

- Introduction of a career system for judges accompanied with salary and remuneration reform.

- Reinforcement of capacities and professionalism by means of increasing the role of magistrates' school.

- Establishment of the Court of High Crimes.

- Establishment of new intermediate centers and commercial arbitrage ones which are going to be alternative choices to the private sectors ${ }^{14}$

- Greater accessibility by vulnerable groups to legal assistance.

- Legal and procedural improvements to increase judicial transparency and notes to the parties and the public

- Complete reform of the notary and advocate system.

- Measures to reinforce the prosecutor bodies.

66. The objectives and program measures for the justice system are described in detail in the annexes of this document as well as in the Document on the System of Justice Reform.

\footnotetext{
${ }^{14}$ At the beginning of 2003 started the activity the first center for Trade Arbitrage and Intermediation (an independent center registered as non-for-profit organization whose founders are a group of independent jurists), as a product of a Governmental project with WB support.
} 


\section{E.1.2 PUBLIC ORDER}

67. The enhancement of public order, the strengthening of personal and community security as well as the fight against crime including organized crime, have constituted one of the fundamental priorities during 2002.

68. The reform strategy targeting security forces and prosecution services, in accordance with the long-term sectoral reform program, has included the following features: i) a structural analysis and the improvement of the coordination between structures. ii) Strengthening of human resources through recruiting, training (including the strengthening role of the Academy of Order iii) strengthening of monitoring and evaluation as well as the introduction of performance incentives, iv) increase of cooperation with specialized international bodies, v) improvement of tools and technology for the intelligence service and information technology vi) increased attention to crime prevention vii) introduction of the democratic culture among the public order forces including strengthening the respect for human rights and improved relations with the public. vii) Legal amendments and ratification of the international conventions.

69. Public order has

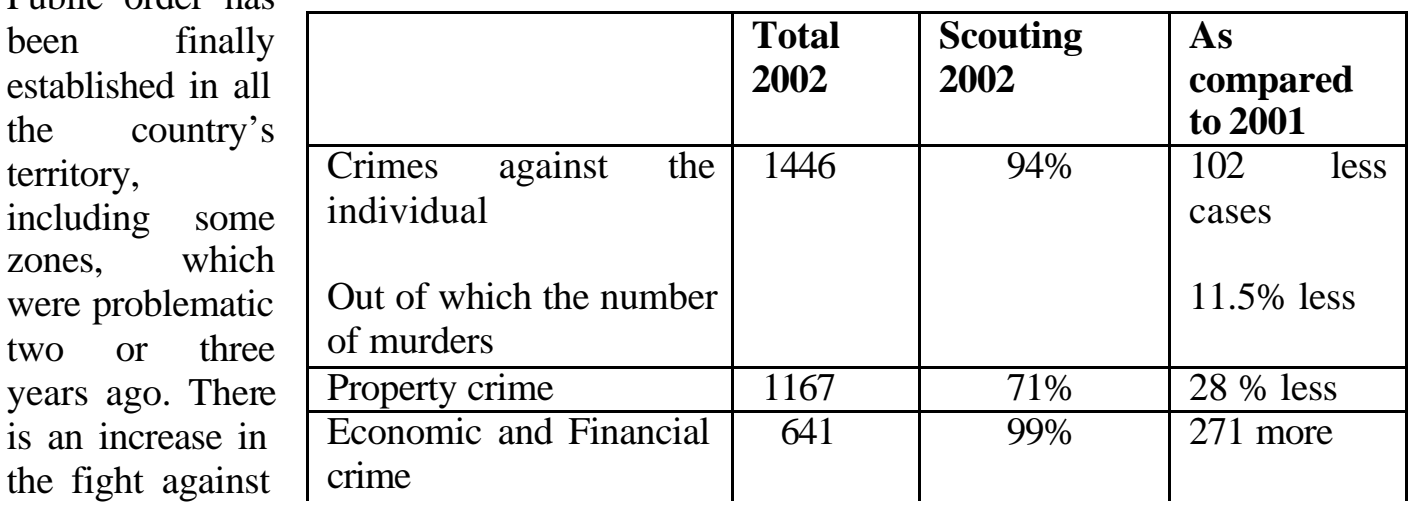

organized crime.

70. Initial successes have been noticed even in the fight against organized crime and illicit trafficking such as the complete elimination of the clandestine traffic of illegal emigrants publicly commended by the Italian Government and other international institutions. Meanwhile, the structure set up in the Ministry of Finance to prevent money laundering has frozen 36 bank accounts. Nevertheless, these successes are only preliminary and modest when compared to the gravity of the problem. To combat organized crime, particularly the international organized crime, greater efforts must be made by the Albanian Government as well as more support is required by the specialized international institutions.

71. The evaluation of the implementation of priority public measures has highlighted the weaknesses in the fight against organized crime and security, the fact that the initial reforms will give very positive effects in meeting the challenges, which become increasingly more complex.

72. The 2003-2006 medium term period aims at:

a. Fighting organized crime and trafficking a) elimination of illegal human being traffick b) sharply reducing children and female trafficking c) clear results in the fight against drug trafficking such as cannabis sativa production d) cracking down on organized crime structures and the fight against international terrorism e) increasing the effectiveness of the investigation related to money laundering. 
b. Security and public order in general a) strengthening public order (personal and community) across the country by responding to the regional urban and rural cases b) further reducing the rate of serious crimes by means of increasing surveillance and crime prevention c) reducing financial and property crime d) increasing road traffic security

73. The above-mentioned aims and objectives will be based on deepening the reform in public order structures and in the prosecutor's office, as well as, in all the other state institutions that play an important role in this field.

a. The recruitment and career system in the related structures, performance evaluation and monitoring, the incentive and renumeration system will be improved.

b. Training and other activities to increase capacities will be undertaken, thus increasing the position and role of the Public Order Academy,

c. Training within public order structures will be improved, especially training in the information and surveillance function,

d. Important investments in increasing and improving technology are will be carried out,

e. The collaboration with international partners in the fight against organized crime and terrorism will be intensified and expanded,

f. Legal and procedural improvements in the criminal code as well as in adopting domestic legislation on international agreements and treaties in the criminal field are will continue,

g. Crime statistics will be improved and different methods will be adopted to give complete and clear information to the public;

74. 2003-2006 medium term objectives and measures in the field of public order are described in more details in the Medium Term Program of the Ministry of Public Order and other institutions.

\section{E.1.3 PUBLIC ADMINISTRATION REFORM}

75. The institutional reforming process includes The Council of Ministers, other ministries and central institutions. Reforms are designed to ensure a more effective division among policy-making, policy execution, the executive, evaluation and audit structures and their decentralization to the regions. Improvements have been made in inter-institutional relationships meanwhile the delegation, and decentralization of authority has begun to show positive results.

76. The main success factor in the reform in the public administration has been the implementation of the civil servant status. The recruitment, horizontal and vertical movements in the civil administration are being undertaken through testing, a process which follows the publication of the vacancies in the printed media. The average number of the participants for each test increased from 5.4 persons in 2001 to 7 persons in 2002, thus increasing the chances for recruiting a better quality of personnel. In previous years the recruitment without any previous testing was the general rule, where, in 2002, this practice accounts for only a small and justifiable minority of recruitment actions.

77. During 2002, all civil servants went through the testing phase according to the legislation. The role of General Secretary was defined, representing the highest position in the civil service and serving as a link between the political and administrative level of the departments inside the ministry and in other institutions. The opportunity to appeal to the Civil Service Commission has contributed to the decrease of the political pressure in the cases of quitting posts, and an increase in stability. 
78. During 2002, increases of the salary structure were undertaken. This has resulted in greater stability within the civil service (the number of cases of leaving the post has consistently decreased in comparison with 2001), and there is an increased interest in state employment

79. Professional capacities in the public administration have increased. The Training Institute of Public Administration has undertaken comprehensive training. E.g. In March 2003 the comprehensive training of training of 600 civil servants began.

80. The implementation of the Civil Servant Status while successful at the central level has been less at the regional level and has been accompanied by several problems. During 2002, CSC and DOPA, have undertaken some measures in order to implement this status during 2003 and 2004.

81. The continuation and deepening of public administration reform will remain a priority among institutional reforms, being at the same time a key point for all governmental institutions. The areas of reform are clearly expressed at the priority actions programme 2003-2006, which has two main objectives:

- Strengthening of the administration's stability. The main actions here refer to a) improvement of the legal and institutional regulations defining the division between the political and the administrative level including the rights and obligations of each; b) strengthening of the Civil Service Commission's role as an instrument to reduce abuses in the framework of the Civil Servant Status; c) insuring the full implementation of the Civil Servant Status and other principles of public administration in the units of regional governance, where problems most occur, and the expansion of the principles of the Civil Servant Status in other government institutions like fiscal institutions, the customs and the diplomatic service,; d) promotion and education of stakeholders to the importance of strengthening administrative stability versus political imperatives. A detailed programme of activities supports the main areas of these measures.

- Increase in the performance of the public administration and civil servants. This is presently a problem area, and will require greater attention during the medium run (20032006). Civil service stability and high performance are closely related. According to the evaluations made, there is the risk that the performance of the civil servant degenerate which would put into danger the whole process of reform and cause needless bottlenecks inside the administration. The objective of increasing public administration performance is supported by an entire set of mid term measures that will be concentrated on the improvement of the system of high performance through motivation, discouraging poor performance and the abrogation of pofessional responsibilities in the administration and among civil servants. The main elements consist of: a) structural improvements, clarification of mandates, responsibilities and authority inside the ministries and at the inter ministerial level. b) adoption of a clear and monitorial scope of work for each civil servant c) initiating objective performance evaluation instruments. d) Adoption of appropriate motivation instruments, such as bonuses, and disciplinary actions. e) The above-mentioned approaches will be supported by expanding training opportunities and other activities that will increase the managerial capacities, including human recourses management capacities, in the administration, where the TIPA will play an important role.

82. The detailed programme of medium-term measures (2003-2006) is provided as annexes to this document and also in the Medium-Term Programme of DOPA and CSC. 


\section{E.1.4 PUBLIC FINANCE REFORM}

83. The improvement of fiscal administration and the management public resources has been considered of special importance for facing the challenges of long term development and European integration, as well as for securing the needed financial resources for the NSSED implementation.

84. The main reform priorities of the tariff and customs organs were: i) the organizational improvement, ii) extension of ICT. iii) Strengthening of internal control, iv) increased professionalism and staff motivation, v) adoption of improved standards for the tariff and customs procedures and vi) the improvement of the constructive and more transparent reporting to the business community. By the end of 2002, the tariff revenues increased by $24 \%$ as compared to the factic achievement in 2001 (or an increase of about 97 billion lek). There is as well, a considerable increase in the number of the registered taxpayers. Despite some of the problems that appeared, even the customs experienced a modest revenue increase in the range of $2,4 \%$ as compared to 2001 or 1.2 billion lek $^{15} .^{16}$ Meanwhile, progress in the 2003 fiscal framework, the closing of the duty-free shops as well as the organizational measures taken, have started to yield positive results in the first quarter of $2003^{17}$.

85. The reforms which began show that if implemented they can yield positive results even taking into consideration administrative weaknesses. The continuation and deepening of these reforms is considered as the key tool for achieving the medium term period objectives 2003-2006. During this period it is going to be accomplished the full passing of tax administration from custom administrations to the tax ones. To this end, reform in this area will have greater importance attached to it. It's purpose is to provide better administrative responses to the implementation of the development policies, and in particular, to the policies of encouraging private sector development, to the further liberalization of markets, to using fiscal incentives, to the continued fiscal decentralization reforms etc. These reforms have begun to be implemented and those undertaken remain the basic underpinnings of reforms of both tax and customs administration. While the sustainability has been increased in both administrations, further attention will be concentrated on such measures, which will increase their performance, transparency, the strengthening of the fight against fiscal evasion and that against trafficking, financial and economic crime, including money laundering. The increase of professionalism and investments in improving existing information and communications technology are going to be important measures. Strengthening of the fight against evasion will be accompanied by improving the information of both administrations aiming at eleminting the existing abuses, which are obstacles to business activity. The specific objectives and measures of the program have been presented in the annexes of this document.

\footnotetext{
15 Major problems occurred in 2002 along with the effects of the general reduction in tariffs within the framework of the WTO and free trade agreements with other countries in the region.

16 The large discrepancies between the tariff revenues should be corrected following structural changes to the revenue collection schemes such as VAT and the import of energy and machinery.

17 As compared to the period January-February 2002, during the same period in 2003, tariff revenues increased by about 25 per cent. It is a fact that during these two months, there have been positive results in the collection of VAT and excise revenues where the increases are 28 and 50 per cent respectively. [Only in these two voices, there is collection of about 500 million lek more. Even the customs realized about 520 million lek more for the same period. This makes no sense] Important steps actions have been undertaken by the administration against fiscal evasion.
} 
86. With respect to income and expenditure program, progress has been achieved in the analytical instruments being used in the annual budget exercise, reporting and updating of the NSSED. Considerable progress has been achieved in opening up these processes to the media and public. Improvements have been made in public expenditure management procedures, standards/criteria and in the continuous monitoring of the revenues versus expenditures and cash-flow management. Internal auditing functions were improved and the external control was enhanced during 2002 and more disciplinary measures were undertaken, including penal reporting. The increase in technology was another important priority for measures undertaken during 2002. Financial management reform will continue at the present pace, which is considered to be well targeted by highlighting the increase inefficiency and transparency in budget drafting and implementation.

87. Financial management reform will continue along appropriate present lines, by underlining increased efficiency, transparency and predictability through planning and implementing the annual and three-year budget frameworks. For this reason, legal and procedural improvements will be carried out, and advanced standards of forecasting and managing public finances will be adopted, especially, regarding enhanced linkages among development policies the allocation and administration of state funds. Another important approach will be the strengthening of the capacities of financial administration structures, as well as the completion of the system's automation. The strengthening of domestic and foreign financial control, the increase of transparency and the opening up of the central and local budget processes to the participation of civil society and the public will also be another important approach of the medium-term priority measures.

88. The improvement of the public procurement system has been a very important reform priority. During 2002, considerable progress was made in i) improvement of public procurement regulation, ii) strengthening the Agency of Public Procurement, iii) decrease of the number and value of sole-sourced bids and the centralized procurement of some standard goods was agreed upon for the procurement of a large number of goods and services common across the administration. Despite these measures, the public procurement system is not yet effective and transparent. This is why the deepening of the reforms throughout the system is a continuing priority.

89. While the improvement of the procurement methodologies and rules as well as increasing the capacities, the priority measures for 2003-2006 are linked with the aim of strengthening the accountability and the transparency of the procurement system. Some of the main measures for the improvement of the performance are I) improvement of the law and rules of public procurement ii) improvement of the database and information on markets, improvement of the linkages between the budgeting and procurement processes. On the other hand, making clear the accountability during the procurement process, expanding the access of media and the beneficiaries during the procurement process, improving the appeal procedures and links between the procurement and supervision of the contracts implementation, objective evaluation of the performance of the delivery of the goods and services by the suppliers are some of the main directions for strengthening the accountability and the transparency of the public procurement system

90. During the second half of 2002, measures to register and take an inventory of state assets were increased and improvements were made to the management of public companies by strengthening the role of The Supervising Board, monitoring its performance, auditing and control.

91. In the 2003-2006 medium-term period, we will complete the inventory and registration of state assets in the Real Estate Property. Meanwhile, we will improve the criteria and standards by which they are administered, including the transparency of their disposition 
and sale. We also will complete the transfer of certain assets to instances of local government.

\section{E.1.5 DECENTRALIZATION REFORMS}

92. Decentralization reform and the empowerment of local authorities have been key priorities as they are considered as directly linked with the NSSED objectives. Reform implementation during 2002 was carried out with clear and determined steps albeit with some needed adjustments.

93. During 2002 concrete measures were undertaken for transferring the competencies linked with the exclusive functions of municipalities and communes. As a result, all sectors have been devolved, except water and sewage. Regarding these sectors, CoM has adopted the policy document and action plan for the decentralization of the sector, which is in line with the other components of the overall reform of the water sector such as its commercialization and privatization. Regarding the shared functions of education, social care and public health there is the need for a more in-depth analyses and a more deliberate devolution through a better harmonization of the newly begun reforms in each sector with the roles of the local governments in each of these sectors.

94. The fiscal framework for 2003 together with the new adjustments to the formula for the distribution of the total pool of unconditional transfers from the state budget to local governments was a very important step in fiscal decentralization reform. The model adopted ensures on one side larger opportunities and scope for authorities of local governments to increase their revenues from local taxes and fees but on the other side promotes a higher level of accountability for managing these resources as well as the transparency of local governments During January-February 2002 all local government unit responded very well to these new fiscal opportunities and responsibilities through a rational and transparent process of adopting the new local taxes, fees and local budgets. The process of transferring property rights for immovable property has effectively started gradually and will increase in 2003

95. Local governing units are responding ever better to the needs for greater governance and managerial capacities. Meanwhile greater opportunities for training and assistance have been offered to them.

96. The positive effects of the decentralization reform have become visible in a great number of municipalities and communes across Albania and efforts in this direction will be continued and expanded. Thus:

- High school education; $\mathfrak{t}$ is being designed an agreement for a pilot project between the Ministry of Education and Municipality of Tirana, for the implementation of the competences of local government at high school education level, including the competences over investments and personnel assignment. Meanwhile, it is close to being complete the final draft of the document of high school politics, aiming the implementation at a national level of this function for the organs of local government;

- Social security; common working groups of MLG\&D and ML\&SM, have designed a draft on the social support in function of the decentralization process. Meanwhile, through a decision of the Council of Ministers, it will be applied a pilot programme with a revised scheme for the social support, with criterias in help of decision-making, including in it even the practical contribute of the beneficial.

97. At the end of the 2003-2006 medium-term period, the Government will have completed the decentralization process in accordance with the Constitution, the Decentralization 
Strategy and the Local Autonomy European Charter. The complete transfer of assets and the total transfer of financial and fiscal competencies will be complete. At the end of this period, the definition of the common functions and the clarification of the position of the local government will be complete (education, health service, social assistance, civil defense, etc). By the end of this period, will be completed also the reform of the administrative-territorial divisions, according to an analytical, participatory and consensual process, which is going to optimize such a division and create the basis for more effective and efficient local governance which will respond to local objectives, economic and demographic trends. In addition to the strengthening of the municipalities and communes, during this period we will aim at enhancing inter-communal co-operation with the District Council, so as to make possible the drafting and implementation of the regional and local development strategy, in response to the social and economic developments of the country.

\section{E.1.6 LEGISLATIVE REFORMS}

98. During 2002, The Albanian Parliament made progress in improving the effectiveness and the democratic character of the legislative process and its constitutional role in law enforcement oversight. The strengthening of the technical capacities, the enhancing of transparency, and the inclusion of the public in the legislative process and the election reform will be the priorities of the legislature in the coming period.

\section{E.1.7 IMPLEMENTATION OF ANTI-CORRUPTION MEASURES}

99. The fight against corruption remains a priority of the public agenda among all state structures. In the context of the national anti-corruption strategy in 2002-2003 an Action Plan on Preventing and Fighting Corruption has been integrated and includes specified measures on increasing the legislative efficiency, the civil servant reform, the improvement of transparency and the integrity of business transactions, public procurement, and public awareness. In the monitoring and implementation activities to strengthen the Monitoring Anti-corruption Group (MACG) were involved the Albanian Coalition of the Civil Society against Corruption and, Business Committee.

100. According to the assessment of the States Groups against Corruption GRECO, the establishment of this multidisciplinary instrument, the MACG has been a great achievement. Its structure together with the Permanent Unit comprised of a secretariat and investigating mechanism, and the linkage between MACG with the other institutions, as well as the direct support to the SPAI initiative have been successful. Albania has undertaken numerous activities to tackle corruption. In a short period of time it has been prepared an efficient legislative framework in support of the effective anti-corruption policies. Some new laws on the functioning of the High Council of Justice, the Prosecutor's office, notary service, bailiffs offices etc have been approved. The Penal Code has been composed of clauses regarding the penal corruption as well as other penal activities closely linked with corruption including passive and active briberies. Some of these clauses have been amended or changed recently in compliance with the international instrument and with the current situation in Albania.

101. The fight against corruption has been primarily based on the implementation of institutional, economic and legal reforms. The approval of legal and sub-legal acts or amendments and changes to the existing laws have shown to be important improvements. The most obvious improvement has been to the following: "for advocate", some changes in the law "for notary" the "usage of planned budgetary funds for goods, services, and constructions" which minimize the abuse on funds. The Council of Ministers approved the draft law to amend the law on the prevention of money laundering. The Council of 
Ministers approved amendments to the penal code and the law on the power of the judiciary. Work is ongoing for changes to other legislation. For example, the parliament has approved the draft law on the internal audit in the public sector. All of the current legislation has been aimed at the fight against corruption. These changes have been undertaken in accordance to EU requirements to fight corruption.

102. The investigation and prosecution against corruption have been intensified and a number of cases are ongoing. The Anti-corruption Unit has undertaken a series of studies, the recommendation of which have impacted legal reform. These include: "Penal sanctioning of corruption send to the Prosecutor's Office by the Ministries and central institutions, from 2001 and onwards to the first half of 2002; "On Issuing and Administrating the notary licenses by the Ministry of Justice, As Well As the Way the State and Public Control System on the Notary Functions Operate, " and "On Preventing and Fighting the Trafficking of Stolen Motor Vehicle", "Simplification of the Public Service in Central Administration".

103. By deepening transparency and eliminating unnecessary bureaucratic barriers in he public services provided by central administrative institutions, the Anti-corruption Unit has undertaken a wide Microsystems study on" Simplification of the Public Service in the Central Administration". The purpose of this study was to promote the simplification, normalization, unification of all of the procedures and technical criteria with regards to the delivery of all public services offered by center administrative institutions as well as the reform of the services and appeal procedures. The objective is to reduce the number of license, streamlinee similar units and functions and create a -"one stop shop". In addition to transparency and public information, the office of the State Minister to the Prime Minister has proposed the setting up of a three-party Committee, with representatives from the Government's specialized structures, the General Prosecutor, and civil society and media. The purpose is to exchange information and provide systematic follow-up to complains, penal prosecution of corruption and above all, public information on results of the decisions via the print and electronic media.

104. The National Strategy for the Fight Against Corruption, primarily a two-three yearstrategy was translated into an annual Action Plan, under Anti-corruption and Stability pact auspices. The new action plan for the period 2003-2004 will have the same vision as 2002-2003 Action Plan, but will set accurate targets, consolidate achievements already made and set concrete short-term objectives. This strategy has consisted of: implementation of the anti corruption law, declaration of assets and the financial holdings of public and elected officials; ongoing public administration reform increasing the transparency and integrity of commercial transactions and by promoting public awareness. It has also consisted of support to; administrative control mechanisms; reinforcement of legislation and strengthening public financial management.

\section{E.2 PRIVATE AND FINANCIAL SECTOR DEVELOPMENT}

105. The fundamental objectives and the priority public measures envisioned by the NSSED for 2002 have progressed in the following way:

\section{E.2.1 INSTITUTION CONSOLIDATION AND MARKET FORMALIZATION}

106. The main measures undertaken during this period for the achievement of the above objective have consisted in: 
- The drafting and approval of the new draft-law "On the Protection of Economic Competition," which calls for the establishment of the Agency for the Protection of Economic Competition as the institution that will deal with law enforcement.

- Beginning work on the computerization of the customs system, starting from the central level and then proceeding with the districts. The computerization of the Tirana and Durres customs systems is planned to finish in 2003.

- The improvement of the composition of the Independent Tax Appeal Commission, adding two representatives from the business community.

\section{E.2.2 PRIVATE ENTREPRENEURSHIP PROMOTION}

107. The actions undertaken in this area during 2002 include the following:

- The beginning of the implementation of the World Bank project (worth \$11.2 million) for the facilitation of trade and transport.

- Improving the access to information on businesses, through publications in the media and on-line of tax institutions and the establishment of the Center for the Publication of Legal Acts and Bylaws.

- The installation of special telephone lines for the registration of complaints both against the tax and customs authorities and other public bodies.

- Work has begun to implement the new bankruptcy law.

\section{E.2.3 SME DEVELOPMENT}

108. In order to implement this objective, a number of concrete measures were taken in 2002 such as:

- The establishment of a department for business promotion policies in the Ministry of the Economy;

- The drafting and approval of a special law on the SMEs which aims at supporting SME development with concrete programs and projects;

- The full legal framework has been prepared to set up the SME Agency and within the first half of 2003, this agency will become operational;

- Through an Italian Government grant, a scheme was prepared to guarantee credits to SMEs;

- Through a European Training Foundation project, training programs for SME were organized in the districts of Elbasan and Korce.

109. A marked progress was achieved during 2002 in the relationships between the banking system and businesses. The granting of credit continued to increase despite the difficulties that the Savings Bank encountered in the course of 2002. The credit surplus for the economy was 45.9 million lek ${ }^{18}$ while the new credit granted running this year was 54.4 billion lek. Micro credit schemes expanded.

\section{E.2.4 FOREIGN DIRECT INVESTMENT PROMOTION}

110. The general foreign investment climate improved in two areas:

- The security of investors has increased throughout the country as a result of the strengthening of security and public order measures.

- Investments in infrastructure, particularly in road construction, have been completed which is attracting foreign direct investment.

\footnotetext{
${ }^{18}$ The credit portfolio includes the credit surplus transferred to the Credit Treatment Agency (ATK), 8.7 billion lek.
} 
111. Considerable work was done during 2002 to:

- Draft and approve a full legal package for the establishment of the Foreign Investment Promotion Agency/ANIH, which has now become operational.

- The Ministry of the Economy, in cooperation with other public and private institutions, is preparing the draft guide for foreign investors, which will be published in the first half of 2003.

- In cooperation with FIAS, the government undertook a study on the administrative barriers to investing, based on which the measures to reduce or eliminate these barriers will be implemented.

112. The value of foreign investments for 2002 was estimated to be $\$ 143$ million. Compared to 2001, this figure is declining, but if we subtract privatization investments for 2001, foreign direct investments for 2002 are higher.

\section{E.2.5 TRADE LIBERALIZATION AND EXPORT PROMOTION}

113. In the context of public priority measures envisioned in the NSSED, during 2002:

- The export development strategy was approved;

- The draft-law on the establishment of the Agency for the Promotion of Exports was prepared and is expected to be approved by parliament in the first six months of 2003;

- Bilateral negotiations with the signatory countries of the Memorandum of Understanding for the further Liberalization and Facilitation of the Regional Trade were concluded, while the Agreement of Free Trade with Macedonia entered into force in August 2002.

\section{E.2.6 FINANCIAL SECTOR DEVELOPMENT}

114. The restructuring and strengthening of the financial sector was characterized by these developments:

- While its privatization was unsuccessful, the Savings Bank underwent initial restructuring efforts and is improving its performance considerably.

- Beginning in October 2002, the citizens' deposits will be insured by virtue of the law "On the insurance of deposits" enacted in March 2002 The Deposit Insurance Agency began to function at the same time.

- The Supervisory Council of the Bank of Albania has approved the "Manual for Taking Correcting Measures." It has also continued to periodically publish data on the banking system and provide non-banking financial statistical reporting.

115. Financial sector reform has undergone progress in the following areas:

- The legal and regulatory basis for the functioning of the Tirana Stock Exchange was improved. The Stock Exchange was removed from the Bank of Albania to create an independent institution;

- The insurance market also was expanded both with new services and expanded coverage in the regions. Progress is also being made in the preparation and privatization of the INSIG, which after its successful expansion in Kosovo obtained a license to open offices in Macedonia.

116. The improvement banking services was accompanied by the following activities:

- The completion of the of the World-Bank funded RTGS which began in 2001 and was ongoing in 2002, is expected at the end of 2003;

- At the end of 2002, the banking system in Albania was composed of 14 commercial banks, as compared to 10 banks, which existed in 1997. Nine new branches were 
opened in 2002 and 1 agency that operates in the market. The number of currency exchange offices increased considerably from 38 in 2001 to 58 at the end of 2002;

- The activities micro-credit schemes spread considerably. There are seven such schemes in operation now, which have extended their credit granting activities into new areas of the country, including the poorest regions. There was also a considerable increase in the number of credit issued and the average loan amount; (Table 7 shows the results of three such schemes)

- The Bank of Albania has simplified the application process for granting approvals to extend the network of banking services across Albania. In all of the cases where the extension of the network was approved, approval was given based on the sound financial situation of the banks. 
Table 7: Micro-credit Schemes Progress

\begin{tabular}{|c|c|c|c|c|c|c|c|c|}
\hline \multirow[t]{3}{*}{ Mauntain Area Financing Fund } & & \multicolumn{7}{|c|}{ Year of Activity } \\
\hline & \multicolumn{2}{|c|}{$\frac{1}{2000}$} & \multicolumn{2}{|c|}{2001} & \multicolumn{2}{|c|}{2002} & \multicolumn{2}{|c|}{2003 (Plan) } \\
\hline & Amount in \$ & $\begin{array}{l}\text { Cummulative } \\
\text { growth }\end{array}$ & Amount in \$ & $\begin{array}{l}\text { Cummulative } \\
\text { growth }\end{array}$ & Amount in $\$$ & $\begin{array}{l}\text { Cummulative } \\
\text { growth }\end{array}$ & Amount in $\$$ & $\begin{array}{l}\text { Cummulative } \\
\text { growth }\end{array}$ \\
\hline Autstanding balance of credits & $\$ 1,400,000$ & $100.00 \%$ & $\$ 1,800,000$ & $128.57 \%$ & $\$ 4,100,000$ & $292.86 \%$ & $\$ 6,000,000$ & $428.57 \%$ \\
\hline \begin{tabular}{|l|} 
Number of active clients \\
\end{tabular} & 3200 & $100.00 \%$ & 3100 & $96.88 \%$ & 3700 & $115.63 \%$ & 4140 & $129.38 \%$ \\
\hline Average credit & 447 & $100.00 \%$ & 576 & $128.86 \%$ & 1,100 & $246.09 \%$ & 1,450 & $324.38 \%$ \\
\hline Area of activity & $\begin{array}{l}\text { Tropoje, Has, } \\
\text { Diber Puke }\end{array}$ & Kukes, & $\begin{array}{l}\text { Tropoje, Has, } \\
\text { Diber, Puke, } \\
\text { Mirdite, Bulqi }\end{array}$ & $\begin{array}{l}\text { Kukes, } \\
\text { Mat, } \\
\text { ize }\end{array}$ & $\begin{array}{l}\text { Tropoje, Has, } \\
\text { Diber, Puke, } N \\
\text { Bulqize, Korce } \\
\text { Permet, Berat }\end{array}$ & $\begin{array}{l}\text { Kukes, } \\
\text { Mat, Mirdite, } \\
\text { e, Pogradec, }\end{array}$ & $\begin{array}{l}\text { Tropoje, Has, } \\
\text { Diber, Puke, N } \\
\text { Bulqize, Korce } \\
\text { Permet, Berat, } \\
\text { Kolonje, Tepel } \\
\text { Skrapar }\end{array}$ & $\begin{array}{l}\text { Kukes, } \\
\text { Mat, Mirdite, } \\
\text { e, Pogradec, } \\
\text { Librazhd, } \\
\text { lene, }\end{array}$ \\
\hline \multirow[t]{3}{*}{ Rural Finance Fund } & \multicolumn{8}{|c|}{ Year of Activity } \\
\hline & \multicolumn{2}{|c|}{2000} & \multicolumn{2}{|c|}{2001} & \multicolumn{2}{|c|}{2002} & \multicolumn{2}{|c|}{2003 (Plan) } \\
\hline & Amount in \$ & \begin{tabular}{|l|}
$\begin{array}{l}\text { Cummulative } \\
\text { growth }\end{array}$ \\
\end{tabular} & Amount in $\$$ & $\begin{array}{l}\text { Cummulative } \\
\text { growth }\end{array}$ & Amount in \$ & $\begin{array}{l}\text { Cummulative } \\
\text { growth }\end{array}$ & Amount in $\$$ & $\begin{array}{l}\text { Cummulative } \\
\text { growth }\end{array}$ \\
\hline Autstanding balance of credits & $\$ 2,673,760$ & $100.00 \%$ & $\$ 3,685,186$ & $137.83 \%$ & \begin{tabular}{l|l|l|} 
& $\$ 5,427,917$ \\
\end{tabular} & $203.01 \%$ & N.A & \\
\hline Number of active clients & 4423 & $100.00 \%$ & 5277 & $119.31 \%$ & 6380 & $144.25 \%$ & N.A & \\
\hline Average credit & 767 & $100.00 \%$ & 939 & $122.43 \%$ & 1,176 & $153.32 \%$ & N.A & \\
\hline Area of activity & $\begin{array}{l}\text { Tirane, Elbase } \\
\text { Vlore, Kruje, } \\
157 \text { fshatra }\end{array}$ & $\begin{array}{l}\text { an, Gramsh, } \\
\text { Gjithsej }\end{array}$ & \begin{tabular}{|l} 
Tirane, Elbasa \\
Vlore, Kruje, \\
Lushnje, Fier, \\
173 fshatra
\end{tabular} & $\begin{array}{l}\text { an, Gramsh, } \\
\text { Durres, } \\
\text { Gjithsej }\end{array}$ & $\begin{array}{l}\text { Tirane, Elbasa } \\
\text { Vlore, Kruje, I } \\
\text { Lushnje, Fier, } \\
\text { Gjithsej } 248 \mathrm{fs}\end{array}$ & $\begin{array}{l}\text { an, Gramsh, } \\
\text { Durres, } \\
\text { Kavaje, } \\
\text { shatra }\end{array}$ & $\overline{\text { N.A }}$ & \\
\hline Besa Foundation (urban Microc & redit) & & & & Year of $A$ & Activity & & \\
\hline & 200 & & 200 & & 200 & & $2003(\mathrm{~F}$ & Plan) \\
\hline & Amount in \$ & $\begin{array}{l}\text { Cummulative } \\
\text { growth }\end{array}$ & Amount in \$ & $\begin{array}{l}\text { Cummulative } \\
\text { growth }\end{array}$ & Amount in \$ & $\begin{array}{l}\text { Cummulative } \\
\text { growth }\end{array}$ & Amount in \$ & $\begin{array}{l}\text { Cummulative } \\
\text { growth }\end{array}$ \\
\hline Autstanding balance of credits & $\$ 4,973,482$ & $100.00 \%$ & $\$ 6,936,598$ & $139.47 \%$ & $\$ 10,417,637$ & $209.46 \%$ & $\$ 12,118,869$ & $243.67 \%$ \\
\hline Number of active clients & 2637 & $100.00 \%$ & 3417 & $129.58 \%$ & 4488 & $170.19 \%$ & 5375 & $203.83 \%$ \\
\hline Average credit & 1,886 & $100.00 \%$ & 2,030 & $107.64 \%$ & 2,321 & $123.06 \%$ & 2,255 & $119.57 \%$ \\
\hline Area of activity & $\begin{array}{l}\text { Tirane, Shkod } \\
\text { Elbasan, Kava } \\
\text { Gjirokaster, S }\end{array}$ & $\begin{array}{l}\text { der, Berat, } \\
\text { aje, } \\
\text { Shijak, Puke }\end{array}$ & $\begin{array}{l}\text { Tirane, Shkod } \\
\text { Elbasan, Kava } \\
\text { Gjirokaster, S } \\
\text { Korce, Vlore, } \\
\text { Lezhe, Sarand }\end{array}$ & $\begin{array}{l}\text { ler, Berat, } \\
\text { aje, } \\
\text { hijak, Puke, } \\
\text { Pogradec, } \\
\text { de }\end{array}$ & $\begin{array}{l}\text { Tirane, Shkod } \\
\text { Elbasan, Kava } \\
\text { Gjirokaster, Sh } \\
\text { Korce, Vlore, } \\
\text { Lezhe, Sarand } \\
\text { Gramsh, Lush }\end{array}$ & $\begin{array}{l}\text { der, Berat, } \\
\text { aje, } \\
\text { hijak, Puke, } \\
\text { Pogradec, } \\
\text { de, Durres, } \\
\text { ajje }\end{array}$ & $\begin{array}{l}\text { Tirane, Shkod } \\
\text { Elbasan, Kava } \\
\text { Gjirokaster, Sh } \\
\text { Korce, Vlore, } \\
\text { Lezhe, Sarand } \\
\text { Gramsh, Lush }\end{array}$ & $\begin{array}{l}\text { ler, Berat, } \\
\text { ije, } \\
\text { hijak, Puke, } \\
\text { Pogradec, } \\
\text { le, Durres, } \\
\text { nje }\end{array}$ \\
\hline
\end{tabular}

\section{E.2.7 THE MEDIUM-TERM PROGRAM FOR FINANCIAL AND PRIVATE SECTOR DEVELOPMENT}

117. Support for private sector development for the 2003-2006 period will continue according to the priority areas and the instruments already targeted. It will be based on reinforcing market institutions, increasing access to credit and financial services, expanding information and the use of technology, improving public services for business, and 
continuing policies aimed at economic integration. The policies and measures will be implemented on an ongoing basis with the involvement of the business community.

118. The public priority measures in achieving these objectives have consisted of continuing the structural reforms already in process in all key components. In addition to the specific measures defined in the NSSED, private sector development will be facilitated by a number of inter-sectoral measures, such as, the improvement of governance, law enforcement infrastructure development, particularly the energy sector, reforms in the judicial system and further market liberalization

119. After completing the study on the administrative barriers to the private sector development and foreign investments completed by FIAS, on March 2003, the Government has committed itself to establishing an inter-ministerial working group to define the priority actions to co-ordinate the government's program, based on the study's recommendations. This document was subject to wide consultations with stakeholders including the business community, civil society, and donors. Currently working groups have been established which function according to the main priorities of the proposed reforms.

120. For the longer term, government policies have been developed consistent with the SAA and aim at:

- Harmonizing the legislation with the EU standards to increase the international competitiveness of the private sector;

- Ensuring the sustainable exploitation of natural resources;

- Export market development and diversification;

Creating additional sources of revenue generation by diversifying product lines and markets.

121. Free Trade Agreements have been concluded with all countries of the region. Trading regimes have to be negotiated in the context of the Stabilization-Association Agreement, thus expanding opportunities for the business community. The increase of economic competitiveness will be the pillar of structural reforms in this field for the future.

122. The strengthening of the banking sector and financial market development will be key to structural reforms. The privatization of the Savings Bank has been expected to increase competition and increase of the inter-banking activities while promoting private sector growth. The strengthening of the market's supervisory system, the harmonization of legislation with the EU standards establishing financial services in accordance with European practices will remain a priority. The incorporation of non-banking financial institutions into the monitoring and supervisory system will increase the sustainability of the overall system and increase public confidence in these institutions.

\section{E.3 INFRASTRUCTURE DEVELOPMENT}

\section{E.3.1 POWER SECTOR}

123. The Albanian electrical power grid had to cope with major challenges during 2002. Imports increased relative to previous years to keep pace with the increased demand for electricity power. While in 2000 , electricity imports accounted for $17.46 \%$ of local consumption; this figure was 32.5\% in 2001 and $42.3 \%$ in 2002. State subsidies for the energy sector of energy reached 7.5 billion lek in 2002. However, as a result of the creation of water reserves, the electricity supply was much improved at the end of 2002 and in 2003. To improve the sector's performance during 2002 and consistent with NSSED objectives, reforms were undertaken in the following priority areas: 


\section{Improvement of KESH's economic and financial indicators}

124. The improvement of KESH's economic and financial indicators was considered as a fundamental condition for achieving other strategic objectives in this sector. To this end, penalties were imposed on those who have abused the energy supply such as power cuts commensurate with the level of failure of clients to pay their electricity bills based geographical location Work is underway to implement a differentiated method for every consumer, install new meters, consolidate KESH's internal discipline, and conduct public awareness raising campaigns.

125. The indicators of the losses of electricity in the grid and the revenues for 2000-2001 and 2002 for KESH have marked a considerable improvement year over year, they are shown in the following figures:

\begin{tabular}{|l|l|l|l|}
\hline & Year 2000 & Year 2001 & Year 2002 \\
\hline Losses & $43.4 \%$ & $38.1 \%$ & $35.3 \%$ \\
\hline Invoiced amount & $61.56 \%$ & $84.53 \%$ & $89.9 \%$ \\
\hline
\end{tabular}

Gradual liberalization and improvement of the legal framework in the energy sector

126. Energy prices were increased bearing in mind the consumer's ability to pay.

\section{Enhancing import, transmission, and distribution capacities}

127. Considerable investments were made during 2002 in the interconnection lines, the transmission and the distribution grid. As a result of this, technical problems restricting imports were overcome, making possible a more effective and sustainable power supply to a greater number of consumers.

\section{Electrical energy sector restructuring}

128. The re-organization process of KESH has started, consisting mostly of its unbundling in three departments (generation, transmission, and distribution). Efforts continued to pave the way for the sector's privatization according to the strategic plan on the generation and distribution of energy.

\section{Reforms for the 2003-2006 medium-term period}

129. According to the medium-term energy sector program, the implementation of the measures to strengthen he sector's discipline will be sustained along with capital investments to increase production. KESH's transmission distribution capacity will be reinforced to integrate it with the regional and European networks. Creating space for private sector investments has also encouraged energy substitution and diversification.

130. More specifically, the objectives consist of (i) setting up a sound financial and technical sector by improving the management system and resources and customer services; (ii) improving the legal and regulatory system by means of supporting the energy regulatory authority, (iii) the reorganization of KESH by separating it into three companies; (iv) preparing the privatization process for the distributions and generation of power as well as attracting private investment to the sector; (v) participating in the regional and European energy market. The Government has drafted a number of programs under implementation, in order to improve the situation in this sector. According to the program already approved and up to 2006, the reduction of energy sector losses are estimated at about 30 $\%$, while with regards to the level of collection, it is expected to increase to $96 \%$ from 89.9 in 2002. With respect to energy, its diversification and substitution, a number of different externally-financed projects such as the construction of a thermal power plant in 
Vlorë, the rehabilitation of the hydropower facility at Casic (Kaskave), the continued strengthening of the energy transmission-distribution network and the installation of meters have been and will be undertaken.

\section{E.3.2 TRANSPORTATION AND TELECOMMUNICATIONS}

131. The expansion and improvement of transportation infrastructure capacity has also been a priority objective. For this purpose:

- Major public investments have been made with the support of international partners to: i) rehabilitate and expand the major North - South and East- West corridors, the regional main connecting arteries, and other roads of national importance ii) extend and rehabilitate the regional, urban, and rural roads consistent with trends in economic and demographic growth and the objectives to increase the access of the poor areas to the main road network. Expenditures have also increased for the maintenance of the extended road network. Ownership transfer and maintenance of rural and urban roads at the organs of local governance, and the gradual transfer of road networks into entrepreneurial contracts (towards privatization), is expected to give positive effect in this direction.

- Investments have been made to enhance the capacity of the ports of Durres, Vlore, Shengjin, and Saranda to handle vehicular traffic. The capacity of Mother Theresa airport has increased and the tender process to award a concessionary contract for its administration has begun.

132. Rapid progress has also been made in the telecommunications sector of where the mobile telephone service has registered a total of 800,000 subscribers as compared to about 400,000 in 2000; the number of subscribers with fixed phone lines has also increased, the number of internet users has grown considerably, and the first effects of the penetration of rural telephones have started to be observed. The privatization of Alb telecom and the granting of a new license for cellular telephones is being implemented. The postal service is also subject to reform measures creating the possibility for the provision of private services in this sector.

133. The key medium-term objectives during 2003-2006 in the development of transportation and telecommunication infrastructure remain the establishment of a modern infrastructure network, so as to reduce the economic costs and reduce poverty, particularly in rural area. To this end, the measures programmed, for the completion of the national road network and its inclusion in the pan-European transportation network as well as the deepening of the privatization of infrastructure services of the services (road, naval, air transport) and the improvement of the institutional and regulatory framework have been the main priority objectives of the Government. The improvement in the urban and rural road network as well as the improvement of the maintenance of the road network have also been priority objectives. Moreover, efforts in the air transportation sector, including the attraction of private investment will continue. The deepening of telecommunication sector liberalization, the expansion of the telephone network, particularly in rural areas and the attraction of information and communications technology companies have been important priorities in the development of the private sector in this field. The Government has been adopting incentives and sector support policies.

\section{E.3.3 WATER SUPPLY}

134. The water supply sector has suffered major problems regarding its capacity, extension, access, water quality and the sector's management, administrative and financial capacity. Major steps have been taken to address these issues. Considerable investments in the sector have led to a greater water supply, that is, an increase from 2 to 3 to 6 to 9 hours a 
day for about 1 million consumers in urban and rural areas of the country, and greater water quality. The implementation of management reforms in the sector has been another priority. The transformation of the water enterprises into public associations is near completion and the process to transfer the ownership and administration to local authorities has begun has. This is a process that is being carried out along with the privatization through concessions of some of the largest water supply companies which has already been implemented such as in Elbasan, or which is underway as in Durres, Fier, Lezhe, Saranda, Kavaja, Berat-Kucove and other areas. During 2002, water rates were increased to cover costs. The administrative discipline in the sector has increased and as a result, the level of revenues from the payment of bills has increased from 54\% in 2001 to $65 \%$ in 2002 Moreover, many unlawful connections to the water system have been cut off. Sector reforms will continue to ensure greater discipline, privatization, decentralization, and the completion of major public investments.

135. Sectoral reform from 2003-2006 will continue to emphasize strengthening discipline, privatization and decentralization, as well as the completion of the large public investments. The measures undertaken by the Government during the last year have had positive effects in increasing water supply efficiency. The Government realizes that further improvements to the water supply remain a long-term commitment due to its fragile state and its great need for investments. The proposed reforms in the sector's strategic document of the sector will provide benefits to the population on an ongoing basis. Thus decentralization reforms will continue to empower local authorities, as will the practice of concession granting and other forms of private sector participation. Further improvement to pricing policies, improvements to quality services will be maintained. The Government will approve the water and wastewater strategy together with the national strategy for this sector. Reforms to date have had positive impacts on the quality of services to the population.

\section{E.4 HUMAN RESOURCES DEVELOPMENT}

\section{E.4.1 EDUCATION}

136. The main drivers of the MoES's education reform program are the NSSED, European norms, standards and national aspirations. In 2002, education expenditures represented $3.4 \%$ of GDP and $11 \%$ of general public expenditures. In 2001, these indicators became $3.1 \%$ and $9.8 \%$ respectively

137. To improve the sector's effectiveness in 2002: MoES i) concluded its restructuring with the support of the World Bank; ii) drafted a new Set of Functioning Regulations of the Ministry, which enable it to better target the Ministry's policy setting activities; iii) set up the Minister's Council, composed of education provider and dient representatives, to serve as the first instance to examine the Ministry's policy decisions; and iv) began to train Ministry staff with foreign experts.

138. In the context of increasing basic education, we can mention that:

- The rate of school dropouts has decreased. In 1998-1999, it was 3.2\%; in 1999-2000, it was reduced to $2.8 \%$, while in 2000-2001, it dropped to $2.4 \%$. For scholastic year that follows, the projection of the level of school abandoning at national level is $1.8 \%$. During the school year 2001-2002, about $64 \%$ of the students who completed primary education continued on to high school. During 2002-2003 school year, this figure was $66 \%$.

- The legal package for financial support for children from poor families, planned for 2002-2004, is not final yet. However, $\$ 6.4$ million contributed by international donors 
are operational. They were granted in 2002 and will continue to cover activities through2004. In particular, funds will be used to facilitate the participation conditions of children from economic ally disadvantaged families and from poor areas ${ }^{19}$.

- With respect to the provision of textbooks, the MoES ensured that there exist no differences between rural and urban areas. Mo ES plans the free use of books for the next school year byre-using textbooks.

- In 2002, 12.2\% more funding was directed for investments, including donor funding compared to 2001, while an increase of $7.5 \%$ has been foreseen for 2003, over2002. In 2002, 132 objects were completed, including 92 rehabilitations and 40 new buildings financed with funds from 2001. In 2003, 163 projects consisting of 126 rehabilitations and 37 new buildings are planned to conclude. On a national level, $47.8 \%$ of school facilities, which accommodate $30.5 \%$ of the students, need rehabilitation.

139. In the context of increasing the quality of the teaching staff:

- MoES has concluded the restructuring of the pre-university salaries. In 2002, salaries were increased by $12 \%$. Compared to 2000 , in 2002 , the salaries of the teachers, as a share of the per capita GDP, changed from $142.3 \%$ to $147.8 \%$.

- MoES has drafted a national needs assessment for teacher without the required education. The IPR has completed training modules for these teachers. The share of the teachers who meet the standards of MoES rose from $74.3 \%$ in 2000, to $81.2 \%$ in 2002.

- A project targeting correspondence studies in teaching faculties in in universities has concluded. It will continue to further training of the teachers who lack the appropriate education. Soon this system will start to be functional.

140. Regarding the increase in participation in vocational education and its adaptation to better satisfy labor market needs, we might mention that:

- In the 2002-2003, a total of 1751 more students were enrolled in schools, compared to the previous year. The share of students in vocational education was $15.4 \%$ during 2001-2002 school year and 16\% in the 2002-2003 school year.

- Domestic investments for vocational education in 2002 accounted for $34.6 \%$ of the investments in secondary education in general. In 2003, this ndicator is higher at $41.5 \%$. Planned investments for vocational education in 2003 will be 0.0217 times higher than in 2001.

- The Parliament adopted the "Law on Vocational Education and Formation," which makes possible the creation of a unified system of vocational education, training and life-long learning. Several regulations have been drafted, which have entered into force, and others are in the process of being drafted. In 2002-2003, MoES implemented a two-tier curriculum for six professions as an important step to increase school autonomy.

- A study on the establishment of a National Center for Vocational Training and Education was concluded in 2002. This Center will conduct studies for the reform of the VET system.

141. The program of priority measures in the education sector will deepen the reforms in the whole system in order to attain the objectives set. The reorganization of the educational system and the institutional relations will lead to de-concentration and decentralization to local authorities and school autonomy, while MoES will strengthen its leading,

\footnotetext{
19 The aid given consists mainly on grants given from the Department of Agriculture in USA in the framework of Global Initiative on Food and Education. It is the second year of its implementation in Albania through MERCY-USA, CARE INTERNATIONAL. This aid is given for the poor regions, aiming the increase in the level of attending the schools through free food distribution.
} 
coordinating, and monitoring role. Programs for creating greater access to education, particularly for the poor, ameliorating educational facilities, increasing the capacities and the motivation of the staff, enrollment rates in the high schools and the expansion of the vocational education will continue, while passing gradually to more rational models of the education system's expansion. Reform will be extended also to the University education by increasing the autonomy and improving the quality of the teaching methodology in accordance with the country's long-term development needs.

142. The main objectives of the Albanian Ministry of Education and Science for the 20032006 medium term period are as follows:

- The completion of the drafting of the national education strategy;

- Administrative and financial reform in the education system;

- Increasing the basic education participation beyond 98,5\% of the children;

- Providing education services to children difficulty and minority children;

- Increasing the high school participation rate to beyond $72 \%$ pupils, graduating the secondary school;

- Massive profilization of the high school general formation

- Drafting the framework of the basic curricula.

- Constructing or rehabilitating education infrastructure so $90 \%$ of the student population may receive their instruction in conformity to official standards.

143. The following objectives are critical to sectoral reform and development:

- Community participation, as;

- Strengthening the accountability of the education system

- The modernization of education information systems.

144. The long-term objectives will be achieved gradually and consistently according to European education standard. The Government envisages achieving the following targets by 2015 :

- The inclusion of all children in the basic education;

- Ensuring a quality basic education for all children;

- Achieving the enrolment rate for secondary education at $90 \%$

- The average duration school attendance not less then 13.5 years.

\section{E.4.2 HEALTH}

145. The final objective of the health system is the improvement of the health indicators, which will be accomplished through i) increasing the effectiveness and efficiency in the use of material, human, and financial resources of the health system, ii) improved access to minimal health services; and iii) specific interventions in special health sectors.

146. The first two areas have dictated the need to formulate and implement an entire strategy of reforming the health system, which has major problems regarding its effectiveness, efficiency, accessibility, and quality. The problems appear both at the level of coordination and strategic programming and in the provision of services.

147. The formulation of a clear strategy of health sector reform has been concluded. During 2002, a number of important measures were taken, while implementing this strategy, such as:

- Restructuring the Ministry of Health, prioritizing its role of a policy making, monitoring, and coordinating institution. The institutional strengthening was also extended to the Department of Public Health, the Institute of Health Insurance and Care, and to the managerial level of other public health institutions. Several 
improvements have been made regarding monitoring and auditing and public involvement in the monitoring and evaluation process of the health services. Preparations were made to start the computerization of the health system in Tirana.

- In light of the major problems existing in the financing scheme, along with partial improvements to the primary care health insurance scheme, family medicine and medicine, two pilot projects for extending the insurance service to the hospital and outpatient services - project of the Regional Health Agencies and Durres hospital are being successfully implemented and efforts have been made to launch a pilot project in Berat. The IHIC has begun drafting a comprehensive policy of health insurance and has strengthened its institutional and professional capacities.

- The tools and the planning processes, the measures and the budget have been improved. The launch of the master plan for the health system in the Tirana region has begun.

148. To improve access to and the quality of health care services, resources have increased year over year still, however, the sector remains far from a satisfactory level of funding. The public expenditures in 2002 for health accounted for $2.7 \%$ of the GDP and $8.49 \%$ of the total public expenditures, while in 2001 they were $2.0 \%$ and $6.47 \%$ respectively

149. Through the budgetary allocation and donor funding, 49 health centers and 38 polyclinics were built or rehabilitated and noticeable changes were performed to the hospitals of Shkodra, Vlora, Durres, Berat, Peshkopi and Korca. Partial improvements were made also to the network of other health centers in communes and municipalities. The supply of equipment and medicine has improved and a considerable training was organized for medical staff consisting of 456 doctors and 1826 nurses.

150. Through individual interventions and the support of the donors, it was possible to vaccinate the population, particularly over $97 \%$ of the children and mothers. Improvements in technology and the capacity of the laboratory network have been made, particularly for the inspection of drinking water. The network of outpatient clinics for the mother and child were extended and the system of monitoring epidemiological diseases was improved.

151. The Public health sector remains problematic. For this reason, it will remain a priority sector regarding general reform as well as financial support. Reforms to the in health care system will be based on the Ten-year Strategy for the sector as well as on the experience gained from projects and studies carried out.

152. Given the fragile state of the sector, it is a priority sector for the period 2003-2006. The public expenditure for the health care sector will be increased from $2.7 \%$ of GDP in 2002 to $3.2 \%$ of GDP in 2006 .

153. In the framework of the NSSED, the objectives of the health care service consist of: (i) an increase in the effectiveness and efficiency in resource allocation; (ii) ensuringaccess to and equity in improved-quality health services across the country; (iii) an improvement of the health targets through interventions in special areas.

154. The effective and efficient use of increased resources will be achieved by: i) restructuring the whole system, by making a modification to the role of the Ministry of Health, so as to formulate, implement and monitor the health policies ii) improve the planning process, carrying out studies to fully estimate financial gaps, management needs and the better allocation of sources; iii) decentralization of competencies to local institutions (establishing of the regional health authority) and strengthening the position of professional organizations (which will play an important role in dealing with ethics and 
the rights and responsibilities of patients and service providers.); iv) the continued fight against corruption; v) gradually setting up information systems aiming at integrating networks, flow and gathering of information and vi) supporting the privatization process in the health service, as well as, monitoring the private sector activities.

155. The financial sustainability health services will be achieved through reforms to the health insurance scheme. To this end, the health insurance strategy and the associate regulatory arrangements will be an important area of reform in 2003. The capacity of the health insurance institute will be strengthened vis-à-vis new and improved insurance schemes.

156. To ensure improvements in access and equity, in the health service across the country the following key targets are (i) completion of the initial health sanitary services. (During 2003-2006 the Government will aim at providing all of the needs for health centers at the level of the commune and over 50\% of the needs for the clinics for every village, by providing the necessary infrastructure and setting up the health staff. For that purpose 80 health centers must and 400 clinics be constructed or rehabilitated) (ii) preparation of the master plan for the health service development in two districts; iii) reorganization of hospital services; by setting up regional hospitals. (These hospitals must provide specialized services, which presently can only be found in Hospital University Centre in Tirana (HUCT)) (iv) the motivation of health service staff; (v) the improvement of the private licensing procedures, aiming at insuring services in rural zones and small cities as well as the better motivation of the staff working in these areas.

157. The improvement of health targets through interventions in special areas will be achieved by improving health promotion, limiting and preventing the propagation of contagious disease, tuberculosis, STD, improving maternal and child care, etc. We will provide the vaccines including those in the obligatory schedule of vaccines for $100 \%$ coverage of the population In addition; the Government will ensure a safe food and water supply, as well as ensure the ongoing and further expansion of the existing programs in this area. At the end of the medium term period we aim at reducing infant mortality by 14 deaths per 1000 live births, from 17,5 in 2002, while the mortality rate is anticipated to decline from 22.7 deaths per 1000 live births in 2002 to under level of 15 deaths per 1000 live births in 2006. We are also aiming at reducing the incidence of diarrhoeal diseases from 1400 for 100 thousands on less than 600 cases for 100 thousands of inhabitants.

158. In the framework of the strategy an important emphasis will be placed to particular categories of patients such as: mental patients, the chronically and terminally ill. In addition to regular conditions in the psychiatrics the Government will aim at expanding services

\section{E.5 SOCIAL POLICIES}

159. The focus of social policies is assisting those most vulnerable segments of the population, enhancing their involvement in decision-making and guaranteeing access to basic facilities and services.

160. Economic opportunities and increased benefits to the poor have been seen as the main priorities.

161. The need to guarantee a minimal level of income and essential services for the poor has required more effective enabling and compensatory policies and instruments. 


\section{E.5.1 PREVENTIVE AND CURATIVE SOCIAL POLICIES}

162. The increase of the employment rate has been a fundamental social policy objective. The prolonged existence of an informal sector, accompanied by informal employment has been a priority issue and is being treated with the necessary care so that the reduction of informal employment has temporary and minimal effects on employment and in the standard of living. A special focus has been the enhancement of the employment level of the poor.

163. Employment promotion through professional training was considered as a primary objective based on the strategy and the measures linked with it. Thus, 21 new vocational training courses were opened in 2002 and a total of 12,000 people were trained, of whom only $40 \%$ were employed. The state budget spent about 270 million lek for the period 2001-2002 for the establishment and improvement of training centers. Private initiative is assuming a greater importance in this area.

164. The expansion of employment services and the enhancement of their effectiveness (both the public and private) have been other important priorities for employment policies. In 2002, the number of cases of employment mediation increased $37 \%$ compared to 2001 . The number of the unemployed registered in the labor offices dropped from 180,000 in 2001 to 172,300 in 2002. According to a standard definition of the ILO and under the LSMS standards, the level of unemployment was $10 \%$.

165. Because of budget cuts, only 160 new projects were implemented in 2002 . These projects aimed at increasing the level of employment through salary and social insurance subsidies for businesses. This led to the employment of 4167 job seekers. In the meantime, the funding of 155 projects that were carried over from the 2001 continued, resulting in the employment of 3,500 other job seekers. These projects have targeted people in need. At the same time, other models are being implemented, such as social businesses, which create more suitable opportunities for the employment and integration of specific social categories.

166. For 2003-2006 period we aim to increase the employment rate and reduce the level of unemployment. This objective will be mainly supported by economic growth policies and by private sector development. Through employment policies the Government will achieve an annual average increase in the level of employment by 18000 persons in 2003 and by 22000 persons every year there after.

167. Meantime the reduction of the rate of informality in the labor markes is an important goal but also addressing the controversial effect of such policy. The achievement of this goal will be insured by improvement of the legal regulation, adoption of incentives and institutional strengthening measures.

168. Programs for employment promotion through training as well as through improvement of the performance of the employment intermediary services will continue. Strengthening the public centers for intermediation and training will support this goal, through promotioning the private and civil society services in this area and promotion of contemporary models of such as social business. The projects for employment promotion through subsidy of the social insurance costs will continue aiming to provide employment opportunities to around 5000 persons each year.

169. Active employments programs will aim to include more the unemployed poor persons and social cases identified through poverty data and statistics that the Government has gathered. 


\section{E.5.2 FACILITATING AND ALLEVIATING SOCIAL POLICIES}

170. The high-income poverty rate in the rural and urban areas and mainly the medium-term effects of the preventive social policies to reduce poverty have necessitated the need for considerable and sustained economic assistance, which accounted for 4.23 billion lek in 2002. The measures taken, consisting of studies and assessments, the institutional consolidation of the distribution network, the increase of transparency, and the consolidation of the capacities made possible: i) the increase in the level of inclusion of the poor, both due to the reduction of their absolute number (according to the most recent poverty assessment) and a better targeting, ii) the increase of the level of the coverage of the needs of the families by economic assistance with about 10\% more compared to 2001 .

171. Further reforms to the economic assistance scheme remains an essential need. The main priorities of the schemes' improvement, in terms of increasing the level of coverage, the amount of assistance, and the consolidation of its curative nature will be: i) the decentralization of the economic assistance schemes, beginning from pilot projects ii) the harmonization of economic aid with mechanisms of social protection and care, and promoting employment iii) the gradual orientation of the schemes towards the minimum living standards.

172. Considerable cash payments continued in 2002 for broad social categories and for narrow groups, while economic and social developments led to an increase of the kinds of social groups in need, because along with the traditional groups, transition has generated new categories of vulnerable groups and individuals requiring social care, such as violated women and girls, drug and alcohol abusers, street children and senior citizens without support.

173. Therefore, along with the improvement of the traditional system of cash payments and institutionalized care, the reform of the shift from social care nto community care has begun. One of the largest programs in this direction is the program that is being implemented in cooperation with the WB which includes NGOs, local authorities and communities, and which is increasingly targeting the social groups in need through their organizations.

174. Housing problems are very acute. Some have been inherited and some are accumulated. Despite the efforts made in this sector, the improvements made have been only modest. The considerable needs and high costs to satisfy those requirements and budgetary constraints require the use of alternative means, which are still under discussion. The formulation of realistic measures in support of unsheltered is primary objective in year 2003.

175. Medium-run reforms 2003-2006 in direction of aid policies comprise a main direction in the field of social policies not only for the fact of the big need for reform but also for the high public cost that they represent. As a consequence, the increase of social support for the poor and social categories in danger will mainly come through the increase of efficiency and effectivity of social support for these categories and individuals.

176. In the medium term will continue the programme of economic help of poverty through financial support of poor families. Meanwhile the number of these families is foreseen to decrease in 2006 by $12 \%$ from the actual number. The average degree of support will reach the double of the actual level (or about 52115 leke month per family in absolute value). The institutional empowerment, improvement of the data base, accomplishment of the verifications and cooperation with the local government will serve to the $100 \%$ 
coverage of all the poor families decreasing the abusements that occur today in the administration process of this scheme.

177. The social support for the category of handicaps will continue to increase aiming that support reaches the value of 7000 leks per month in 2006 or about $120 \%$ higher than 2002.

178. Social assistance through financial support will be combined better with the policies, social active and curative services and further more considering the multidimensional profile of poverty. At this aim will start the reformation of the scheme through pilot projects in some municipalities and communes of the country hat will facilitate the further decentralization of the poverty and this help will be combined with the policies of employment, expansion of the model of social business. It is aimed that thought this reform, public investments, inclusion of civil society and local communities, in the end of the medium term achieve a increase with $13 \%$ of the number of clients in residential services and about $60 \%$ in community services. An important characteristic will be the offer of according to the specific needs of each category in risk (children, young people, women, handicaps, old) related not only to the traditional social problems but also those more current (drugs, abuse, etc).

\section{E.5.3 SOCIAL INSURANCE}

179. The main interventions during 2002 in the social insurance scheme have included the lowering of contributions and raising the pension age, and the inclusion in the scheme of the rural population as contributors and the reduction of social insurance evasion. The institutional consolidation of the IHIC, capacity strengthening, the adoption of the incentives for spreading the insurance system, and the increase in of computerization of the schemes has supported reforms in this area.

180. Although these measures did not accomplish all of the objectives laid down in the program, they have produced positive effects in the improvement of the balance between the insurance scheme and the reduction of the state subsidies. During 2002, pensions in the cities and, particularly, in the rural areas, experienced and their alignment increased. The pensions of the other social categories were also raised, while the state budget subsidies were reduced by about 3.046 billion lek.

181. The system of social security has entered the implementation step of its complete and long-term reform, according to the defined steps of sector strategy implementation with a time expansion till 2050. In the medium run it is aimed first of all the strengthening of financial stability of social security scheme tending to narrow annually the difference between expenditures and income by 3-4\%. This goal will be accomplished through the enlargement of the contributor's base and also the optimization of social obligations level. The main measures relate to the ennarrowment of informality in labor market and also with institutional empowerment of the structures. There will be general raises of level of pensions, $10 \%$ for urban zones and 20\% for rural ones continuing with a further ennarrowment. It will be evaluated the possibility of an adoption of the scheme of pension indexation. The institutional empowerment of the Institute of Social Security will be supported from the enlargement of the local security agencies. 


\section{E.6 ENVIRONMENTAL PROTECTION AND SUSTAINABLE NATURAL RESCOURCES MANAGEMENT.}

182. Sustainable development is a priority for the country's economic and social development. The related public priority measures have been developed and implemented in accordance with the objectives and their plan for 2002 .

183. In light of serious environmental degradation and the misuse of the resources during transition, the main aim in the field of environment has been to reverse this trend and create the conditions for sustainable development.

184. Institutional strengthening and the increase in effectiveness in the implementation of the law, along with legal improvements that have been and continue to be made in the legal framework of the environment have been the main areas where efforts were concentrated in 2002. To this end, the Ministry of Environment and the Regional Agencies were restructured and pilot programs began to consolidate them and the Environment Inspectorate. A significant amount of training was organized for staff and the facilities and technologies made available to them were improved.

185. In cooperation with various international organizations and with civil society, work has been done to organize education and awareness campaigns on the importance of environment protection.

186. The reduction of pollution from existing resources was the priority measure taken, linking it with the environment and health dimensions of poverty. The measures have been concentrated in the hot spots according to a study conducted in 2000-2001, ranking the interventions according to the level of their public and community risk and the remediation options and costs. Considerable improvements were made also to the urban landscape, which have recovered public spaces and rehabilitated parks and green areas. Disciplinary actions were undertaken against illegal construction. The increase in public investments is expected to improve the urban environment, particularly the air, over the medium-term period.

187. The measures for the sustainable development and exploitation of natural resources have been another important priority in the environment field, which has helped to focus interventions in terms of development, greater access to the communities, of poverty reduction. Through the strengthening of the law enforcement and the adoption of incentives it is expected that on mid term the level of damage caused and the misuse of forests, land, coastal areas, water basins, and riverbeds will reduce. Pilot areas and projects for their sustainable use are being created.

188. The preparation and the adoption of long-term, public policy documents and instruments and their integration with the reforms of other relevant sectors, the transformation of environmental policies into cross-cutting policies for other reforms are also important directions of the measures and activities carried out in 2002.

189. Environmental policies are aimed at achieving sustainable development. The long-term objective will be to gradually achieve the environmental standards in line with Albania's commitments to the association process with the EU.

190. The 2003-2006 medium-term goals will be to: i) halt the process of serious environmental degradation, which has been taking place over the past decade; ii) create conditions for 
the rehabilitation of the polluted areas in accordance with minimum security standards; iii) increase the sustainable use of environmental resources.

191. The attainment of these objectives will have positive effects both on growth and poverty reduction,. The priority for public interventions will be those areas, in which a) high levels of the exposure of the populationto environmental hazards have been identif ied, b) considerable environmental values/assets and resources are at risk, c) the impact of the damage falls primarlily on the poor. Priority measures include:

- Consolidation of the environmental structures: In this regard attention will be focused on: the consolidation of the Ministry of Environment, the Regional Environment Agencies, the environmental inspectorate, the newly established Environmental Institute, the national environmental monitoring network etc.; the strengthening of the relations and cooperation with the European Environmental Agency (EEA) (as a component part of the efforts for the European integration); the identification of the responsibilities of other central and local institutions in the environmental area; the establishment/consolidation of the linkages between them, including disaster management institutions in cases of natural emergencies. The establishment of the Inter-Sectorial Committee for the Implementation of the National Action Plan on the Environment, under the chair of the Prime Minister, will contribute to the harmonization and the integration of the environmental issues into sector and macro policies for a Albania's sustainable development.;

- Preparation of environmental policy documents and instruments: The Ministry of the Environment will cooperate in the preparation of many important policy documents, such as: the national strategy for environmental protection, the strategy on the integrated monitoring of the environment and environmental education in schools etc. The implementation of the environmental policies will be facilitated by the application of the regulatory instruments (laws, decisions, discharge norms etc.), economic instruments (eco-taxes), and the updated environmental legislation, which has been recently approved. Special attention during the short and medium-term periods will be attached to the completion of drafting and approximation of the basic legal package on environment, the preparation and approval of the sub-legal acts for its implementation, and the application of important communication instruments, such as periodical reports on the State of the Environment in Albania, the launching of the Home Page of the Ministry of the Environment on the internet, environmental education in schools, closer cooperation and relations with the media, cooperation with civil society and efforts to increase its awareness and secure its participation in the drafting of the policy documents on environment, the achievement of of commitments stemming from international environmental conventions etc.

- Reduction of the existing pollution: the attention will be focused on those pollution sources, which: a) are close to inhabited areas; b) risk economic activity or undermine development, and c) their effects fall primarily on the poor. The measures consist of a limited number of research interventions and/or priority and emergency interventions for rehabilitation: a) analyses and rehabilitation interventions in the environmental "Hot Spots"; b) elemination of the toxic substances; c) reduction and management of the (historical or current) industrial pollutants; d) achievement of the commitments stemming from international conventions ratified by Albania.

- Sustainable use of resources: A series of measures will be implemented for this purpose during the medium-term period. They will create conditions for the sound management of resources and equitable access, especially for the poor, to them. The measures will focus on the sustainable protection and management of the resources, which are more vulnerable to be damaged, such as forests, agricultural 
land, fragile eco-systems, crossborder lakes etc. The measures will be combined, such as: i) sustainable protection and management of the crossborder lake ecosystems and the country's everglades; ii) reclassification and expansion of the protected areas and the establishment of the structures for their protection.

\section{E.7 INTEGRATED RURAL DEVELOPMENT}

192. Integrated rural development is an NSSED priority. It aims at: i) reducing the rural poverty through the sustainable growth of production and increased incomes; ii) the promotion of vocational training and alternative employment in farming and non-farming activities like agrifood, rural tourism, handicrafts, iii) the creation of equal opportunities regarding the quality of services; (iv) the improvement of the rural infrastructure such as roads, rural markets, the water and sewerage system, the reduction of the power cuts; (v) the increased access to financial resources and credit and the expansion of non-banking financial services; (vi) the enhancement of rural community organization, linkages and participation, and vii) the reduction of internal migration.

193. Agriculture and agri-food. The agriculture and agrifood sector has continued to be a major source of economic growth and poverty reduction in the country. On the basis of the considerable weight that this sector has in the GDP structure (33\%) and the sizeable percentage of the population living and working in rural areas (55\%), the increase in incomes from vegetable production, livestock, agro-industry, fishing, and forestry remains one of the main instruments for the economic and social development of the country. In 2002, particular attention was devoted to the accomplishment of the sector's basic objectives such as, i) the drafting and implementation of the sector strategies and support policies for the sustainable growth of production and the enhancement of its competitive capacity in the domestic and foreign markets, (ii) the increase of food safety and consumer protection, (iii) the sustainable exploitation and management of natural resources such as the preservation of the land, water, pastures, forests, and the protection of biodiversity; (iv) the development of institutional capacities capable of drafting and implementing agricultural policies consistent with regional and European integration.

194. Based on output, outcome and impact indicators, there was been a noticeable year over year growth trend in the sector in 2000 and 2001. It is worth noting that there was a considerable increase in public investments in the rehabilitation of irrigation and drainage systems, an increase in licenses issued to cultivate saplings and seeds, an increase the artificial insemination livestock, and the number of livestock farms. The use of chemical fertilizers, pesticides, and farming machinery has increased.

\section{E.7.1 ACHIEVEMENT OF PRIORITY OBJECTIVES AND MEASURES TAKEN IN 2002}

195. Arable land. Efforts to improve the legal and regulatory framework for the functioning of the land market continued with the elimination of the fundamental legal barriers that might hinder land transactions. The registration system of immoveable assets is operational throughout the country. However, it suffered severe operational problems during 2002 due to the temporary reduction of foreign financing. Regarding land consolidation, work was carried out to study some pilot areas to enlarge of the size of agricultural holdings.

196. The irrigation and drainage system. The restructuring of the Water Departments in the districts was concluded reducing their number by $34 \%$. The coverage of irrigation systems has increased to 19,500 from 18,000 planned hectares of land and the drainage 
area 17,000 from 16,000 planned hectares. The use of water pumps and the heavy machinery for drainage and irrigation has improved considerably.

197. Vegetable production. During 2002, greenhouse vegetable production increased in hothouses increased, while orchard, vineyard and olive production was a priority. The planting of rew fruit trees increased, although the demands of the sector far outstrip available credit. Considerable investments have been made in building greenhouses. A total of 40 hectares of green houses were built in 2002 only.

198. Livestock production and veterinary services. Commercial livestock production was revived in 2002. Some 20 Centers of Artificial Insemination were set up and about 36\% of the livestock have been inseminated on a national level. Livestock feeding has improved and the number of farms has increased. The Genealogical Books of the Livestock were consolidated. Increased livestock production has come as a result of the enhanced productivity per head of cattle.

199. Advisory Services. Public advisory services were extended throughout the country and two regional centers were set up and offer specialized free advice to the farmers. The following activities have been organized: training programmes, dissemination of research results, leaflets, and other publications representing over 2300 pages, and the preparation and the distribution of 12 technical and technological brochures. The new concept of contracted services has been publicized and the drafts of some model contracts have been prepared, which the contracted service providers will implement. In order to strengthen the dissemination of sector information, 32 information centers were set up in those areas where agriculture is one of the predominant economic activities.

200. Agri-food. At present, there are about 2,000 agro-processing facilities with over 10,000 employed, but only a small part of the local production is processed in these facilities. The greatest investments have been those made in the floor milling industry, the production of the soft drinks, meat processing, olive oil processing, milk processing, and others. During 2002 and in the context of the $2 \mathrm{KR}$ project, credit was issued to establish new agro-processing lines. Efforts have been made to improve the sector's regulatory environment, such as the law on "The manufacturing and trading of the olive oil.

201. Agricultural marketing. With the establishment of the marketing sector at the Agri-food Department in the Ministry of Agriculture and Agri-food, major steps were taken to improve the market infrastructure through the creation of wholesale markets and storage facilities in rural areas. The Ministry established close cooperation with international partners working in this field such as GTZ as well as in this field with the 2KR Project and the Agricultural Services Project,

202. Consumer protection and food safety. The rehabilitation and the equipping of the regional laboratories of the food inspection services concluded in 2002 and the training of the technical staff working in these laboratories and the food inspectors was completed. Approximately 250 new labels have been approved for more than 80 producers. Eleven regulations were issued which strengthen the implementation of nutrition legislation and the conduct of a number of rigorous inspections of food products that are produced, imported, and marketed in the country. Work has been done to approximate Albanian foodstuffs legislation with that of the EU

\section{E.7.2 SUSTAINABLE NATURAL RESOURCES MANAGEMENT}

203. Fishing and aquaculture. To better utilize the country's water basins, two fishing management organizations have been set up in Fier and Elbasan. These are two areas with 
a high concentration of water basins, which were provided with the necessary spawn. Rehabilitation began in the Saranda and Vlora fishing ports. Work has been carried out to monitor the coast areas and those cultivating bivalve mollusks. Some interventions were undertaken in lagoons in order to provide their access to the open sea and improve their hydrological balance. A database was set up to monitor the fish reserves according to FAO and EU standards. In addition, a differentiated fuel price for fisherman was established in the framework of Albania's new law on excises. An agreement for the establishment of a General Fishing Committee for the Mediterranean was approved in principle (GFCM), which paves the way to Albania's membership in this important FAO organization.

204. Forests and pastures occupy about $50 \%$ of the country's total area (36\% forests and $14 \%$ pastures). To monitor and protect forested areas, an inter-ministerial Task Force was set up. The Task Force has made significant progress in reducing illegal cutting and the trafficking in timber. The transfer of the state-owned forests to the communes for their use continued. Special measures were also taken to preserve fauna.

205. Institutional reform. In the context of institutional support for integrated rural development, the following were accomplished in 2002: i) a special sector for rural development was set up, ii) the platform, rules, and mandate were prepared for the National Forum of Rural Development; iii) in cooperation with the World Bank, the draft of the integrated rural development strategy and the institutional structure charged with its implementation was prepared, iv) the restructuring of the Water Departments in the districts was concluded, v) the consolidation of the Agricultural Research Institutes continued, thus reducing their number from 14 to 10, vi) in cooperation with FAO and AT, the General Directorate of Forests and Pastures was restructured and the pilot regional department of Forests and Pastures in Elbasan was set up; vii) the Administration of Protected Areas is being established which is a cooperative effort between the Ministry of Agriculture and Agrifood and the Ministry of Environment.

206. Decentralization and establishment of rural capacities. During 2002, i) the process of the transfer of the natural resources such as pastures, forests, water resources and the irrigation and drainage systems to the local authorities continued, ii) state owned forests were transferred to 26 communes, together with the management plans, and 16 other communes are in the process of taking them over, iii) a number of laws and decisions to improve the regulatory framework of the rural sector have been improved (including the reintroduction of the farming land tax, the establishment and functioning of the regional land administration offices and the establishment of the office for the monitoring of ministry-wide strategies ), iv) the financial support for the Water Users Associations has increased for the rehabilitation of the irrigation and drainage systems and training was been organized for these associations; v) fifteen irrigation schemes were transferred to the Water User Associations and six new associations and four new federations were set up.

207. Financial services and credit: i) the establishment of the urban credit funds and credit unions was encouraged along with the provision of non-banking financial services, ii) work continued to establish new ShKK-s in additional villages and to expand existing ShKK-s to additional villages, iii) the agricultural services project has approved 10 projects to improve new agricultural and agri-food production technologies and tenders have been organized to award 10 new projects; iv) about 37,500 families from 16 districts in the mountainous areas received IFAD funding in the context of the program of the Mountain Areas Development Fund

208. Infrastructure and rural services. During 2002, (i) the Albania Development Fund completed the construction of 55 water pipelines. An additional 18 others are under 
construction, while about 155 water pipelines were rehabilitated with state funds. This has accounted for $67 \%$ of the rural population having access to drinking water, although for only a couple of hours a day; ii) the number of families and villages that have access to the sewage system has increased, iii) 28 new schools were built and 102 elementary and secondary schools were rehabilitated, iv) a considerable number of health centers was rehabilitated, v) 42 telephone operators were licensed to provide rural telephone services and nine of them have started operation with about 6,000 subscribers in 2002, while two cellular telephone operators, AMC and the Vodafone increased considerably their coverage in all rural areas.

209. Integrated rural development will gradually constitute the priority for policies and programmes in all the sectors of rural areas. While agriculture development promotion programmes will continue, the programs for the promotion of non-agricultural activities through the development of infrastructure, services and information, greater access to natural resources, the institutional capacity strengthening of the commune governance will assume greater importance.

\section{E.7.3 2003-2006 MEDIUM-TERM PROGRAM FOR RURAL DEVELOPMENT}

210. Maintaining the growth rate of agriculture, livestock, agri-food, and the fishery and the sustainable management of the natural resources will be the fundamental elements of 2003-2006 medium-term priority actions in the general framework of rural sector development.

211. In this regard the goals will be: (i) priority development of the land market and land ownership consolidation by laying the emphasis on completion of the registration of land, forests, and pastures, and by setting up a comprehensive information system for the land; (ii) continued rehabilitation and improved administration of the irrigation and drainage systems by increasing investments in this area, continued reconstruction of the water companies and establishment of the new drainage boards; consolidation of the water user associations and federations etc.; (iii) increasing the level of mechanization, introduction of new technologies, and improvement of the input quality of inputs through the promotion of investments in these area and project implementation, such as the project for the agricultural production growth $(2 \mathrm{KR})$, the agricultural service project, etc.; increased level of the glasshouse mechanization and production; restructuring and consolidation of the inspection laboratories and the whole certification system (chemical fertilizers, seeds, saplings, livestock fodder, etc.); (iv) consolidation of various agricultural services (advisory, phyto-sanitary, veterinary, zoo technical); (v) improved access to financial resources and credits by stimulating investments in priority sectors (mechanization, greenhouses, orchards, vineyards, livestock farms, processing facilities, etc.) through the development of the credit unions, savings-credit associations, etc, with the support of FFR, MAFF, MADA, etc.

212. The objectives regarding a higher level in the processing of agricultural and livestock products during the 2003-2006 period are: (i) continuous improvement of the processing technologies; (ii) support for establishment of new facilities through the application of Competitive Grant Program (PSHB project) and increased scope of 2KR project; (iii) preparation and improvement of support policies for specific important products, such as grape and wine, milk and dairy products, fresh and processed fruits and vegetables, etc.

213. Priority in the improvement of marketing structures and methods of agri-food products will be given to: (i) increased trade of agr-food products through the establishment of new wholesale markets in Shkodra, Lushnje, Vlor and Korca; (ii) establishment of some pilot procurement, storage, and trading centers; (iii) improvement of the structures for the 
collection and dissemination of the information about markets; (iv) training opportunities and extension of technical assistance to marketing; (v) promotion of the agri-food exports in the framework of the implementation of the Free Trade Agreements in the region and beyond.

214. Consumer protection and food quality during 2003-2006 medium-term period will be achieved through: (i) improvement of the legislation related to the quality, expiry dates and trading conditions of the products; (ii) harmonization of the legislation on food products with that of the EU; (iii) continuous improvement and completion of the standards; (iv) consolidation of the inspectorates in the context of DRBU; (v) strengthening of the laboratory network of goods and food analysis; (vi) strengthening of the veterinary, phyto-sanitary, and quality control of foodstuffs, in general, in the border crossings; (vii) improvement of the cooperation with the Consumer Association and other structures or institutions, which are interested in this area.

215. Sustainable management of the natural resources will be achieved through: (i) improved management of the fisheries through preparation and implementation of specific support policies, support for the establishment and strengthening of the fishery association, and the rehabilitation of the fishing harbors; (ii) increased aquaculture productivity through better utilization of the reservoirs, and fresh and sea waters; (iii) improvement of the structures in charge of managing and monitoring the utilization of the forests and pastures.

216. Integrated rural development will increasingly represent the fundamental method underlying the policies and interventions in all sectors of the rural environment. While the implementation of the programs for the promotion of the agricultural development will continue, a growing importance will be attached to the programs for the promotion of non-agricultural activities through the development of the infrastructure, services, and information, increased access to the natural resources, and the institutional consolidation of the community governance.

\section{E.8 URBAN DEVELOPMENT}

217. The management of urban areas and the crack down on the construction sector were priority public measures. As a result, during 2002, a total of 3528 illegal constructions were demolished, as they were not in conformity with the urban planning regulations as compared to 2671, which were destroyed in 2001. Along with these actions, measures were taken to recover green space, roads, squares and sidewalks. The destruction of illegal constructions was extended to coastal tourist areas and will be continued in 2003. These measures have served to improve the urban planning processes, exert control over land use, and have had a powerful psychological and cultural effect on the citizens.

218. The development of the periurban areas began through the implementation of pilot projects in the Tirana and Kamza municipalities these aimed at creating the model of community-based development and problem solving. Lessons learned will be applied to other cities in the country. This will be an important focus for measures to be taken in the future while considering effective and cost-efficient solutions for longstanding problems.

219. The improvement of infrastructure in general and of urban services (roads, water, sewage, access to telecommunication, waste management,) in particular has been another major priority of the public measures in $2002^{20}$. Public investments donor funding have

\footnotetext{
${ }^{20}$ More detailed data are given in the chapter on infrastructure.
} 
increased and the management of these services has improved and transparency has increased. The above measures have had real and positive impacts on urban development and have initiated the process of creating a new urban management concept.

220. The strengthening of the decision-making and management capacities has been considered as a priority, as expressed through the close cooperation of local authorities with civil society and urban communities in dealing with this issue. As a result of this cooperation, a great number of social activities have been organized on urban development and strategic urban planning. In addition, there have been improvements in the legal framework and numbers of studies on urban development were completed. In addition, a considerable number of pilot projects on urban development are ongoing along with many training activities. Urban planning is becoming, through the involvement of civil society and the media, an important keen issue for the local communities.

221. Although a new concept, urban development is being reflected in the programs and measures to reduce poverty in urban areas and those targeting social assistance, education and health, public order and economic development. Decentralization and the transfer of some functions as the exclusive jurisdiction of the municipalities and the accompanying fiscal decentralization, (which is expected to yield results in 2003), have all created the foundation for then increasingly important role of the municipalities in urban development. This process is contributing to the improved prioritization of the interventions according to the local requirements of every urban area and the effectiveness of these interventions.

222. The public and the international partners have judged the effects of the priority public measures in the urban area as highly successful. These are only initial steps to mitigate urban degradation and embarking on a path of sustainable development.

223. Medium term programme 2003-2006 for urban development, the economic and social transformations of the country and the demographic shifts require the adoption of a longterm vision for a sustainable urban development. The long-term goal is to transform the urban centers into generators of the economic development, civilization, and cohabitation. This will be achieved through policies and measures, which will create conditions for a sustainable urban development by harmonizing three fundamental ele ments of the urban environment: i) effective use of the urban land ii) modernization of the infrastructure, services, and, in general, of urban technology iii) development of the civil culture and the harmonization of the public, community, and private interests

224. The aim in the medium-term period will be to stop completely the urban degradation process and to create the conditions for a sustainable urban development. The specific medium-term objectives regarding the urban areas, in general, are:

- Increased equitable access to infrastructure and public services, and the improvement of their quality: The main measures in this area will consist of the rehabilitation of the infrastructure network of water/sewage; urban road network and traffic; energy distribution; transportation and disposal of urban solid waste, telecommunications etc. The investments will be accompanied by the implementation of measures specified by the sector, such as: commercialization, cost recovery, involvement of the private and/or community capital. The public investments will be based on prospective development programs. The aim will be to increase the effectiveness of investment allocations by focusing them on areas with urbanization tendencies. Educational and health services infrastructure will also be improved by addressing specific urban problems through rehabilitation investments, increased capacities, improved quality of the services and their diversification, increased contribution/participation of the community and the private sector. 
- Increased effectiveness in the use of urban land: The measures in this area will aim at clarifying and guaranteeing property rights, including the completion of the process of property registration and property restitution and compensation; the adoption of methods, standards, and more appropriate procedures for issuing building licenses based on clear plans for prospective development of urban areas and on the community approach.

- The development of the housing sector: This will be achieved through a) planned housing development with the aim of achieving a more effective use of public and private capital by providing the land with ready infrastructure for building construction for different categories of the population, in line with the urban development trends b) legal and institutional improvements to guarantee building safety, consumer protection, and minimum ratios between private, public, and condominium space c) stimulation for projects of dwellings and use of energy efficient and environmentally-friendly building materials d) set of measures promoting the development of the financial market for housing; e) set of measures increasing the effectiveness of the private housing market.

- Further strengthening and guaranteeing of urban safety: In the framework of the consolidation of public order the goal will be to increase safety, particularly, in the urban areas., in which: in addition to measures to strengthen the structures specialized in the fight against crime, urban safety will also be achieved through the education, enhanced awareness of the public increased cooperation with the public and community, the inclusion of the school in this process, and the process of the rehabilitation, re-education, and re-integration of the categories of the drug addicts, and other categories of petty crime offenders, including the minors.

- Improvement of the urban environment. The measures in this area will focus on: continued demolition of illegal constructions occupying vital public areas (parks, squares, sidewalks) and their rehabilitation; the improvement of the air quality and the disciplining of construction, traffic, and industrial activity; rehabilitation and protection of the urban architectural values and the stock of jointly owned dwellings and areas; studies to identify measures for the rehabilitation of the degraded industrial areas, which are located within or near residential areas.

- Development of civil and democratic behavior and culture through support for community life, increased cultural and sports activities, particularly for children and young people, and support for the information services and for the democratic and civic education.

225. The transition processes and the demographic shifts have deteriorated the urban social pathologies. Specific measures aimed at improving social protection for vulnerable categories and their integration into the urban society will be adopted. The main measures in this area are:

- The integration of the suburban areas through the legalization of the dwellings; equitable settlement of property disputes and protection of property rights; providing an adequate and financially affordable level of access to the basic infrastructure through the inclusion of the suburban and periurban communities in all the stages of the projects; adoption of a tariff for the development of the basic infrastructure and for measures to compensate the poor; providing fair access to the educational and health services. The legal and property issues in this area will be resolved in order to carry out a gradual urbanization process in the suburban areas in the municipalities of Tirana and Kamze and this process will begin in some other municipalities, too (Durres, Elbasan, Fier, Vlora, Saranda, etc)

- The reduction of housing problems for low-income families and other social categories through a) public and private investments in the construction of low-cost 
dwellings and consignment under ownership or rent b) orientation of state subsidies on families, which need state assistance for housing, and the development of community-based savings schemes and credit lines to increase the access of these families to housing market.

- The development of the social integration protection services for urban vulnerable categories and employment policies.

226. The urban devebpment will be supported with a number of harmonized institutional and legal reforms. They include i) strengthening of the municipal governance in line with the reform on decentralization; ii) strengthening of the regulatory entities (urban planning councils, construction police etc.), iii) creation of appropriate space for community action and joint-ownership association (condominium)); iv) appropriate settlement of the rights of private property, joint ownership in dwellings, public ownership, and the adoption of the instruments for their implementation and protection, including appropriate forms of compensation; v) completion of regulations on rights and obligations regarding access to infrastructure and urban public services and on building rights vi) enhanced capacities to monitor urban development. The urban governance will be an open process with the participation of the institutional actors and the stakeholder groups. 
F. ESTABLISHMENT OF MONITORING AND EVALUATION SYSTEM

F.1 ESTABLISHMENT OF THE MONITORING AND EVALUATION SYSTEM

F.2 ENCOUNTERED PROBLEMS AND PROPOSED SOLUTIONS 


\section{F. ESTABLISHMENT OF MONITORING AND EVALUATION SYSTEM}

\section{F.1 ESTABLISHMENT OF THE MONITORING AND EVALUATION SYSTEM}

227. The monitoring and evaluation system is considered an integral part of the Strategy, which will be used to follow its progress, attain the objectives, and improve the Strategy during its implementation. Being a key element for the Strategy's implementation, the work to set up this system has begun with the establishment of the required institutional capacities in all main agencies of the central and local governments. The following structures have been established and are operating: the Steering Committee chaired by the prime minister, the Inter-Ministerial Working Group chaired by the Minister of Finance, the Technical Sector Groups, the Monitoring and Evaluation Units and the NSSED Department in the Ministry of Finance.

228. The monitoring and evaluation structures aim to strengthen the policy formulation process through the development of performance indicators to assess Strategy implementation. These units have been set up within all the line ministries which are covered by the NSSED. The monitoring and evaluation unit within the Ministry of Labor and Social Affairs will play a particularly important role in monitoring poverty indicators and analyzing poverty.

229. Terms of reference have been established for all of the monitoring and evaluation units, with a clear definition of their roles, structures and work programs. This constitutes one of the key results achieved in the establishment of the monitoring system. Some of the main duties that these units are covering are:

- The evaluation of the policies, proposals and recommendations for policy directions and policy changes;

- The creation of verifiable and measurable indicators and information systems to track them;

- Cooperation and coordination within the ministries, at the inter-ministerial level and with the NSSED Department in the Ministry of Finances;

- Support for more concrete outcomes of results monitoring.

230. Monitoring and evaluation resources and instruments are critical for the preparation of summary reports and for following the NSSED implementation process. Among the main data sources that are used by the monitoring and evaluation units are the following:

- Grassroots information;

- Data from various departments within the ministries, or from PIU's.

- Information from donors' groups, non-government organizations, the interest groups, and civil society,

231. The 2002 Living Standards Measurement Survey will serve as an important monitoring instrument. The report based on this survey will serve as a standard basis to monitor the progress made in the reduction of poverty in Albania. Such a process together with the assistance of donors such as the World Bank and DFID will help establish a permanent system of surveying the households in order to monitor the poverty and inform social policy development. Even after the completation of such important studies, still there have been limited possibilities for deep analysis of the factors and their effects, of the expected effects of the measures, and relations among input, process product and effect. In many cases the analyses remains only qualitative and are not supported from quantitative ones, the conclusions remain hypothetic and the forecasting takes a degree of wide interval of tolerance. It should be mentioned also that two important instruments in 
the monitoring and evaluation system: like the Qualitative Poverty Assessment and the Administrative Map of Poverty are not widely used by all the monitoring and evaluation units.

232. Referring to the stakeholder partnership, it has been and still is very active, but there is an ongoing need for wider participation in the process, putting emphasis on the poorer levels of society. The government has been and remains opened to the inclusion of civil society, the business community and other actors in evaluation and monitoring.

233. Apart from the above-mentioned achievements, it is worthwhile noting the contribution of line ministries in the drafting of this progress report and the preparation of the revised plan of priority public NSSED measures. Results have been collected from continuous information gathering on the implementation of prioritary public measures defined in the matrix of the Strategy

\section{F.2 ENCOUNTERED PROBLEMS AND PROPOSED SOLUTIONS}

234. Nevertheless some problems have been encountered in connection with the monitoring and evaluation system. They can be summed up as, (i) problems related to the motivation and training of the staff of the monitoring structures; (ii) problems related to the accuracy of the information coming from the primary and seondary data sources, and delays in the data supply; (iii) lack of information in the monitoring indicator tables; (iv) failure to determine the final status of the NSSED Monitoring Unit in all line Ministries as a separate unit and lack of a reliable methodology and relevant literature.

235. In order to resolve these problems in the future and improve the monitoring and evaluation system a fruitful cooperation will be established between all the main monitoring and evaluation structures of the line ministries or other public structures, the governing authorities and the main stakeholders. This will be accompanied by improving of the level of information and data analysis, while providing equipment to the monitoring units and the continuous training to the staff. The monitoring and evaluation units must cooperate more closely with the policy, planning and resource allocation structures in every ministry. It is also important to obtain up-to-date monitoring tools, methodologies and procedures and literature form international partner organizations.

236. The need to set up a nucleus to provide a database in the NSSED Department in the Ministry of Finances is considered to be very important. This will help to make a more accurate analysis of the monitoring and evaluation indicators by relevant sectors. During this year, the monitoring units together with ministry staff and in cooperation with external partners will start the process of discussions and choosing the appropriate sets of indicators. 
G. PROGRESS REPORT CONSULTATIONS 


\section{G. PROGRESS REPORT consultations}

237. The process of analyzing NSSED implementation during 2002, the preparation of the 2003-2006 medium-term program and the preparation of the NSSED long-term vision have been transparent and inclusive of stakeholder groups. They have involved the active participation of local leaders and experts from Albanian institutions, civil society, the business community, academics, and participants from the local and central government and with a close cooperation with Albania's international partners.

238. The consultation process began in October 2002 through the organization of three national consultations with the topics i) growth and the development of the private sector ii) human resource development iii) governance reforms. The NSSED conference marking the first anniversary of the document was organized in November 2002 and provided the opportunity to make the first and integrated analysis of the NSSED during 2002 and the preliminary improvement of the medium and long-term objectives

239. During the preparation of this document, which continued during January -April 2003, 16 consultations were organized across the country on sector developments, the mediumterm program and the long-term visions, and, in particular, on the sectors of education, agriculture, labor and social affairs. The consultations were conducted on a sectoral and regional basis. The NSSED Department advisory group in Tirana organized the former with the representatives of the line ministries and the regional consultations were organized in the country's 12 main districts.

240. The main limitation of the consultations was the short time from the moment of receiving the reports from the ministries to the moment of the organization of the consultations. This had its impact on the quality of the consultations and the credibility of this government initiative. In some cases the discussions were held on crosssector/problematic issues, while in some cases they focused on a single issue. The agriculture and education received more attention than the other sectors.

241. During March-April 2003 period consultations were organized with the large stakeholder groups regarding the long-term vision and the medium-term program of the priority public measures. The main consultations were those with the civil society, the business community, the associations of the municipalities, communes, regions, and a group of deputies. These meetings helped to gather their remarks and suggestions for the improvement of the draft document on the specific issues in which the participants were consulted

242. During these consultations, the participants discussed the problems faced during the implementation of NSSED, the progress made and the challenges ahead, and also the opportunities for a wider inclusion of the representatives of civil society in creating, implementing and monitoring national documents. The most important matters discussed during these consultancies were as follows:

- The experiences gained during the one-year implementation of the priority actions programme and the objective analysis of the degree of reaching the goals.

- Increase of the monitoring and evaluation capacities.

- Carrying on studies and improvements to data and information available.

- Establishing a better link between NSSED and sectorial strategies. These last ones will better adopt and reflect the NSSED goals and approaches

- A better evaluation of the evolution of the basic factors that affect the sectorial and cross-cutting areas developments 
243. On April 23, 2003, the Government organized the National Conference with participation of the Prime Minister itself, which provided a forum for the Government to demonstrate in an open and transparent way the undertaking of its national responsibilities. The consultative process with civil society was discussed in the context of the conference. The breaks out sessions of the conference provide a vehicle for the participants to comment on the Strategy's implementation and suggestions for improvement. The main conclusions of these panels were

- The long-term vision of the Strategy should be enhanced as should the establishment of priorities In the short-term priority should be given to poverty reduction measures followed by stable economic growth.

- The transformation of the document of the Strategy into a nationally owned instrument based on the Albanian reality and local opportunities and taking into account the country's compliance with EU accession and the MDGs. 
ANNEX 1: MATRIX OF REALIZATION OF PRIORITARY PUBLIC MEASURES 2002

H. ANNEX 1: MATRIX OF REALIZATION OF PRIORITARY PUBLIC MEASURES 2002

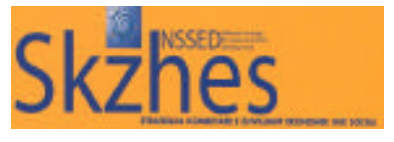


ANNEX 1: MATRIX OF REALIZATION OF PRIORITARY PUBLIC MEASURES 2002

MINISTRY OF HEALTH 
ANNEX 1: MATRIX OF REALIZATION OF PRIORITARY PUBLIC MEASURES 2002

\begin{tabular}{|c|c|c|c|c|c|}
\hline \multicolumn{6}{|c|}{ MINISTRY OF HEALTH } \\
\hline No. & $\begin{array}{l}\text { Priority activity for the year } \\
2002\end{array}$ & $\begin{array}{l}\text { Accomplis } \\
\text { hment } \\
\text { scale } \\
\text { according } \\
\text { to the } \\
\text { criteria }\end{array}$ & $\begin{array}{c}\text { Reasons for } \\
\text { accomplishing the } \\
\text { activity at a lower } \\
\text { scale than envisaged }\end{array}$ & $\begin{array}{l}\text { Measures adopted to enable } \\
\text { accomplishment }\end{array}$ & $\begin{array}{c}\text { New deadline for the } \\
\text { complete accomplishment }\end{array}$ \\
\hline 1. & Training of trainers & 2 & $\begin{array}{l}\text { Lack of organization } \\
\text { and funds. }\end{array}$ & & Depends on securing funds. \\
\hline 2. & $\begin{array}{l}\text { Completion of studies to } \\
\text { accurately assess the needs in } \\
\text { some of the most important } \\
\text { aspects of the system. }\end{array}$ & 1 & Lack of funds. & $\begin{array}{l}\text { Funds have been requested from } \\
\text { the MoE for } 2004 \text {. }\end{array}$ & Depends on securing funds. \\
\hline 3. & $\begin{array}{l}\text { Preparation of two master } \\
\text { regional plans. }\end{array}$ & 1 & Lack of funds. & $\begin{array}{l}\text { Funds requested from the MoE for } \\
2004\end{array}$ & Depends on securing funds. \\
\hline 4. & $\begin{array}{l}\text { Improvement of the financing } \\
\text { system primarily aiming at } \\
\text { strengthening the Health } \\
\text { Insurance Scheme. }\end{array}$ & 3 & & & \\
\hline 5. & $\begin{array}{l}\text { Ongoing decentralization of } \\
\text { authorities. }\end{array}$ & $2-3$ & $\begin{array}{l}\text { The document was } \\
\text { not produced, as there } \\
\text { was no procedure in } \\
\text { place regarding the } \\
\text { material format of the } \\
\text { material by the MLGD } \\
\text { and comments from } \\
\text { other stakeholders. }\end{array}$ & $\begin{array}{l}\text { The first document on } \\
\text { decentralization was produced in } \\
\text { the area of PHC_and PH. To date } \\
\text { no comments have been submitted } \\
\text { from the stakeholders. }\end{array}$ & $\begin{array}{l}\text { The } 2003 \text { decentralization } \\
\text { matrix action plan will be } \\
\text { revised }\end{array}$ \\
\hline 6. & $\begin{array}{l}\text { Establishment of the Monitoring } \\
\text { Unit by } \mathrm{MoH} \text {. }\end{array}$ & 4 & & & \\
\hline 7. & $\begin{array}{l}\text { Preparation and implementation } \\
\text { of a anti-corruption program. }\end{array}$ & & & & \\
\hline 8. & $\begin{array}{l}\text { Construction rehabilitation, } \\
\text { equipping and the training of staff } \\
\text { of about } 80 \text { Health Centers and }\end{array}$ & 4 & $\begin{array}{l}\text { It has been envisaged } \\
\text { that } 25 \mathrm{HC} \text { and } 40 \\
\text { outpatient clinics shall }\end{array}$ & & Completed on schedule \\
\hline
\end{tabular}

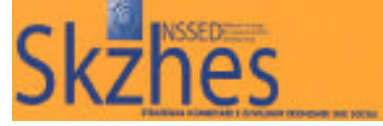


ANNEX 1: MATRIX OF REALIZATION OF PRIORITARY PUBLIC MEASURES 2002

\begin{tabular}{|c|c|c|c|c|c|}
\hline & 400 out- patient clinics & & $\begin{array}{l}\text { be built every year. } \\
\text { The } 400 \text { outpatient } \\
\text { clinics are anticipated } \\
\text { to be built up to the } \\
\text { end of } 2004 \\
\text { considering } \\
\text { decentralization These } \\
\text { facilities shall be } \\
\text { transferred to the local } \\
\text { government } \\
\text { structures. }\end{array}$ & & \\
\hline 9. & $\begin{array}{l}\text { Consolidation of five major } \\
\text { hospitals into regional hospitals. }\end{array}$ & 4 & & & \\
\hline 10. & $\begin{array}{l}\text { Staff motivation in rural areas to } \\
\text { prevent their migration to urban } \\
\text { centers. }\end{array}$ & 2 & $\begin{array}{ll}\text { Limited } & \text { financial } \\
\text { resources. } & \end{array}$ & $\begin{array}{l}\text { Adoption of measures to reform of } \\
\text { the wage system }\end{array}$ & This should be clarified \\
\hline 11. & $\begin{array}{l}\text { Ensuring } 100 \% \text { vaccination rate } \\
\text { of children up to two years of } \\
\text { age, Its extension to other age } \\
\text { groups and the gradual inclusion } \\
\text { of new EPI vaccines, to be } \\
\text { gradually funded by the } \mathrm{MoH}\end{array}$ & 4 & $\begin{array}{l}\text { Hepatitis B vaccine } \\
\text { has been secured and } \\
\text { the number of } \\
\text { Hepatitus B cases has } \\
\text { fallen }\end{array}$ & & $\begin{array}{l}\text { The necessary budget } \\
\text { allocation for } 2003 \text { has been } \\
\text { made. }\end{array}$ \\
\hline 12. & $\begin{array}{l}\text { The programme will be } \\
\text { maintained and expanded }\end{array}$ & 4 & $\begin{array}{lr}\text { Polio and } & \text { German } \\
\text { measles } & \text { reduction } \\
\text { programmes } & \text { are } \\
\text { underway } & \text { and } \\
\text { secured. } & \text { No Polio } \\
\text { cases were reported in } \\
2002 \text {. } \\
\end{array}$ & & Completed on schedule \\
\hline 13. & $\begin{array}{l}\text { Programme improvement and } \\
\text { extension, strategy preparation } \\
\text { and consolidation of the } \\
\text { legislative framework. }\end{array}$ & 4 & & & \\
\hline 14. & Improved district surveillance & 4 & Public & & Accomplished on time. \\
\hline
\end{tabular}


ANNEX 1: MATRIX OF REALIZATION OF PRIORITARY PUBLIC MEASURES 2002

\begin{tabular}{|c|c|c|c|c|c|}
\hline & $\begin{array}{l}\text { systems (laboratories, } \\
\text { equipment, training) to monitor } \\
\text { potable water and food quality. }\end{array}$ & & $\begin{array}{l}\text { laboratories in } 8 \\
\text { districts were supplied } \\
\text { with modern } \\
\text { equipment. Training of } \\
\text { staff on water quality } \\
\text { control was carried } \\
\text { out. Disease detection } \\
\text { systems } \\
\text { for LSHP at the } \\
\text { regional level were } \\
\text { provided. }\end{array}$ & & \\
\hline 15. & $\begin{array}{l}\text { Expansion of mother and child } \\
\text { counseling center network, staff } \\
\text { training and equipment }\end{array}$ & 4 & $\begin{array}{l}\text { Quality of mother and } \\
\text { child counseling } \\
\text { centers in PHC has } \\
\text { been improved. } \\
\text { Equipment } \\
\text { medicine have been } \\
\text { distributed to treat } \\
\text { pregnant women. Staff } \\
\text { has been trained on } \\
\text { different issues } \\
\text { pertaining to women } \\
\text { and child health care. }\end{array}$ & & Completed on schedule. \\
\hline 16. & $\begin{array}{l}\text { Conclude the Mental Health } \\
\text { strategy. } \\
\text { continuation of the OMS_project } \\
\text { in this area and its extension to } 4 \\
\text { other districts (establishment of } \\
\text { community centers with } \\
\text { multidisciplinary teams, that will } \\
\text { ensure the integration of people } \\
\text { released from the hospitals into } \\
\text { the communities). }\end{array}$ & 3 & $\begin{array}{l}\text { Draft community } \\
\text { mental health policy } \\
\text { has been prepared. } \\
\text { Approval is envisaged } \\
\text { for the first quarter of } \\
2003 \text {. }\end{array}$ & $\begin{array}{l}\text { Policy document will be approved } \\
\text { within the first quarter of } 2003 \text {. } \\
\text { Policy implementation will begin in } \\
2003 \text {. }\end{array}$ & $\begin{array}{l}\text { Strategy is to be completed } \\
\text { the end by the end of } 2004 \text {. }\end{array}$ \\
\hline 17. & $\begin{array}{l}\text { Implementation of a public health } \\
\text { programs information system }\end{array}$ & 3 & Pertains mainly to: & $\begin{array}{l}\text { Standardization of the } \\
\text { documentation in the pilot health }\end{array}$ & $\begin{array}{l}\text { December } 2002 \text { and the } \\
\text { reviewing of the hospital }\end{array}$ \\
\hline
\end{tabular}


ANNEX 1: MATRIX OF REALIZATION OF PRIORITARY PUBLIC MEASURES 2002

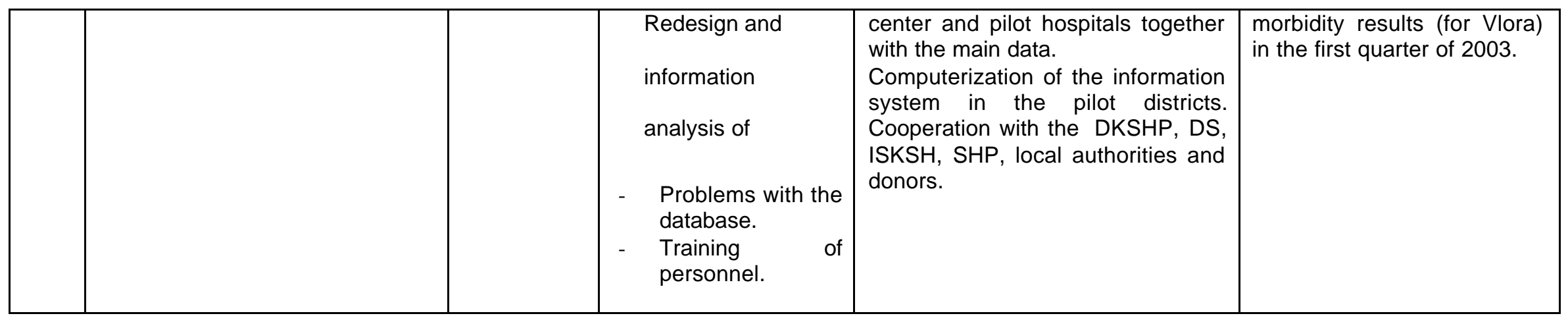


ANNEX 1: MATRIX OF REALIZATION OF PRIORITARY PUBLIC MEASURES 2002

DEPARTMENT OF PUBLIC ADMINISTRATION 


\begin{tabular}{|c|c|c|c|c|c|}
\hline \multicolumn{6}{|c|}{ DEPARTMENT OF PUBLIC ADMINISTRATION } \\
\hline No. & Priority public measures for 2002 & $\begin{array}{l}\text { Level of } \\
\text { achieveme } \\
\text { nt } \\
\text { according } \\
\text { to the } \\
\text { objectives' } \\
\text { criteria (1 } \\
\text { to } 5) 1=\text { not } \\
\text { achieved } \\
5= \\
\text { completel } \\
\text { y achieved }\end{array}$ & $\begin{array}{l}\text { Reasons for the lower- } \\
\text { than planned level of } \\
\text { achievement of } \\
\text { objectives }\end{array}$ & $\begin{array}{l}\text { Measures taken to } \\
\text { ensure } \\
\begin{array}{l}\text { achievement of the } \\
\text { objectives }\end{array}\end{array}$ & $\begin{array}{l}\text { Revised schedule he to achieve } \\
\text { objectives }\end{array}$ \\
\hline 1. & $\begin{array}{l}\text { Objective } 2 \text { Where's objective 1): } \\
\text { Structural improvement and } \\
\text { implementation of the laws } \\
\text { 1. Preparation of a general study } \\
\text { on the structure of the public } \\
\text { administration. } \\
\text { 2. Preparation of a methodology } \\
\text { for the establishment of its } \\
\text { structures. } \\
\text { 3. Approval of the model's } \\
\text { structures. } \\
\text { 4. Conclusion of the evaluation } \\
\text { process for civil servants and } \\
\text { the training of immediate } \\
\text { supervisors to evaluate } \\
\text { individual work performance. } \\
\text { 5nd of probation period for civil } \\
\text { servants. }\end{array}$ & $\begin{array}{l}4 \\
4 \\
4 \\
3\end{array}$ & $\begin{array}{l}\text { Lack of knowledge of } \\
\text { immediate supervisors of } \\
\text { the process and the } \\
\text { failure to grasp the } \\
\text { importance of staff } \\
\text { evaluations } \\
\text { Frequent rotation of } \\
\text { immediate supervisors } \\
\text { and the general } \\
\text { secretaries in some }\end{array}$ & $\begin{array}{l}\text { Training of immediate } \\
\text { supervisors. }\end{array}$ & March 2003 \\
\hline
\end{tabular}


ANNEX 1: MATRIX OF REALIZATION OF PRIORITARY PUBLIC MEASURES 2002

\begin{tabular}{|c|c|c|c|c|c|}
\hline & $\begin{array}{l}\text { 6. Improvement of recruitment } \\
\text { procedures according to the } \\
\text { best standards and models. }\end{array}$ & 4 & ministries. & & \\
\hline 2. & $\begin{array}{l}\text { Objective 3: Strengthening of the } \\
\text { institutions involved in reform } \\
\text { implementation } \\
\text { 2- Strengthening of the Department } \\
\text { of Public Administration } \\
\text { 3- Consolidating the human } \\
\text { resources management units in the } \\
\text { ministries. } \\
\text { 4- Strengthening the role of the } \\
\text { General Secretaries }\end{array}$ & 2 & $\begin{array}{l}\text { Improper understanding } \\
\text { of the role of the General } \\
\text { Secretaries by the } \\
\text { political staff and by the } \\
\text { General Secretaries } \\
\text { themselves }\end{array}$ & $\begin{array}{l}\text { Drafting of a decision } \\
\text { by the Council of } \\
\text { Ministers for defining } \\
\text { the powers of the } \\
\text { General Secretary }\end{array}$ & 2003 \\
\hline 3. & $\begin{array}{l}\text { Objective 4: Raising the } \\
\text { professionalism of of the public } \\
\text { administration } \\
\text { 1. Drafting of a Training Strategy } \\
\text { of the Public Administration } \\
\text { 2. Operation and strengthening of } \\
\text { the Training Institute of the } \\
\text { Public Administration. }\end{array}$ & 4 & & & \\
\hline
\end{tabular}

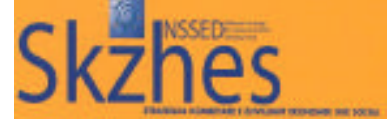


ANNEX 1: MATRIX OF REALIZATION OF PRIORITARY PUBLIC MEASURES 2002

\begin{tabular}{|c|c|c|c|c|c|}
\hline & $\begin{array}{l}\text { 3. Preparation and } \\
\text { implementation of training } \\
\text { programs. }\end{array}$ & 4 & & & \\
\hline 4. & $\begin{array}{l}\text { Objective 5: Legal } \\
\text { improvement } \\
\text { 1. Preparation of the Law on } \\
\text { Ethics of the Public } \\
\text { Administration. } \\
\text { 2. Improvement of the legal } \\
\text { framework. }\end{array}$ & 4 & & & \\
\hline 5. & $\begin{array}{l}\text { Objective 6: Improvement of the } \\
\text { salary system } \\
\begin{array}{l}\text { 1- } \\
\text { foproval of the salary structure } \\
\text { for civil servants }\end{array} \\
\text { 2- Improvement of the salary } \\
\text { structure for education and } \\
\text { health care staff } \\
\text { 3- Implementation of the new } \\
\text { salary system throughout the } \\
\text { public administration. }\end{array}$ & $\begin{array}{l}4 \\
4\end{array}$ & & & \\
\hline 6. & $\begin{array}{l}\text { Objective 7: Development of } \\
\text { information technology } \\
\text { 1. Drafting of the information } \\
\text { technology strategy. } \\
\text { 2. Completion of the civil servants } \\
\text { data-base }\end{array}$ & 3 & $\begin{array}{l}\text { Difficulties for the line } \\
\text { ministries to collect and } \\
\text { enter information. } \\
\text { Frequent changes of } \\
\text { (what) structures }\end{array}$ & $\begin{array}{l}\text { Appointment and } \\
\text { training of permanent } \\
\text { data entry staff }\end{array}$ & 2004 \\
\hline
\end{tabular}

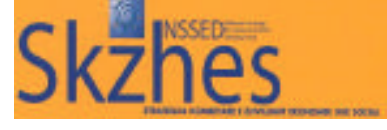


ANNEX 1: MATRIX OF REALIZATION OF PRIORITARY PUBLIC MEASURES 2002

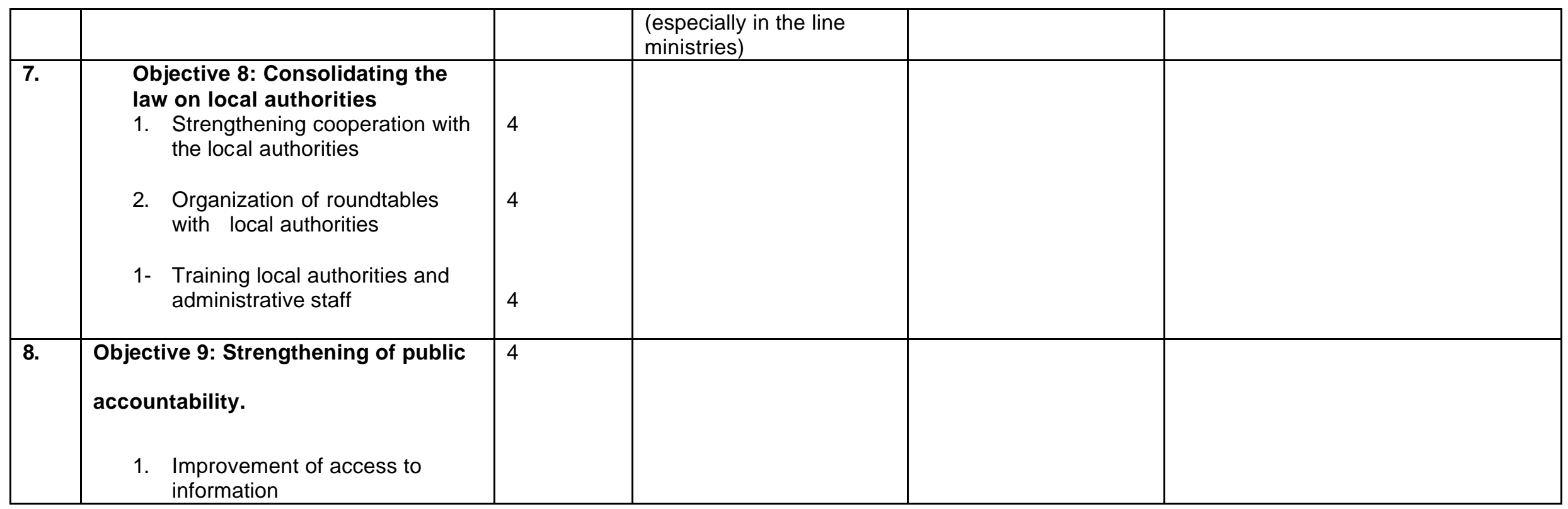


ANNEX 1: MATRIX OF REALIZATION OF PRIORITARY PUBLIC MEASURES 2002

MINISTRY OF ECONOMY

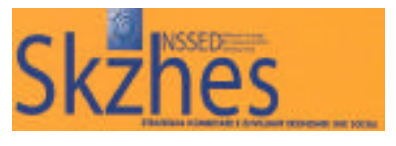


ANNEX 1: MATRIX OF REALIZATION OF PRIORITARY PUBLIC MEASURES 2002

\section{MINISTRY OF ECONOMY}

\begin{tabular}{|c|c|c|c|c|c|}
\hline No. & Priority Actions for 2002 & $\begin{array}{l}\text { Level of } \\
\text { fulfillment } \\
\text { according to } \\
\text { the criteria set }\end{array}$ & $\begin{array}{l}\text { Reasons for } \\
\text { fulfillment at a lower } \\
\text { level than planned }\end{array}$ & $\begin{array}{l}\text { Measures taken to make } \\
\text { possible their realization }\end{array}$ & $\begin{array}{l}\text { New deadline for their } \\
\text { complete realization }\end{array}$ \\
\hline 1. & $\begin{array}{l}\text { Increasing the transparency } \\
\text { of the tax administration } \\
\text { authorities }\end{array}$ & 3 & $\begin{array}{l}\text { Organizational } \\
\text { problems }\end{array}$ & $\begin{array}{l}\text { Extension of the computer } \\
\text { network to the district customs } \\
\text { and tax offices }\end{array}$ & 2004 \\
\hline 2. & $\begin{array}{l}\text { Consolidation of the } \\
\text { Competition Department }\end{array}$ & 3 & $\begin{array}{l}\text { Organizational } \\
\text { problems and } \\
\text { improvement of } \\
\text { legislation }\end{array}$ & $\begin{array}{l}\text { Cooperation with the donors, } \\
\text { CARDS program }\end{array}$ & $2003-2004$ \\
\hline 3. & Approval of the SME law & 4 & & $\begin{array}{l}\text { Its approval will strengthen } \\
\text { related institutions. }\end{array}$ & 2003 and on \\
\hline 4. & $\begin{array}{l}\text { Preparation of the legal } \\
\text { framework to establish SME } \\
\text { agencies }\end{array}$ & 3 & $\begin{array}{l}\text { Problems of } \\
\text { coordination with } \\
\text { other institutions } \\
\end{array}$ & $\begin{array}{l}\text { The approval by the Government } \\
\text { of the bylaws, the status of the } \\
\text { agency, the budget }\end{array}$ & First half of 2003 \\
\hline 5. & $\begin{array}{l}\text { Establishment of the Credit } \\
\text { Guarantee Fund }\end{array}$ & 2 & $\begin{array}{l}\text { Completion of the } \\
\text { study to establish the } \\
\text { fund }\end{array}$ & $\begin{array}{l}\text { Financial support by the Italian } \\
\text { Government }\end{array}$ & $2003-2004$ \\
\hline 6. & Establishment of the $\mathrm{ANIH}$ & 4 & & With FIAS assistance & Making it functional 2003 \\
\hline 7. & $\begin{array}{l}\text { Approval of the Export } \\
\text { Promotion Agency }\end{array}$ & 4 & & $\begin{array}{l}\text { Completed with the technical } \\
\text { assistance of GTZ }\end{array}$ & Ongoing \\
\hline 8. & $\begin{array}{l}\text { Establishment of the Export } \\
\text { Promotion Agency }\end{array}$ & 3 & $\begin{array}{lr}\text { Law is } & \text { pending } \\
\text { approval } & \text { by } \\
\text { Parliament } & \end{array}$ & $\begin{array}{l}\text { Full package of bylaws pursuant } \\
\text { to the approval of the law has } \\
\text { been prepared But the law has } \\
\text { not yet been approved. }\end{array}$ & 2003 \\
\hline
\end{tabular}


ANNEX 1: MATRIX OF REALIZATION OF PRIORITARY PUBLIC MEASURES 2002

MINISTRY OF INDUSTRY AND ENERGY 
ANNEX 1: MATRIX OF REALIZATION OF PRIORITARY PUBLIC MEASURES 2002

\section{MINISTRY OF INDUSTRY AND ENERGY}

\begin{tabular}{|c|c|c|c|c|c|}
\hline No & Actions to be undertaken & $\begin{array}{l}\text { The } \\
\text { responsible } \\
\text { institution }\end{array}$ & Deadline & Periodic assessment & $\begin{array}{l}\text { Effects } \\
\text { in the } \\
\text { budget }\end{array}$ \\
\hline \multirow[t]{9}{*}{1.} & Improvement of the management of energy resources & & & & \\
\hline & $\begin{array}{l}1.1 \text { A new law on the Energy Sector was drafted, which } \\
\text { enhances the role of ERE (ERA - Energy Regulatory } \\
\text { Agency) and phases out government's role in electricity } \\
\text { price setting. }\end{array}$ & $\begin{array}{l}\text { The } \\
\text { government }\end{array}$ & 2002 & $\begin{array}{l}\text { The new law on the Electric Energy Sector } \\
\text { was approved on } 4 \text { December, } 2002 \text { by the } \\
\text { Council of Ministers and now is under } \\
\text { deliberation in the parliamentary committees }\end{array}$ & \\
\hline & $\begin{array}{l}1.2 \text { The law facilitating the establishment of new power } \\
\text { generation plants was drafted and passed }\end{array}$ & MIE & 2002 & Has been approved & \\
\hline & $\begin{array}{l}\text { 1.3.A plan of measures to improve KESH's technical- } \\
\text { financial indicators was prepared and approved }\end{array}$ & $\mathrm{KESH}+\mathrm{MIE}$ & 2002 & $\begin{array}{l}\text { Achievement of the technical -financial } \\
\text { targets was monitored, despite variations } \\
\text { observed from one quarter to another }\end{array}$ & \\
\hline & $\begin{array}{l}\text { 1.4 The Electrical energy sector policy document was } \\
\text { drafted and approved for the period July 2002-June } 2006 \text {. }\end{array}$ & MIE & & $\begin{array}{l}\text { Planned targets are followed up by the } \\
\text { Secretariat of the Task Force and three of } \\
\text { them have been carried over to } 2003\end{array}$ & \\
\hline & $\begin{array}{l}\text { 1.5 The action plan for the improvement of the technical- } \\
\text { financial indicators of KESH joint stock co. for } 2003-2004 \\
\text { was drafted. }\end{array}$ & $\mathrm{KESH}+\mathrm{MIE}$ & 2002 & $\begin{array}{l}\text { The achievement of KESH's technical- } \\
\text { financial targets indicators will be monitored } \\
\text { on a monthly basis. }\end{array}$ & \\
\hline & 1.6 The approval of the electricity pricing structure & $\begin{array}{l}\text { Council of } \\
\text { Ministers }\end{array}$ & 2002 & $\begin{array}{l}\text { With the setting of a price ceiling, KESH will } \\
\text { negotiate with ERA the actual price of } \\
\text { electrical energy. }\end{array}$ & \\
\hline & $\begin{array}{l}\text { 1.7 Privatization of local HEC-s was concluded and the } \\
\text { planned HECs were given for utilization with concessions. }\end{array}$ & $\begin{array}{l}\text { KESH + MIE + } \\
\mathrm{ME}\end{array}$ & $\begin{array}{l}\text { December } \\
2002\end{array}$ & $\begin{array}{l}\text { Preparation of the necessary privatization } \\
\text { tendering documentation }\end{array}$ & \\
\hline & $\begin{array}{l}\text { 1.8 The drafting of the National Energy Strategy energy } \\
\text { The first part of the prepared draft was introduced }\end{array}$ & $\mathrm{AKE}+\mathrm{MIE}$ & June 2003 & $\begin{array}{l}\text { Introduction of the energy data-base and } \\
\text { consultations for future directions of the } \\
\text { energy strategy }\end{array}$ & \\
\hline \multirow[t]{2}{*}{2} & $\begin{array}{l}\text { 2. Enhancement of the import and generation } \\
\text { capacities of the energy grid and its integration into the } \\
\text { Balkan and European energy grids }\end{array}$ & & & & \\
\hline & $\begin{array}{l}2.1 \text { Implementation of the: } 220 \mathrm{~kW} \text { Elbasan } 1 \text { Elbasan } 2 \text { line; } \\
\text { the enhancement of the } 400 / 220 / 30 \mathrm{~kW} \text { Elbasan } 2 \\
\text { substation. } \\
\text { A feasibility study for building a new Thermo Electric Power }\end{array}$ & $\mathrm{KESH}$ & $\begin{array}{l}\text { August } \\
2002 \\
\text { June } 2003\end{array}$ & Assembly and operation of the facility & \\
\hline
\end{tabular}


ANNEX 1: MATRIX OF REALIZATION OF PRIORITARY PUBLIC MEASURES 2002

\begin{tabular}{|c|c|c|c|c|c|}
\hline No & Actions to be undertaken & $\begin{array}{l}\text { The } \\
\text { responsible } \\
\text { institution }\end{array}$ & Deadline & Periodic assessment & $\begin{array}{l}\text { Effects } \\
\text { in the } \\
\text { budget }\end{array}$ \\
\hline & $\begin{array}{l}\text { Station. } \\
\text { A Feasibility study for a } 400 \mathrm{~kW} \text { inter-grid link between } \\
\text { Albania and Montenegro. }\end{array}$ & & & & \\
\hline & $\begin{array}{l}\text { 2.2 Unbundling of KESH into three divisions: generation, } \\
\text { transmission and distribution. }\end{array}$ & $\mathrm{KESH}+\mathrm{MIE}$ & 2002 & $\begin{array}{l}\text { Unbundling of KESH into three divisions has } \\
\text { taken place as the first step towards its } \\
\text { unbundling. }\end{array}$ & \\
\hline & $\begin{array}{l}\text { 2.3 Drafting and implementation of least-cost investment } \\
\text { programs for the rehabilitation of existing facilities for the } \\
\text { generation of electrical energy, the building of new facilities } \\
\text { and the consolidation of the transmission and distribution } \\
\text { energy grid }\end{array}$ & $\begin{array}{l}\text { KESH joint } \\
\text { stock co. }\end{array}$ & 2002 & $\begin{array}{l}\text { A feasibility study has been conducted and } \\
\text { the final report is expected to be delivered } \\
\text { over in February } 2003 .\end{array}$ & \\
\hline & $\begin{array}{l}2.4 \text { Implementation of the measures to reduce the demand } \\
\text { for electrical energy and encourage energy substitution and } \\
\text { increased energy efficiency }\end{array}$ & MIE & 2002 & The above-mentioned study was concluded. & \\
\hline
\end{tabular}

MI\&E -Ministry of Industry and Energy

MF - Ministry of Finance

ME - Ministry of Economy
MPCS - Ministry of Labor and Social Affairs

ERE - Energy Regulatory Entity 
ANNEX 1: MATRIX OF REALIZATION OF PRIORITARY PUBLIC MEASURES 2002

MINISTRY OF TRANSPORT AND TELECOMMUNICATIONS 
ANNEX 1: MATRIX OF REALIZATION OF PRIORITARY PUBLIC MEASURES 2002

\section{MINISTRY OF TRANSPORT AND TELECOMMUNICATIONS}

\begin{tabular}{|c|c|c|c|c|c|}
\hline No. & $\begin{array}{l}\text { Proprietary Public Measures } \\
\text { for } 2002\end{array}$ & $\begin{array}{l}\text { Level of } \\
\text { fulfilment } \\
\text { according to the } \\
\text { criteria set: }\end{array}$ & $\begin{array}{l}\text { Reasons for a lower level of } \\
\text { realization than planned }\end{array}$ & $\begin{array}{l}\text { Measures taken to make possible } \\
\text { the realization of the targets }\end{array}$ & $\begin{array}{l}\text { New deadline } \\
\text { for } \\
\text { the complete } \\
\text { fulfillment }\end{array}$ \\
\hline 1. & $\begin{array}{l}\text { Objective } 1 \\
\text { Rehabilitation of the existing } \\
\text { transportation } \\
\text { Network infrastructure } \\
\end{array}$ & & & & \\
\hline 1.1 & $\begin{array}{l}\text { Completion of the first phase of } \\
\text { the rehabilitation of the } \\
\text { transportation corridors }\end{array}$ & 3 & $\begin{array}{l}\text { Interruption of work by in } \\
\text { Rrogozhine-Elbasan. } \\
\text { Contractor did not fulfill the graph } \\
\text { of the Qukes-Qafe. Thane road } \\
\text { work } \\
\text { Revision of the Elbasan-Librazhd } \\
\text { road works required and secured } \\
\text { supplementary funds. }\end{array}$ & $\begin{array}{l}\text { East-West Corridor } \\
\text { Work has concluded from Durres- } \\
\text { Rrogozhine } \\
65 \text { percent of the work from } \\
\text { Rrogozhine-Elbasan has been } \\
\text { completed. } \\
\text { The revision of the Elbasan- } \\
\text { Librazhd road works was } \\
\text { completed and and contracts have } \\
\text { been awarded. } \\
\text { The building of the Librazhd-Qukes } \\
\text { road was concluded and work is } \\
\text { now underway to build two bridges } \\
\text { in Drag stun. } \\
\text { Qukes-Qafe Thane roadwork is } \\
\text { underway and will be completed } \\
\text { within the first } 6 \text { months of } 2003 \text {. } \\
\text { Work on the Korçe-Kapshtice road } \\
\text { has concluded } \\
\text { The feasibility study for. Qafe } \\
\text { Thane-Pogradec-Korçe road is in } \\
\text { place. }\end{array}$ & 2003 \\
\hline
\end{tabular}




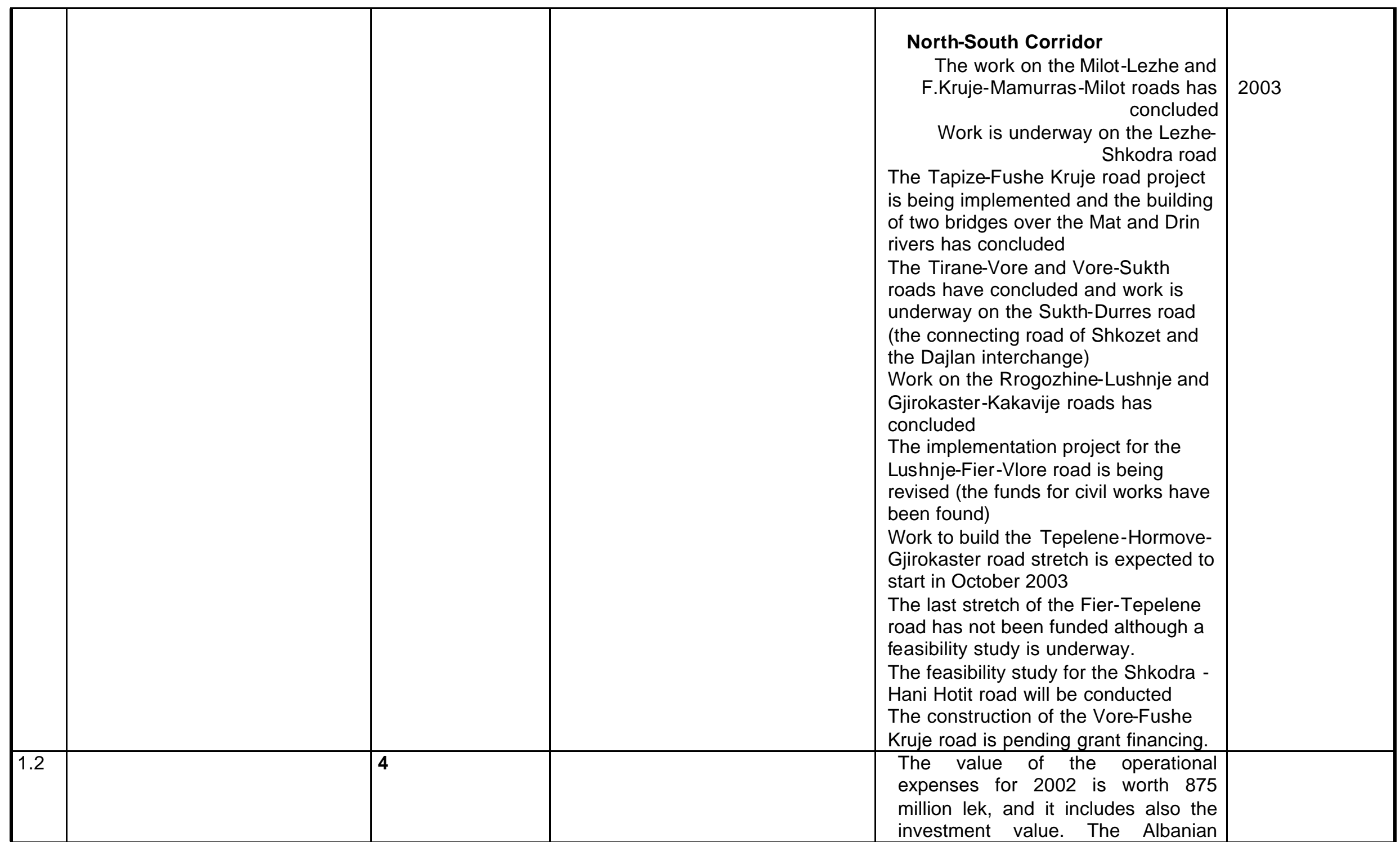


ANNEX 1: MATRIX OF REALIZATION OF PRIORITARY PUBLIC MEASURES 2002

\begin{tabular}{|c|c|c|c|c|c|}
\hline & & & & $\begin{array}{l}\text { Parliament has ratified the credit } \\
\text { worth } \$ 17 \text { million. In the context of } \\
\text { this project, work has begun to } \\
\text { repair the streets of Tirana. This } \\
\text { work is planned to last } 6.5 \text { months } \\
\text { and consists of the rehabilitation of } \\
\text { the Don Bosco road, and the } \\
\text { improvement of M.Gjollesha and } \\
\text { Bajram.Curri roads. A tender for six } \\
\text { contracts is underway for the } \\
\text { national roads and for five contracts } \\
\text { for rural roads. The tender and the } \\
\text { selection of the supervisor for the } \\
\text { work to build and maintain the } \\
\text { national and rural roads is } \\
\text { underway. In the case of the two } \\
\text { kinds of maintenance (routine and } \\
\text { periodic) the services will be } \\
\text { contracted to private suppliers. }\end{array}$ & \\
\hline 1.3 & $\begin{array}{l}\text { Completion of studies and } \\
\text { detailed projects for the } \\
\text { construction of scenic roads and } \\
\text { the Durres-Kukes Morine road. }\end{array}$ & 2 & $\begin{array}{l}\text { After the feasibility study tender } \\
\text { was concluded and the winner was } \\
\text { selected, it was cancelled and the } \\
\text { procedures restarted. }\end{array}$ & $\begin{array}{l}\text { Some work was done on the scenic } \\
\text { roads such as Orikum-Dhermi, } \\
\text { Velipoje, Divjake, Seman and Koplik- } \\
\text { Razem, as well as on the road that } \\
\text { links Albania with Montenegro (the } \\
\text { Muriqan road) } \\
\text { The feasibility study for the Durres- } \\
\text { Kukes-Morine road has been funded } \\
\text { and the contract has been signed and } \\
\text { is due to be completed by July } 2003 \text {. }\end{array}$ & 2003 \\
\hline
\end{tabular}


ANNEX 1: MATRIX OF REALIZATION OF PRIORITARY PUBLIC MEASURES 2002

\begin{tabular}{|c|c|c|c|c|c|}
\hline 1.4 & $\begin{array}{l}\text { Conclusion of works in } \\
\text { the harbors of Durres, } \\
\text { Vlora, Shengjin and } \\
\text { Saranda }\end{array}$ & 4 & & $\begin{array}{l}\text { Durres harbor } \\
\text { The first phase for the ferry docks and warehouses } \\
\text { no. } 5 \& 6 \text { has been concluded, while the second phase for } \\
\text { the construction of the ferry docks is ongoing; } \\
\text { The credit for the rehabilitation of the Durres Harbor has } \\
\text { been approved, with which the engineering network will be } \\
\text { completed. Two } 40-50 \text { ton derricks will be purchased and } \\
\text { the breakwater will be completed; } \\
\text { The drafting of the project for the passenger terminal is } \\
\text { ongoing. Also the arrangement of the container space; for } \\
\text { the port's access and egress roads and the process to } \\
\text { establish the customs area is ongoing. }\end{array}$ & \\
\hline & & 1 & $\begin{array}{l}\text { The tender for the Vlora Harbor } \\
\text { works is pending. }\end{array}$ & $\begin{array}{l}\text { Vlora Harbor } \\
3 \text { million Euros have been allocated ( } 2.7 \text { for the } \\
\text { construction and } 0.3 \text { for the supervision) for the } \\
\text { completion of the first phase of works in the city's port. } \\
\text { The contractor has suspended the works for four years. } \\
\text { Twelve Million Euros from the Italian Coop. have been } \\
\text { committed for the second phase of the Master Plan. } \\
\text { Additional funding is being searched for the new port. }\end{array}$ & 2005 \\
\hline & & 4 & & $\begin{array}{l}\text { Saranda and Shengiin Harbours } \\
\text { With the funds from the state budget } 50 \text { meters of wall in } \\
\text { the Port of Shengjini and, } 48 \text { meters in the Port of } \\
\text { Saranda were constructed and the first phase of the } \\
\text { Harbor Office was completed. }\end{array}$ & \\
\hline 1.5 & $\begin{array}{l}\text { Rail network rehabilitation } \\
\text { is ongoing on the } \\
\text { (Durres-Tirane and } \\
\text { Durres-Rrogozhine), } \\
\text { Shkoder-Hani Hotit lines } \\
\text { as is the feasibility study } \\
\text { for the connection with } \\
\text { Macedonia }\end{array}$ & 3 & & $\begin{array}{l}\text { With funds from the state budget ( } 316 \text { million lek) } 11.2 \mathrm{~km} \\
\text { of the Shkodra-Bajze line were reconstructed in addition to } \\
\text { the rehabilitation of the whole segment. } 7.5 \text { million USD } \\
\text { were invested on the Tirane-Durres line, some } \\
\text { infrastructure improvements were made such as } \\
\text { passenger stations, storage space, and signals; The pre- } \\
\text { feasibility study for the Vore-Hani Hot-it line was segment } \\
\text { completed }\end{array}$ & \\
\hline
\end{tabular}

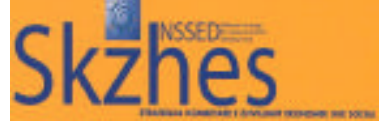


ANNEX 1: MATRIX OF REALIZATION OF PRIORITARY PUBLIC MEASURES 2002

\begin{tabular}{|c|c|c|c|c|}
\hline 1.6 & $\begin{array}{l}\text { The completion of the } \\
\text { concessionary contract } \\
\text { for the construction of the } \\
\text { new passenger terminal } \\
\text { at Rinas Airport and the } \\
\text { new aircraft-parking } \\
\text { apron. }\end{array}$ & 4 & & $\begin{array}{l}\text { Progress has been made to prepare the tender } \\
\text { documentation to choose the holder of the concession and } \\
\text { the contractor to construct the new passengers terminal in } \\
\text { the Rinas Airport "Mother Tereza"; The new aircraft } \\
\text { parking apron standing area was been completed. ; The } \\
\text { Master Plan, has been revised; The agreement to } \\
\text { implementation air traffic control the master plan has been } \\
\text { signed; The feasibility study for the air navigation service } \\
\text { has been completed }\end{array}$ \\
\hline 2 & $\begin{array}{l}\text { Objective } 2 \\
\text { The commercialization of } \\
\text { transport services and } \\
\text { privatization of state } \\
\text { services }\end{array}$ & & & \\
\hline 2.1 & $\begin{array}{l}\text { Improvement of } \\
\text { regulatory framework and } \\
\text { institutional capacity }\end{array}$ & 4 & & $\begin{array}{l}\text { Several laws and by-laws have been approved in the field } \\
\text { of road and maritime transportation. } \\
\text { Agreements have been prepared on road and maritime } \\
\text { transportation and the appropriate documentation has } \\
\text { been prepared aiming at the adherence to international } \\
\text { conventions. }\end{array}$ \\
\hline 3 & $\begin{array}{l}\text { Objective } 3 \\
\text { The deepening of } \\
\text { liberalization in the } \\
\text { telecommunication sector }\end{array}$ & 3 & $\begin{array}{l}\text { Because of lack of investor } \\
\text { interest, the privatization of } \\
\text { Albtelecom did not proceed as } \\
\text { planned }\end{array}$ & $\begin{array}{l}\text { In the mobile market the number of subscribers has } \\
\text { increased } 800.000 \text {, the number of the fixed telephone line } \\
\text { subscribers has doubled to } 208.000 \text {, the internet market } \\
\text { has reached } 12.000 \text { users. }\end{array}$ \\
\hline
\end{tabular}


ANNEX 1: MATRIX OF REALIZATION OF PRIORITARY PUBLIC MEASURES 2002

MINISTRY OF PUBLIC ORDER 
ANNEX 1: MATRIX OF REALIZATION OF PRIORITARY PUBLIC MEASURES 2002

MINISTRY OF PUBLIC ORDER

\begin{tabular}{|c|c|c|c|c|c|}
\hline No. & $\begin{array}{l}\text { Proprietary Public Measures } \\
\text { for } 2002\end{array}$ & $\begin{array}{l}\text { Level of } \\
\text { fulfilment } \\
\text { according to } \\
\text { the criteria } \\
\text { set: }\end{array}$ & $\begin{array}{l}\text { Reasons for a lower } \\
\text { level of realization } \\
\text { than planned }\end{array}$ & $\begin{array}{l}\text { Measures taken to make possible the } \\
\text { realization of the targets }\end{array}$ & $\begin{array}{l}\text { New deadline for } \\
\text { the complete } \\
\text { fulfillment }\end{array}$ \\
\hline & $\begin{array}{l}\text { I.THE STRENGTHENING OF } \\
\text { PUBLIC ORDER AND THE } \\
\text { FIGHT AGAINST ORGANIZED } \\
\text { CRIME }\end{array}$ & & & & \\
\hline 1. & $\begin{array}{l}\text { The increase in } \\
\text { measures regarding } \\
\text { order and tranquility }\end{array}$ & 3 & & $\begin{array}{l}\text { The police presence, cooperation with citizens } \\
\text { and the preparation of approaches for } \\
\text { alternative policing structures and the } \\
\text { reallocation of human resources have } \\
\text { increased and been undertaken. }\end{array}$ & 2005 \\
\hline 2. & $\begin{array}{l}\text { The increase of exploration and } \\
\text { striking force of the Criminal } \\
\text { Police }\end{array}$ & 3 & Process & $\begin{array}{l}\text { Increased evidence gathering capacity for } \\
\text { criminal cases. } \\
\text { Redoubling the efforts of central crime-fighting } \\
\text { structures, such as the Sub-department for } \\
\text { Combating Organized Crime, including the } \\
\text { Sector for Combating Economic\& Financial } \\
\text { Crime, the Central Services for Combating A } \\
\text { Drugs and Illegal Trafficking. }\end{array}$ & 2003 \\
\hline 3. & $\begin{array}{l}\text { The increased combating of the } \\
\text { illegal trafficking. }\end{array}$ & 4 & & $\begin{array}{l}\text { The equipping of all police units (Regional } \\
\text { WIT Office) in order to fulfill its duties } \\
\text { The equipping of the special unit (Delta) for } \\
\text { the prevention of illegal maritime trafficking. }\end{array}$ & \\
\hline 4. & $\begin{array}{l}\text { The achievement of national } \\
\text { operations to combat drugs }\end{array}$ & 3 & Process & $\begin{array}{l}\text { Capacity building related to the inter- } \\
\text { ministerial activities combating drugs. } \\
\text { Evidence gathering on drug traffickers. } \\
\text { Deepened cooperation, largely with law } \\
\text { enforcement agencies of neighboring }\end{array}$ & 2003 \\
\hline
\end{tabular}


ANNEX 1: MATRIX OF REALIZATION OF PRIORITARY PUBLIC MEASURES 2002

\begin{tabular}{|c|c|c|c|c|c|}
\hline & & & & $\begin{array}{l}\text { countries to combat drugs more efficiently. } \\
\text { The announcement of the National Committee } \\
\text { to Combat Drugs and the preparation of the } \\
\text { Strategy to Combat Drugs. }\end{array}$ & \\
\hline \multirow[t]{2}{*}{5.} & $\begin{array}{l}\text { The undertaking of national } \\
\text { operations to combat drugs }\end{array}$ & 3 & Process & $\begin{array}{l}\text { The Identification of areas of the cultivation of } \\
\text { narcotic plants and their destruction. }\end{array}$ & 2003 \\
\hline & $\begin{array}{l}\text { THE STRENGTHENING OF } \\
\text { POLICE STRUCTURES AND } \\
\text { REDUCTION of ABUSES OF } \\
\text { AUTHORITY }\end{array}$ & & & & \\
\hline \multirow[t]{2}{*}{1.} & $\begin{array}{l}\text { Fight against corruption and } \\
\text { abuse of authority by the police }\end{array}$ & 3 & $\begin{array}{l}\text { In this regard, } \\
\text { admirable results of the } \\
2002 \text { van be } \\
\text { mentioned. } \\
\text { Process }\end{array}$ & $\begin{array}{l}\text { The order of the Minister of Public Order for } \\
\text { the information process. The study, analysis } \\
\text { and evaluation of operational materials } \\
\text { Verification of police services prescribed } \\
\text { under the service's regulations. } \\
\text { Study and analysis of corruption within } \\
\text { Ministry structures and measures to fight } \\
\text { corruption in police services. }\end{array}$ & \\
\hline & $\begin{array}{l}\text { INTEGRATED } \\
\text { MANAGEM BNT }\end{array}$ & & & & \\
\hline 1. & $\begin{array}{l}\text { Preparing the common border } \\
\text { strategy }\end{array}$ & 4 & & $\begin{array}{l}\text { Creation of working group to prepare the } \\
\text { Border Control Strategy integrated } \\
\text { Management. } \\
\text { Preparation of the amendments related to the } \\
\text { law on "Borders Police" } \\
\text { Preparation of the draft regulation on the } \\
\text { "Functioning of Border Police Services" }\end{array}$ & $\begin{array}{l}2003 \\
2003 \\
2003\end{array}$ \\
\hline 2. & $\begin{array}{l}\text { Definition of the Border Police's } \\
\text { common tasks and those of the } \\
\text { Customs Department }\end{array}$ & 3 & & $\begin{array}{l}\text { Signing of several agreements with the } \\
\text { Customs I Department to coordinate actions } \\
\text { against the illegal movement of people and } \\
\text { goods. } \\
\text { Common action plan in accordance with the } \\
\text { Theory of Integrated Border Management. }\end{array}$ & \\
\hline 3. & Institutional collaboration with & & & Collaboration with: & \\
\hline
\end{tabular}

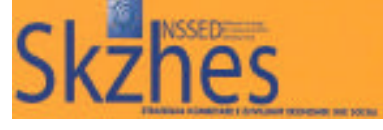


ANNEX 1: MATRIX OF REALIZATION OF PRIORITARY PUBLIC MEASURES 2002

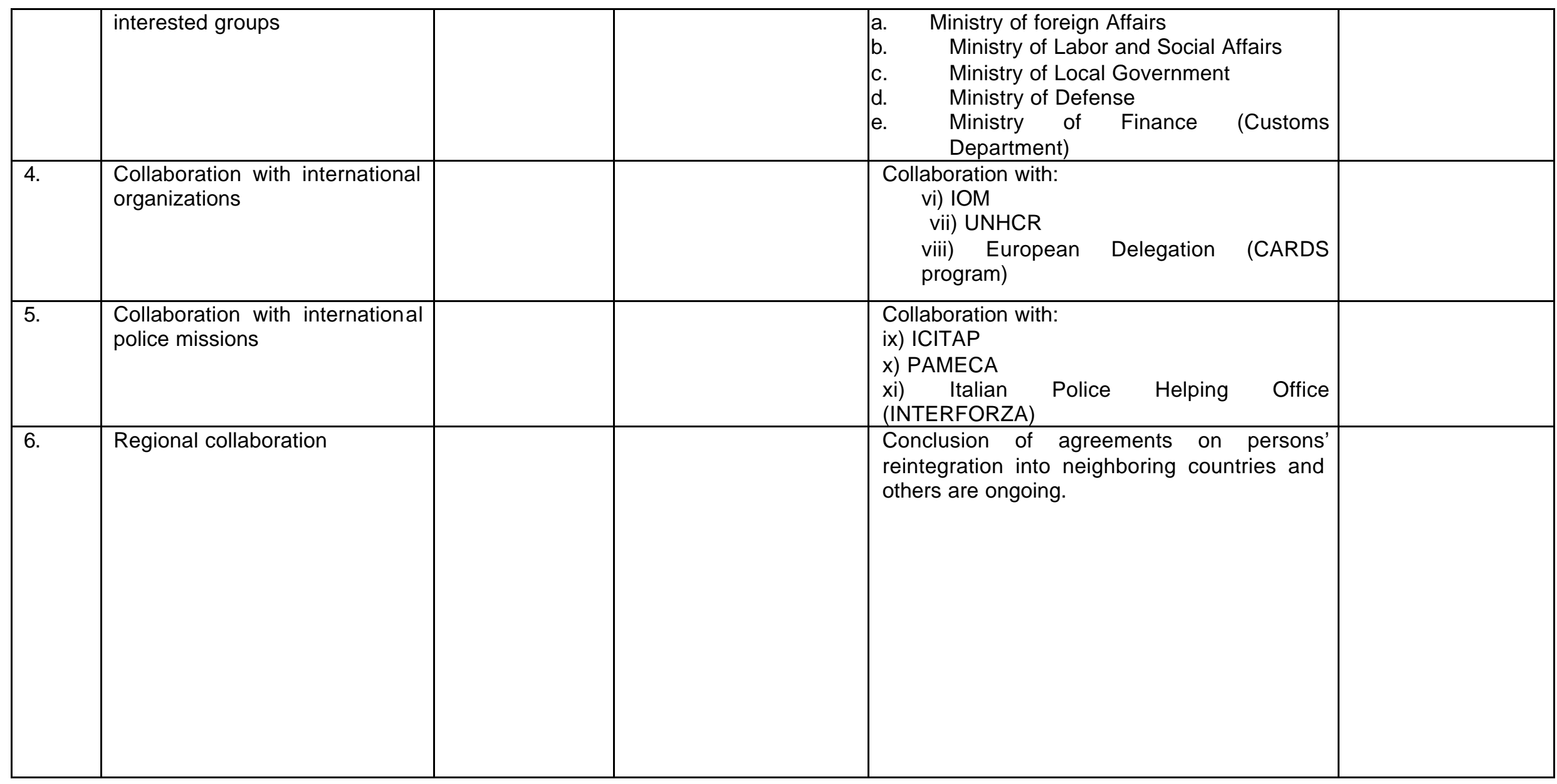


ANNEX 1: MATRIX OF REALIZATION OF PRIORITARY PUBLIC MEASURES 2002

MINISTRY OF AGRICULTURE AND FOOD

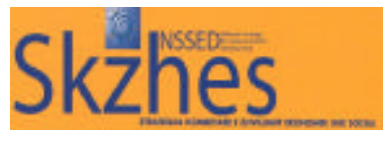


ANNEX 1: MATRIX OF REALIZATION OF PRIORITARY PUBLIC MEASURES 2002

\section{MINISTRY OF AGRICULTURE AND FOOD}

\begin{tabular}{|c|c|c|c|c|c|}
\hline No. & $\begin{array}{l}\text { Prioritary Public Measures } \\
\text { for } 2002\end{array}$ & $\begin{array}{l}\text { Level of } \\
\text { fulfilment } \\
\text { according to } \\
\text { the criteria } \\
\text { set: }\end{array}$ & $\begin{array}{l}\text { Reasons for a lower } \\
\text { level of realization } \\
\text { than planned }\end{array}$ & $\begin{array}{l}\text { Measures taken to make possible the } \\
\text { realization of the targets }\end{array}$ & $\begin{array}{l}\text { New deadline for } \\
\text { the complete } \\
\text { fulfillment }\end{array}$ \\
\hline 1. & $\begin{array}{l}\text { Objective: Growth in agricultural } \\
\text { products, livestock, foodstuffs } \\
\text { and the fishery of } 5 \%\end{array}$ & & & & \\
\hline 1.1 & $\begin{array}{l}\text { Result: Resolution of land } \\
\text { ownership and the development } \\
\text { of an arable land market. }\end{array}$ & & & & \\
\hline 1.1 .1 & $\begin{array}{l}\text { Creation of land administration } \\
\text { offices in all districts }\end{array}$ & 4 & & & \\
\hline 1.1 .2 & 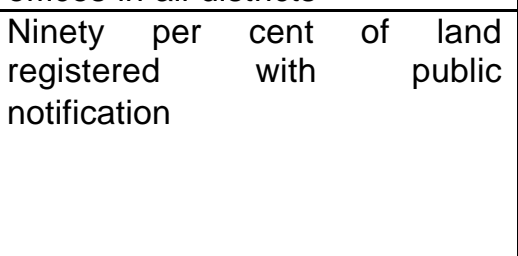 & 2 & $\begin{array}{l}\text { Interruption of foreign } \\
\text { funding }\end{array}$ & $\begin{array}{l}\text { Financial support from the Albanian } \\
\text { Government to cover the functional } \\
\text { expenditures of NMP/SRPP until the } \\
\text { reallocation of foreign funding resumes. New } \\
\text { contracts have been put into place to support } \\
\text { land registration in urban and rural areas. }\end{array}$ & End of 2004 \\
\hline 1.1 .3 & $\begin{array}{l}\text { Improvement and strengthening } \\
\text { of cadastral services within the } \\
\text { Land Administration Offices }\end{array}$ & 4 & & & \\
\hline 1.1 .4 & $\begin{array}{l}\text { Increase in the use of arable } \\
\text { land }\end{array}$ & 3 & $\begin{array}{l}\text { Despite an increase in } \\
\text { the amount of land } \\
\text { under cultivation and } \\
\text { farm incomes, much } \\
\text { more is needed to be } \\
\text { done into convincing } \\
\text { farmers to work their } \\
\text { land. }\end{array}$ & $\begin{array}{l}\text { Improved collaboration amongst technical } \\
\text { departments within the MoA with other } \\
\text { institutions and local government. } \\
\text { The commencement of the second phase of } \\
\text { Land Use Project. }\end{array}$ & Ongoing \\
\hline
\end{tabular}


ANNEX 1: MATRIX OF REALIZATION OF PRIORITARY PUBLIC MEASURES 2002

\begin{tabular}{|c|c|c|c|c|c|}
\hline 1.1 .5 & $\begin{array}{l}\text { Improvements to agricultural } \\
\text { land legislation }\end{array}$ & 4 & & & \\
\hline 1.2 & $\begin{array}{l}\text { The result: Growth of } \\
\text { investments in watering system } \\
\text { and drainage rehabilitation }\end{array}$ & & & & \\
\hline 1.2 .1 & $\begin{array}{l}\text { Enlargement of rehabilitation } \\
\text { project activities in water and } \\
\text { drainage on the central plains }\end{array}$ & 4 & & & \\
\hline 1.2 .2 & $\begin{array}{l}\text { The maintenance and } \\
\text { expansion of small-scale water } \\
\text { rehabilitation projects in } \\
\text { mountainous areas }\end{array}$ & 3 & $\begin{array}{l}\text { Restructuring of Water } \\
\text { Works Rehabilitation } \\
\text { Fund }\end{array}$ & Enhanced coordination with FRVU structures & \\
\hline 1.2 .3 & $\begin{array}{l}\text { Water enterprise restructuring } \\
\text { and transformation into Water } \\
\text { Boards }\end{array}$ & $\overline{4}$ & & & \\
\hline 1.2 .4 & $\begin{array}{l}\text { Support for the creation of } \\
\text { Water Users Associations and } \\
\text { Federations (WUAF) }\end{array}$ & 4 & & & \\
\hline 1.2 .5 & $\begin{array}{l}\text { Training of WUAF heads in the } \\
\text { organizational development and } \\
\text { management. }\end{array}$ & 4 & & & \\
\hline 1.2 .6 & 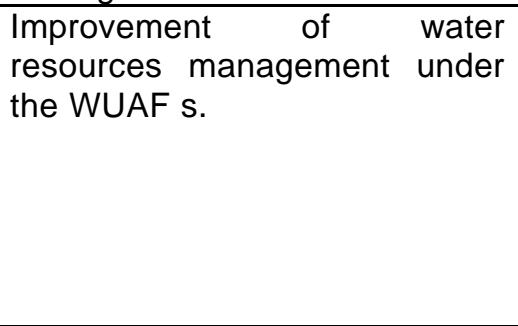 & 3 & $\begin{array}{l}\text { The consolidation of } \\
\text { WUAFs and the } \\
\text { stability of their water } \\
\text { management systems } \\
\text { Co-operation with } \\
\text { farmers } \\
\text { Electricity } \\
\text { increases }\end{array}$ & $\begin{array}{l}\text { Technical and financial assistance WUAFs. } \\
\text { Ongoing training for WUAFs. }\end{array}$ & \\
\hline 1.3 & $\begin{array}{l}\text { The result: Increase in access } \\
\text { and quality of farming } \\
\text { machinery and agricultural } \\
\text { inputs. }\end{array}$ & & & & \\
\hline 1.3 .1 & $\begin{array}{l}\text { Increased investments in } \\
\text { agricultural technologies. and } \\
\text { improved legislation. }\end{array}$ & 4 & & & \\
\hline 1.3 .2 & Introduction of new production & 4 & & & \\
\hline
\end{tabular}

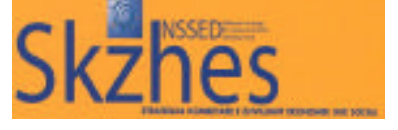


ANNEX 1: MATRIX OF REALIZATION OF PRIORITARY PUBLIC MEASURES 2002

\begin{tabular}{|c|c|c|c|c|c|}
\hline & technologies & & & & \\
\hline 1.3 .3 & $\begin{array}{l}\text { Restructuring } r \text { and } \\
\text { strengthening of regulatory } \\
\text { institutions and seeds and } \\
\text { seedlings certification } \\
\text { (Inspectorate of State Control of } \\
\text { Seeds and Seedlings) etc. }\end{array}$ & 3 & $\begin{array}{l}\text { Insufficient } \\
\text { collaboration with line } \\
\text { institutions and local } \\
\text { governments }\end{array}$ & $\begin{array}{l}\text { Strengthening of the inspection network and } \\
\text { collaboration with customs }\end{array}$ & \\
\hline 1.3 .4 & Enhanced seed quality & 3 & $\begin{array}{l}\text { Delays in the allocation } \\
\text { of funds for seed } \\
\text { control labs }\end{array}$ & Establishment of procedures and training. & \\
\hline 1.3 .5 & $\begin{array}{l}\text { The changing of agricultural } \\
\text { activity and extension of } \\
\text { greenhouses, orchards and } \\
\text { vineyards }\end{array}$ & 3 & Lack of credit. & $\begin{array}{l}\text { Better project coordination which granting } \\
\text { institutions }\end{array}$ & \\
\hline 1.3 .6 & $\begin{array}{l}\text { The creation of breed and } \\
\text { fodder improvement centers }\end{array}$ & 4 & & & \\
\hline 1.4 & $\begin{array}{l}\text { The result: Improvement in } \\
\text { access and quality of } \\
\text { agriculture and animal } \\
\text { husbandry services }\end{array}$ & 4 & & & \\
\hline 1.4 .1 & $\begin{array}{l}\text { The maintenance } r \text { and } \\
\text { extension of programs } \\
\text { improvement of veterinary } \\
\text { prophylactics and animal health } \\
\text { including several projects } \\
\text { undertaken in collaboration with } \\
\text { Veterinary Research Institution }\end{array}$ & 3 & $\begin{array}{l}\text { Lack of funding for } \\
\text { complete control of } \\
\text { animal diseases }\end{array}$ & $\begin{array}{l}\text { A study on the structure of veterinary services } \\
\text { will be prepared. }\end{array}$ & \\
\hline 1.4 .2 & $\begin{array}{l}\text { Strengthening of counseling } \\
\text { services throughout the } \\
\text { country. }\end{array}$ & 3 & $\begin{array}{l}\text { Insufficient funds from } \\
\text { the state budged for the } \\
\text { undertaking of } \\
\text { programmed activities. } \\
\text { Reduction in extension } \\
\text { employees of up to } \\
30 \%\end{array}$ & $\begin{array}{l}\text { Maintenance of established information } \\
\text { centers. } \\
\text { Strengthening of the role of communications } \\
\text { (publications, folders, documentaries), training } \\
\text { and farm research. }\end{array}$ & \\
\hline
\end{tabular}


ANNEX 1: MATRIX OF REALIZATION OF PRIORITARY PUBLIC MEASURES 2002

\begin{tabular}{|c|c|c|c|c|c|}
\hline 1.4 .3 & $\begin{array}{l}\text { Support for private information } \\
\text { services in areas of high } \\
\text { productivity }\end{array}$ & 4 & & & \\
\hline 1.4 .4 & $\begin{array}{l}\text { Restructuring of agricultural } \\
\text { research institutes }\end{array}$ & 3 & $\begin{array}{lr}\text { Insufficient } & \text { financial } \\
\text { resources } & \text { for } \\
\text { infrastructure } & \text { and } \\
\text { logistics support } & \\
\end{array}$ & $\begin{array}{l}\text { Consolidation of IFSR and the mobilization of } \\
\text { financial resources to support research } \\
\text { projects. }\end{array}$ & 2004 \\
\hline 1.4 .5 & $\begin{array}{l}\text { Foundation of the National } \\
\text { Agricultural Research and } \\
\text { Agricultural Information Service } \\
\text { Center; } \\
\text { First phase of the creation of } \\
\text { the Institute for Field Seeds } \\
\text { Research (IFSR) which is a } \\
\text { consolidation of } 4 \text { institutes }\end{array}$ & 4 & & & \\
\hline 1.4 .6 & $\begin{array}{l}\text { Development of cost-recovery } \\
\text { practices including farm } \\
\text { research projects, undertaken } \\
\text { in collaboration with information } \\
\text { services structures. }\end{array}$ & 3 & $\begin{array}{l}\text { These funds are } \\
\text { limited. Moreover, } \\
\text { farmers have neither } \\
\text { the ability nor the } \\
\text { willingness to pay for } \\
\text { such services. }\end{array}$ & $\begin{array}{l}\text { Better and increased use of domestically and } \\
\text { externally-funded research projects. }\end{array}$ & 2010 \\
\hline 1.5 & $\begin{array}{l}\text { Increased access to financial } \\
\text { services and credit }\end{array}$ & & & & \\
\hline 1.5 .1 & $\begin{array}{l}\text { Greater access to financial } \\
\text { resources and investment credit } \\
\text { in priority sectors, } \\
\text { (greenhouses, orchards, } \\
\text { vineyards) and in animal } \\
\text { husbandry, mainly through the } \\
\text { extension of such schemes as } \\
\text { VCF/SC of FFR Rural Finance } \\
\text { Fund and those of MAFF } \\
\text { Mountain Areas Development } \\
\text { Fund and the introduction of } \\
\text { other financial enterprises of } \\
\text { rural areas. }\end{array}$ & 3 & $\begin{array}{l}\text { The activities planned } \\
\text { by MADA have not yet } \\
\text { commenced due to } \\
\text { project delays }\end{array}$ & $\begin{array}{l}\text { Improvement of collaboration with MADA and } \\
\text { MoA and other projects }\end{array}$ & \\
\hline 1.5 .2 & Development of crediting & 4 & & & \\
\hline
\end{tabular}

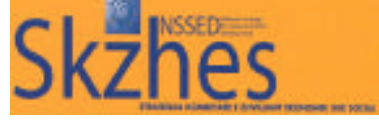


ANNEX 1: MATRIX OF REALIZATION OF PRIORITARY PUBLIC MEASURES 2002

\begin{tabular}{|c|c|c|c|c|c|}
\hline & $\begin{array}{l}\text { cooperatives through the } \\
\text { creation of saving-crediting } \\
\text { companies }\end{array}$ & & & & \\
\hline 1.5 .3 & $\begin{array}{l}\text { Fast and } \text { efficient } \\
\text { implementation of the MADF } \\
\text { program }\end{array}$ & 3 & & $\begin{array}{l}\text { The setting up of the regional office, staff } \\
\text { training, improvement of inter-institutional } \\
\text { collaboration }\end{array}$ & 2007 \\
\hline 1.5 .4 & $\begin{array}{l}\text { Increase the availability of } \\
\text { credit and expand the Rural } \\
\text { Financing Fund, and the } \\
\text { Mountain Areas Development } \\
\text { Fund (MAFF) and other } \\
\text { crediting organizations }\end{array}$ & 4 & & & \\
\hline 1.6 & $\begin{array}{l}\text { The Result: improvement in } \\
\text { fishery management and } \\
\text { expanding the activity in this } \\
\text { sector }\end{array}$ & & & & \\
\hline 1.6 .1 & $\begin{array}{l}\text { Improvements to the new law } \\
\text { on the fishery }\end{array}$ & 4 & & & \\
\hline 1.6 .2 & $\begin{array}{l}\text { Drafting and application of } \\
\text { specific policies for the support } \\
\text { of the fishery related to the } \\
\text { access to inputs }\end{array}$ & 3 & $\begin{array}{l}\text { Delays in the approval } \\
\text { of fuel price differential }\end{array}$ & $\begin{array}{l}\text { Drafting CMD for the identification of fuel } \\
\text { distribution point for fuel used in fishing } \\
\text { vessels and regulations of the interested } \\
\text { ministries. } \\
\text { Coordination with the General Taxation } \\
\text { Department and other ministries }\end{array}$ & July 2003 \\
\hline 1.6 .3 & $\begin{array}{l}\text { Resumption of fish production } \\
\text { activities }\end{array}$ & 4 & & & \\
\hline 1.6 .4 & $\begin{array}{l}\text { The establishment of pilot } \\
\text { aquaculture schemes }\end{array}$ & 4 & & & \\
\hline 1.6 .5 & $\begin{array}{l}\text { Exploitation of aquaculture in } \\
\text { coastal waters }\end{array}$ & 3 & $\begin{array}{l}\text { The procedures are } \\
\text { blocked by the } \\
\text { Technical Secretariat of } \\
\text { National Council of } \\
\text { Water }\end{array}$ & $\begin{array}{l}\text { Negotiations with the Secretariat for the } \\
\text { approval of the common DCM along with the } \\
\text { Secretariat of KKU in the Ministry of Tourism }\end{array}$ & April 2003 \\
\hline 1.6 .6 & $\begin{array}{l}\text { Creation and strengthening of } \\
\text { Fishermen Associations to }\end{array}$ & 4 & & & \\
\hline
\end{tabular}

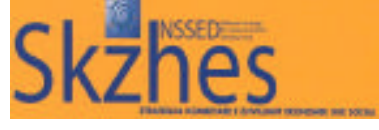


ANNEX 1: MATRIX OF REALIZATION OF PRIORITARY PUBLIC MEASURES 2002

\begin{tabular}{|c|c|c|c|c|c|}
\hline & manage the fishery & & & & \\
\hline 1.6 .7 & $\begin{array}{l}\text { Rehabilitation of fishing ports to } \\
\text { ensure the optimal hygienic } \\
\text { conditions, fishery and } \\
\text { navigation standards (first } \\
\text { phase) }\end{array}$ & 3 & $\begin{array}{l}\text { Fishery project has } \\
\text { begun with a 2-month } \\
\text { delay. } \\
\text { Barriers for the works } \\
\text { beginning } \\
\text { compliance with the } \\
\text { Durres Harbor Master } \\
\text { Plan. }\end{array}$ & $\begin{array}{l}\text { The process for the completion of the first } \\
\text { phase is going on. }\end{array}$ & $\begin{array}{l}2003 \text { first phase } \\
2004 \text { full process }\end{array}$ \\
\hline 2 & $\begin{array}{l}\text { Objective: The growth of the } \\
\text { level of Agricultural, animal and } \\
\text { fishery production }\end{array}$ & & & & \\
\hline 2.1 & $\begin{array}{l}\text { Result the increase degree of } \\
\text { the agro production }\end{array}$ & & & & \\
\hline 2.1 .1 & $\begin{array}{l}\text { Promotion of technological } \\
\text { improvements and } \\
\text { establishment of new lines of } \\
\text { agro-production }\end{array}$ & 4 & & & \\
\hline 2.1 .2 & $\begin{array}{l}\text { The implementation of } \\
\text { Competitive Grant Programs } \\
\text { (ASP program) for the } \\
\text { introduction of new production } \\
\text { technologies }\end{array}$ & 4 & & & \\
\hline 2.1 .3 & $\begin{array}{l}\text { The maintenance and } \\
\text { expansion of project activities } \\
\text { for the Food Production Growth } \\
(2 \mathrm{KR}) \text { for credit for agro- } \\
\text { production }\end{array}$ & 4 & & & \\
\hline 3. & $\begin{array}{l}\text { Objective: Improvement of } \\
\text { domestic and foreign marketing } \\
\text { of agricultural products. }\end{array}$ & & & & \\
\hline
\end{tabular}


ANNEX 1: MATRIX OF REALIZATION OF PRIORITARY PUBLIC MEASURES 2002

\begin{tabular}{|c|c|c|c|c|c|}
\hline 3.1 & $\begin{array}{l}\text { The Result: the establishing } \\
\text { and strengthening of } \\
\text { distribution facilities }\end{array}$ & & & & \\
\hline 3.1 .1 & $\begin{array}{l}\text { Establishment of wholesale } \\
\text { markets in Tirana, Shkodra, } \\
\text { Lushnje, Vlora and Korca } \\
\text { (Project of Agricultural } \\
\text { Services) }\end{array}$ & 2 & $\begin{array}{l}\text { Barriers to construct } \\
\text { wholesales market's in } \\
\text { the Municipality of Vlora }\end{array}$ & $\begin{array}{l}\text { Improvement of collaboration with local } \\
\text { governments }\end{array}$ & 2007 \\
\hline 3.1 .2 & $\begin{array}{l}\text { Establishment in some rural } \\
\text { areas of distribution, storage } \\
\text { and retail facilities for } \\
\text { agricultural products. }\end{array}$ & 3 & $\begin{array}{ll}\text { Insufficient } & \text { external } \\
\text { funding }\end{array}$ & & \\
\hline 3.1 .3 & $\begin{array}{l}\text { Improvements in export } \\
\text { marketing and promotion. }\end{array}$ & 4 & & & \\
\hline 3.1 .4 & $\begin{array}{l}\text { Improvements to the } \\
\text { organization of agricultural } \\
\text { product' marketing including the } \\
\text { involvement of entrepreneurs }\end{array}$ & 4 & & & \\
\hline 3.1 .5 & $\begin{array}{l}\text { Establishment of structures for } \\
\text { the collection and diffusion to } \\
\text { farmers of market information }\end{array}$ & 4 & & & \\
\hline 3.1 .6 & $\begin{array}{l}\text { Technical assistance to } \\
\text { improve the quality of the } \\
\text { labeling and packaging of } \\
\text { agricultural products. }\end{array}$ & 4 & & & \\
\hline 3.2 & $\begin{array}{l}\text { The result: improvement of } \\
\text { legislation and product quality } \\
\text { control }\end{array}$ & & & & \\
\hline 3.2 .1 & $\begin{array}{l}\text { Completion of the rehabilitation } \\
\text { and equipping of regional food } \\
\text { inspection laboratories }\end{array}$ & 3 & $\begin{array}{l}\text { Technical delays with } \\
\text { the tendering process }\end{array}$ & $\begin{array}{l}\text { The tender has been concluded and } \\
\text { equipment is expected to arrive }\end{array}$ & 2003 \\
\hline 3.2 .2 & $\begin{array}{l}\text { Completion of legislation on } \\
\text { quality and marketing standards }\end{array}$ & 4 & & & \\
\hline 3.2 .3 & The strengthening of veterinary & 4 & & & \\
\hline
\end{tabular}

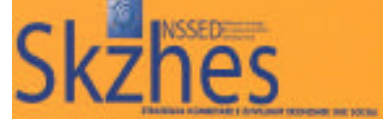


ANNEX 1: MATRIX OF REALIZATION OF PRIORITARY PUBLIC MEASURES 2002

\begin{tabular}{|c|c|c|c|c|c|}
\hline & inspection facilities & & & & \\
\hline 3.2 .4 & $\begin{array}{l}\text { Legislation harmonization on } \\
\text { food production with that of the } \\
\text { EU }\end{array}$ & 4 & & & \\
\hline 3.2 .5 & $\begin{array}{l}\text { The completion of studies on } \\
\text { increased competitiveness in } \\
\text { local and international product } \\
\text { markets. }\end{array}$ & 4 & & & \\
\hline 4 & $\begin{array}{l}\text { Objective: } \\
\begin{array}{l}\text { exploitation } \\
\text { resources. }\end{array}\end{array}$ & & & & \\
\hline 4.1 & $\begin{array}{l}\text { The result: Support to the } \\
\text { management of forests, } \\
\text { pastures and infrastructure } \\
\text { serving rural areas. }\end{array}$ & & & & \\
\hline 4.1 .1 & $\begin{array}{l}\text { Strengthening of environmental } \\
\text { management structures at the } \\
\text { local level (communes and } \\
\text { regions) }\left(^{*}\right)\end{array}$ & & & & \\
\hline 4.1 .2 & $\begin{array}{l}\text { Completion of legislation on } \\
\text { long term natural resources } \\
\text { leasing, such as pastures, etc. }\end{array}$ & 2 & $\begin{array}{l}\text { Insufficient coordination } \\
\text { with the local } \\
\text { governments in the } \\
\text { application of legislation } \\
\text { on the setting up of the } \\
\text { Forest Leasing Board. } \\
\text { Suspension of the } \\
\text { leasing of state } \\
\text { property. }\end{array}$ & $\begin{array}{l}\text { Ongoing monitoring and coordination with the } \\
\text { local governments }\end{array}$ & \\
\hline 4.1 .3 & $\begin{array}{l}\text { The ongoing transfer/use of } \\
\text { forests and pastures to the } \\
\text { communes }\end{array}$ & 4 & & & \\
\hline 4.1 .4 & $\begin{array}{l}\text { Maintenance of co- } \\
\text { management practices of water } \\
\text { resources by the fishery } \\
\text { through Fishery Management }\end{array}$ & 4 & & & \\
\hline
\end{tabular}

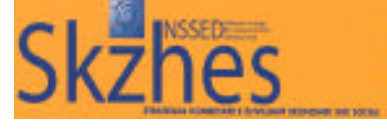


ANNEX 1: MATRIX OF REALIZATION OF PRIORITARY PUBLIC MEASURES 2002

\begin{tabular}{|c|c|c|c|c|c|}
\hline & Organizations (FMO) & & & & \\
\hline 4.2 & $\begin{array}{l}\text { The result: Strengthening } \\
\text { natural resources management } \\
\text { capacities }\end{array}$ & & & & \\
\hline 4.2 .1 & $\begin{array}{l}\text { Improvement of management } \\
\text { structures responsible for the } \\
\text { exploitation of forests and } \\
\text { pastures }\end{array}$ & 3 & $\begin{array}{l}\text { Late establishment of } \\
\text { the Elbasan Regional } \\
\text { Directorate }\end{array}$ & $\begin{array}{l}\text { Strengthening the capacity and defining the } \\
\text { mandate of the ERDE with the aim of using it } \\
\text { as a model for the establishment of other } \\
\text { directorates }\end{array}$ & June 2003 \\
\hline 4.2 .2 & $\begin{array}{l}\text { Strengthening the forest service } \\
\text { to ensure the sustainable usage } \\
\text { of forests and pastures } \\
\text { (rehabilitation and protection) }\end{array}$ & 3 & 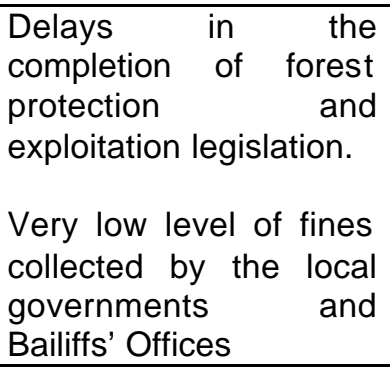 & $\begin{array}{l}\text { Deepening of the legislative and strategic } \\
\text { framework for forests and Pastures }\end{array}$ & \\
\hline 4.2 .3 & $\begin{array}{l}\text { Creation of the legal framework } \\
\text { on the management and } \\
\text { exploitation of the fishery's } \\
\text { water resources. }\end{array}$ & 4 & & & \\
\hline 4.2 .4 & $\begin{array}{l}\text { Protection of land from erosion } \\
\text { through forestation and } \\
\text { (mountain barriers) }\end{array}$ & 3 & $\begin{array}{l}\text { Insufficient funds for } \\
\text { erosion protection }\end{array}$ & $\begin{array}{l}\text { Increase in funding and } \\
\text { improved institutional cooperation (, MoA, } \\
\text { MLGD and MoF). }\end{array}$ & \\
\hline 4.2 .5 & $\begin{array}{l}\text { Rehabilitation of drainage } \\
\text { systems to eliminate overflows } \\
\text { in the north-east region (Look at } \\
1.2 \text { ) }\end{array}$ & & & & \\
\hline 5 & $\begin{array}{l}\text { Objective: Generation of } \\
\text { employment and incomes from } \\
\text { non-agricultural activities in } \\
\text { rural areas }\end{array}$ & & & & \\
\hline 5.1 & $\begin{array}{l}\text { Promotion of micro-enterprises } \\
\text { through micro-financing and } \\
\text { advisory programs and services }\end{array}$ & 3 & Insufficient credit & $\begin{array}{l}\text { Better coordination between advisory and } \\
\text { crediting institutions }\end{array}$ & \\
\hline 5.2 & $\begin{array}{ll}\text { Employment } & \text { generation } \\
\text { through public works programs; }\end{array}$ & 4 & & & \\
\hline
\end{tabular}

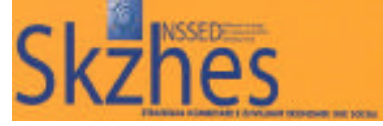


ANNEX 1: MATRIX OF REALIZATION OF PRIORITARY PUBLIC MEASURES 2002

\begin{tabular}{|l|l|l|l|l|l|}
\hline & $\left({ }^{*}\right)$ & & \\
\hline 5.3 & $\begin{array}{l}\text { The strengthening and } \\
\text { expansion of credit } \\
\text { cooperatives }\end{array}$ & $\begin{array}{l}\text { The creation of marketing and } \\
\text { information centers }\end{array}$ & 4 & & \\
\hline 5.4 & $\begin{array}{l}\text { Promotion of agro-tourism } \\
\text { activities, harvesting and } \\
\text { production of medicinal plants, } \\
\text { handicrafts etc. }\end{array}$ & $\begin{array}{l}\text { While NGOs and } \\
\text { donors Improved collaboration with the central and } \\
\text { contributed to activities } \\
\text { in this area, the } \\
\text { involvement of local } \\
\text { government has been } \\
\text { weak. }\end{array}$ & \begin{tabular}{l} 
Iocal governments \\
\hline 5
\end{tabular} \\
\hline
\end{tabular}


ANNEX 1: MATRIX OF REALIZATION OF PRIORITARY PUBLIC MEASURES 2002

MINISTRY OF TERRITORIAL ADJUSTMENT AND TOURISM 
ANNEX 1: MATRIX OF REALIZATION OF PRIORITARY PUBLIC MEASURES 2002

\section{MINISTRY OF TERRITORIAL ADJUSTMENT AND TOURISM}

\begin{tabular}{|c|c|c|c|c|c|}
\hline N0. & $\begin{array}{l}\text { Priority activity for the year } \\
2002\end{array}$ & $\begin{array}{l}\text { Accomplishment } \\
\text { scale according to } \\
\text { the criteria }\end{array}$ & $\begin{array}{c}\text { Reasons for } \\
\text { accomplishing the } \\
\text { activity at a lower } \\
\text { scale than } \\
\text { envisaged }\end{array}$ & $\begin{array}{l}\text { Measures adopted to enable } \\
\text { accomplishment }\end{array}$ & $\begin{array}{l}\text { New deadline for the } \\
\text { complete } \\
\text { accomplishment }\end{array}$ \\
\hline 1. & $\begin{array}{l}\text { Preparation of the national } \\
\text { urban development strategy. }\end{array}$ & 2 & - & - & Proceeding as scheduled \\
\hline 2. & $\begin{array}{l}\text { Preparation of regional } \\
\text { strategies. }\end{array}$ & 1 & & & $2005-2007$ \\
\hline 3. & $\begin{array}{l}\text { Improvement and completion of } \\
\text { the urban planning legal } \\
\text { framework. }\end{array}$ & 1 & $\begin{array}{l}\text { Insufficient financing } \\
\text { and assistance }\end{array}$ & $\begin{array}{l}\text { External assistance has been } \\
\text { required. }\end{array}$ & To be reviewed in 2003 . \\
\hline 4. & $\begin{array}{l}\text { Identification of key national } \\
\text { projects; their preparation and } \\
\text { approval in compliance with the } \\
\text { law. }\end{array}$ & 2 & $\begin{array}{l}\text { Insufficient financing } \\
\text { and assistance }\end{array}$ & Reorganization & $\begin{array}{l}\text { Previous deadline } 2003- \\
2005 \text { remains in force }\end{array}$ \\
\hline 5. & $\begin{array}{l}\text { Greater efforts directed to work } \\
\text { on urban studies and projects in } \\
\text { the main cities. }\end{array}$ & 2 & & & Proceeding as scheduled \\
\hline 6. & $\begin{array}{l}\text { Completion of technical quotas } \\
\text { and standards and detailed } \\
\text { indicators to facilitate the } \\
\text { projects. }\end{array}$ & 1 & & & It can not be assessed yet \\
\hline 7. & Water Infrastructure Sector & & & & \\
\hline 8. & $\begin{array}{l}\text { Project completion followed by } \\
\text { additional externally-funded } \\
\text { projects. }\end{array}$ & 3 & $\begin{array}{l}\text { Slow disbursement } \\
\text { rates, deadline } \\
\text { postponement. }\end{array}$ & $\begin{array}{l}\text { Strengthening of cooperation, } \\
\text { improvement of procedures }\end{array}$ & $\begin{array}{l}\text { The deadlines are different } \\
\text { according to the projects }{ }^{21} \text {. }\end{array}$ \\
\hline 9. & $\begin{array}{l}\text { Completion of the } \\
\text { commercialization of public } \\
\text { utilities. }\end{array}$ & 3 & Average rate & & \\
\hline 10. & Approval of amendments to the & & & & \\
\hline
\end{tabular}


ANNEX 1: MATRIX OF REALIZATION OF PRIORITARY PUBLIC MEASURES 2002

\begin{tabular}{|c|c|c|c|c|c|}
\hline & $\begin{array}{l}\text { water supply enterprises' } \\
\text { statute. }\end{array}$ & & & & \\
\hline 11. & $\begin{array}{l}\text { Completion of the merger of } \\
\text { water supply with sewage } \\
\text { enterprises. }\end{array}$ & 3 & Slow rate & & \\
\hline 12. & $\begin{array}{l}\text { Application of sewage service } \\
\text { tariffs, establishment of cost } \\
\text { recovery water and sewage } \\
\text { tariffs, increase in collection } \\
\text { rates and reduction of illegal } \\
\text { connections. }\end{array}$ & 2 & $\begin{array}{l}\text { Institutional } \\
\text { difficulties and lack } \\
\text { of legislation and } \\
\text { coordination. }\end{array}$ & $\begin{array}{l}\text { Local government awareness } \\
\text { increase and better coordination } \\
\text { with ERRU. }\end{array}$ & 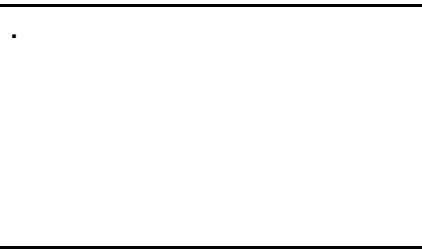 \\
\hline 13. & $\begin{array}{l}\text { Encouragement of private } \\
\text { participation through } \\
\text { management contracts. }\end{array}$ & 3 & $\begin{array}{l}\text { Delays in } \\
\text { implementation. }\end{array}$ & $\begin{array}{l}\text { Work is being carried out } \\
\text { according to the new projects } \\
\text { and schedules. }\end{array}$ & $\begin{array}{l}\text { Schedules are different } \\
\text { according to the projects. }^{22}\end{array}$ \\
\hline 14. & $\begin{array}{l}\text { Encouragement of other forms } \\
\text { of participation, through water } \\
\text { sector management contracts }\end{array}$ & 1 & $\begin{array}{l}\text { Not properly } \\
\text { acquainted with. }\end{array}$ & $\begin{array}{l}\text { Consultations with other } \\
\text { stakeholders are required. }\end{array}$ & \\
\hline 15. & $\begin{array}{l}\text { Transfer of enterprise asset } \\
\text { ownership to municipalities and } \\
\text { communes. }\end{array}$ & 1 & $\begin{array}{l}\text { Lack of legislation } \\
\text { and slow rate }\end{array}$ & $\begin{array}{l}\text { A clear Action Plan should be } \\
\text { prepared based on the } \\
\text { decentralization law. }\end{array}$ & \\
\hline 16. & $\begin{array}{l}\text { Amendment of the law allowing } \\
\text { the municipalities to establish } \\
\text { water services tariffs. }\end{array}$ & 2 & $\begin{array}{l}\text { Difficulties in } \\
\text { institutional } \\
\text { reconciliation }\end{array}$ & $\begin{array}{l}\text { Consultations among respective } \\
\text { institutions. }\end{array}$ & $\begin{array}{l}\text { To take place during } \\
\text { February. }\end{array}$ \\
\hline 17. & $\begin{array}{l}\text { Municipal and commune } \\
\text { personnel training on water and } \\
\text { sewage tariffs, methodologies } \\
\text { and rules. }\end{array}$ & 2 & & $\begin{array}{l}\text { Better coordination and } \\
\text { reconciliation of existing } \\
\text { possibilities. }\end{array}$ & During February \\
\hline 18. & $\begin{array}{l}\text { Workshop on linking water } \\
\text { policies to cost recovery and } \\
\text { payment possibilities by low- } \\
\text { income families. }\end{array}$ & 1 & $\begin{array}{l}\text { Organization } \\
\text { method, the program } \\
\text { and the participants } \\
\text { have not been yet } \\
\text { specified. }\end{array}$ & $\begin{array}{l}\text { More clear definition of the } \\
\text { objectives and program of the } \\
\text { workshop. }\end{array}$ & \\
\hline 19. & Rural water infrastructure & & & & \\
\hline 20. & Approval of the rural strategy by & 3 & Legal difficulties and & Removal of barriers. & \\
\hline
\end{tabular}


ANNEX 1: MATRIX OF REALIZATION OF PRIORITARY PUBLIC MEASURES 2002

\begin{tabular}{|c|c|c|c|c|c|}
\hline & the Government. & & & & \\
\hline 21. & $\begin{array}{l}\text { Establishment of the water } \\
\text { agency for the rural areas at the } \\
\text { central and local level, } \\
\text { promotion of rural community } \\
\text { participation in the } \\
\text { establishment of the community } \\
\text { water associations. }\end{array}$ & 1 & $\begin{array}{l}\text { Hindered by the lack } \\
\text { of strategy approval. }\end{array}$ & Approval of the rural strategy. & $\begin{array}{l}\text { Pending the approval of } \\
\text { the rural strategy }\end{array}$ \\
\hline 22. & $\begin{array}{l}\text { Ensure technical assistance for } \\
\text { the implementation, operation } \\
\text { and maintenance of the water } \\
\text { supplies and sewage network. }\end{array}$ & 1 & $\begin{array}{l}\text { Hindered by the lack } \\
\text { of strategy approval. }\end{array}$ & Approval of the rural strategy. & $\begin{array}{l}\text { Pending the approval of } \\
\text { the rural strategy }\end{array}$ \\
\hline 23. & $\begin{array}{l}\text { Preparation of new tariff } \\
\text { strategies supported by the rural } \\
\text { community and of the water } \\
\text { supply system standards in } \\
\text { compliance with the acceptable } \\
\text { tariffs. }\end{array}$ & 1 & $\begin{array}{l}\text { Hindered by the lack } \\
\text { of strategy approval. }\end{array}$ & Approval of the rural strategy. & $\begin{array}{l}\text { Pending the approval of } \\
\text { the rural strategy }\end{array}$ \\
\hline 25. & $\begin{array}{l}\text { Encouragement of consultations } \\
\text { with donors on initiating new } \\
\text { water projects } \\
\text { in the rural areas based on the } \\
\text { strategy. }\end{array}$ & 1 & $\begin{array}{l}\text { Hindered by the lack } \\
\text { of strategy approval. }\end{array}$ & Approval of the rural strategy. & $\begin{array}{l}\text { Pending the approval of } \\
\text { the rural strategy }\end{array}$ \\
\hline 26. & $\begin{array}{l}\text { Approval of the potable water } \\
\text { supply and sewage strategy by } \\
\text { the Council of Ministers. }\end{array}$ & 3 & & & \\
\hline 27. & $\begin{array}{l}\text { Preparation and approval of the } \\
\text { Action Plan on policy } \\
\text { implementation and the } \\
\text { institutional aspects of the water } \\
\text { strategy. }\end{array}$ & 1 & $\begin{array}{l}\text { Hindered by the lack } \\
\text { of strategy approval. }\end{array}$ & Approval of the strategy. & $\begin{array}{l}\text { Pending the approval of } \\
\text { the rural strategy }\end{array}$ \\
\hline 28. & $\begin{array}{l}\text { Definition of institutional } \\
\text { responsibilities and reporting. }\end{array}$ & 1 & $\begin{array}{l}\text { To be completed in } \\
\text { compliance with the } \\
\text { strategy. }\end{array}$ & Approval of the strategy. & $\begin{array}{l}\text { Pending the approval of } \\
\text { the rural strategy }\end{array}$ \\
\hline 29. & $\begin{array}{l}\text { Establishment of consumers } \\
\text { associations. }\end{array}$ & 1 & $\begin{array}{l}\text { To be completed in } \\
\text { compliance with the } \\
\text { strategy. }\end{array}$ & Approval of the strategy. & $\begin{array}{l}\text { Pending the approval of } \\
\text { the rural strategy }\end{array}$ \\
\hline
\end{tabular}


ANNEX 1: MATRIX OF REALIZATION OF PRIORITARY PUBLIC MEASURES 2002

MINISTRY OF EDUCATION AND SCIENCE 
ANNEX 1: MATRIX OF REALIZATION OF PRIORITARY PUBLIC MEASURES 2002

\section{MINISTRY OF EDUCATION AND SCIENCE}

\begin{tabular}{|c|c|c|c|c|c|}
\hline H.1 & $\begin{array}{l}\text { Priority activity for the year } \\
\qquad 2002\end{array}$ & $\begin{array}{l}\text { Accomplishment } \\
\text { scale according to } \\
\text { the criteria }\end{array}$ & $\begin{array}{c}\text { Reasons for } \\
\text { accomplishing } \\
\text { the activity at a } \\
\text { lower scale than } \\
\text { envisaged) }\end{array}$ & $\begin{array}{l}\text { Measures adopted to } \\
\text { enable accomplishment }\end{array}$ & $\begin{array}{l}\text { New deadline for the complete } \\
\text { accomplishment }\end{array}$ \\
\hline 1. & $\begin{array}{l}\text { Preparation of the administrative } \\
\text { and financial reform strategy. } \\
\text { Rationalizing of the sector } \\
\text { functions at the central, local, } \\
\text { and school level. } \\
\text { Establishment or consolidation } \\
\text { of the new MoES structures } \\
\text { engaged in planning, analysis, } \\
\text { and human resources and } \\
\text { financial management functions. } \\
\text { Establishment of NSSED } \\
\text { Monitoring Unit. } \\
\text { Gradual implementation of } \\
\text { the administrative and } \\
\text { financial reform starting with } \\
\text { pilot projects. } \\
\text { Preparation and implementation } \\
\text { of the personnel management } \\
\text { training at the central, local and } \\
\text { school level to consolidate the } \\
\text { staff's ability to carry out the } \\
\text { new functional responsibilities. }\end{array}$ & $\begin{array}{l}4 \\
3\end{array}$ & $\begin{array}{l}\text { Late arrival of the } \\
\text { structure by DAP. } \\
\text { Late arrival of the } \\
\text { structure by DAP. }\end{array}$ & $\begin{array}{l}\text { Rational definition and } \\
\text { implementation of the } \\
\text { functions has started. } \\
\text { Implementation has } \\
\text { started at the central level } \\
\text { and it is now starting at } \\
\text { the other levels. }\end{array}$ & $\begin{array}{l}\text { June } 2003 \\
\\
\text { June } 2003\end{array}$ \\
\hline 3. & $\begin{array}{l}\text { Analysis of factors affecting the } \\
\text { demand for basic education by } \\
\text { the family sub-groups having a } \\
\text { tendency to abandon schooling. } \\
\text { Preparation and piloting of the } \\
\text { programs to increase school }\end{array}$ & 3 & $\begin{array}{l}\text { 1. Study has not } \\
\text { been completed } \\
\text { as the diagnostic } \\
\text { questionnaires } \\
\text { have not been } \\
\text { completed in } \\
\text { specific areas in }\end{array}$ & $\begin{array}{l}\text { 1. Cooperation with } \\
\text { district Education } \\
\text { Directorates on the } \\
\text { preparation of the } \\
\text { diagnostic } \\
\text { questionnaires. }\end{array}$ & December 2003 \\
\hline
\end{tabular}


ANNEX 1: MATRIX OF REALIZATION OF PRIORITARY PUBLIC MEASURES 2002

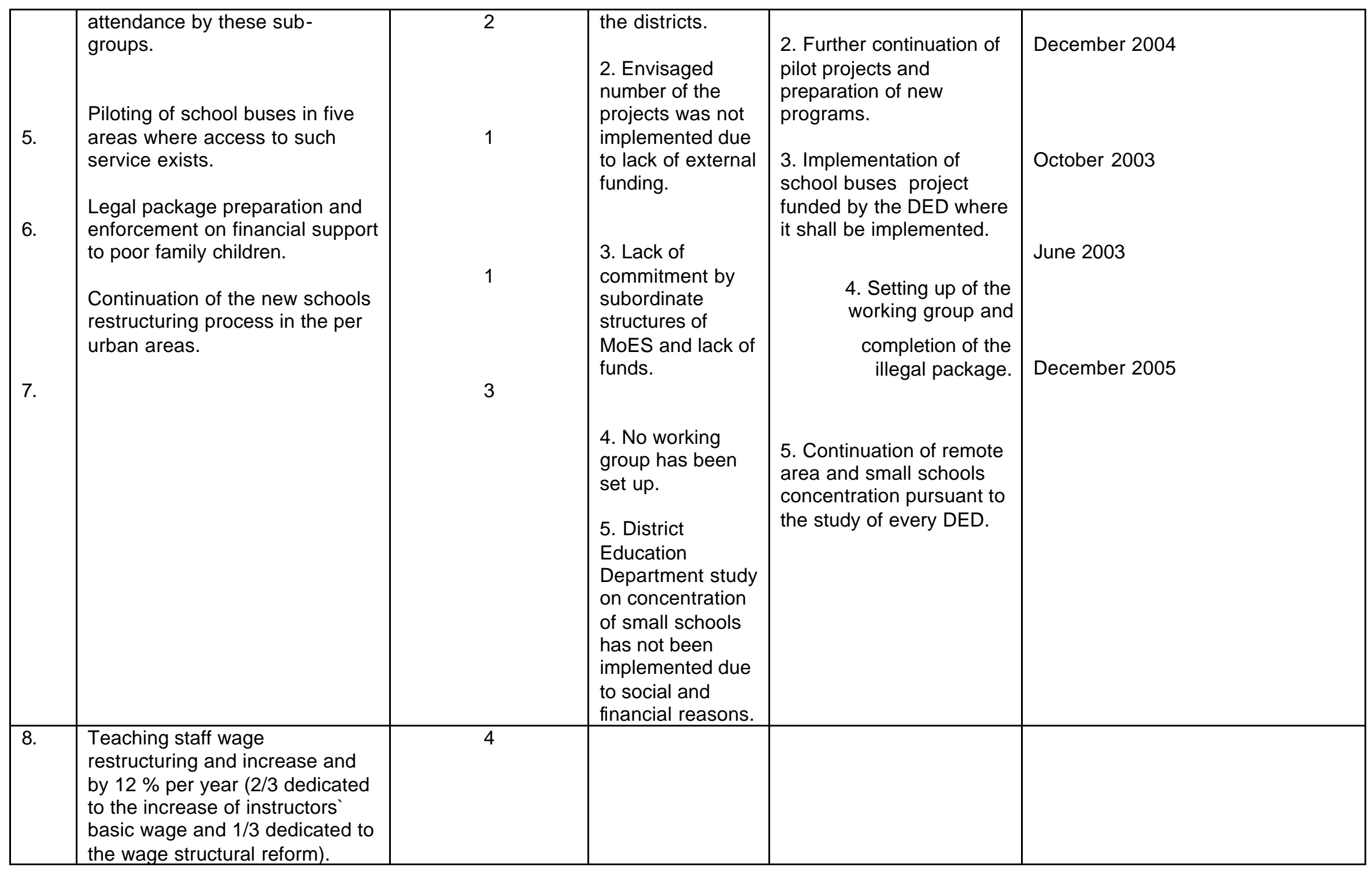

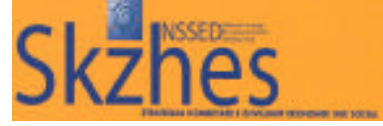


ANNEX 1: MATRIX OF REALIZATION OF PRIORITARY PUBLIC MEASURES 2002

\begin{tabular}{|c|c|c|c|c|c|}
\hline . & $\begin{array}{l}\text { Increase in compensation for } \\
\text { instructors working in } \\
\text { disadvantaged areas. } \\
\text { Preliminary analysis of the } \\
\text { factors to attract well-trained } \\
\text { instructors to rural and difficult } \\
\text { peril-urban areas. } \\
\text { Preparation and testing of the } \\
\text { program for instructors with } \\
\text { inadequate training and } \\
\text { education. } \\
\text { Identification of instructors to be } \\
\text { trained, training planning and its } \\
\text { implementation. }\end{array}$ & 4 & 2. Lack of funds. & $\begin{array}{l}\text { 2. New management of } \\
\text { the wage fund increase. }\end{array}$ & September 2003 \\
\hline 12. & $\begin{array}{l}\text { Decentralization of vocational } \\
\text { education curricula. } \\
\text { Preparation of legislative } \\
\text { framework to enable the } \\
\text { establishment of vocational } \\
\text { schools based on regional } \\
\text { planning of labor market means. } \\
\text { Publication of teaching and } \\
\text { learning materials supporting the } \\
\text { new curriculum. }\end{array}$ & 4 & $\begin{array}{l}\text { 3. Lack of funds. } \\
\text { 4. Lack of funds. }\end{array}$ & $\begin{array}{l}\text { 3.Funds needed. } \\
\text { 4. Funds needed. }\end{array}$ & $\begin{array}{l}\text { 3. Completed in } 2005 . \\
\text { 4. Completed in } 2005 . \\
\text { 5. Completely in } 2005 \text {. }\end{array}$ \\
\hline
\end{tabular}

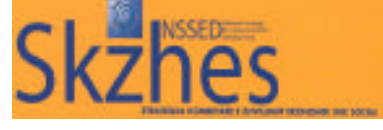


ANNEX 1: MATRIX OF REALIZATION OF PRIORITARY PUBLIC MEASURES 2002

\begin{tabular}{|l|l|l|l|l|l|}
\hline 15. & $\begin{array}{l}\text { Restructuring or establishment } \\
\text { of } 5 \text { boarding vocational } \\
\text { education and training schools } \\
\text { to benefit the rural and peri- } \\
\text { urban areas. }\end{array}$ & $\begin{array}{l}\text { 5. Not } \\
\text { implemented. }\end{array}$ & $\begin{array}{l}\text { 5. Implementation to be } \\
\text { carried out via external } \\
\text { financing. }\end{array}$ & \\
16. & $\begin{array}{l}\text { Preparation, piloting and } \\
\text { retraining for vocational school } \\
\text { instructors. }\end{array}$ & 3 & & \\
\hline
\end{tabular}


ANNEX 1: MATRIX OF REALIZATION OF PRIORITARY PUBLIC MEASURES 2002

MINISTRY OF LABOR AND SOCIAL AFFAIRS 
ANNEX 1: MATRIX OF REALIZATION OF PRIORITARY PUBLIC MEASURES 2002

\section{MINISTRY OF LABOR AND SOCIAL AFFAIRS}

\begin{tabular}{|c|c|c|c|c|c|}
\hline Nr. & Priority actions for year 2002 & $\begin{array}{l}\text { The scale } \\
\text { of } \\
\text { fulfillment } \\
\text { see above } \\
\text { according } \\
\text { to the } \\
\text { standards: }\end{array}$ & $\begin{array}{l}\text { The reasons for lower } \\
\text { scale of fulfillment than } \\
\text { forecasted }\end{array}$ & $\begin{array}{l}\text { Measures taken to make } \\
\text { possible the performance }\end{array}$ & $\begin{array}{l}\text { The new schedule of total } \\
\text { fulfillment }\end{array}$ \\
\hline \multicolumn{6}{|c|}{ Field/ Sector: Labor Market } \\
\hline 1. & $\begin{array}{l}\text { Employment incentives via } \\
\text { professional training }\end{array}$ & & & & \\
\hline $1 . \mathrm{A}$ & $\begin{array}{l}\text { Preparation of the professional } \\
\text { training strategy }\end{array}$ & 4 & - & - & - \\
\hline $1 . B$ & $\begin{array}{l}\text { Expansion the number of } \\
\text { professional training centers }\end{array}$ & 4 & - & - & - \\
\hline $1 . \mathrm{C}$ & $\begin{array}{l}\text { Completion of the legal } \\
\text { framework in the education and } \\
\text { professional training fields }\end{array}$ & 3 & $\begin{array}{l}\text { Low level of } \\
\text { collaboration with the } \\
\text { Ministry of Education } \\
\text { and Science }\end{array}$ & Reforming the joint work group & February 2003 \\
\hline 2. & $\begin{array}{l}\text { Deepening the institutionalization } \\
\text { and formalization of the labor } \\
\text { market }\end{array}$ & & & & \\
\hline $2 . A$ & $\begin{array}{l}\text { Increasing the number of } \\
\text { employment services }\end{array}$ & 4 & - & - & - \\
\hline $2 . B$ & $\begin{array}{l}\text { Training staff in order to improve } \\
\text { the quality of the employment } \\
\text { services }\end{array}$ & 4 & - & - & - \\
\hline $2 . \mathrm{C}$ & $\begin{array}{l}\text { Stimulating the formation and the } \\
\text { strengthening of the private } \\
\text { institution that offer employment } \\
\text { services }\end{array}$ & 2 & $\begin{array}{l}\text { Small number of private } \\
\text { institutions that offer this } \\
\text { kind of service. Low } \\
\text { level of capacities for } \\
\text { negotiation }\end{array}$ & $\begin{array}{l}\text { Improvement of the legal basis for } \\
\text { private employment agencies }\end{array}$ & 2003 and on \\
\hline
\end{tabular}


ANNEX 1: MATRIX OF REALIZATION OF PRIORITARY PUBLIC MEASURES 2002

SOCIAL INSURANCE INSTITUTE 
ANNEX 1: MATRIX OF REALIZATION OF PRIORITARY PUBLIC MEASURES 2002

\begin{tabular}{|c|c|c|c|c|c|}
\hline \multicolumn{6}{|c|}{ SOCIAL INSURANCE INSTITUTE } \\
\hline & $\begin{array}{l}\text { Objective A: } \\
\text { Increase the number of } \\
\text { contributors }\end{array}$ & 3 & $\begin{array}{l}\text {-Non-full performance in } \\
\text { collecting contributions } \\
\text { from state and non-state } \\
\text { bodies. } \\
\text {-High level of informality } \\
\text {-Lack of collaboration of } \\
\text { State Employment } \\
\text { Supervisor Office and } \\
\text { Tax Department. } \\
\text {-Lack of efficiency in the } \\
\text { work of the structures } \\
\text { responsible for } \\
\text { contributions }\end{array}$ & $\begin{array}{l}\text { Changes in the structure of the } \\
\text { Department and the sectors of } \\
\text { contributions. } \\
\text { Defining the monitoring indicators } \\
\text { for each department and sector } \\
\text { Compiling and signing the } \\
\text { management contract } \\
\text { Raising the level of collaboration } \\
\text { between State Employment } \\
\text { Supervision Office and Tax } \\
\text { Department. } \\
\text { Collecting the contribution arrears }\end{array}$ & On going process \\
\hline $1 . \mathrm{A}$ & $\begin{array}{l}\text { Including the rural population in } \\
\text { the social insurance } \\
\text { contributions. }\end{array}$ & & $\begin{array}{l}\text { Reactions to the } \\
\text { gradual increase in the } \\
\text { pension age } \\
\text {-Lack of quality of the } \\
\text { regional departments } \\
\text { and inspectors. }\end{array}$ & $\begin{array}{l}\text { Public feedback to be included in } \\
\text { the social insurance scheme. } \\
\text { Creating new structures to increase } \\
\text { the efficiency of the social } \\
\text { insurance scheme in the rural } \\
\text { areas. }\end{array}$ & On going process \\
\hline $1 . \mathrm{B}$ & $\begin{array}{l}\text { Elimination of pension } \\
\text { differences }\end{array}$ & 3 & Lack of funds & $\begin{array}{l}\text { Measures taken to execute the last } \\
\text { phase of closing the differences } \\
\text { between the pensions }\end{array}$ & September 2003 \\
\hline $1 . \mathrm{C}$ & Improvement of the legislation & 4 & & & \\
\hline $1 . \mathrm{D}$ & $\begin{array}{l}\text { Merging the urban and rural } \\
\text { schemes into one. }\end{array}$ & 2 & $\begin{array}{l}\text { Low number of } \\
\text { contributors especially in } \\
\text { the rural scheme. } \\
\text { Low level of the rural } \\
\text { pensions. } \\
\text { Lack of funds to hasten } \\
\text { this process. }\end{array}$ & $\begin{array}{l}\text { Continuation of the process of } \\
\text { matching these two pension } \\
\text { categories according to the ten- } \\
\text { year program. } \\
\text {-Gradual increase of contributions } \\
\text { from in agriculture self- } \\
\text { employment. } \\
\text {-Increasing the level of rural areas } \\
\text { more than the rate of increase in } \\
\text { the urban areas. }\end{array}$ & On going process \\
\hline 1.F. & Improving the audit, evaluation. & 3 & Lack shown in evading & Improvements in the structure of & During 2003 \\
\hline
\end{tabular}

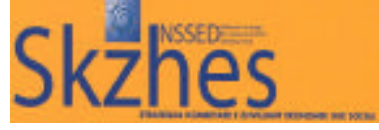


ANNEX 1: MATRIX OF REALIZATION OF PRIORITARY PUBLIC MEASURES 2002

\begin{tabular}{|c|c|c|c|c|c|}
\hline & & & $\begin{array}{l}\text { the conclusions and } \\
\text { measures taken during } \\
\text { the audit process. } \\
\text { Lack of efficiency and } \\
\text { prevention effect of the } \\
\text { controls made. }\end{array}$ & $\begin{array}{l}\text { the audit sectors. } \\
\text { Measures taken for increasing the } \\
\text { skills of the audit specialists. } \\
\text { Measures for protecting and } \\
\text { maintaining the documentation. }\end{array}$ & \\
\hline & $\begin{array}{l}\text { Objective 2: } \\
\text { Reducing budget subsidies for } \\
\text { pension funds. }\end{array}$ & 3 & Lack of funds & $\begin{array}{l}\text { Increase in the national } \\
\text { contributions }\end{array}$ & $2003-2005$ \\
\hline $2 . A$ & $\begin{array}{l}\text { Operationalzing the number of } \\
\text { insurance and, automation the } \\
\text { information system. }\end{array}$ & 2 & $\begin{array}{l}\text { Lack of technology } \\
\text { upgrades. } \\
\text { Lack of financing of the } \\
\text { planned projects. } \\
\text { Legal changes in the } \\
\text { operating of the civil } \\
\text { status offices. }\end{array}$ & $\begin{array}{l}\text { Procurement of technical } \\
\text { assistance for analysis of } \\
\text { information and proposals for } \\
\text { solution. }\end{array}$ & 2003 \\
\hline $2 . B$ & Ongoing staff qualification & 3 & $\begin{array}{l}\text { Lack of external } \\
\text { financing for personnel } \\
\text { qualification. }\end{array}$ & $\begin{array}{l}1 \text { year personnel qualification } \\
\text { program }\end{array}$ & 2003 \\
\hline $2 . \mathrm{C}$ & Improving the quality of services. & 2 & $\begin{array}{l}\text { Lack of monitoring } \\
\text { indicators for all sectors. } \\
\text { Low-level quality of } \\
\text { reception offices. }\end{array}$ & $\begin{array}{l}\text { Designing the monitoring indicators } \\
\text { for each sector and job description. } \\
\text { Increased technical assistance } \\
\text { "analysis of work flow in DRSSH" } \\
\text { Measures taken to improve the } \\
\text { system of pension payments }\end{array}$ & 2003 \\
\hline 2.D & $\begin{array}{l}\text { Institutional development at all } \\
\text { levels. }\end{array}$ & 3 & $\begin{array}{l}\text { Organizational } \\
\text { weaknesses } \\
\text { organization and poor } \\
\text { sharing of information }\end{array}$ & $\begin{array}{l}\text { Improvements in the legal } \\
\text { framework. } \\
\text { Increase in the management } \\
\text { capacity of the institution. } \\
\text { Expanding the study \& forecast } \\
\text { activities. } \\
\text { Completing the social insurance } \\
\text { scheme with supplementary } \\
\text { schemes and private ones. }\end{array}$ & \\
\hline
\end{tabular}


ANNEX 1: MATRIX OF REALIZATION OF PRIORITARY PUBLIC MEASURES 2002

\begin{tabular}{|c|c|c|c|c|c|}
\hline \multicolumn{6}{|c|}{ Economic Assistance and Social Care } \\
\hline & $\begin{array}{l}\text { Objective I. Increase in the } \\
\text { coverage of poor people. }\end{array}$ & & & & \\
\hline $1 . \mathrm{A}$ & $\begin{array}{l}\text { - Creation of the social protection } \\
\text { fund }\end{array}$ & 1 & $\begin{array}{l}\text { The Fund has been } \\
\text { created but no funding } \\
\text { has been allocated to it }\end{array}$ & & 2004 \\
\hline $1 . \mathrm{B}$ & $\begin{array}{l}\text { Identification and measurement } \\
\text { of social -economical indicators, } \\
\text { estimators of the social - } \\
\text { economical situation of the } \\
\text { regions. }\end{array}$ & 3 & & $\begin{array}{l}\text { The Database is improved. Its } \\
\text { been compiled the Poverty Map } \\
\text { divided by regions. }\end{array}$ & Ongoing. \\
\hline 1.C. & $\begin{array}{l}\text { Allocations of block funding from } \\
\text { the state budget dependent upon } \\
\text { the social - economic indicators. }\end{array}$ & 3 & $\begin{array}{l}\text { The guidelines are not } \\
\text { complete. }\end{array}$ & $\begin{array}{l}\text { Measures are being taken to } \\
\text { improve the manner of calculating } \\
\text { the block grant of Economic } \\
\text { Assistance. With the new law the } \\
\text { criteria of fund allocation will } \\
\text { improve. }\end{array}$ & 2004 \\
\hline 1.D. & $\begin{array}{l}\text { Full decentralization of the } \\
\text { scheme. }\end{array}$ & 2 & $\begin{array}{l}\text { Decentralization is } \\
\text { ongoing. }\end{array}$ & $\begin{array}{l}\text { Local governments manage the } \\
\text { funds and target the economic } \\
\text { assistance. The collaboration } \\
\text { between structures of local } \\
\text { government is strengthened. } \\
\text { Strengthening the managing } \\
\text { structures of the scheme. This year } \\
\text { the decentralization in some } \\
\text { communes and pilot cities will } \\
\text { begin. }\end{array}$ & 2006 \\
\hline
\end{tabular}


ANNEX 1: MATRIX OF REALIZATION OF PRIORITARY PUBLIC MEASURES 2002

\begin{tabular}{|c|c|c|c|c|c|}
\hline 1.F. & Employees Training & 4 & & & \\
\hline 1.E. & Completing the legal framework & $\begin{array}{l}\text { (The } \\
\text { (Thjectives } \\
\text { for year } \\
2002 \text { are } \\
\text { fulfilled) }\end{array}$ & $\begin{array}{l}\text { The review of the } \\
\text { legislation, and its } \\
\text { adaptation to the local } \\
\text { government } \\
\text { decentralization. }\end{array}$ & $\begin{array}{l}\text { Drafting the organic law for social } \\
\text { services. }\end{array}$ & 2004 \\
\hline & $\begin{array}{l}\text { Objective II. } \\
\text { Increase in the rate of coverage } \\
\text { of socio-economic needs of } \\
\text { families via Economic Assistance. }\end{array}$ & & & & \\
\hline $2 . A$ & $\begin{array}{l}\text { Creating the social - economic } \\
\text { database for social groups. }\end{array}$ & 2 & & $\begin{array}{l}\text { Completing the map with data of } \\
\text { the social - economic situation for } \\
\text { the communes and cities. }\end{array}$ & 2004,2005 \\
\hline $2 . \mathrm{B}$ & $\begin{array}{l}\text { Harmonization of economic } \\
\text { assistance with the other } \\
\text { mechanisms of social protection. }\end{array}$ & 2 & $\begin{array}{l}\text { Development of } \\
\text { implementation } \\
\text { mechanism is required }\end{array}$ & $\begin{array}{l}\text { Measures are taken to increase } \\
\text { cooperation with the National } \\
\text { Employment Service. . }\end{array}$ & 2004,2005 \\
\hline 2.C & $\begin{array}{l}\text { Gradually orientating the system } \\
\text { to minimum living standards }\end{array}$ & 2 & $\begin{array}{l}\text { The study is completed } \\
\text { but the minimum living } \\
\text { standards are not yet } \\
\text { proclaimed. }\end{array}$ & $\begin{array}{l}\text { The study has served as a } \\
\text { reference point for the delivery of } \\
\text { the block - grants of economic } \\
\text { assistance. The calculation of this } \\
\text { sum is moving towards the } \\
\text { minimum living standard. }\end{array}$ & 2004.2005 \\
\hline
\end{tabular}


ANNEX 1: MATRIX OF REALIZATION OF PRIORITARY PUBLIC MEASURES 2002

\begin{tabular}{|c|c|c|c|c|c|}
\hline $2 . \mathrm{D}$ & $\begin{array}{l}\text { Reforming the legal framework to } \\
\text { achieve the active programs. }\end{array}$ & 1 & & $\begin{array}{l}\text { Improvements are being made in } \\
\text { the legal area and the pilot } \\
\text { programs will start in } 4 \\
\text { Administrative Units. }\end{array}$ & \\
\hline $2 . E$ & $\begin{array}{l}\text { Preparation of the model of } \\
\text { including the poor people in the } \\
\text { social businesses }\end{array}$ & 2 & & $\begin{array}{l}\text { The study phase is completed and } \\
\text { other measures are in development }\end{array}$ & 2004 \\
\hline $2 . F$ & - Employees Training & 3 & Lack of funds & $\begin{array}{l}\text { - Training programs are designed } \\
\text { Measures are being taken to } \\
\text { strengthen the institutional } \\
\text { capacities of the Regional Offices } \\
\text { (pilot) }\end{array}$ & 2004 \\
\hline & $\begin{array}{l}\text { Objective III. Implementation of } \\
\text { social protection programme. }\end{array}$ & & & & \\
\hline $3 . A$ & $\begin{array}{l}\text { Calculation of the minimum living } \\
\text { standards }\end{array}$ & 4 & & & \\
\hline $3 . \mathrm{B}$ & Defining the available coverage & & & & \\
\hline \multicolumn{6}{|c|}{ Social Care } \\
\hline & $\begin{array}{l}\text { Objective I. - Total territorial } \\
\text { coverage with social services in } \\
\text { accordance with the quantitative } \\
\text { and qualitative needs of social } \\
\text { categories that are vulnerable or } \\
\text { at risk }\end{array}$ & & & & \\
\hline
\end{tabular}


ANNEX 1: MATRIX OF REALIZATION OF PRIORITARY PUBLIC MEASURES 2002

\begin{tabular}{|c|c|c|c|c|c|}
\hline $1 . \mathrm{A}$ & $\begin{array}{l}\text { Design of the social service } \\
\text { strategies }\end{array}$ & 4 & & & \\
\hline $1 . \mathrm{B}$ & $\begin{array}{l}\text { Improvements in the legislation } \\
\text { for social service decentralization }\end{array}$ & 2 & & $\begin{array}{l}\text { Working groups are being created } \\
\text { for drafting the law for social } \\
\text { services and defining the } \\
\text { competencies of local } \\
\text { governments. }\end{array}$ & 2004 \\
\hline 1.C. & Staff Training & 4 & & & \\
\hline 1.D & $\begin{array}{l}\text { Financing from the National } \\
\text { Social Protection Fund. }\end{array}$ & 1 & $\begin{array}{l}\text { The Social Protection } \\
\text { National Fund hasn't } \\
\text { been approved yet. }\end{array}$ & & \\
\hline 1.E & Cooperation with NGO-s & 4 & & & \\
\hline $1 . \mathrm{F}$ & $\begin{array}{l}\text { Harmonization with the economic } \\
\text { assistance scheme. }\end{array}$ & 2 & $\begin{array}{l}\text { Creation of social } \\
\text { services in all regions is } \\
\text { beginning. }\end{array}$ & $\begin{array}{l}\text {-Improvement of the evaluation of } \\
\text { social needs (database). } \\
\text { Completing the Poverty Map. }\end{array}$ & 2004,2005 \\
\hline $1 . \mathrm{K}$ & Creation of local day centers & 3 & Lack of funds & $\begin{array}{l}\text { External funding has been } \\
\text { requested and projects are ongoing } \\
\text { to create new centers. Services are } \\
\text { being expanded of Tirana, Vlora, } \\
\text { Durres, Shkoder, and Elbasan. }\end{array}$ & \\
\hline & $\begin{array}{l}\text { Objective II. Increasing the } \\
\text { number and improving the quality } \\
\text { of social services. }\end{array}$ & & & & \\
\hline $2 . A$ & $\begin{array}{l}\text { Expanding the cooperation with } \\
\text { external partners. }\end{array}$ & 4 & & & \\
\hline $2 . \mathrm{B}$ & Staff training & 4 & & & \\
\hline $2 . \mathrm{C}$ & $\begin{array}{l}\text { Inclusion of the Social Work } \\
\text { Faculty }\end{array}$ & 4 & & & \\
\hline
\end{tabular}

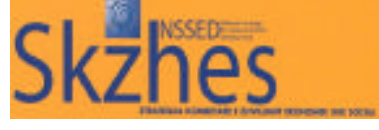


ANNEX 1: MATRIX OF REALIZATION OF PRIORITARY PUBLIC MEASURES 2002

MINISTRY OF LOCAL GOVERNMENT AND DECENTRALIZATION 
ANNEX 1: MATRIX OF REALIZATION OF PRIORITARY PUBLIC MEASURES 2002

\begin{tabular}{|c|c|c|c|c|c|}
\hline \multicolumn{6}{|c|}{ MINISTRY OF LOCAL GOVERNMENT AND DECENTRALIZATION } \\
\hline Nr. & Priority actions for year 2002 & $\begin{array}{l}\text { The scale of } \\
\text { fulfillment } \\
\text { according to } \\
\text { the standards: }\end{array}$ & $\begin{array}{l}\text { The reasons for lower } \\
\text { scale of fulfillment than } \\
\text { forecasted }\end{array}$ & $\begin{array}{l}\text { Measures taken to make } \\
\text { possible the performance }\end{array}$ & $\begin{array}{l}\text { The new schedule of total } \\
\text { fulfillment }\end{array}$ \\
\hline & $\begin{array}{l}\text { 1. Completion of the legal } \\
\text { framework and its } \\
\text { implementation in the devolution } \\
\text { of powers within the functions of } \\
\text { local governments Bodies. }\end{array}$ & & & & \\
\hline 1 & $\begin{array}{l}\text { Delegating the functions of water } \\
\text { supply, sanitation and urban land } \\
\text { management. }\end{array}$ & 4 & & $\begin{array}{l}\text { Preparations of amendments for } \\
\text { changes in the laws regarding the } \\
\text { field, enterprises financial balance, } \\
\text { dividing the systems and the way } \\
\text { of transfer in the local units are } \\
\text { being made. Drafting and } \\
\text { approving the law "For urban } \\
\text { planning and land management" }\end{array}$ & 2003 \\
\hline 2 & $\begin{array}{l}\text { Divided functions of education, } \\
\text { public health, civil protection, } \\
\text { social protection, public order. }\end{array}$ & 3 & & $\begin{array}{l}\text { Document regarding the } \\
\text { decentralization policies for the } \\
\text { education and health sectors are } \\
\text { drafted and a decision is expected } \\
\text { from the KND } \\
\text { Drafting the formula of } \\
\text { unconditional distribution is a } \\
\text { NSSED priority. Amendments to } \\
\text { the existing law and drafting the } \\
\text { sub - legal acts. }\end{array}$ & 2003 \\
\hline 3 & $\begin{array}{l}\text { The regulation related to } \\
\text { delegated functions. }\end{array}$ & 4 & & $\begin{array}{l}\text { Drafting a number of normative } \\
\text { acts for civil service reform. The } \\
\text { ongoing pilot project for } \\
\text { "Modernizing the civil status". The } \\
\text { foundation of National Register of } \\
\text { Civil Status. Preparation of a }\end{array}$ & 2003-2005 \\
\hline
\end{tabular}

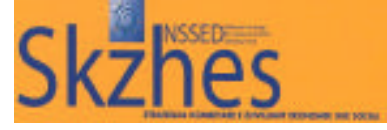


ANNEX 1: MATRIX OF REALIZATION OF PRIORITARY PUBLIC MEASURES 2002

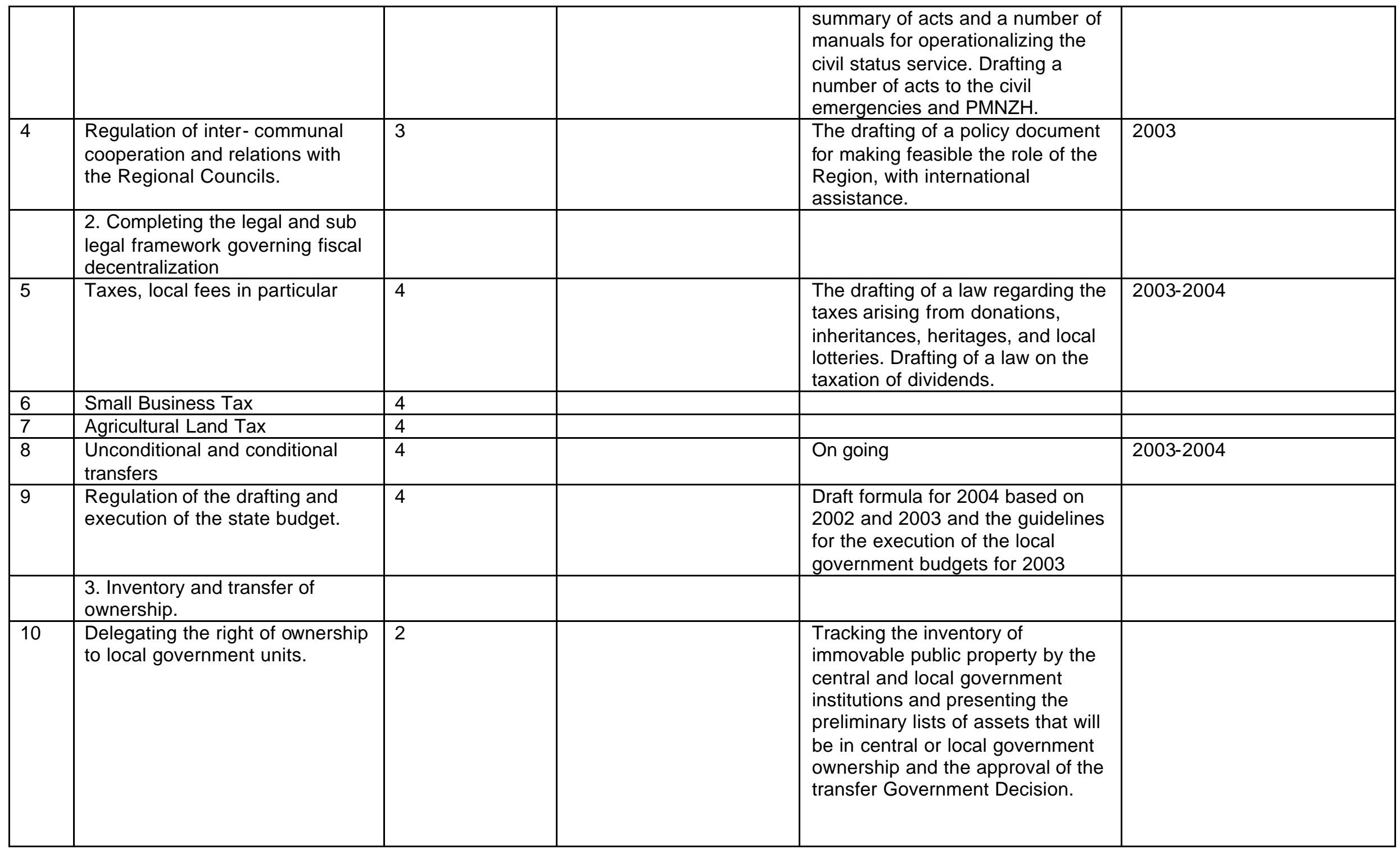


ANNEX 1: MATRIX OF REALIZATION OF PRIORITARY PUBLIC MEASURES 2002

\begin{tabular}{|l|l|l|l|l|l|}
\hline & $\begin{array}{l}\text { 4. Increasing the scale of own } \\
\text { government of the local } \\
\text { organizations. }\end{array}$ & & & \\
\hline 11 & $\begin{array}{l}\text { In-time implementation of the } \\
\text { decentralization plan. }\end{array}$ & 3 & & $\begin{array}{l}\text { Continued racking of the process } \\
\text { via inter department cooperation } \\
\text { according to the action plan } \\
\text { approved by the GED. }\end{array}$ & $2003-2004$ and continuing \\
\hline 12 & $\begin{array}{l}\text { Capacity building through } \\
\text { training in the drafting of regional } \\
\text { development policies and service } \\
\text { provision. }\end{array}$ & 3 & $\begin{array}{l}\text { Organizing in 3 pilot regions the } \\
\text { building of a human resources } \\
\text { center. Drafting the national } \\
\text { strategy for training and drafting a } \\
\text { 1-year training programme. }\end{array}$ & 2003 and continuing \\
\hline
\end{tabular}


ANNEX 1: MATRIX OF REALIZATION OF PRIORITARY PUBLIC MEASURES 2002

BANK OF ALBANIA 
ANNEX 1: MATRIX OF REALIZATION OF PRIORITARY PUBLIC MEASURES 2002

BANK OF ALBANIA

\begin{tabular}{|l|l|l|l|l|l|}
\hline No. & Priority actions for year 2002 & $\begin{array}{l}\text { The scale } \\
\text { of } \\
\text { fulfillment } \\
\text { according } \\
\text { to the } \\
\text { standards: }\end{array}$ & $\begin{array}{l}\text { The reasons for lower } \\
\text { scale of fulfillment } \\
\text { than forecasted }\end{array}$ & $\begin{array}{l}\text { Measures taken to make } \\
\text { possible the performance }\end{array}$ & $\begin{array}{l}\text { The new schedule of total } \\
\text { fulfillment }\end{array}$ \\
\hline 1. & $\begin{array}{l}\text { Adherence the macroeconomic } \\
\text { objectives from the Bank of } \\
\text { Albania (BoA) }\end{array}$ & 4 & & & \\
\hline 2. & $\begin{array}{l}\text { Establishment of the Credit } \\
\text { Information Office }\end{array}$ & 1 & & Reorganizing of the project & \\
\hline 3. & $\begin{array}{l}\text { Development of a deposit } \\
\text { guarantee scheme. }\end{array}$ & 4 & $\begin{array}{l}\text { According to the } \\
\text { agreement }\end{array}$ & Implementation ongoing & December 2003 \\
\hline 4. & $\begin{array}{l}\text { Drafting and implementing a real- } \\
\text { time payments system }\end{array}$ & 2 &
\end{tabular}


ANNEX 1: MATRIX OF REALIZATION OF PRIORITARY PUBLIC MEASURES 2002

MINISTRY OF ENVIRONMENT 
ANNEX 1: MATRIX OF REALIZATION OF PRIORITARY PUBLIC MEASURES 2002

MINISTRY OF ENVIRONMENT

\begin{tabular}{|c|c|c|c|c|c|}
\hline NO. & Priority actions for year 2002 & $\begin{array}{l}\text { The scale } \\
\text { of } \\
\text { fulfillment } \\
\text { according } \\
\text { to the } \\
\text { standards: }\end{array}$ & $\begin{array}{l}\text { The reasons for lower } \\
\text { scale of fulfillment } \\
\text { than forecasted }\end{array}$ & $\begin{array}{l}\text { Measures taken to make } \\
\text { possible the performance }\end{array}$ & $\begin{array}{l}\text { The new schedule of total } \\
\text { fulfillment }\end{array}$ \\
\hline & $\begin{array}{l}\text { Institutional and legal } \\
\text { strengthening }\end{array}$ & & & & \\
\hline & Restructuring of the MoE & 4 & & $\begin{array}{l}\text { Extra funds are requested for } \\
\text { continuing the process beyond } \\
\text { approval. }\end{array}$ & $2003-06$ \\
\hline & $\begin{array}{l}\text { Strengthening the branches and } \\
\text { inspectorates }\end{array}$ & 4 & & $\begin{array}{l}\text { Extra funds are requested for } \\
\text { continuing the process beyond } \\
\text { approval. }\end{array}$ & 2003-06 \\
\hline & $\begin{array}{l}\text { Establishing the Sustainable } \\
\text { Development Committee }\end{array}$ & 1 & $\begin{array}{l}\text { The Inter Ministerial } \\
\text { committee for National } \\
\text { Action for the } \\
\text { Environment will play } \\
\text { this role. }\end{array}$ & $\begin{array}{l}\text { The draft is complete and awaiting } \\
\text { Government approval. }\end{array}$ & \\
\hline & $\begin{array}{l}\text { Defining the authority and } \\
\text { responsibilities for the local } \\
\text { government units in the } \\
\text { environmental field. }\end{array}$ & 1 & Lack of funds & $\begin{array}{l}\text { A Stability Pact project is currently } \\
\text { under review }\end{array}$ & $2003-2006$ \\
\hline & $\begin{array}{l}\text { Defining the role of the line } \\
\text { ministries and central institutions } \\
\text { in implementing the policies and } \\
\text { the legal framework in } \\
\text { environmental protection. } \\
\text { Establishing environmental } \\
\text { structures in central institutions. }\end{array}$ & 1 & Lack of funds & $\begin{array}{l}\text { The revised matrix will establish } \\
\text { contact points for the environment } \\
\text { within the line ministries. }\end{array}$ & $2003-2005$ \\
\hline & $\begin{array}{l}\text { Increasing public awareness and } \\
\text { involvement environmental } \\
\text { protection. }\end{array}$ & 4 & & On going & $2003-2006$ \\
\hline
\end{tabular}


ANNEX 1: MATRIX OF REALIZATION OF PRIORITARY PUBLIC MEASURES 2002

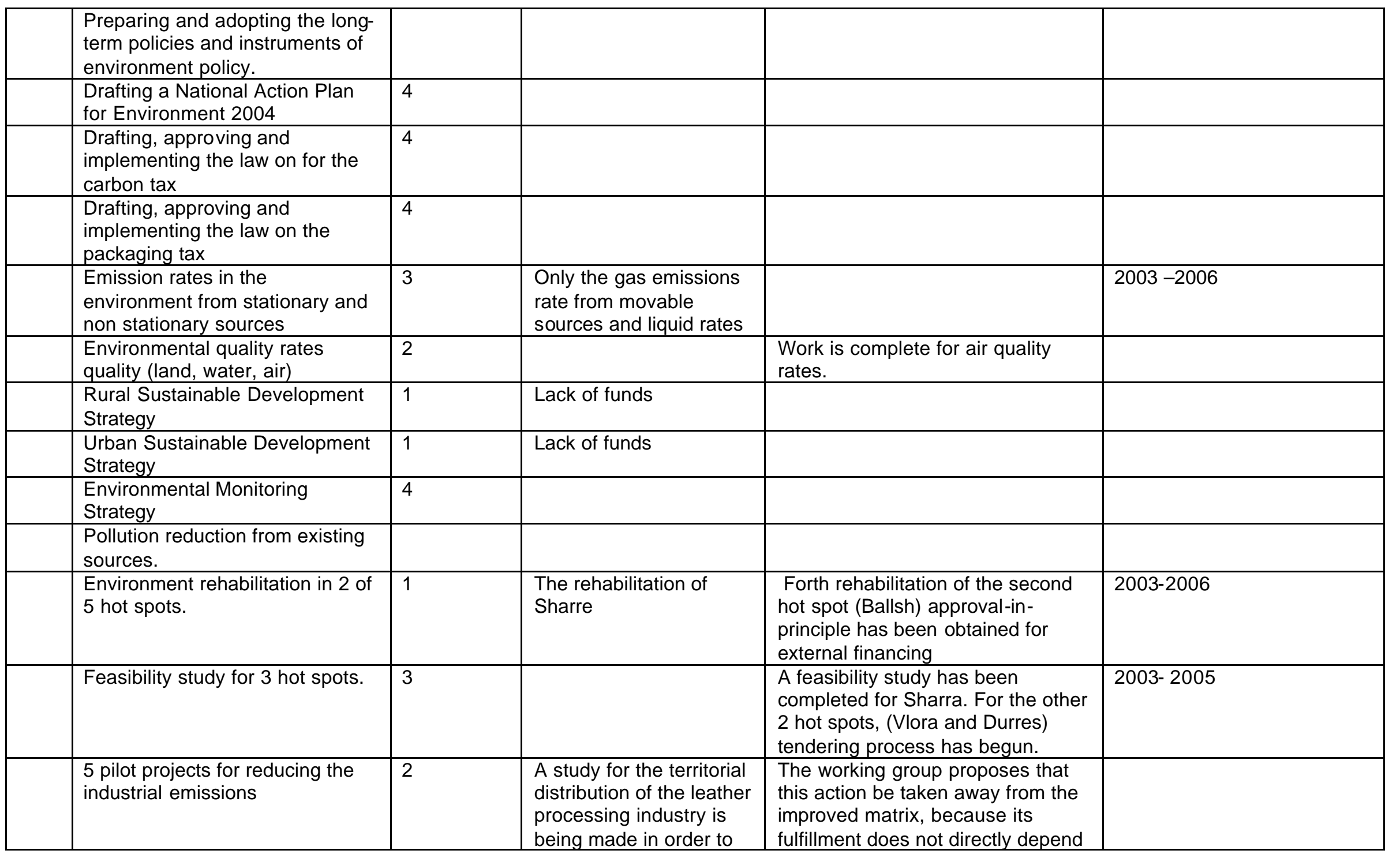


ANNEX 1: MATRIX OF REALIZATION OF PRIORITARY PUBLIC MEASURES 2002

\begin{tabular}{|c|c|c|c|c|}
\hline & & $\begin{array}{l}\text { reduce emissions into } \\
\text { the groundwater. } \\
\text { Insufficient funds. }\end{array}$ & on the MEn. & \\
\hline $\begin{array}{l}\text { Regulating construction and road } \\
\text { maintenance in urban areas with } \\
\text { elevated rates of air pollution. }\end{array}$ & 1 & Lack of funds & $\begin{array}{l}\text { Working group proposes that this } \\
\text { measure should be withdrawn from } \\
\text { the reviewed matrix because the } \\
\text { fulfillment of this measure doesn't } \\
\text { depend on the MoEn }\end{array}$ & \\
\hline $\begin{array}{l}\text { Elimination of } 800 \text { tons of arsenic } \\
\text { solution from the Nitrogen Plant } \\
\text { in Fier }\end{array}$ & 2 & $\begin{array}{l}\text { Tendering documents } \\
\text { are prepared and } \\
\text { awaiting the approval. . } \\
\text { Institutional co-operation } \\
\text { among local and } \\
\text { international institutions } \\
\text { is slow }\end{array}$ & & \\
\hline $\begin{array}{l}\text { Improvements in public services } \\
\text { that are related with the } \\
\text { environment of the city of Tirana. }\end{array}$ & 3 & Not enough funds. & $\begin{array}{l}\text { More funds are required in the } \\
\text { future }\end{array}$ & $2003-2006$ \\
\hline $\begin{array}{l}\text { Measures for sustainable and } \\
\text { development and resource use. }\end{array}$ & & & & \\
\hline $\begin{array}{l}3 \text { pilot projects combating land } \\
\text { erosion }\end{array}$ & 4 & & Ongoing & $2003-2005$ \\
\hline
\end{tabular}


ANNEX 1: MATRIX OF REALIZATION OF PRIORITARY PUBLIC MEASURES 2002

PUBLIC PROCUREMENT AGENCY 
ANNEX 1: MATRIX OF REALIZATION OF PRIORITARY PUBLIC MEASURES 2002

\section{PUBLIC PROCUREMENT AGENCY}

\begin{tabular}{|c|c|c|c|c|c|}
\hline No. & Priority actions for year 2002 & $\begin{array}{l}\text { The scale } \\
\text { of } \\
\text { fulfillment } \\
\text { according } \\
\text { to the } \\
\text { standards: }\end{array}$ & $\begin{array}{l}\text { The reasons for } \\
\text { lower scale of } \\
\text { fulfillment than } \\
\text { forecasted }\end{array}$ & $\begin{array}{l}\text { Measures taken to make } \\
\text { possible the performance }\end{array}$ & $\begin{array}{l}\text { The new schedule of } \\
\text { total fulfillment }\end{array}$ \\
\hline 1. & $\begin{array}{l}\text { Improvements in the legal } \\
\text { framework } \\
\text { - Improvements in the } \\
\text { Government's } \\
\text { Decision "For the rules } \\
\text { of public procurement" } \\
\text { - Improvements in the } \\
\text { Government's } \\
\text { Decision "For public } \\
\text { procurement" } \\
\text { - Drawing the bidding } \\
\text { documents }\end{array}$ & 3 & $\begin{array}{l}\text { These acts will be } \\
\text { accompanied by other } \\
\text { changes depending on } \\
\text { those on the law "For } \\
\text { public procurement" } \\
\\
\text { The preparation of } \\
\text { standard public } \\
\text { procurement modules } \\
\text { will be undertaken }\end{array}$ & $\begin{array}{l}\text { Changes were made to the } \\
\text { sub legal acts, as a result } \\
\text { of problems experienced in } \\
\text { the implementation of the } \\
\text { public procurement } \\
\text { regulations. }\end{array}$ & $\begin{array}{l}\text { Depends on the changes } \\
\text { in the law on public } \\
\text { procurement } \\
\text { September } 2003\end{array}$ \\
\hline 2 & $\begin{array}{l}\text { Monitoring and strengthening the } \\
\text { administrative auditing system }\end{array}$ & 3 & $\begin{array}{l}\text { Lack of equipment and } \\
\text { human resources. }\end{array}$ & Funding is required. & $\begin{array}{l}\text { Depends on the } \\
\text { availability of funds. }\end{array}$ \\
\hline
\end{tabular}


ANNEX 1: MATRIX OF REALIZATION OF PRIORITARY PUBLIC MEASURES 2002

\begin{tabular}{|l|l|l|l|l|l|}
\hline 3 & Training ths APP staff & 3 & Lack of funds & Sourcing of external funds. & $\begin{array}{l}\text { Depends on the } \\
\text { availability of funds. }\end{array}$ \\
\hline 4 & $\begin{array}{l}\text { Training provided by APP to } \\
\text { procurement entities }\end{array}$ & 3 & Lack of funds & Sourcing of external funds & Depends on the \\
availability of funds.
\end{tabular}


ANNEX 2 PROGRAM OF PRIORITY ACTION PLAN 2003

I. ANNEX 2 PROGRAM OF PRIORITY ACTION PLAN 2003

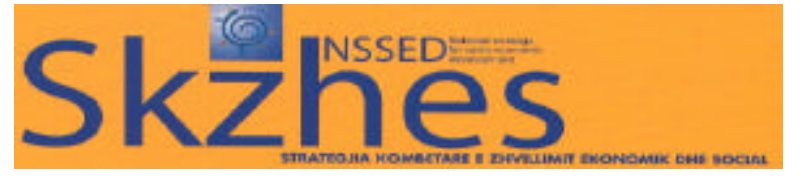


ANNEX 2 PROGRAM OF PRIORITY ACTION PLAN 2003

TABLE 1: MINISTRY OF HEALTH

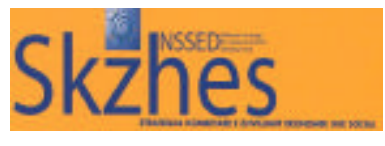


ANNEX 2 PROGRAM OF PRIORITY ACTION PLAN 2003

TABLE 1: MINISTRY OF HEALTH

\begin{tabular}{|c|c|c|c|c|c|}
\hline Field/Sector & Objectives & Priority Public Measures & $\begin{array}{l}\text { Responsable } \\
\text { institution }\end{array}$ & Deadline & $\begin{array}{l}\text { Budgetary effects } \\
\text { (millions leks) }\end{array}$ \\
\hline HEALTH & $\begin{array}{l}\text { - Improvement of } \\
\text { the regulatory } \\
\text { system }\end{array}$ & & & & \\
\hline & $\begin{array}{l}\text { Completion and } \\
\text { improvement of the legal } \\
\text { framework }\end{array}$ & 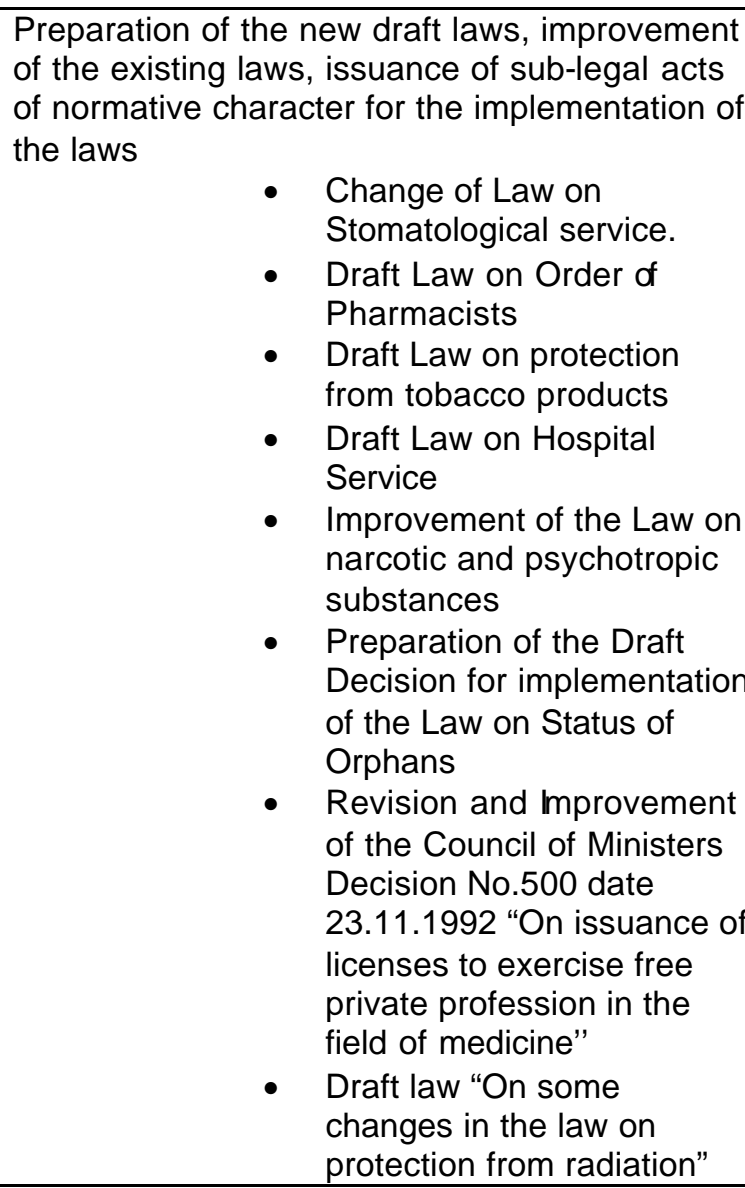 & $\mathrm{HM}$ & $\begin{array}{l}01.2003 \\
02.2003 \\
02.2003 \\
02.2003 \\
\\
02.2003 \\
\\
03.2003 \\
05.2003 \\
08.2003 \\
09.2003 \\
10.2003 \\
12.2003 \\
12.2003\end{array}$ & \\
\hline
\end{tabular}


ANNEX 2 PROGRAM OF PRIORITY ACTION PLAN 2003

\begin{tabular}{|c|c|c|c|c|c|}
\hline Field/Sector & Objectives & Priority Public Measures & $\begin{array}{l}\text { Responsable } \\
\text { institution }\end{array}$ & Deadline & $\begin{array}{l}\text { Budgetary effects } \\
\text { (millions leks) }\end{array}$ \\
\hline & & $\begin{array}{ll}-\quad \text { Draft law "On health } \\
\text { service" } \\
\text { - } \\
\text { Improvement of the legal } \\
\text { framework in the field of } \\
\text { health insurance } \\
-\quad \text { Improvement of the Law on } \\
\text { Food } \\
\text { Draft law on the functioning } \\
\text { of the HM } \\
\text { Organization of the national } \\
\text { conference on the health } \\
\text { legislation }\end{array}$ & & & \\
\hline & Change of the role of $\mathrm{HM}$ & $\begin{array}{l}\text { Revision of the Organizational Structure of the } \\
\text { Health Ministry on the basis of its new role } \\
\qquad \begin{array}{l}\text { The functioning of the } \\
\text { monitoring unit } \\
\text { Analysis of the job positions } \\
\text { in the Health Ministry on the } \\
\text { basis of a specific } \\
\text { questionnaire }\end{array}\end{array}$ & $\mathrm{HM}$ & 2003 & \\
\hline & $\begin{array}{l}\text { Strengthening of the role } \\
\text { of the professional health } \\
\text { organizations }\end{array}$ & $\begin{array}{l}\text { Strengthening of the role of the Doctors' Order } \\
\text { and support for the establishment of new } \\
\text { professional organizations, such as the Orders } \\
\text { of the Dentists, Pharmacists, Nurses, etc. } \\
\qquad \quad \text { Effective application of the } \\
\text { Deontological Code }\end{array}$ & $\begin{array}{l}\text { HM } \\
\text { DFID }\end{array}$ & 2003 & \\
\hline & $\begin{array}{l}\text { Higher effectiveness and } \\
\text { efficiency in the use of } \\
\text { resources }\end{array}$ & & $\begin{array}{l}\text { HM } \\
\text { Dors: } \\
\text { (DFID, ËHO, } \\
\text { World Bank) }\end{array}$ & & \\
\hline
\end{tabular}


ANNEX 2 PROGRAM OF PRIORITY ACTION PLAN 2003

\begin{tabular}{|c|c|c|c|c|c|}
\hline Field/Sector & Objectives & Priority Public Measures & $\begin{array}{l}\text { Responsable } \\
\text { institution }\end{array}$ & Deadline & $\begin{array}{l}\text { Budgetary effects } \\
\text { (millions leks) }\end{array}$ \\
\hline V & $\begin{array}{l}\text { Improprement of the } \\
\text { process of planning, } \\
\text { allocation of resources } \\
\text { and monitoring of their } \\
\text { use at central and local } \\
\text { level }\end{array}$ & 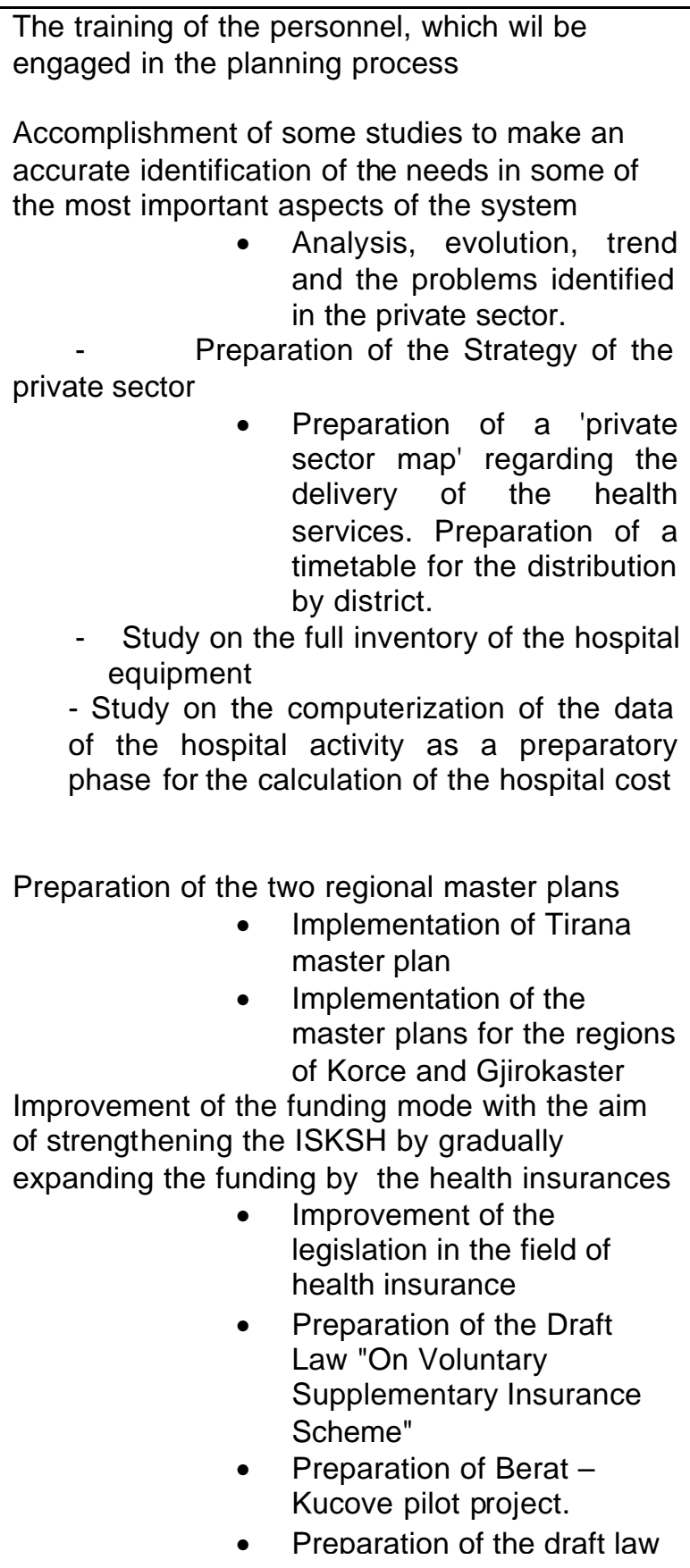 & $\begin{array}{l}\text { HM/DFID } \\
\text { USAID/WHO } \\
\text { HM } \\
\text { HM, WB } \\
\text { HM, Technical } \\
\text { assistance WB } \\
\text { HM } \\
\text { ISKSH } \\
\text { Civil Society } \\
\text { HM } \\
\text { ISKSH/WB } \\
\text { DFID }\end{array}$ & $\begin{array}{l}2003 \\
06.2003 \\
05.2003\end{array}$ & $\begin{array}{l}8 \\
17\end{array}$ \\
\hline
\end{tabular}


ANNEX 2 PROGRAM OF PRIORITY ACTION PLAN 2003

\begin{tabular}{|c|c|c|c|c|c|}
\hline Field/Sector & Objectives & Priority Public Measures & $\begin{array}{l}\text { Responsable } \\
\text { institution }\end{array}$ & Deadline & $\begin{array}{l}\text { Budgetary effects } \\
\text { (millions leks) }\end{array}$ \\
\hline & Minimization of corruption & $\begin{array}{l}\text { Preparation and implementation of a program } \\
\text { on the minimization of corruption }\end{array}$ & $\mathrm{HM}$ & & \\
\hline & $\begin{array}{ll} & \text { Providing } \\
\text { access to } & \text { health } \\
\text { services } & \text { in the } \\
\text { whole } & \text { territory } \\
\text { and } & \text { ensuring } \\
\text { equal } \\
\text { access } \\
\text { for the } \\
\text { citizens } \\
\text { to these } \\
\text { services }\end{array}$ & & $\mathrm{HM}$ & & \\
\hline & $\begin{array}{l}\text { Coverage of the whole } \\
\text { territory by } 100 \% \text { with } \\
\text { Health Centers and } 50 \% \\
\text { with out-patient clinics }\end{array}$ & $\begin{array}{l}\text { Construction and reconstruction of } 40 \text { Health } \\
\text { Centers and } 72 \text { out-patient clinics }\end{array}$ & $\mathrm{HM}$ & 2003 & \\
\hline & $\begin{array}{l}\text { Reorganization of the } \\
\text { hospital service with the } \\
\text { aim of establishing } \\
\text { regional hospitals }\end{array}$ & $\begin{array}{l}\text { Preparation of the law on Hospital service } \\
\text { Improvement of the system of hospital funding } \\
\text { Continuous improvement of the hospital } \\
\text { infrastructure }\end{array}$ & $\mathrm{HM}$ & 2003 & \\
\hline
\end{tabular}


ANNEX 2 PROGRAM OF PRIORITY ACTION PLAN 2003

\begin{tabular}{|c|c|c|c|c|c|}
\hline Field/Sector & Objectives & Priority Public Measures & $\begin{array}{l}\text { Responsable } \\
\text { institution }\end{array}$ & Deadline & $\begin{array}{l}\text { Budgetary effects } \\
\text { (millions leks) }\end{array}$ \\
\hline & $\begin{array}{l}\text { Establishment of a } \\
\text { balance in the } \\
\text { geographical distribution } \\
\text { of the personnel in the } \\
\text { public health system }\end{array}$ & $\begin{array}{l}\text { Preparation of a new map for the distribution of } \\
\text { the personnel, by category } \\
\text { Identification of the current } \\
\text { categories, based on } \\
\text { accurate data about the } \\
\text { types of professions, in } \\
\text { areas where there is not an } \\
\text { adequate ratio among the } \\
\text { professions }\end{array}$ & $\mathrm{HM}$ & 2003 & \\
\hline & $\begin{array}{l}\text { Increase of the role of the } \\
\text { Nurse in the public health } \\
\text { service }\end{array}$ & $\begin{array}{l}\text { Planning and organizatin of the training courses } \\
\text { Establishment of the National Coordinating } \\
\text { Nurse Committee } \\
\text { Standardization of the Nurse Card }\end{array}$ & $\mathrm{HM}$ & 2003 & \\
\hline
\end{tabular}


ANNEX 2 PROGRAM OF PRIORITY ACTION PLAN 2003

\begin{tabular}{|c|c|c|c|c|c|}
\hline Field/Sector & Objectives & Priority Public Measures & $\begin{array}{l}\text { Responsable } \\
\text { institution }\end{array}$ & Deadline & $\begin{array}{l}\text { Budgetary effects } \\
\text { (millions leks) }\end{array}$ \\
\hline & $\begin{array}{l}\text { Ensuring necessary, safe, } \\
\text { and effective drugs at } \\
\text { affordable prices }\end{array}$ & $\begin{array}{l}\text { Improvement and completion of the } \\
\text { pharmaceutical legislation } \\
\text { Improvement of the QKKB structure } \\
\text { - Change of the QKKB status on the } \\
\text { basis of an analysis and approval of } \\
\text { the relevant legal act } \\
\text { Improvement of the management in the hospital } \\
\text { pharmacies } \\
\text { Increase of transparency about the drug prices } \\
\text { - Improvement of the } \\
\text { information about the drug } \\
\text { prices through their } \\
\text { publication } \\
\text { Use of inspection stamp on } \\
\text { drugs circulating in Albania, } \\
\text { relevant regulations }\end{array}$ & $\begin{array}{l}\mathrm{HM} \\
\mathrm{QKKB}\end{array}$ & 2003 & \\
\hline & $\begin{array}{ll}\text { Improve } \\
\text { ment of } \\
\text { the } \\
\text { health } \\
\text { indicators } \\
\text { through } \\
\text { specific } \\
\text { interventi } \\
\text { ons }\end{array}$ & & & & \\
\hline
\end{tabular}


ANNEX 2 PROGRAM OF PRIORITY ACTION PLAN 2003

\begin{tabular}{|c|c|c|c|c|c|}
\hline Field/Sector & Objectives & Priority Public Measures & $\begin{array}{l}\text { Responsable } \\
\text { institution }\end{array}$ & Deadline & $\begin{array}{l}\text { Budgetary effects } \\
\text { (millions leks) }\end{array}$ \\
\hline & $\begin{array}{l}\text { Prevention of EPI } \\
\text { contagious diseases EPI }\end{array}$ & $\begin{array}{l}100 \% \text { coverage of the vaccines included in the } \\
\text { calendar of the obligatory vaccination and the } \\
\text { gradual inclusion of the EPI vaccines } \\
\text { Gradual inclusion of the HM in funding them } \\
\text { with the aim of achieving } 100 \% \text { coverage by the } \\
\text { end of } 2005 \\
\qquad \begin{array}{l}\text { - Training of the staff } \\
\text { responsible for vaccination } \\
\text { - Delivery, maintenance of } \\
\text { the cooling chain } \\
\text { equipment and the } \\
\text { evaluation of this chain. } \\
\text { Improvement of the } \\
\text { laboratory system of } \\
\text { product quality control } \\
\text { Establishment of the } \\
\text { National Authority of } \\
\text { Vaccine Control }\end{array}\end{array}$ & $\begin{array}{l}\text { HM } \\
\text { PHI } \\
\text { UNICEF } \\
\text { GAVI }\end{array}$ & 2003 & \\
\hline
\end{tabular}


ANNEX 2 PROGRAM OF PRIORITY ACTION PLAN 2003

\begin{tabular}{|c|c|c|c|c|c|}
\hline Field/Sector & Objectives & Priority Public Measures & $\begin{array}{l}\text { Responsable } \\
\text { institution }\end{array}$ & Deadline & $\begin{array}{l}\text { Budgetary effects } \\
\text { (millions leks) }\end{array}$ \\
\hline & $\begin{array}{l}\text { Prevention of the spread } \\
\text { of TBC, HIV -AIDS and } \\
\text { IST }\end{array}$ & $\begin{array}{l}\text { Implementation and monitoring of the National } \\
\text { Tuberculosis program for the DOT-S strategy of } \\
\text { the WHO in all the districts } \\
\qquad \begin{array}{l}\text { Increase of the laboratory } \\
\text { diagnostic level of TB } \\
\text { cases. } \\
\text { - } \\
\text { Training of the dispensary } \\
\text { staff. } \\
\text { Collection of regular } \\
\text { information on basis of } \\
\text { standards and } \\
\text { accomplishment of } \\
\text { periodical tests for the } \\
\text { epidemiological situation. } \\
\text { - } \begin{array}{l}\text { Adequate treatment for and } \\
\text { control over all diagnosed } \\
\text { cases }\end{array} \\
\text { Re-evaluation of HIV/AIDS/IST Program and } \\
\text { application of new indicators, preparation of the } \\
\text { action plan for the implementation of the HM } \\
\text { strategy, preparation of the diagnosis methods }\end{array}\end{array}$ & $\begin{array}{l}\mathrm{HM} \\
\mathrm{PHI} \\
\mathrm{WHO}\end{array}$ & 2003 & \\
\hline
\end{tabular}


ANNEX 2 PROGRAM OF PRIORITY ACTION PLAN 2003

\begin{tabular}{|c|c|c|c|c|c|}
\hline Field/Sector & Objectives & Priority Public Measures & $\begin{array}{l}\text { Responsable } \\
\text { institution }\end{array}$ & Deadline & $\begin{array}{l}\text { Budgetary effects } \\
\text { (millions leks) }\end{array}$ \\
\hline & $\begin{array}{l}\text { Prevention of diarrheic } \\
\text { diseases and epidemics }\end{array}$ & $\begin{array}{l}\text { Improvement of the surveillance system in } \\
\text { the districts (laboratories, equipment, } \\
\text { training), which will help to have control } \\
\text { over the quality of potable water and food } \\
-\quad \text { Monitoring of the gastro-intestinal } \\
\text { disorders and intoxications of food origin. } \\
\text { - } \\
\text { Preparation of the Analysis } \\
\text { of the Food and } \\
\text { Nourishment Situation } \\
\text { - Continuous training for } \\
\text { inspectors and } \\
\text { epidemiologists to evaluate } \\
\text { the water quality and the } \\
\text { morbidness originating from } \\
\text { water } \\
\text { Establishment of the } \\
\text { National Regulatory } \\
\text { Authority of Control of } \\
\text { vaccines and the approval } \\
\text { of the regulations for } \\
\text { vaccine control (including } \\
\text { the private sector) } \\
\text { Evaluation of the structures of health anti- } \\
\text { epidemic services in the sea, air, and land } \\
\text { border areas. }\end{array}$ & $\begin{array}{l}\mathrm{HM} \\
\mathrm{PHI}\end{array}$ & 2003 & \\
\hline
\end{tabular}


ANNEX 2 PROGRAM OF PRIORITY ACTION PLAN 2003

\begin{tabular}{|c|c|c|c|c|c|}
\hline Field/Sector & Objectives & Priority Public Measures & $\begin{array}{l}\text { Responsable } \\
\text { institution }\end{array}$ & Deadline & $\begin{array}{l}\text { Budgetary effects } \\
\text { (millions leks) }\end{array}$ \\
\hline & $\begin{array}{l}\text { Reduction of the demand } \\
\text { for drugs, alcohol, and } \\
\text { smoking. }\end{array}$ & $\begin{array}{l}\text { Improvement and expansion of the programs in } \\
\text { the relevant fields, preparation of the strategies } \\
\text { and the consolidation of the legal basis } \\
\text { Approval of the Strategy on Public Health, the } \\
\text { smoking control Strategy, the HIV- AIDS control } \\
\text { Strategy, the Mental Health Strategy } \\
\text { - } \\
\text { Preparation of the alcohol } \\
\text { control Strategy } \\
\text { In cooperation with other } \\
\text { sectors, work will continue } \\
\text { on various programs on this } \\
\text { cross-cutting issues }\end{array}$ & $\begin{array}{l}\mathrm{HM} \\
\mathrm{PHI} \\
\text { Line ministries }\end{array}$ & 2003 & \\
\hline & $\begin{array}{l}\text { Improvement of the } \\
\text { health situation of mother } \\
\text { and child with an impact } \\
\text { on the reduction of the } \\
\text { materinal and infantile } \\
\text { mortality and disease } \\
\text { contraction }\end{array}$ & $\begin{array}{l}\text { Follow the situation of maternal, perinatal and } \\
\text { infantile disease contraction and mortality and } \\
\text { the supervision of the work of the mother and } \\
\text { child services in the KSHP } \\
\text { Continuous monitoring of the law on protection } \\
\text { and breast-fed nourishment } \\
\text { Training of the health staff employed in child } \\
\text { care services with the contemporary concepts } \\
\text { about care, upbringing and nourishment of the } \\
\text { child }\end{array}$ & $\begin{array}{l}\mathrm{HM} \\
\text { UNICEF }\end{array}$ & 2003 & $\begin{array}{l}0.65 \text { a year } \\
8.84 \text { a year }\end{array}$ \\
\hline & $\begin{array}{l}\text { Consolidation of the } \\
\text { mental health community } \\
\text { service and ensuring } \\
\text { continuity of this service }\end{array}$ & $\begin{array}{l}\text { Approval of the Mental Health Strategy. } \\
\text { Training of the mental health employees and } \\
\text { those of the primary health care in the areas of } \\
\text { demonstrative projects } \\
\text { Monitoring and evaluation of the mental health } \\
\text { community services with the emphasis on the } \\
\text { quality of the services }\end{array}$ & $\begin{array}{l}\mathrm{HM} \\
\mathrm{WHO}\end{array}$ & $\begin{array}{l}2003 \\
2003 \\
2 \text { times a } \\
\text { year until } \\
2006\end{array}$ & \\
\hline
\end{tabular}


ANNEX 2 PROGRAM OF PRIORITY ACTION PLAN 2003

\begin{tabular}{|c|c|c|c|c|c|}
\hline Field/Sector & Objectives & Priority Public Measures & $\begin{array}{l}\text { Responsable } \\
\text { institution }\end{array}$ & Deadline & $\begin{array}{l}\text { Budgetary effects } \\
\text { (millions leks) }\end{array}$ \\
\hline & $\begin{array}{l}\text { Monitoring and better } \\
\text { coordination of the } \\
\text { specific programs in the } \\
\text { above fields }\end{array}$ & 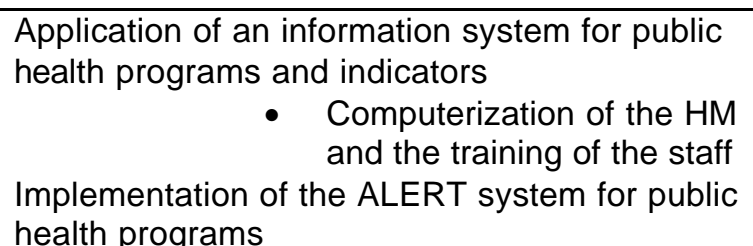 & $\begin{array}{l}\mathrm{HM} \\
\mathrm{PHI} \\
\mathrm{ECHO} \\
\mathrm{WHO}\end{array}$ & 2003 & \\
\hline
\end{tabular}


ANNEX 2 PROGRAM OF PRIORITY ACTION PLAN 2003

TABLE 2: MINISTRY OF FINANCE 
ANNEX 2 PROGRAM OF PRIORITY ACTION PLAN 2003

TABLE 2: MINISTRY OF FINANCE

\begin{tabular}{|c|c|c|c|c|}
\hline No. & Priority Objectives & $\begin{array}{l}\text { Planned measures and } \\
\text { actions }\end{array}$ & $\begin{array}{l}\text { Responsible } \\
\text { institution }\end{array}$ & $\begin{array}{l}\text { Deadline and } \\
\text { notes }\end{array}$ \\
\hline 1. & $\begin{array}{l}\text { Increase and consolidation } \\
\text { of the stability of the } \\
\text { macroeconomic situation }\end{array}$ & & & \\
\hline 1.1 & $\begin{array}{l}\text { Sustainable Economic growth } \\
\text { - } \\
\text { Real economic growth } \\
\text { by } 6 \% \text {. } \\
\text { Reduction of overall } \\
\text { decifit to } 6.5 \% \text { of } \\
\text { GDP. } \\
\text { - Reduction of } \\
\text { domestically financed } \\
\text { deficit below } 2.6 \% \text { of } \\
\text { GDP } \\
\text { Control over inflation } \\
\text { rate, } 2-4 \% \text { a year }\end{array}$ & $\begin{array}{ll}\text { - } & \text { Cautious economic } \\
\text { policy } \\
\text { - }\end{array}$ & $\begin{array}{l}\text { Government, its } \\
\text { structures, structures } \\
\text { of the Finance } \\
\text { Ministry, Bank of } \\
\text { Albania }\end{array}$ & $\begin{array}{l}\text { During whole } \\
2003\end{array}$ \\
\hline 2 & $\begin{array}{l}\text { Budgetory and fiscal } \\
\text { policies }\end{array}$ & & & \\
\hline 2.1 & $\begin{array}{l}\text { Improvement of the } \\
\text { preparation, } \\
\text { compilation, and } \\
\text { presentation of the } \\
\text { draft budget. } \\
\text { Improved coordination } \\
\text { of the sector policies } \\
\text { in line with the } \\
\text { medium-term } \\
\text { development priorities } \\
\text { through better } \\
\text { harmonization of the } \\
\text { resources with the } \\
\text { government's priority }\end{array}$ & $\begin{array}{l}\text { Preparation of the New } \\
\text { Organic Budget Law } \\
\text { and presentation to the } \\
\text { government } \\
\text { Preparation of the } \\
\text { instruction for the } \\
\text { implementation of the } \\
\text { New Organik budget } \\
\text { law, which will help to } \\
\text { improve the procedures } \\
\text { and the standards for } \\
\text { budget drafting } \\
\text { Preparation of } 2004- \\
\text { 2006 MTEF on basis of }\end{array}$ & $\begin{array}{l}\text { Budget Department, } \\
\text { Legislation } \\
\text { Department } \\
\text { DFID, in } \\
\text { consultation with EU, } \\
\text { WB and IMF }\end{array}$ & $\begin{array}{l}\text { First draft } \\
\text { September } \\
2003\end{array}$ \\
\hline
\end{tabular}


ANNEX 2 PROGRAM OF PRIORITY ACTION PLAN 2003

\begin{tabular}{|c|c|c|c|c|}
\hline & objectives. & $\begin{array}{l}\text { the NSSED } \\
\text { Drafting of the } \\
\text { Instruction for the } \\
\text { preparation of the } 2003 \\
\text { state budget } \\
\text { Training of the MoF } \\
\text { staff and the sector } \\
\text { ministries }\end{array}$ & & $\begin{array}{l}10 \text { July } 2003 \\
10 \text { July } 2003 \\
\text { During whole } \\
\text { year }\end{array}$ \\
\hline 2.2 & $\begin{array}{l}\text { Enhanced effectiveness in the } \\
\text { use of public funds and the } \\
\text { application of a strong } \\
\text { financial discipline during the } \\
\text { budget implementation }\end{array}$ & $\begin{array}{l}\text { Drafting of the } \\
\text { instruction for the } \\
\text { implementation of } 2003 \\
\text { budget } \\
\text { Preparation of the draft } \\
\text { decision on the number } \\
\text { of the budgetary } \\
\text { employees by ministry } \\
\text { and the budgetary } \\
\text { institutions } \\
\text { Drafting of the } \\
\text { Instructions for the } \\
\text { evaluation of the } \\
\text { investment projects } \\
\text { Expansion of the fiscal } \\
\text { decentralization reform, } \\
\text { preparation of joint } \\
\text { instructions }\end{array}$ & $\begin{array}{l}\text { Budget Department } \\
\text { Budget Department } \\
\text { Budget Department } \\
\text { MoF, (Budget } \\
\text { Department) MPVD }\end{array}$ & $\begin{array}{l}\text { January } 2003 \\
\text { March } 2003 \\
\text { March } 2003 \\
\text { During whole } \\
\text { year }\end{array}$ \\
\hline 2.3 & $\begin{array}{l}\text { Improvements in the budget } \\
\text { system and the budgetory } \\
\text { procedures }\end{array}$ & $\begin{array}{l}\text { Improvement of the budgetory } \\
\text { classification in accordance } \\
\text { with the GFS standards }\end{array}$ & $\begin{array}{l}\text { Department of } \\
\text { Budget, Treasury, } \\
\text { and Accounting }\end{array}$ & $\begin{array}{l}\text { During whole } \\
\text { year }\end{array}$ \\
\hline 2.4 & $\begin{array}{l}\text { Strengthening of the } \\
\text { capacities }\end{array}$ & $\begin{array}{l}\text { Training of the staff of the } \\
\text { Budget and Treasury } \\
\text { Department and other } \\
\text { structures of the MoF. } \\
\text { Consolidation, among others, } \\
\text { through the revision of the }\end{array}$ & $\begin{array}{l}\text { World Bank, DoPA, } \\
\text { DFID Department of } \\
\text { Budget and Treasury }\end{array}$ & $\begin{array}{l}\text { During the } \\
\text { year }\end{array}$ \\
\hline
\end{tabular}

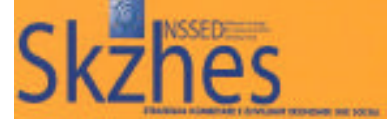


ANNEX 2 PROGRAM OF PRIORITY ACTION PLAN 2003

\begin{tabular}{|c|c|c|c|c|}
\hline & & functions of the local branches & & \\
\hline 2.5 & $\begin{array}{l}\text { Management of the public } \\
\text { resources and expenditures } \\
\text { through treasury structures } \\
\text { Securing domestic borrowing } \\
\text { at the lowest possible cost } \\
\text { Management of the foreign } \\
\text { debt and the foreign financing }\end{array}$ & $\begin{array}{l}5 \text { Consolidation and the } \\
\text { strengthening of the } \\
\text { operations in the treasury } \\
\text { system }\end{array}$ & $\begin{array}{l}\text { Macroeconomic } \\
\text { Department, Budget } \\
\text { Department, Tax and } \\
\text { Budget Departments } \\
\\
\text { Treasury } \\
\text { Department } \\
\text { Treasury } \\
\text { Department, MoF } \\
\text { MoF, Treasury } \\
\text { Department and BoA } \\
\text { Treasury } \\
\text { Department } \\
\text { Treasury } \\
\text { Department } \\
\text { Treasury } \\
\text { Department }\end{array}$ & $\begin{array}{l}\text { Until March } \\
2003 \\
\text { During the } \\
\text { year }\end{array}$ \\
\hline 2.6 & $\begin{array}{l}\text { Reforms for progress in the } \\
\text { tax administration }\end{array}$ & & & \\
\hline 2.6 .1 & $\begin{array}{l}\text { Problems of the } \\
\text { Administration }\end{array}$ & $\begin{array}{l}\text { Establishment of the } \\
\text { new structures on } \\
\text { functional basis } \\
\text { - } \quad \text { Finalization of the }\end{array}$ & $\begin{array}{l}\text { MoF and General } \\
\text { Tax Department }\end{array}$ & February 2003 \\
\hline
\end{tabular}

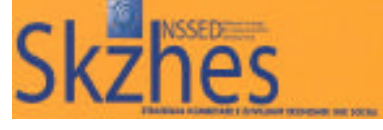


ANNEX 2 PROGRAM OF PRIORITY ACTION PLAN 2003

\begin{tabular}{|c|c|c|c|c|c|}
\hline & & & $\begin{array}{l}\text { procedurial manuals of } \\
\text { the tasks for every } \\
\text { sector and office, such } \\
\text { as the manual of the } \\
\text { register, evaluation, } \\
\text { collection, appeal, } \\
\text { finances, evasion, and } \\
\text { investigation } \\
\text { - Full implementation of } \\
\text { the functions of the } \\
\text { audit } \\
\text { Identification of the } \\
\text { objectives for every } \\
\text { local office } \\
\text { Preparation of the } \\
\text { relevant instructions } \\
\text { Establishment of the } \\
\text { registration system of } \\
\text { the social and health } \\
\text { insurance contributors } \\
\text { Beginning the collection } \\
\text { of the social and health } \\
\text { insurances for } 300 \\
\text { large taxpayers } \\
\text { Implementation of the } \\
\text { media program for the } \\
\text { education }\end{array}$ & $\begin{array}{l}\text { General Tax } \\
\text { Department } \\
\text { General Tax } \\
\text { Department } \\
\text { General Tax } \\
\text { Department } \\
\text { General Tax } \\
\text { Department } \\
\text { General Tax } \\
\text { Department } \\
\\
\text { General Tax } \\
\text { Department } \\
\text { and SIl }\end{array}$ & $\begin{array}{l}\text { By end of June } \\
\text { January } 2003 \\
\text { By the end of } \\
\text { the year } \\
\text { Third Quarter } \\
\text { By end of June } \\
\text { During the } \\
\text { year }\end{array}$ \\
\hline 2.6 .2 & Procedurial improvements & & $\begin{array}{l}\text { Settlement of the arrears } \\
\text { to the tax administration, } \\
\text { acceptance and the } \\
\text { signing of the } \\
\text { memorandums of } \\
\text { understanding }\end{array}$ & $\begin{array}{l}\text { Structures of the } \\
\text { GTD and MoF }\end{array}$ & January 2003 \\
\hline 2.6 .3 & $\begin{array}{l}\text { Improvements in the legal } \\
\text { framework }\end{array}$ & & $\begin{array}{l}\text { Preparation of the draft } \\
\text { sub-legal acts for the } \\
\text { implementation of the new } \\
\text { fiscal package }\end{array}$ & GTD structures & January 2003 \\
\hline
\end{tabular}


ANNEX 2 PROGRAM OF PRIORITY ACTION PLAN 2003

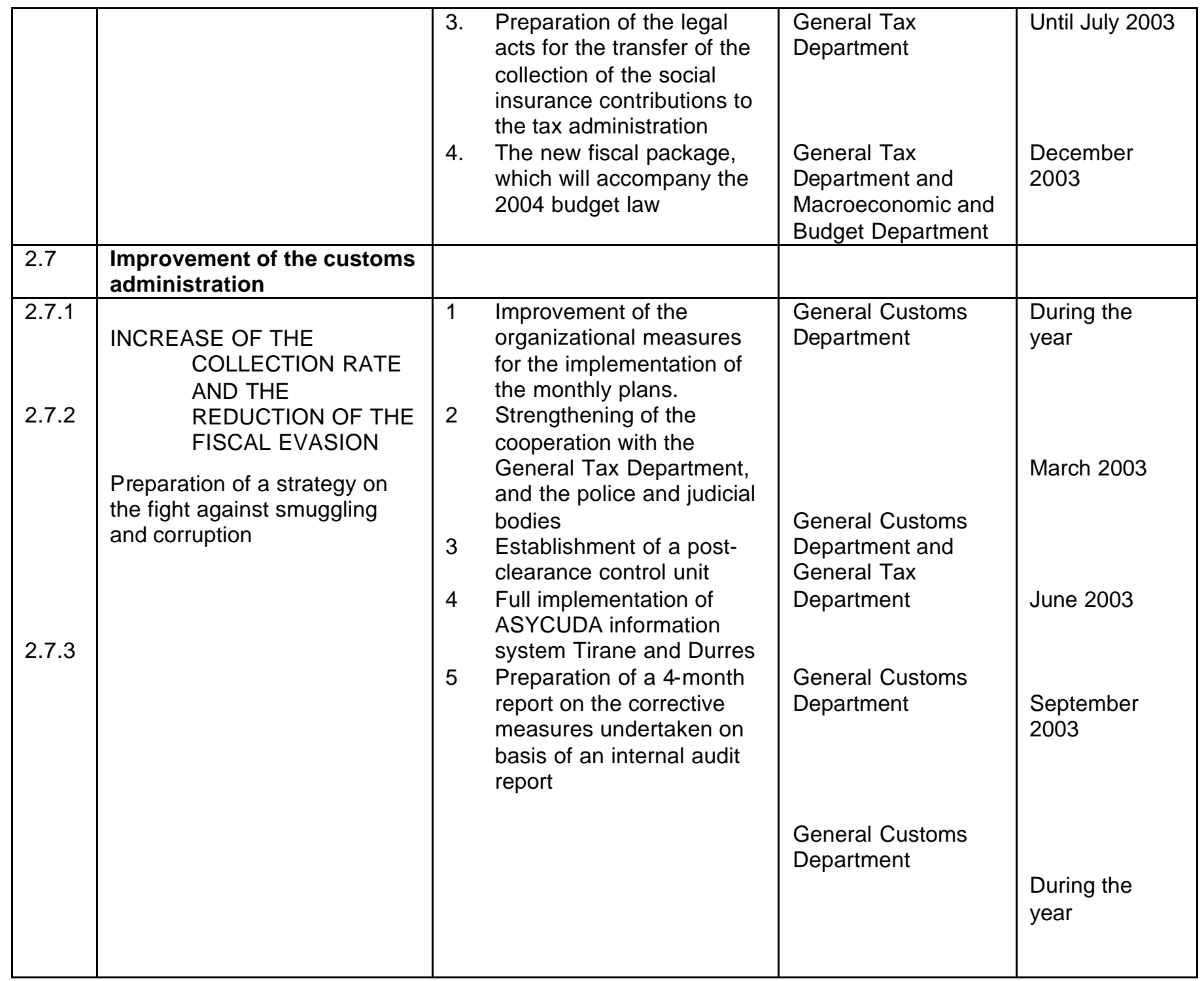


ANNEX 2 PROGRAM OF PRIORITY ACTION PLAN 2003

\begin{tabular}{|c|c|c|c|c|}
\hline & & & $\begin{array}{l}\text { General Customs } \\
\text { Department }\end{array}$ & \\
\hline 3. & STRUCTURAL REFORM & & & \\
\hline 3.1 & $\begin{array}{l}\text { Bringing Insurance } \\
\text { Supervision Commission } \\
\text { into full operation and in } \\
\text { accordance with the } \\
\text { international standards }\end{array}$ & - & $\begin{array}{l}\text { Full } \\
\text { restructuring } \\
\text { of the } \\
\text { activity of } \\
\text { Insurance } \\
\text { Supervisory } \\
\text { Commission } \\
\text { and } \\
\text { functional } \\
\text { division of } \\
\text { tasks to } \\
\text { precede } \\
\text { preparation } \\
\text { of the new } \\
\text { law } \\
\text { In } \\
\text { cooperation } \\
\text { with KMS } \\
\text { and WB } \\
\text { assistance, } \\
\text { preparation } \\
\text { of the new } \\
\text { law "On } \\
\text { insurance } \\
\text { and } \\
\text { reassurance } \\
\text { " }\end{array}$ & $\begin{array}{l}\text { 6-month period } \\
\text { of } 2003 \\
\text { June } 2003\end{array}$ \\
\hline
\end{tabular}


ANNEX 2 PROGRAM OF PRIORITY ACTION PLAN 2003

\begin{tabular}{|c|c|c|c|c|}
\hline \multirow[t]{3}{*}{3.2} & $\begin{array}{l}\text { Bringing Tirana Bourse } \\
\text { into full operation }\end{array}$ & $\begin{array}{l}\text { Bringing the primary } \\
\text { treasury bill market in } \\
\text { Tirana Bourse into } \\
\text { operation } \\
\text { Modelling of the } \\
\text { primary treasury bill } \\
\text { market. } \\
\text { Transfer of the register } \\
\text { from the BoA to } \\
\text { Bourse. } \\
\text { Official opening of the } \\
\text { market } \\
\text { Follow the procedures } \\
\text { for the signing of the } \\
\text { memorandum of } \\
\text { understanding on } \\
\text { cleaning and regulation } \\
\text { of the transactions in } \\
\text { securities } \\
\text { Receiving the final } \\
\text { license from the } \\
\text { commission of } \\
\text { securities }\end{array}$ & $\begin{array}{l}\text { Bourse/MoF } \\
\text { Bourse, MoF } \\
\text { Bourse , / KLV } \\
\text { MoF }\end{array}$ & $\begin{array}{l}\text { Second } \\
\text { quarter of } \\
2003 \\
\text { January } 2003 \\
2003\end{array}$ \\
\hline & Credit Treatment Agency & & & \\
\hline & & $\begin{array}{l}\text { Implementation of the } \\
\text { tasks laid down in } \\
\text { conformity with FSAC } \\
\text { agreement: } \\
\text { To be settled: } \\
-15 \% \text { of portfolio } \\
-10 \% \text { e portfolio } \\
-50 \% \text { of the value and } \\
\text { number of the assets }\end{array}$ & ATK & $\begin{array}{l}\text { During the } \\
\text { year } \\
\text { June } 2003 \\
\text { June 2003- } \\
\text { June } 2004\end{array}$ \\
\hline
\end{tabular}


ANNEX 2 PROGRAM OF PRIORITY ACTION PLAN 2003

\begin{tabular}{|c|c|c|c|c|}
\hline 3.4 & $\begin{array}{l}\text { Restructuring of the } \\
\text { Savings Bank with the aim } \\
\text { of bringing it to the point of } \\
\text { sale }\end{array}$ & & & \\
\hline 3.4 .1 & $\begin{array}{l}\text { Restructuring of the } \\
\text { Savings Bank }\end{array}$ & $\begin{array}{l}\text { 1.Transfer of the pension } \\
\text { and fiscal services. } \\
\text { 2. Restructuring of the Bank } \\
\text { network } \\
\text { 3. Further development of } \\
\text { the IT and } \\
\text { Telecommunications } \\
\text { 3. Reduction and the } \\
\text { qualitative improvement of } \\
\text { the staff. } \\
\text { 4. Regional extension of } \\
\text { the Savings Bank } \\
\text { 5.Marketing }\end{array}$ & $\begin{array}{l}\text { MoF Savings Bank, } \\
\text { Privatization Group }\end{array}$ & $\begin{array}{l}\text { 30.March } 2003 \\
\text { May } 2003 \\
\text { October } 2003 \\
\text { Continuing } \\
\text { During the } \\
\text { year } \\
\text { During the } \\
\text { year }\end{array}$ \\
\hline \multirow[t]{2}{*}{3.4 .2} & $\begin{array}{l}\text { II-Privatization of the } \\
\text { Savings Bank Lmt. }\end{array}$ & & & \\
\hline & & 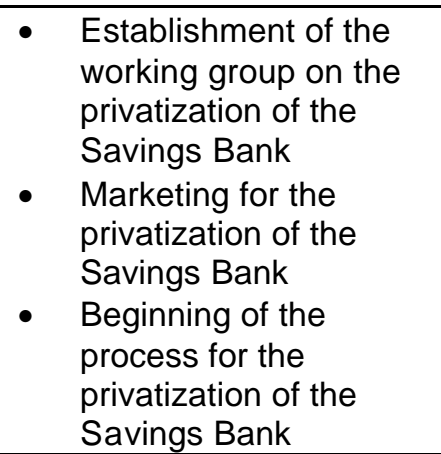 & MoF/BK & $\begin{array}{l}\text { January } 2003 \\
\text { During } 2003 \\
\text { October } 2003\end{array}$ \\
\hline 3.5 & INSIG & & & \\
\hline
\end{tabular}


ANNEX 2 PROGRAM OF PRIORITY ACTION PLAN 2003

\begin{tabular}{|c|c|c|c|c|c|}
\hline & & & $\begin{array}{l}\text { Selection of the advisor } \\
\text { for the privatization of } \\
\text { INSIG } \\
\text { - Preparation of the } \\
\text { action plan, updated by } \\
\text { the INSIG board, to } \\
\text { resolve the investment } \\
\text { problem for the first } \\
\text { phase of the INSIG's } \\
\text { privatization } \\
\text { Waiting for offers from } \\
\text { IFC and EBRD for the } \\
\text { first phase of INSIG's } \\
\text { privatization } \\
\text { Follow the process of } \\
\text { the privatization and } \\
\text { the completion of the } \\
\text { first phase of the } \\
\text { privatization }\end{array}$ & $\begin{array}{l}\text { MoF } \\
\text { INSIG General } \\
\text { Department Lmt } \\
\text { MoF } \\
\text { MoF/INSIG }\end{array}$ & $\begin{array}{l}\text { January } 2003 \\
\text { February } 2003 \\
\text { March } 2003 \\
\text { June } 2003\end{array}$ \\
\hline \multirow[t]{3}{*}{3.6} & $\begin{array}{l}\text { Coordination of the Fight } \\
\text { Against organized crime and } \\
\text { money laundering }\end{array}$ & & & & \\
\hline & & 1 & $\begin{array}{l}\text { Preparation of the } \\
\text { necessary changes in law } \\
\text { No..8610 date } 17.05 .2000 \\
\text { "On money laundering } \\
\text { prevention" based on the } \\
\text { international Conventions, } \\
\text { which have been signed } \\
\text { and ratified, the } \\
\text { recommendations of the } \\
\text { Council of Europe, the US } \\
\text { Treasury Department and } \\
\text { the World Bank } \\
\text { Preparation of the sub- } \\
\text { legal acts, }\end{array}$ & DBLPP & March 2003 \\
\hline & & & 1 Improvement and & DBLKPP & June 2003 \\
\hline
\end{tabular}


ANNEX 2 PROGRAM OF PRIORITY ACTION PLAN 2003

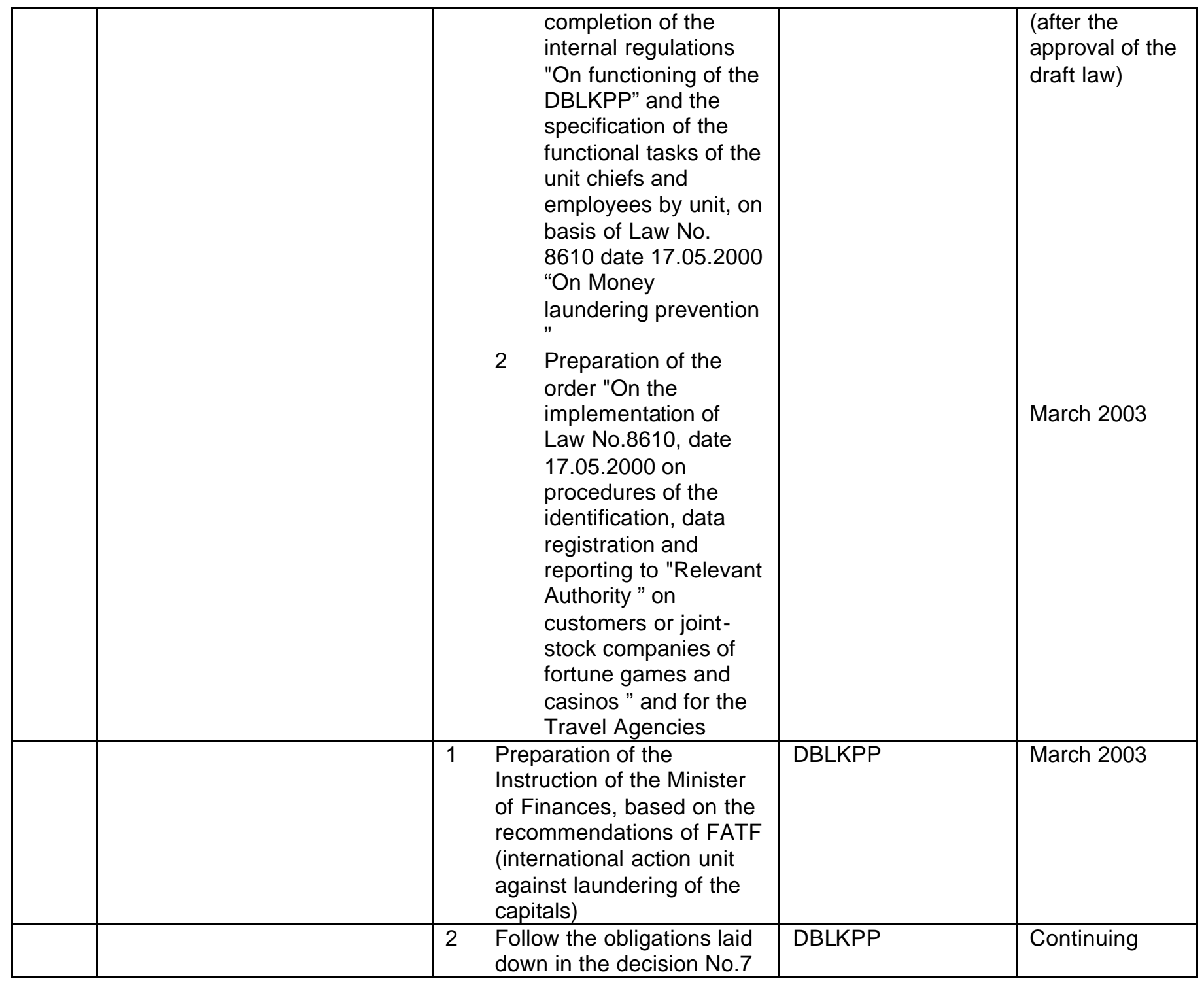


ANNEX 2 PROGRAM OF PRIORITY ACTION PLAN 2003

\begin{tabular}{|c|c|c|c|c|c|}
\hline & & & $\begin{array}{l}\text { date } 15.10 .2001 \text { of the } \\
\text { Assembly of Albania "On } \\
\text { the fight against terrorism } \\
\text { and reporting on measures } \\
\text { taken and results achieved } \\
\text { ", the Instructions of the } \\
\text { Ministry and the } \\
\text { obligations laid down in the } \\
\text { National Plan }\end{array}$ & & \\
\hline & & 3 & $\begin{array}{l}\text { Preparation of the } \\
\text { instruction for the entities } \\
\text { subject to the } \\
\text { implementation of the Law } \\
8610 \text { date } 17.05 .2000 \text { on } \\
\text { the money laundering } \\
\text { prevention, based on } \\
\text { special recommendations } \\
\text { of FATF (GAFI) }\end{array}$ & $\begin{array}{l}\text { DBLKPP } \\
\text { Legislative Support } \\
\text { Department }\end{array}$ & March 2003 \\
\hline 3.7 & $\begin{array}{l}\text { Strengthening of the Public } \\
\text { Accounting }\end{array}$ & 6 & $\begin{array}{l}\text { Preparation of the final } \\
\text { draft law "On accounting " } \\
\text { Finalization of the manual } \\
\text { for the facilitation of the } \\
\text { implementation of } \\
\text { budgetory Classification } \\
\text { Preparation of the } \\
\text { summary Balance Sheet of } \\
\text { all budgetory institutions } \\
\text { and local government } \\
\text { bodies } \\
\text { Preparation of the } \\
\text { accounting instruction for } \\
\text { closure of } 2003\end{array}$ & $\begin{array}{l}\text { Accounting } \\
\text { Department } \\
\\
\text { Accounting } \\
\text { Department, Budget } \\
\text { Department and } \\
\text { Treasury } \\
\text { Department }\end{array}$ & $\begin{array}{l}\text { June } 2003 \\
\text { June } 2003 \\
\text { June } 2003 \\
\text { November } \\
2003\end{array}$ \\
\hline
\end{tabular}


ANNEX 2 PROGRAM OF PRIORITY ACTION PLAN 2003

\begin{tabular}{|c|c|c|c|c|}
\hline & & & $\begin{array}{l}\text { Accounting } \\
\text { Department }\end{array}$ & \\
\hline $\begin{array}{l}\text { Strengthening of the Internal } \\
\text { Financial Audit }\end{array}$ & $\begin{array}{l}4 \\
5\end{array}$ & $\begin{array}{l}\text { Preparation of the sub- } \\
\text { legal acts for the } \\
\text { implementation of the law } \\
\text { on "Internal audit " } \\
\text { Strengthening of the } \\
\text { capacities in the internal } \\
\text { audit department through } \\
\text { training } \\
\text { Strengthening of the } \\
\text { capacities in the sector } \\
\text { ministries } \\
\text { Approval of the } 2003 \\
\text { financial audit plan } \\
\text { Strengthening of the } \\
\text { cooperation on the audit } \\
\text { coordination with High } \\
\text { State Control, and the } \\
\text { Customs and Tax } \\
\text { Administrations }\end{array}$ & $\begin{array}{l}\text { Financial DPKBF } \\
\text { Financial DPKBF } \\
\text { Financial DPKBF } \\
\text { Financial DPKBF }\end{array}$ & $\begin{array}{l}\text { During the } \\
\text { year } \\
\text { During the } \\
\text { year } \\
\text { January } 2003\end{array}$ \\
\hline & & & & $\begin{array}{l}\text { During whole } \\
\text { year }\end{array}$ \\
\hline
\end{tabular}


ANNEX 2 PROGRAM OF PRIORITY ACTION PLAN 2003

TABLE 3: GENERAL DEPARTMENT OF CUSTOMS 
TABLE 3:GENERAL DEPARTMENT OF CUSTOMS

\begin{tabular}{|c|c|c|c|c|c|}
\hline & Objective & Activity & Deadline & Responsibility & $\begin{array}{l}\text { BUDGETORY } \\
\text { EFFECTS }\end{array}$ \\
\hline \multicolumn{6}{|c|}{ (1) Fiscal mission: Maximum increase of tax collection } \\
\hline \multicolumn{5}{|c|}{ Maximum possible collection of payable revenus through: } & MILL. LEKS \\
\hline 1 & $\begin{array}{l}\text { Increase of the } \\
\text { collection rate } \\
\text { and reduction of } \\
\text { the leaks in the } \\
\text { system to a } \\
\text { minimum }\end{array}$ & $\begin{array}{l}\text { Improvement of the organizational measures to implement the } \\
\text { monthly and annual revenue plans, which are approved by the } \\
\text { Ministry of Finances. } \\
\text { [Identification, in cooperation with the Ministry of Finances, of } \\
\text { the targets of monthly and annual plans, in million leks] }\end{array}$ & $\begin{array}{l}\text { Agreement with } \\
\text { Ministry on } \\
\text { annual plan by } \\
31 / 12 / 2002 \\
\text { Monthly } \\
\text { reporting on } \\
\text { monthly and } \\
\text { annual } \\
\text { progressive } \\
\text { collection, not } \\
\text { later than 5th of } \\
\text { next month }\end{array}$ & $\begin{array}{l}\text { GD, Deputy } \\
\text { Directors }\end{array}$ & \\
\hline 1.0 .1 & & $\begin{array}{l}\text { Comparison of the annual figures, with year } 2002 \text {, for the } \\
\text { revenues collected from the detection of smuggled goods and } \\
\text { the application of fines on violations, with the aim of identifying } \\
\text { additional (organizational or structural) measures to improve } \\
\text { the situation. Identification of the monthly and annual targets, in } \\
\text { million leks, for the revenues to be collected from detection of } \\
\text { smuggled goods and the application of the fines. }\end{array}$ & $\begin{array}{l}\text { Monthly } \\
\text { reporting on } \\
\text { monthly results } \\
\text { and annual } \\
\text { progressive } \\
\text { results, not later } \\
\text { than 5th of } \\
\text { next month. }\end{array}$ & $\begin{array}{l}\text { GD; } \\
\text { Technical } \\
\text { Deputy Director, } \\
\text { DOH; } \\
\text { Regional } \\
\text { Directors }\end{array}$ & \\
\hline 1.0 .2 & & $\begin{array}{l}\text { Comparison of the annual figures, with year 2002, of the } \\
\text { number of the coupled transits within the specific period of time, } \\
\text { with the aim of identifying the measures for the improvement of } \\
\text { the situation, as well as the collection of obligations and the } \\
\text { application of sanctions against unclosed transits. }\end{array}$ & $\begin{array}{l}\text { Monthly } \\
\text { reporting on } \\
\text { monthly results } \\
\text { and annual } \\
\text { progressive } \\
\text { results, not later } \\
\text { than 10th of } \\
\text { next month. }\end{array}$ & $\begin{array}{l}\text { Technical } \\
\text { Deputy Director, } \\
\text { Statistics } \\
\text { Department, } \\
\text { Department of } \\
\text { Procedures, } \\
\text { Regional } \\
\text { Managers, } \\
\text { Regional } \\
\text { Directors } \\
\end{array}$ & \\
\hline
\end{tabular}


ANNEX 2 PROGRAM OF PRIORITY ACTION PLAN 2003

\begin{tabular}{|c|c|c|c|c|c|}
\hline 1.0 .3 & & $\begin{array}{l}\text { In cooperation with CAM-A, accomplishment of quarterly } \\
\text { revisions of the transit regime to identify further relevant } \\
\text { procedures and to ensure that the approved procedures are } \\
\text { adequately implemented, are in accordance with the EU } \\
\text { standards, and respond to the national needs, taking acount of } \\
\text { the risks to the revenues. }\end{array}$ & $\begin{array}{l}30 / 03 / 2003 \\
30 / 06 / 2003 \\
30 / 09 / 2003 \\
30 / 11 / 2003\end{array}$ & $\begin{array}{l}\text { Department of } \\
\text { Procedures and } \\
\text { Collection of } \\
\text { Obligations; } \\
\text { CAM-A }\end{array}$ & $\begin{array}{l}\text { Foreign } \\
\text { assistance } \\
1 \text { million leks }\end{array}$ \\
\hline 1.0 .4 & & $\begin{array}{l}\text { Identification of the number of the transits with coupled TIR } \\
\text { Carnet and the measures, which should be taken to collect } \\
\text { them, in accordance with the conditions and the deadlines of } \\
\text { the Guarantee Agreement with ANALTIR. }\end{array}$ & $\begin{array}{l}\text { In compliance } \\
\text { with deadlines } \\
\text { set in } \\
\text { Guarantee } \\
\text { Agreement with } \\
\text { ANALTIR } \\
\text { 30/04/2003 }\end{array}$ & $\begin{array}{l}\text { DPVD; Finance } \\
\text { Department, } \\
\text { D.O.H, Internal } \\
\text { Audit; Deputy } \\
\text { Technical Chief; } \\
\text { Deputy } \\
\text { Adminitrative } \\
\text { Chief }\end{array}$ & 1 million leks \\
\hline 1.1 & $\begin{array}{l}\text { Continued } \\
\text { implementation } \\
\text { of the National } \\
\text { Program on the } \\
\text { administration of } \\
\text { the customs } \\
\text { debt }\end{array}$ & $\begin{array}{l}\text { Initiation of a more aggressive program for a more effective } \\
\text { management of the collection of the customs debt, with the aim } \\
\text { of reducing the gap in the revenues and increasing the } \\
\text { revenues. Necessary measures will be taken to increase the } \\
\text { effectiveness in the field of customs debt management. }\end{array}$ & $31 / 03 / 2003$ & $\begin{array}{l}\text { Department of } \\
\text { Procedures and } \\
\text { Collection of } \\
\text { Obligations; } \\
\text { CAM-A }\end{array}$ & 2 million leks \\
\hline 1.2 & $\begin{array}{l}\text { Strengthening of } \\
\text { the function of } \\
\text { the Internal } \\
\text { Audit }\end{array}$ & $\begin{array}{l}\text { Adoption of corrective measures for the shortcomings identified } \\
\text { by the High State Control, the Inspectorate of the Minister, and } \\
\text { the Internal Audit of the Customs Administration. } \\
\text { In cooperation with CAM-A, revision of the effectiveness and } \\
\text { efficiency of the Internal Audit Department }\end{array}$ & $\begin{array}{l}\text { 31/01/2003 and } \\
\text { continuing } \\
\text { during } 2003 \\
30 / 06 / 2003\end{array}$ & $\begin{array}{l}\text { Department in } \\
\text { General } \\
\text { Customs } \\
\text { Department, } \\
\text { Regional } \\
\text { Departmet, } \\
\text { customs } \\
\text { branches } \\
\text { Internal Audit } \\
\text { Department; }\end{array}$ & \\
\hline
\end{tabular}


ANNEX 2 PROGRAM OF PRIORITY ACTION PLAN 2003

\begin{tabular}{|c|c|c|c|c|c|}
\hline & & & & CAM-A & \\
\hline 1.3 & $\begin{array}{l}\text { Generation of } \\
\text { the indicative } \\
\text { data on basis of } \\
\text { the procedures } \\
\text { of the Internal } \\
\text { Audit structure }\end{array}$ & $\begin{array}{l}\text { The audits are carried out on the basis of the cycle and } \\
\text { procedures of the internal audit structure, the problems and } \\
\text { measures are identified, and reports for the GD are prepared }\end{array}$ & $\begin{array}{l}\text { Continuing } \\
\text { during } 2003\end{array}$ & $\begin{array}{l}\text { Internal Audit } \\
\text { Department }\end{array}$ & $\begin{array}{l}\text { Foreign } \\
\text { assistance }\end{array}$ \\
\hline 1.3 .1 & & $\begin{array}{l}\text { The audits are carried out and quartely reports on the } \\
\text { application of the customs value are prepared for the GD, the } \\
\text { Finance Minister, and the IMF }\end{array}$ & $\begin{array}{l}\text { On basis of } \\
\text { Agreement with } \\
\text { IMF Mission }\end{array}$ & $\begin{array}{l}\text { Internal Audit } \\
\text { Department }\end{array}$ & \\
\hline 1.4 & $\begin{array}{l}\text { Strengthening of } \\
\text { the system to } \\
\text { achieve good } \\
\text { administration }\end{array}$ & $\begin{array}{l}\text { Preparation of the quarterly reports and the anual report on the } \\
\text { internal audit to achieve the transparency and accurate } \\
\text { reporting of the internal audit system. } \\
\text { When audits of whatever kind identify problems pertaining to } \\
\text { the Discriplinary Committee, reports are prepared and } \\
\text { measures, which will be examined by the Committee, are } \\
\text { proposed. }\end{array}$ & $\begin{array}{l}\text { First annual } \\
\text { report until } \\
31 / 04 / 2003\end{array}$ & $\begin{array}{l}\text { Internal Audit } \\
\text { Department }\end{array}$ & \\
\hline 1.5 & $\begin{array}{l}\text { Professional } \\
\text { application of all } \\
\text { aspects of the } \\
\text { WTO } \\
\text { methodology for } \\
\text { the customs } \\
\text { evaluation }\end{array}$ & $\begin{array}{l}\text { With the continuous assistance of CAM-A, improvement of the } \\
\text { policies and procedures of the Department of the Evaluation } \\
\text { and Origin with the aim of ensuring the most effective } \\
\text { application of all aspects of WTO methodology regarding the } \\
\text { customs evaluation. } \\
\text { Improved ability of the Department to store and maintain } \\
\text { significant and adequate reference information about the } \\
\text { relevant international prices of the goods imported to Albania. } \\
\text { Control and instructions about the way they are applied. } \\
\text { Provision of catalogues. }\end{array}$ & $\begin{array}{l}\text { Continuing } \\
\text { during } 2003\end{array}$ & $\begin{array}{l}\text { Department of } \\
\text { Tariff, Value, } \\
\text { and Origin; } \\
\text { Technical } \\
\text { Deputy Director; } \\
\text { CAM-A }\end{array}$ & $\begin{array}{l}\text { Foreign } \\
\text { assistance } \\
1,3 \text { million leks }\end{array}$ \\
\hline 1.5 .1 & & $\begin{array}{l}\text { Preparation of an annual control plan to achieve quality in the } \\
\text { more accurate implementation of the local instructions related }\end{array}$ & $28 / 02 / 2003$ & $\begin{array}{l}\text { Department of } \\
\text { Tariff, Value, }\end{array}$ & \\
\hline
\end{tabular}


ANNEX 2 PROGRAM OF PRIORITY ACTION PLAN 2003

\begin{tabular}{|c|c|c|c|c|c|}
\hline 1.6 & $\begin{array}{l}\text { Improvements in } \\
\text { the System of } \\
\text { Classification } \\
\text { and Codification } \\
\text { of the Goods }\end{array}$ & $\begin{array}{l}\text { to the application of WTO methodology for the customs } \\
\text { evaluation in the operational customs points. } \\
\text { Ensuring that the Tariff of the Harmonized Nomenclature (WTO } \\
\text { - HS) is in harmony with the latest international version by } \\
\text { applying an annual program for the Change of the Tariff. }\end{array}$ & $31 / 03 / 2003$ & $\begin{array}{l}\text { and Origin; } \\
\text { Internal Audit } \\
\text { Department; } \\
\text { CAM-A } \\
\text { Department of } \\
\text { Tariff, Value, } \\
\text { and Origin } \\
\text { Judicial } \\
\text { Department, } \\
\text { Technical } \\
\text { Deputy Director }\end{array}$ & 1,5 million leks \\
\hline 1.6 .1 & $\begin{array}{l}\text { Control over } \\
\text { strict } \\
\text { application of } \\
\text { the tariff } \\
\text { classification of } \\
\text { the goods }\end{array}$ & $\begin{array}{l}\text { Updating of the Explanatory Notes of the HS Tariff in line with } \\
\text { the international amendments, and their translation into the } \\
\text { Albanian language. } \\
\text { Preparation of an annual control program regarding the } \\
\text { accurate and standard application of the tariff classification by } \\
\text { the Customs Offices. }\end{array}$ & $\begin{array}{l}30 / 11 / 2003 \\
\text { Program until } \\
28.3 .03 \text { and } \\
\text { reporting every } \\
\text { two months, not } \\
\text { later than 10th } \\
\text { day of the } \\
\text { month following } \\
\text { the audit period }\end{array}$ & $\begin{array}{l}\text { Department of } \\
\text { Tariff, Value, } \\
\text { and Origin; } \\
\text { CAM-A } \\
\text { Department of } \\
\text { Tariff, Value, } \\
\text { and Origin in } \\
\text { cooperation with } \\
\text { Audit } \\
\text { Department; } \\
\text { Regional } \\
\text { Branches; } \\
\text { Regional } \\
\text { Departments }\end{array}$ & \\
\hline 2 & $\begin{array}{l}\text { Ensuring } \\
\text { necessary } \\
\text { resources for } \\
\text { the facilitation } \\
\text { and acceleration } \\
\text { of the } \\
\text { operations, and } \\
\text { the increase of }\end{array}$ & $\begin{array}{l}\text { Making improvements in the infrastructure (constructions and } \\
\text { reconstructions), by the dates specified in the } 2003 \text { investment } \\
\text { plan. }\end{array}$ & $\begin{array}{l}\text { Report on } \\
\text { progress and } \\
\text { forecasting, for } \\
\text { works in } \\
2003, \text { should be } \\
\text { submitted on } \\
\text { 30.06; } 30.09, \& \\
31.12 .2003\end{array}$ & $\begin{array}{l}\text { Director of } \\
\text { Logistics } \\
\text { Department; } \\
\text { Finance } \\
\text { Department; } \\
\text { Deputy } \\
\text { Administrative } \\
\text { Director } \\
\end{array}$ & 60 million leks \\
\hline
\end{tabular}


ANNEX 2 PROGRAM OF PRIORITY ACTION PLAN 2003

\begin{tabular}{|c|c|c|c|c|c|}
\hline & $\begin{array}{l}\text { the } \\
\text { effectiveness }\end{array}$ & & & & \\
\hline 2.1 & & $\begin{array}{l}\text { Evaluation of the resources and equipment required for } 2003 \\
\text { and preparation of the relevant investment plan. }\end{array}$ & $31 / 1 / 2003$ & $\begin{array}{l}\text { Director of } \\
\text { Logistics } \\
\text { Department; } \\
\text { Finance } \\
\text { Department; } \\
\text { Deputy } \\
\text { Administrative } \\
\text { Director } \\
\end{array}$ & \\
\hline 2.2 & & $\begin{array}{l}\text { Control on good operation and good maintenance of the } \\
\text { communication system, the control systems, and the weighing } \\
\text { systems. Reporting and proposal of corrective measures. }\end{array}$ & $\begin{array}{l}\text { Continuing } \\
\text { during } 2003\end{array}$ & $\begin{array}{l}\text { Director of } \\
\text { Logistics } \\
\text { Department; } \\
\text { Finance } \\
\text { Department; } \\
\text { Deputy } \\
\text { Administrative } \\
\text { Director }\end{array}$ & 100 million leks \\
\hline 2.3 & & $\begin{array}{l}\text { In cooperation with CAM-A, the effectiveness and efficiency of } \\
\text { the policies, working methods and the procedures used by the } \\
\text { Logistics Department are revised. }\end{array}$ & $30 / 06 / 2003$ & $\begin{array}{l}\text { Director of } \\
\text { Logistics } \\
\text { Department; } \\
\text { Audit } \\
\text { Department ; } \\
\text { CAM-A }\end{array}$ & \\
\hline 4 & $\begin{array}{l}\text { Improvement of } \\
\text { the } \\
\text { management } \\
\text { and the greater } \\
\text { efficiency of the } \\
\text { Operational \& } \\
\text { Investigative } \\
\text { Department }\end{array}$ & $\begin{array}{l}\text { Restructuring of the Operational \& Investigative Department, in } \\
\text { particular, of the Information Department based on the } \\
\text { approved structure. }\end{array}$ & $31 / 01 / 2003$ & $\begin{array}{l}\text { Deputy } \\
\text { Administrative } \\
\text { Director; DOH } \\
\text { Director; } \\
\text { Personnel } \\
\text { Director }\end{array}$ & \\
\hline 5. & Implementation & Identification of the number and value of the cases of violations & Compilation of & GD; $\mathrm{DOH}$ & \\
\hline
\end{tabular}

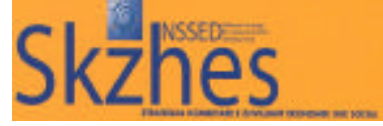


ANNEX 2 PROGRAM OF PRIORITY ACTION PLAN 2003

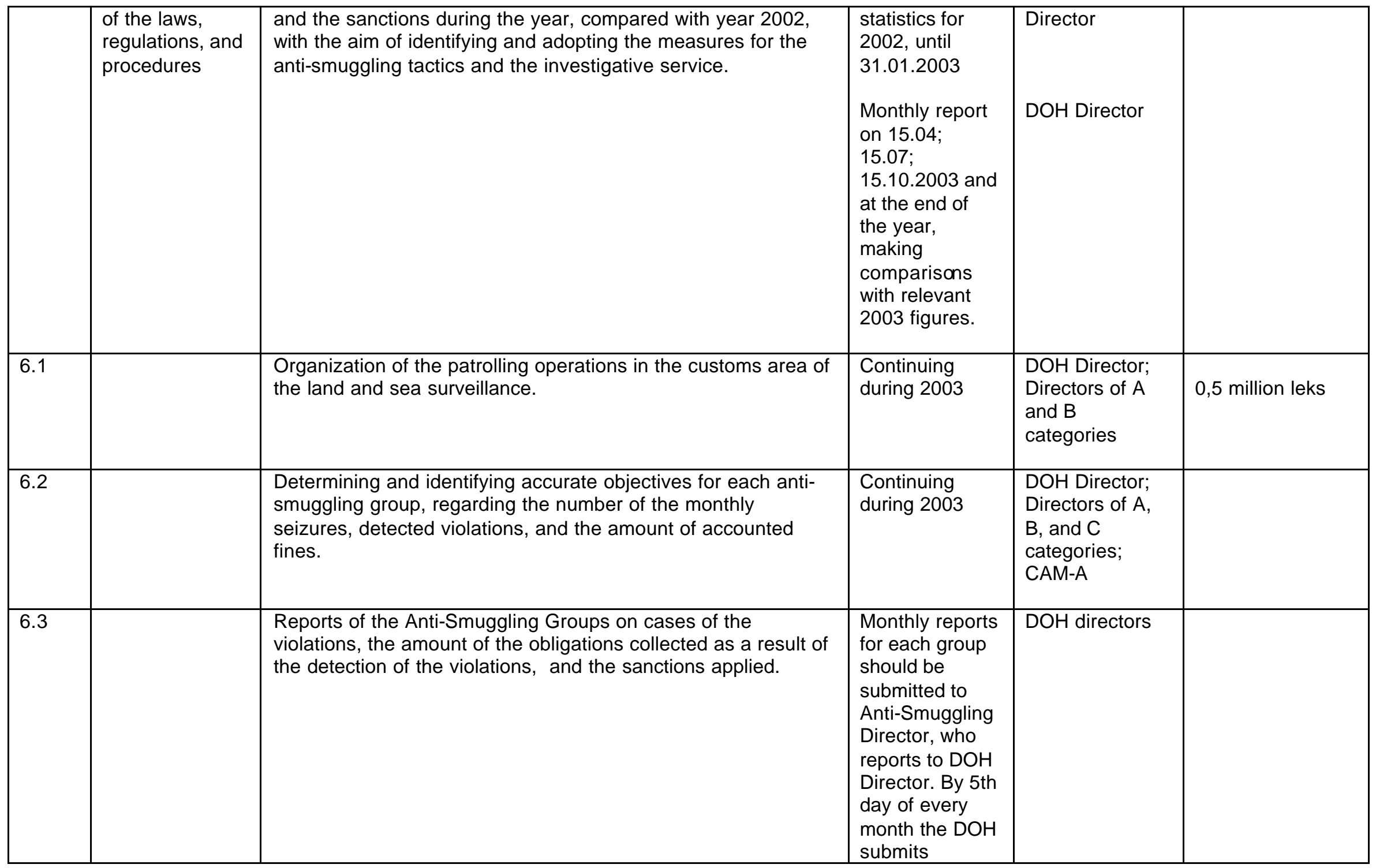


ANNEX 2 PROGRAM OF PRIORITY ACTION PLAN 2003

\begin{tabular}{|c|c|c|c|c|c|}
\hline & & & $\begin{array}{l}\text { monthly report } \\
\text { to the General } \\
\text { Director }\end{array}$ & & \\
\hline 6.4 & $\begin{array}{l}\text { Increase of the } \\
\text { efficiency of the } \\
\text { Naval Anti } \\
\text { Smuggling Unit }\end{array}$ & $\begin{array}{l}\text { The requests of the naval units for maintenance and logists are } \\
\text { fulfilled so that the boats are in a position to undertake effective } \\
\text { and efficient operational services. }\end{array}$ & $\begin{array}{l}\text { Continuing } \\
\text { during } 2003\end{array}$ & $\begin{array}{l}\text { Sea Anti- } \\
\text { Smuggling } \\
\text { Department } \\
\text { Anti-Smuggling } \\
\text { Department, } \\
\text { Finance } \\
\text { Department } \\
\text { Technical } \\
\text { Department } \\
\end{array}$ & 30 million leks \\
\hline 6.4 .1 & & $\begin{array}{l}\text { In cooperation with CAM-A, the effectiveness and efficiency of } \\
\text { the naval anti-smuggling Unit is revised. }\end{array}$ & $31 / 03 / 03$ & $\begin{array}{l}\text { Sea Anti- } \\
\text { Smuggling; } \\
\text { Department } \\
\text { Anti-Smuggling } \\
\text { Department; } \\
\text { Audit } \\
\text { Department; } \\
\text { CAM-A }\end{array}$ & \\
\hline 6.4 .2 & & $\begin{array}{l}\text { In cooperation with CAM-A, preparation of an operational plan } \\
\text { regarding management issues for the further development and } \\
\text { consolidation of the naval anti-smuggling unit. }\end{array}$ & $30 / 05 / 03$ & $\begin{array}{l}\text { Sea Anti- } \\
\text { Smuggling } \\
\text { Department; } \\
\text { Logistics } \\
\text { Department; } \\
\text { Anti-Smuggling } \\
\text { Department; } \\
\text { CAM-A }\end{array}$ & \\
\hline 6.4 .3 & & $\begin{array}{l}\text { In cooperation with CAM-A, the development and } \\
\text { implementation of a stable and professional training program } \\
\text { for the inspection of the navigable means and other transport } \\
\text { means on their board. }\end{array}$ & $30 / 05 / 03$ & $\begin{array}{l}\text { Sea Anti- } \\
\text { Smuggling } \\
\text { Department; } \\
\text { Personnel } \\
\text { Department; } \\
\text { Anti-Smuggling } \\
\text { Department; } \\
\text { CAM-A }\end{array}$ & \\
\hline
\end{tabular}


ANNEX 2 PROGRAM OF PRIORITY ACTION PLAN 2003

\begin{tabular}{|c|c|c|c|c|c|}
\hline $\begin{array}{l}6.4 .4 \\
6.4 .5\end{array}$ & & $\begin{array}{l}\text { Expansion and improvement of the cooperation with the port } \\
\text { authorities, police, and the naval groups of Guardia di Finanza. } \\
\text { Chief of the Naval Anti-Smuggling Unit will report, in written, to } \\
\text { the Anti-Smuggling Director on the monthly activity and the } \\
\text { results of this activity in terms of the number, kind, and value of } \\
\text { the detected customs violations, including the number of } \\
\text { sanctions applied. A report on the practical and statistical } \\
\text { efficiency of this unit is submitted once in two months to the } \\
\text { GD. }\end{array}$ & $\begin{array}{l}\text { Continuing } \\
\text { during } 2003 \\
\text { Monthly reports } \\
\text { no later than } \\
5 \text { th day of the } \\
\text { next month }\end{array}$ & $\begin{array}{l}\text { Sea Ant- } \\
\text { Smuggling } \\
\text { Department } \\
\text { Sea Ant- } \\
\text { Smuggling } \\
\text { Department; } \\
\text { Anti-Smuggling } \\
\text { Deprtment,; } \\
\text { DOH Director }\end{array}$ & \\
\hline 6.5 & $\begin{array}{l}\text { Establishment of } \\
\text { an effective } \\
\text { service for } \\
\text { Information and } \\
\text { Investigation }\end{array}$ & $\begin{array}{l}\text { In the framework of the Sector Strategies for the development } \\
\text { of the Customs Information service (which includes the } \\
\text { regulations for the flow of information, requests for information, } \\
\text { the information sources, the information format, the formal and } \\
\text { informal intellligence network etc.) and the Sector Strategy for } \\
\text { the development of the Customs Investigative service. They } \\
\text { should be in full accordance with the objectives of the 4-year } \\
\text { Modernization Strategy, which is in line with the relevant } \\
\text { standards for pre-accession to the EU (EU-Blueprints). }\end{array}$ & $\begin{array}{l}\text { Continuing } \\
\text { during } 2003\end{array}$ & $\begin{array}{l}\text { B \& A } \\
\text { information } \\
\text { categories; DOH } \\
\text { Director; } \\
\text { Judicial } \\
\text { Department; } \\
\text { Deputy } \\
\text { Technical } \\
\text { Director; CAM-A }\end{array}$ & $\begin{array}{l}\text { Foreign } \\
\text { assistence } \\
2 \text { millon leks }\end{array}$ \\
\hline 6.5 .1 & & $\begin{array}{l}\text { Preparation and application of the Regulations, which } \\
\text { guarantee the good functioning of the information network, the } \\
\text { protection of the secret, and the identification of procedures for } \\
\text { the renumeration of the informers. }\end{array}$ & $30 / 04 / 2003$ & $\begin{array}{l}\text { DOH; Judicial } \\
\text { Director; Deputy } \\
\text { Technical } \\
\text { Director; CAM-A }\end{array}$ & \\
\hline 6.5 .3 & & $\begin{array}{l}\text { Further development and the tangible improvement of the } \\
\text { efficiency of the Information Department regarding the volume } \\
\text { and increase of the information, and the ways for its } \\
\text { transmission. } \\
\text { Assistance in the examination of the methods for the collection } \\
\text { and dissimination of the information, advice and } \\
\text { recommendations on the strategic activity of ADSH in the field } \\
\text { of information. }\end{array}$ & $30 / 06 / 2003$ & CAM-A; DOH & \\
\hline
\end{tabular}


ANNEX 2 PROGRAM OF PRIORITY ACTION PLAN 2003

\begin{tabular}{|c|c|c|c|c|c|}
\hline $\begin{array}{l}6.5 .4 \\
6.5 .5\end{array}$ & & $\begin{array}{l}\text { Further development of the risk specification and risk analysis } \\
\text { techniques. } \\
\text { Development of the information structures for the facilitation of } \\
\text { their activity in the fight against trafficking, both in cases of } \\
\text { sensitive and prohibited goods. }\end{array}$ & $\begin{array}{l}30 / 06 / 2003 \\
\text { Continuing } \\
\text { during } 2003\end{array}$ & $\begin{array}{l}\text { CAM-A; DOH } \\
\text { CAM-A; DOH }\end{array}$ & \\
\hline 6.6 & $\begin{array}{l}\text { Strengthening of } \\
\text { the bilateral and } \\
\text { multilateral } \\
\text { cooperation in } \\
\text { the field of } \\
\text { information } \\
\text { exchange }\end{array}$ & $\begin{array}{l}\text { Expansion and application of the information exchange } \\
\text { systems built on international networks operating on basis of } \\
\text { the SEMS system. } \\
\text { Through the Coordinating Official in SECI Center, support for } \\
\text { the use of SEMS Evaluating Screen by the main trading } \\
\text { partners of the ADSH. }\end{array}$ & $\begin{array}{l}30 / 06 / 2003 \\
31 / 03 / 2003\end{array}$ & $\begin{array}{l}\text { DOH; CAM-A } \\
\\
\text { NenDrejtori } \\
\text { Teknik; DVOT; } \\
\text { DOH; CAM-A }\end{array}$ & 13 million leks \\
\hline 6.6 .1 & & $\begin{array}{l}\text { Adoption of measures for a more effective use of the program } \\
\text { on information exchange through RILO of OBD system and the } \\
\text { prepration of monthly reports for the GD on the effective use of } \\
\text { this system (statistics about the volume of exchanges plus } \\
\text { violations detected through the communication). Quarterly } \\
\text { summary report for DMJ on the use or problems posed by the } \\
\text { application of this channel of information. }\end{array}$ & $\begin{array}{l}\text { Process, which } \\
\text { will continue } \\
\text { during whole } \\
2003 \text {. } \\
\text { The monthly } \\
\text { report to GD } \\
\text { should be } \\
\text { submitted no } \\
\text { later than 10th } \\
\text { day of the next } \\
\text { month. The } \\
\text { quarterly report } \\
\text { for DMJ should } \\
\text { be submitted by } \\
\text { 15th day of the } \\
\text { month following } \\
\text { the end of the } \\
\text { quarter }\end{array}$ & $\begin{array}{l}\text { Deputy } \\
\text { Technical } \\
\text { Director; } \\
\text { Department of } \\
\text { Origin, Value, } \\
\text { and Tariff;; } \\
\text { DOH; }\end{array}$ & \\
\hline 6.6 .2 & & The Information Department, in cooperation with DMJ, ensure & Reports to GD & DOH, Deputy & \\
\hline
\end{tabular}




\begin{tabular}{|c|c|c|c|c|c|}
\hline & & $\begin{array}{l}\text { that the requests sent to the customs administrations of the } \\
\text { main trading partner countries, with which Albania has ratified } \\
\text { Agreements on Mutual Administrative Assistance in the Field of } \\
\text { Customs (Italy, Greece, Turkey \& Maceedonia), are in } \\
\text { conformity with the provisions of the agreements and the } \\
\text { principle of reciprocity. To this end the Information Department } \\
\text { will make use of the provisions of the bilateral agreements, the } \\
\text { RILO system and the Service of the Organization of the Fight } \\
\text { Against Customs Violations ((EU-OLAF), including SECI } \\
\text { Agreement on information exchange, and will report to the GD } \\
\text { about the level of the use of these channels of information. }\end{array}$ & $\begin{array}{l}\text { will be quartely } \\
\text { and be } \\
\text { submitted by } \\
5 \text { th day of the } \\
\text { month coming } \\
\text { after the period } \\
\text { covered by the } \\
\text { report }\end{array}$ & $\begin{array}{l}\text { Administrative } \\
\text { Director }\end{array}$ & \\
\hline 6.6.3 & & $\begin{array}{l}\text { Consolidation and increased efficiency of the only focal point } \\
\text { for the exchange of information, which has been set up in the } \\
\text { framework of SECl. }\end{array}$ & $\begin{array}{l}\text { Continuing } \\
\text { during } 2003\end{array}$ & $\begin{array}{l}\text { DOH; CAM-A, } \\
\text { Customs offices }\end{array}$ & \\
\hline 6.7 & $\begin{array}{l}\text { Greater } \\
\text { effectiveness of } \\
\text { the selective } \\
\text { customs } \\
\text { inspections } \\
\text { through the use } \\
\text { of SEMS as an } \\
\text { instrument for } \\
\text { the facilitation of } \\
\text { the generation } \\
\text { of intelligence } \\
\text { and risk analysis }\end{array}$ & $\begin{array}{l}\text { Continuous increase of the effectiveness in the use of SEMS to } \\
\text { ensure that the information of this system is used for the } \\
\text { purpose of carrying out selective customs inspections. }\end{array}$ & $\begin{array}{l}\text { Continuing } \\
\text { during } 2003\end{array}$ & $\begin{array}{l}\text { DOH; CAM-A, } \\
\text { Customs offices }\end{array}$ & 2 million leks \\
\hline 6.7 .1 & & $\begin{array}{l}\text { The DOH Director will prepare, for the General Director, } \\
\text { monthly reports on the effectiveness and the level of use of } \\
\text { SEMS for intelligencebased selective customs inspections. }\end{array}$ & $\begin{array}{l}\text { Continuing } \\
\text { during } 2003\end{array}$ & $\mathrm{DOH}$ & \\
\hline 6.8 & $\begin{array}{l}\text { Strengthening of } \\
\text { the cooperation } \\
\text { with the } \\
\text { institutions in }\end{array}$ & $\begin{array}{l}\text { Strengthening of the cooperation with the Public Order Ministry, } \\
\text { General Tax Department, SHISH, General Prosecution Office, } \\
\text { Court, etc. }\end{array}$ & $\begin{array}{l}\text { Continuing } \\
\text { during } 2003\end{array}$ & $\begin{array}{l}\text { GD } \\
\text { departments; } \\
\text { DOH; CAM-A }\end{array}$ & \\
\hline
\end{tabular}

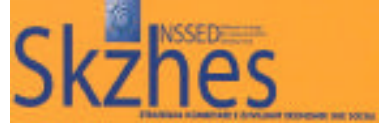


ANNEX 2 PROGRAM OF PRIORITY ACTION PLAN 2003

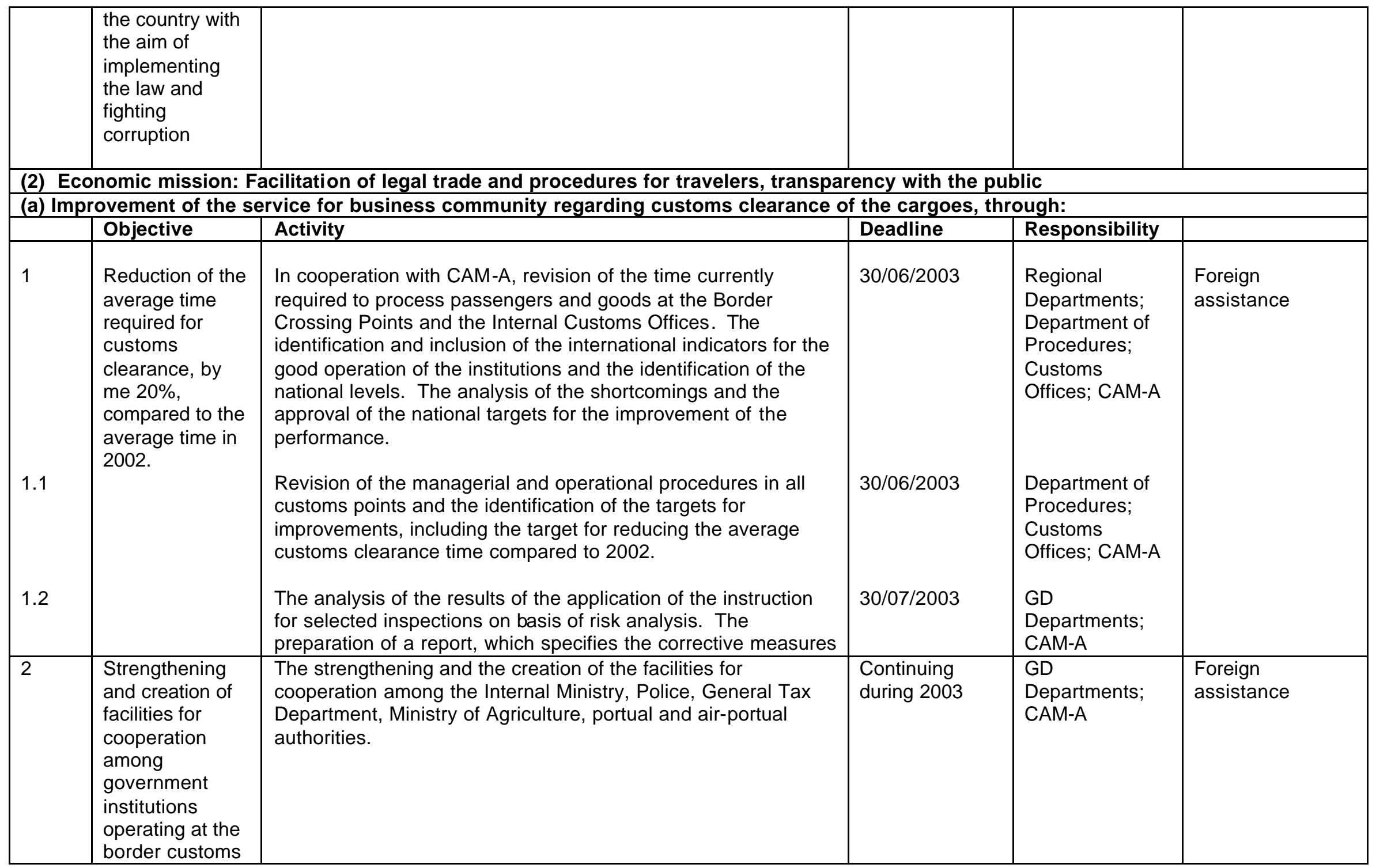


ANNEX 2 PROGRAM OF PRIORITY ACTION PLAN 2003

\begin{tabular}{|c|c|c|c|c|c|}
\hline & $\begin{array}{l}\text { points within the } \\
\text { country under } \\
\text { the umbrella of } \\
\text { the Integrated } \\
\text { Border } \\
\text { Management }\end{array}$ & & & & \\
\hline \multicolumn{6}{|c|}{ (b) Post-clearance inspections: More effective management of risks to revenues through: } \\
\hline 3 & $\begin{array}{l}\text { Expansion of } \\
\text { the concept of } \\
\text { post-clerance } \\
\text { inspections } \\
\text { accompanied } \\
\text { with the } \\
\text { clearance of the } \\
\text { declarations of } \\
\text { the trade goods }\end{array}$ & $\begin{array}{l}\text { With the assistance of CAM-A, establishment, training, and } \\
\text { development of external control groups charged with the } \\
\text { development and implementation of a post-clearance program } \\
\text { in the businesses' facilities to check whether they have } \\
\text { complied with the customs norms through financial and topical } \\
\text { control-audits based on specific systems for the inspection of } \\
\text { the international trade activity of the operators. }\end{array}$ & $30 / 04 / 2003$ & $\begin{array}{l}\text { Customs offices; } \\
\text { Regional } \\
\text { Offices; } \\
\text { Departmet of } \\
\text { Procedures; } \\
\text { Judicial } \\
\text { Department; } \\
\text { Training Unit; } \\
\text { CAM-A }\end{array}$ & \\
\hline 3.1 & & $\begin{array}{l}\text { With the assistance of CAM-A, the establishment of the Large } \\
\text { Trader Unit, the preference is to work in cooperation with the } \\
\text { General Tax Department, to focus the attention on the biggest } \\
\text { traders, who generate most of the customs revenus, and the } \\
\text { accomplishment of systematic financial inspections to ensure } \\
\text { full compliance with the customs procedures for the } \\
\text { international trade activities. }\end{array}$ & $30 / 04 / 2003$ & $\begin{array}{l}\text { Departmet of } \\
\text { Procedures; } \\
\text { Judicial } \\
\text { Department; } \\
\text { Training Unit; } \\
\text { CAM-A }\end{array}$ & \\
\hline 3.2 & & $\begin{array}{l}\text { The inclusion of the CAM-A advisors in the operational } \\
\text { investigative activities to provide practical training to the } \\
\text { customs investigators during the working process. }\end{array}$ & $\begin{array}{l}\text { Continuing } \\
\text { during } 2003\end{array}$ & $\begin{array}{l}\text { DOH } \\
\text { Judicial } \\
\text { Department; } \\
\text { CAM-A }\end{array}$ & \\
\hline 3.3 & $\begin{array}{l}\text { Increase of the } \\
\text { effectiveness of } \\
\text { the customs } \\
\text { inspections and } \\
\text { the } \\
\text { administration of }\end{array}$ & $\begin{array}{l}\text { Continued implementation of the inspection program for all } \\
\text { companies, which operate with the procedures of the active } \\
\text { processing and the customs warehouse. }\end{array}$ & $\begin{array}{l}\text { Monthly } \\
\text { revision of the } \\
\text { program (by } \\
\text { annual cycler) } \\
\text { continuing } \\
\text { during } 2003\end{array}$ & $\begin{array}{l}\text { Customs offices; } \\
\text { regional offices; } \\
\text { Department of } \\
\text { Procedures; } \\
\text { Judicial } \\
\text { Department; }\end{array}$ & \\
\hline
\end{tabular}


ANNEX 2 PROGRAM OF PRIORITY ACTION PLAN 2003

\begin{tabular}{|c|c|c|c|c|c|}
\hline 3.4 & $\begin{array}{l}\text { the economic } \\
\text { customs } \\
\text { procedures }\end{array}$ & $\begin{array}{l}\text { Revision of the existing regulations and the compilation of new } \\
\text { regulations for the uncovered sectors. }\end{array}$ & $\begin{array}{l}\text { Continuing } \\
\text { during } 2003\end{array}$ & $\begin{array}{l}\text { Deputy } \\
\text { Technical } \\
\text { Director }\end{array}$ & \\
\hline \multicolumn{6}{|c|}{ (c) Improvement of the service to travelers at entry/exist points, through: } \\
\hline 5.1 & $\begin{array}{l}\text { Reduction of the } \\
\text { waiting time at } \\
\text { the crossing } \\
\text { point, by } 20 \% \text { of } \\
\text { the average } \\
\text { time in } 2002\end{array}$ & $\begin{array}{l}\text { Establishment of the Working Groups for the application of the } \\
\text { Red-Green Channel Project in all border crossing points, where } \\
\text { it is appropriate. } \\
\text { Operational agreements with institutions, which operate at the } \\
\text { border crossing points for the application of the two passage } \\
\text { channel system (Red-Green) }\end{array}$ & $\begin{array}{l}28 / 03 / 2003 \\
30 / 04 / 2003\end{array}$ & $\begin{array}{l}\text { GD; Deputy } \\
\text { General } \\
\text { Directors; } \\
\text { Department of } \\
\text { Procedures, } \\
\text { Customs Offices } \\
\text { GD; Deputy } \\
\text { General } \\
\text { Directors; } \\
\text { Department of } \\
\text { Procedures, } \\
\text { Customs Offices }\end{array}$ & 1 million leks \\
\hline \multicolumn{6}{|c|}{ (d) Improvement of the management of resources and administration of the Customs Administration through } \\
\hline 6 & $\begin{array}{l}\text { Increase of the } \\
\text { effectiveness of } \\
\text { the Regional } \\
\text { Departments }\end{array}$ & $\begin{array}{l}\text { Restructuring of the Regional Departments, the identification } \\
\text { and delegation of responsibilities and competencies so that this } \\
\text { structure facilitates the communication among the customs } \\
\text { offices and the technical department at the center, becomes a } \\
\text { basis for the preliminary processing of information and a } \\
\text { structure, which checks the implementation of the operational } \\
\text { procedures. In particular: } \\
\text { Institutionalization of the regional responsibilities (including the } \\
\text { appeal provisions) for the technical specialization for the tariff } \\
\text { classification and the evaluation. The appeals against the }\end{array}$ & $30 / 04 / 2003$ & $\begin{array}{l}\text { GD } \\
\text { Departments; } \\
\text { CAM-A }\end{array}$ & 3 million leks \\
\hline
\end{tabular}

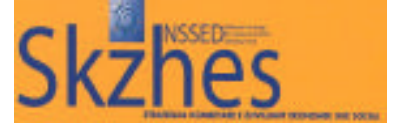


ANNEX 2 PROGRAM OF PRIORITY ACTION PLAN 2003

\begin{tabular}{|c|c|c|c|c|c|}
\hline & & $\begin{array}{l}\text { decisions made at a regional level are submitted to the customs } \\
\text { GD. } \\
\text { The institutionalization of the regional responsibilities for the } \\
\text { human resource management, including the changes in the } \\
\text { personnel / transfers within the region and the professional } \\
\text { qualification of the personnel within the region. }\end{array}$ & & & \\
\hline 7 & $\begin{array}{l}\text { Increased } \\
\text { efficiency of the } \\
\text { leading officials } \\
\text { through the } \\
\text { clear } \\
\text { identification of } \\
\text { the } \\
\text { responsibilities, } \\
\text { roles, and } \\
\text { competencies, } \\
\text { followed with } \\
\text { clear } \\
\text { competencies } \\
\text { regarding the } \\
\text { decentralization } \\
\text { of the decision- } \\
\text { making and the } \\
\text { delegation of the } \\
\text { competencies. }\end{array}$ & $\begin{array}{l}\text { Customs GD will analyze and identify the operational needs for } \\
\text { the division of responsabilities and competencies with the aim } \\
\text { of using the competencies for the implementation of the } \\
\text { management plans and the management of information for top } \\
\text { officials. }\end{array}$ & $30 / 04 / 2003$ & $\begin{array}{l}\text { GD; Deputy } \\
\text { Directors; CAM- } \\
\text { A }\end{array}$ & \\
\hline 8 & $\begin{array}{l}\text { Implementation } \\
\text { of a } \\
\text { computerized } \\
\text { system for the } \\
\text { processing of } \\
\text { the customs } \\
\text { declarations. }\end{array}$ & $\begin{array}{l}\text { Application of the ASYCUDA++ prototype for Albania, including } \\
\text { the requirements of the local language. }\end{array}$ & until31/03/2003 & $\begin{array}{l}\text { Project } \\
\text { Manager; } \\
\text { UNCTAD; CAM- } \\
\text { A }\end{array}$ & $\begin{array}{l}\text { Foreign financing } \\
\text { EUE+ } \\
\text { World Bank } \\
\text { In TTFSE } \\
\text { framework }\end{array}$ \\
\hline 8.1 & & $\begin{array}{l}\text { Comparative testing of the prototype to chech whether it fulfills } \\
\text { the requirements of the DPD. }\end{array}$ & $\begin{array}{l}\text { Until } \\
30 / 04 / 2003\end{array}$ & $\begin{array}{l}\text { Deputy } \\
\text { Administrative }\end{array}$ & \\
\hline
\end{tabular}

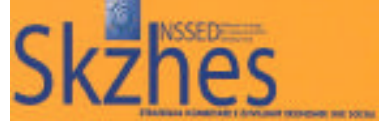


ANNEX 2 PROGRAM OF PRIORITY ACTION PLAN 2003

\begin{tabular}{|c|c|c|c|c|c|}
\hline & & & & $\begin{array}{l}\text { Director; Project } \\
\text { Manager; } \\
\text { UNCTAD } \\
\text { CAM-A }\end{array}$ & \\
\hline 8.2 & & $\begin{array}{l}\text { Modification of the prototype on the basis of the approved } \\
\text { request. }\end{array}$ & $\begin{array}{l}\text { Until } \\
31 / 05 / 2003\end{array}$ & $\begin{array}{l}\text { Deputy } \\
\text { Administrative } \\
\text { Director; Project } \\
\text { Manager; } \\
\text { UNCTAD } \\
\text { CAM-A }\end{array}$ & \\
\hline 8.3 & & $\begin{array}{l}\text { Application and testing, as a pilot project, of ASYCUDA++ } \\
\text { system and the relevant operational procedures in Tirana } \\
\text { interior customs office. }\end{array}$ & $\begin{array}{l}\text { Until } \\
\text { 30/06/2003 } \\
\text { completion } \\
31 / 08 / 2003\end{array}$ & $\begin{array}{l}\text { Deputy } \\
\text { Administrative } \\
\text { Director; Project } \\
\text { Manager; } \\
\text { UNCTAD } \\
\text { CAM-A }\end{array}$ & \\
\hline 8.5 & & $\begin{array}{l}\text { Application and testing, as a pilot project, of ASYCUDA++ } \\
\text { system and the relevant operational procedures in the other } \\
\text { approved pilot points. } \\
\text { Beginning to extend the system to the main customs points. }\end{array}$ & $\begin{array}{l}\text { Until } \\
\text { 07/09/2003 } \\
\text { completion } \\
\text { 01/12/2003 } \\
\\
\text { 01/02/2004 }\end{array}$ & $\begin{array}{l}\text { Deputy } \\
\text { Administrative } \\
\text { Director; Project } \\
\text { Manager; } \\
\text { UNCTAD } \\
\text { CAM-A } \\
\\
\text { Deputy } \\
\text { Administrative } \\
\text { Director; Project } \\
\text { Manager; } \\
\text { UNCTAD } \\
\text { CAM-A }\end{array}$ & 3 million leks \\
\hline \multicolumn{6}{|c|}{ (e) Public Relations } \\
\hline & Objective & Activity & Deadline & Responsibility & \\
\hline 9 & Increased & Further intensification of the relations with the public, the & Continuing & Public Relations & \\
\hline
\end{tabular}


ANNEX 2 PROGRAM OF PRIORITY ACTION PLAN 2003

\begin{tabular}{|c|c|c|c|c|c|}
\hline & $\begin{array}{l}\text { transparency } \\
\text { and information } \\
\text { of the public and } \\
\text { the business } \\
\text { community }\end{array}$ & $\begin{array}{l}\text { publication and periodical propagation of the customs } \\
\text { legislation, the publication and distribution of the practical } \\
\text { guides to help the passengers and the economic operators to } \\
\text { act in conformity with the customs provisions. }\end{array}$ & during 2003 & $\begin{array}{l}\text { Chief. Logistics } \\
\text { Department, } \\
\text { Finance } \\
\text { Department }\end{array}$ & 0,5 million leks \\
\hline 9.1 .1 & & $\begin{array}{l}\text { In the framework of the partnership with the business, the } \\
\text { updating of an active plan for the organization of roundtable } \\
\text { meetings with the business to give information and collect } \\
\text { suggestions and opinions about operational issues. In } \\
\text { particular, this method should be used to inform the business } \\
\text { community about the ASYCUDA++ system. }\end{array}$ & $\begin{array}{l}\text { Continuing } \\
\text { during } 2003\end{array}$ & $\begin{array}{l}\text { Public Relations } \\
\text { Chief; GD } \\
\text { Departments; } \\
\text { Project Manager } \\
\text { ASYCUDA; } \\
\text { CAM-A }\end{array}$ & \\
\hline 9.1 .2 & & $\begin{array}{l}\text { Providing information, with transparency, to the mass media } \\
\text { and the public about the activity of the Customs Administration, } \\
\text { the organization of regular press conferences }\end{array}$ & $\begin{array}{l}\text { Continuing } \\
\text { during } 2003\end{array}$ & $\begin{array}{l}\text { Public Relations } \\
\text { Chief }\end{array}$ & 1 million leks \\
\hline 9.1 .3 & & $\begin{array}{l}\text { The establishmet of informative corners at every customs office } \\
\text { with leaflets and posters to help the passengers and the } \\
\text { economic operators. }\end{array}$ & $\begin{array}{l}\text { Continuing } \\
\text { during } 2003\end{array}$ & $\begin{array}{l}\text { Public Relations } \\
\text { Chief; GD } \\
\text { Departments; } \\
\text { Finance } \\
\text { Department; } \\
\text { CAM-A }\end{array}$ & 0,3 million leks \\
\hline 9.2 & & $\begin{array}{l}\text { The development of a strategy for launching and updating an } \\
\text { effective www Customs Web Site on the internet to provide } \\
\text { information to the broad public }\end{array}$ & $31 / 12 / 2003$ & $\begin{array}{l}\text { Computerization } \\
\text { Deparrtment; } \\
\text { Public Relations } \\
\text { Unit; GD } \\
\text { Departments; } \\
\text { Finance } \\
\text { Department; } \\
\text { CAM-A }\end{array}$ & \\
\hline \multicolumn{6}{|c|}{ (3) Protective mission: Protection of society } \\
\hline \multicolumn{6}{|c|}{ Introduction of bans and restrictions on import/exports and transits, through: } \\
\hline 1 & $\begin{array}{l}\text { Interception or } \\
\text { sequestration of } \\
\text { the suspicious }\end{array}$ & $\begin{array}{l}\text { The number, kind, tendency, and values of the seized or } \\
\text { sequestrated cargoes, as well as the blockages and seizures of } \\
\text { transported goods should be determined. }\end{array}$ & $31 / 01 / 2003$ & $\overline{\mathrm{DOH}}$. & \\
\hline
\end{tabular}


ANNEX 2 PROGRAM OF PRIORITY ACTION PLAN 2003

\begin{tabular}{|c|c|c|c|c|c|}
\hline \multirow{3}{*}{1.1} & cargoes & & & & \\
\hline & $\begin{array}{l}\text { Fight against the } \\
\text { drug trafficking } \\
\text { and those } \\
\text { involved in it }\end{array}$ & $\begin{array}{l}\text { Enhanced integration of the anti-drug group in the customs into } \\
\text { the anti-smuggling operational groups for a more effective } \\
\text { organization in the fight against the drug traffic and the people } \\
\text { involved in it. }\end{array}$ & $31 / 3 / 2003$ & $\mathrm{DOH}$ & 0,5 million leks \\
\hline & & $\begin{array}{l}\text { Implementation of the Memorandum on Understanding on } \\
\text { bilateral assistance in the fight against the drug traffic and the } \\
\text { people involved in it }\end{array}$ & $\begin{array}{l}\text { Continuing } \\
\text { during } / 2003\end{array}$ & $\mathrm{DOH}$ & \\
\hline 1.2 & & $\begin{array}{l}\text { The strengthening of cooperation with the structures of the } \\
\text { Public Order Ministry, the Prosecution Office, SHISH, and the } \\
\text { RILO (ZKA) Offices of the World Customs Organization and } \\
\text { database should be established for the identification of the } \\
\text { trends and risk analysis .| }\end{array}$ & $31 / 03 / 2003$ & $\mathrm{DOH}$ & \\
\hline 1.4 & $\begin{array}{l}\text { Fight against } \\
\text { traffic of arms, } \\
\text { ammunition, } \\
\text { including goods } \\
\text { with double use, } \\
\text { and the traffic of } \\
\text { stolen cars }\end{array}$ & $\begin{array}{l}\text { Coordination of the cooperation with the specialized structures } \\
\text { (Public Order Ministry, Defense Ministry, SHISH, etc.) with the } \\
\text { aim of stepping up the fight against such trafficking activities. }\end{array}$ & $\begin{array}{l}\text { Continuing } \\
\text { during } 2003\end{array}$ & $\begin{array}{l}\text { DOH, GD } \\
\text { Departments; } \\
\text { CAM-A } \\
\\
\text { DOH, GD } \\
\text { Departments; } \\
\text { CAM-A }\end{array}$ & $\begin{array}{l}\text { Foreign } \\
\text { assistance }\end{array}$ \\
\hline 2 & $\begin{array}{l}\text { Sanctions for } \\
\text { violations and } \\
\text { penalizations } \\
\text { (criminal } \\
\text { prosecution) of } \\
\text { the offenders }\end{array}$ & $\begin{array}{l}\text { Determining the number of sanctions and criminally prosecuted } \\
\text { offenders during } 2002 \text {. }\end{array}$ & $31 / 01 / 2003$ & $\mathrm{DOH}$ & \\
\hline 2.1 & & $\begin{array}{l}\text { Determining the targets for } 2003 \text { and periodical reporting on the } \\
\text { sanctions and penalizations (filing of criminal charges) }\end{array}$ & $\begin{array}{l}\text { Quarterly } \\
\text { reports }\end{array}$ & $\mathrm{DOH}$ & \\
\hline
\end{tabular}

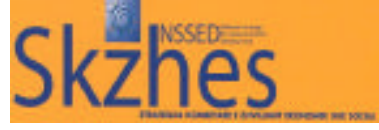


ANNEX 2 PROGRAM OF PRIORITY ACTION PLAN 2003

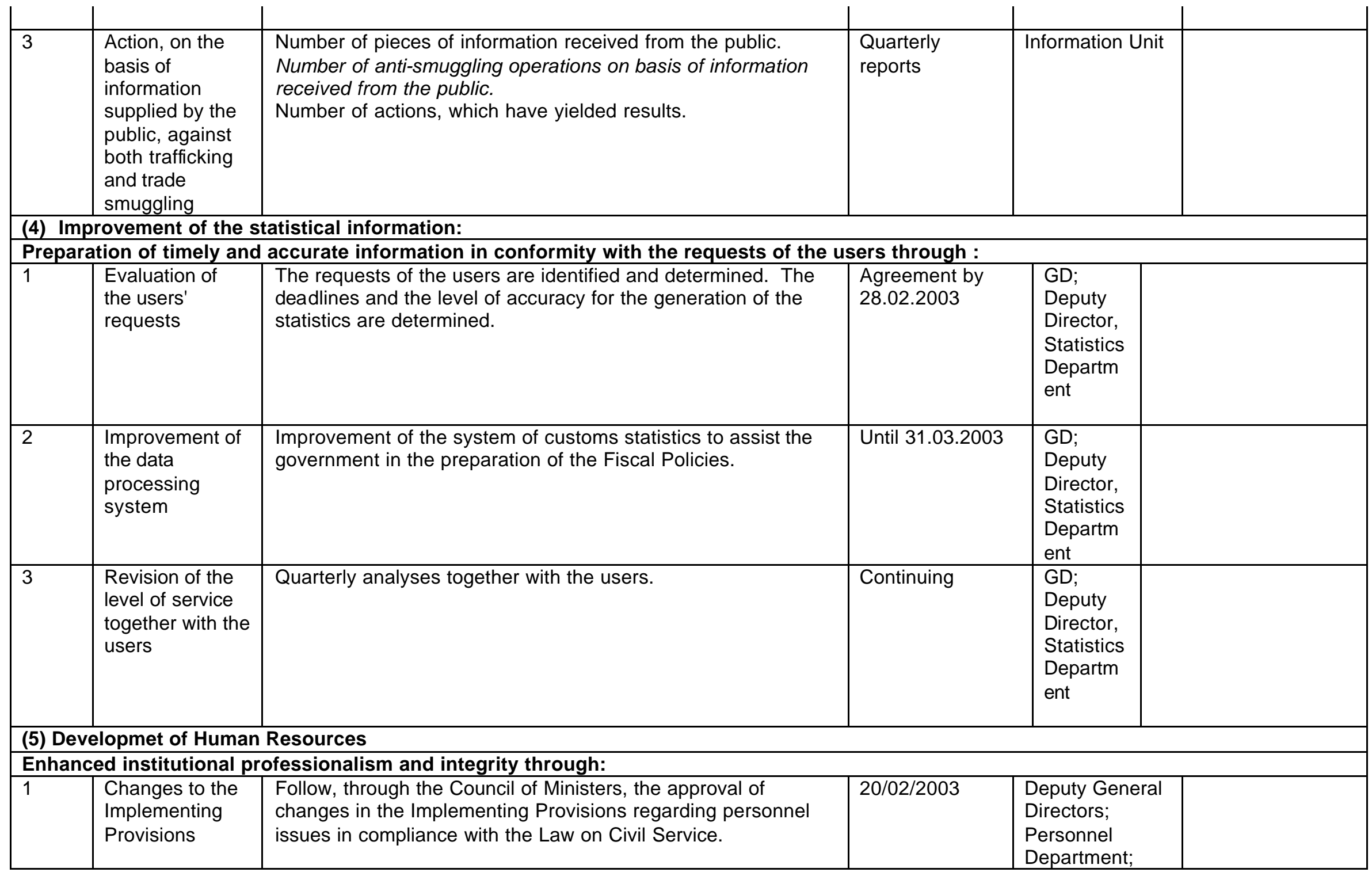


ANNEX 2 PROGRAM OF PRIORITY ACTION PLAN 2003

\begin{tabular}{|c|c|c|c|c|}
\hline & & & & $\begin{array}{l}\text { Judicial } \\
\text { Department }\end{array}$ \\
\hline 1.1 & $\begin{array}{l}\text { Evaluation of } \\
\text { the Personnel }\end{array}$ & $\begin{array}{l}\text { In cooperation with CAM-A and operational directors, the } \\
\text { development and documentation of the job evaluation for all } \\
\text { operational posts in the customs. The revision of this activity } \\
\text { with the aim of introducing a common national standard for } \\
\text { similar posts. }\end{array}$ & $\begin{array}{l}\text { Initial project } \\
30 / 04 / 2002 \\
\text { Revision of the } \\
\text { national } \\
\text { standards } \\
15 / 06 / 2003\end{array}$ & $\begin{array}{l}\text { Deputy } \\
\text { Administrative } \\
\text { Director; } \\
\text { Personnel Chief; } \\
\text { Judicial } \\
\text { Department, } \\
\text { CAM-A }\end{array}$ \\
\hline 1.1 & & $\begin{array}{l}\text { Ensuring that the annual evaluation reports are completed in } \\
\text { compliance with the system, for all the employees. }\end{array}$ & $\begin{array}{l}31 / 05 / 2003 \\
\text { Quarterly } \\
\text { reports no later } \\
\text { than } 20 \text { days } \\
\text { after payment } \\
\text { of bonuses }\end{array}$ & $\begin{array}{l}\text { Deputy } \\
\text { Administrative } \\
\text { Director; } \\
\text { Personnel Chief }\end{array}$ \\
\hline 2.1 & $\begin{array}{l}\text { Strengthening of } \\
\text { the internal } \\
\text { discipline and } \\
\text { fight against } \\
\text { corruption }\end{array}$ & $\begin{array}{l}\text { Identification of the number of disciplinary violations during the } \\
\text { year and comparison with } 2001 \text { to identify the phenomena and } \\
\text { approve the corrective measures (legal, organizational, } \\
\text { structural) }\end{array}$ & $\begin{array}{l}\text { Compilation of } \\
\text { statistics for } \\
2002 \text { until } \\
31 / 01 / 2003 \\
\text { Quarterly report } \\
\text { until } 15.04 ; \\
15.07 ; \\
15 / 10 / 2003 \text { and } \\
\text { at the end of } \\
\text { the year } \\
\text { compared with } \\
2002\end{array}$ & $\begin{array}{l}\text { Personnel } \\
\text { Department } \\
\text { Personnel } \\
\text { Department }\end{array}$ \\
\hline 2.2 & & $\begin{array}{l}\text { In cooperation with CAM-A, revision and strengthening of the } \\
\text { personnel recruitment process to achieve the development of } \\
\text { the ADSH as an organization with a high reputation and } \\
\text { integrity. }\end{array}$ & $31 / 03 / 2003$ & $\begin{array}{l}\text { Deputy } \\
\text { Administrative } \\
\text { Director; } \\
\text { Personnel } \\
\text { Department; } \\
\text { CAM-A }\end{array}$ \\
\hline
\end{tabular}


ANNEX 2 PROGRAM OF PRIORITY ACTION PLAN 2003

\begin{tabular}{|c|c|c|c|c|c|}
\hline 2.3 & & $\begin{array}{l}\text { Support for and monitoring of the Commission for the } \\
\text { Verification of the Assets of the Customs Personnel as an } \\
\text { integral part of the Anti Corruption Plan of the Albanian } \\
\text { Government. }\end{array}$ & $\begin{array}{l}\text { Continuing } \\
\text { during } 2003\end{array}$ & $\begin{array}{l}\text { Deputy } \\
\text { Administrative } \\
\text { Director; } \\
\text { Personnel } \\
\text { Department; } \\
\text { CAM-A }\end{array}$ & \\
\hline 3 & $\begin{array}{l}\text { Measures for } \\
\text { the motivation of } \\
\text { the personnel }\end{array}$ & $\begin{array}{l}\text { In cooperation with CAM-A, revision and auditing of the } \\
\text { schemes for rewards and bonuses during the 2002-2003 } \\
\text { period. }\end{array}$ & $31 / 05 / 2003$ & $\begin{array}{l}\text { Audit } \\
\text { Department; } \\
\text { Personnel Chief; } \\
\text { CAM-A }\end{array}$ & 205 million leks \\
\hline 4 & $\begin{array}{l}\text { Presentation of } \\
\text { a stable } \\
\text { structure for the } \\
\text { professional } \\
\text { qualification of } \\
\text { the customs } \\
\text { personnel in all } \\
\text { the country }\end{array}$ & $\begin{array}{l}\text { In cooperation with CAM-A, revision and issuance of } \\
\text { recommendations for significant changes in the mechanism for } \\
\text { the training of the personnel in the customs with the aim of } \\
\text { creating a long-term stable and professional environment by } \\
\text { using adequate policies, procedures, resources, and means. }\end{array}$ & $\begin{array}{l}30 / 03 / 2003 \text { and } \\
\text { continuing } \\
\text { during } 2003\end{array}$ & $\begin{array}{l}\text { Personnel } \\
\text { Department } \\
\text { Finance } \\
\text { Department; } \\
\text { CAM-A }\end{array}$ & \\
\hline 5 & $\begin{array}{l}\text { Giving } \\
\text { guarantees that } \\
\text { the personnel } \\
\text { has received the } \\
\text { right training, in } \\
\text { the right place } \\
\text { and at the right } \\
\text { time }\end{array}$ & $\begin{array}{l}\text { Based on a training strategy for the ADSh and with the support } \\
\text { of foreign experts, when it is necessary, the preparation of a } \\
\text { national training plan with a long-term, sustainable, and } \\
\text { professional program, which covers all customs issues. The } \\
\text { development of a Training Resource Plan and a relevant } \\
\text { analysis of shortcomings. Identification of the national needs } \\
\text { for the training infrastructure. }\end{array}$ & $31 / 03 / 2003$ & $\begin{array}{l}\text { Personnel } \\
\text { Department } \\
\text { CAM-A }\end{array}$ & 1 million leks \\
\hline 5.1 & & $\begin{array}{l}\text { Planning of the needs for training and continuous training } \\
\text { courses for the ADSh directors with the aim of increasing } \\
\text { overall efficiency of the directors, in particular in sectors of: } \\
\text { Strategic planning and use of indicators for the performance of } \\
\text { the institution and the relevant analyses of the phenomena; } \\
\text { Analysis of the job place }\end{array}$ & $31 / 03 / 2003$ & $\begin{array}{l}\text { Training Unit; } \\
\text { CAM-A }\end{array}$ & \\
\hline
\end{tabular}




\begin{tabular}{|c|c|c|c|}
\hline 5.1 .2 & $\begin{array}{l}\text { The analysis of the needs for the training of the personnel in } \\
\text { the field of the implementation of TIR convention, and the } \\
\text { implementation of an effective training program for the } \\
\text { enhancement of the professional skills in this field. } \\
\text { In cooperation with CAM-A, the initiation of a national } \\
\text { sustainable training program for the qualification of the customs } \\
\text { personnel in the practical application of the regulations of } \\
\text { origin, with the emphasis laid, in particular, on the frauds, } \\
\text { which might encountered at present or in the future, as a result } \\
\text { of the implementation of the government's agreements on free } \\
\text { trade. }\end{array}$ & $\begin{array}{l}30 / 03 / 2003 \text { and } \\
\text { continuing } \\
\text { during } 2003 \\
28 / 02 / 2003 \text { and } \\
\text { continuing } \\
\text { during } 2003\end{array}$ & $\begin{array}{l}\text { Judicial } \\
\text { Department; } \\
\text { Personnel } \\
\text { Department } \\
\text { Unit of Value } \\
\text { and Origin; } \\
\text { Training Unit; } \\
\text { CAM-A }\end{array}$ \\
\hline 5.2 & $\begin{array}{l}\text { The development of the professional skills of the internal audit } \\
\text { inspectors. } \\
\text { In compliance with the IMF memorandum, the establishment of } \\
\text { the Post-Clearance Inspection Unit. The analysis of the needs } \\
\text { for training and the development of the professional training for } \\
\text { the personnel engaged in post-clearance inspections. }\end{array}$ & $\begin{array}{l}\text { Continuing } \\
\text { during } 2003 \\
\text { June and } \\
\text { continuing } \\
\text { during } 2003\end{array}$ & $\begin{array}{l}\text { Training Unit; } \\
\text { Internal Audit } \\
\text { Department; } \\
\text { Customs } \\
\text { Offices; CAM-A } \\
\text { Personnel } \\
\text { Department } \\
\text { Regional } \\
\text { Departments; } \\
\text { Customs } \\
\text { Offices, CAM-A }\end{array}$ \\
\hline 5.4 & $\begin{array}{l}\text { In cooperation with CAM-A, the analysis of the needs for } \\
\text { training for the personnel of the Information Department. }\end{array}$ & $31 / 03 / 2003$ & $\begin{array}{l}\text { Training Unit; } \\
\text { DOH } \\
\text { CAM-A }\end{array}$ \\
\hline 5.5 & $\begin{array}{l}\text { Expansion of the knowledge of the Anti-Smuggling Groups in } \\
\text { the field of the customs violations, including the wrong } \\
\text { description of the goods, the frauds with the regulations of the } \\
\text { origin and wrong tariff classification. }\end{array}$ & $\begin{array}{l}\text { Continuing } \\
\text { during } 2003\end{array}$ & $\begin{array}{l}\text { DOH, Personnel } \\
\text { Department; } \\
\text { CAM-A }\end{array}$ \\
\hline 6. & $\begin{array}{l}\text { Organization and completion of the practical training for the } \\
\text { specialists of the Information Department. The identification of } \\
\text { the Resources, and the development of training for the } \\
\text { specialists of the information analysis, in the use of the } \\
\text { ANACAPA information methodology. }\end{array}$ & $30 / 04 / 2003$ & $\begin{array}{l}\text { DOH; Training } \\
\text { Unit; } \\
\text { CAM-A }\end{array}$ \\
\hline 7.1 & $\begin{array}{l}\text { Updating and implementation of a detailed training program for } \\
\text { the management and risk analysis, in particular, emphasizing }\end{array}$ & $31 / 03 / 2003$ & $\begin{array}{l}\text { Training Unit; } \\
\text { UNCTAD; }\end{array}$ \\
\hline
\end{tabular}


ANNEX 2 PROGRAM OF PRIORITY ACTION PLAN 2003

\begin{tabular}{|c|c|c|c|c|}
\hline & & $\begin{array}{l}\text { its interaction with the Selectivity Module of ASYCUDA++ } \\
\text { system. }\end{array}$ & & CAM-A \\
\hline 7.2 & & $\begin{array}{l}\text { Development and implementation of a detailed training } \\
\text { program, which covers all the functions of ASYCUDA++ } \\
\text { system, including the training to increase the overall awareness } \\
\text { of the personnel and the business community. }\end{array}$ & $31 / 07 / 2002$ & $\begin{array}{l}\text { Deputy } \\
\text { Administrative } \\
\text { Director; Project } \\
\text { Manager; CAM- } \\
\text { A; Training Unit; }\end{array}$ \\
\hline 8 & & $\begin{array}{l}\text { Analyzing the needs for training in the field of banned and } \\
\text { restricted goods. The preparation of a training program, the } \\
\text { identification of the requests for resources, and the } \\
\text { implementation of training. }\end{array}$ & $31 / 03 / 2003$ & $\begin{array}{l}\text { DOH; Training } \\
\text { Unit; CAM-A, } \\
\text { Foreign } \\
\text { Relations } \\
\text { Department }\end{array}$ \\
\hline $\begin{array}{l}8.1 \\
8.2\end{array}$ & & $\begin{array}{l}\text { The development and implementation of a sustainable training } \\
\text { program regarding issues of the fight against the traffic of } \\
\text { narcotic substances and the people involved in it. } \\
\text { With the assistance of CAM-A, the development and } \\
\text { implementation of a sustainable training program related to } \\
\text { issues of the fight against illegal traffic of arms, amunition, } \\
\text { goods with double use, and stolen cars. }\end{array}$ & $\begin{array}{l}\text { Continuing } \\
\text { during } 2003 \\
\text { Continuing } \\
\text { during } 2003\end{array}$ & $\begin{array}{l}\text { DOH; Training } \\
\text { Unit; CAM-A } \\
\text { DOH; Training } \\
\text { Unit; CAM-A }\end{array}$ \\
\hline 9 & $\begin{array}{l}\text { Ensuring that } \\
\text { the foreign } \\
\text { resources, } \\
\text { mainly the } \\
\text { assistance in } \\
\text { the framework } \\
\text { of CAM-A, are } \\
\text { used effectively }\end{array}$ & $\begin{array}{l}\text { In compliance with the MoU of the cooperation with CAM-A, } \\
\text { GCD will agree with the Mission on the general and specific } \\
\text { directions of the assistance for the implementation of this } \\
\text { Operational Plan. Thus, CAM-A Mission will present to the } \\
\text { GCD the Reference Terms for Assistance for the } \\
\text { Implementation of } 2003 \text { Operational Plan. }\end{array}$ & $28 / 02 / 2003$ & $\begin{array}{l}\text { Deputy General } \\
\text { Directors; } \\
\text { CAM-A }\end{array}$ \\
\hline 10 & $\begin{array}{l}\text { Monitoring of } \\
\text { the } \\
\text { implementation } \\
\text { of } 2003 \\
\text { Operational } \\
\text { Plan }\end{array}$ & $\begin{array}{l}\text { Following the implementation of the procedures for the } \\
\text { establishment of a system ensuring good administration, the } \\
\text { Internal Audit will monitor the timely and qualitiative } \\
\text { implementation of this Plan and will report to the General } \\
\text { Director on the obstacles or measures, which should be taken } \\
\text { to improve the situation }\end{array}$ & $\begin{array}{l}\text { Continuing } \\
\text { during } 2003\end{array}$ & $\begin{array}{l}\text { Internal Audit } \\
\text { Department }\end{array}$ \\
\hline
\end{tabular}


ANNEX 2 PROGRAM OF PRIORITY ACTION PLAN 2003

TABLE 4: MINISTRY OF ENVIRONMENT

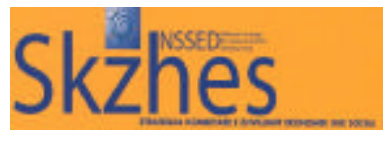


ANNEX 2 PROGRAM OF PRIORITY ACTION PLAN 2003

TABLE 4: MINISTRY OF ENVIRONMENT

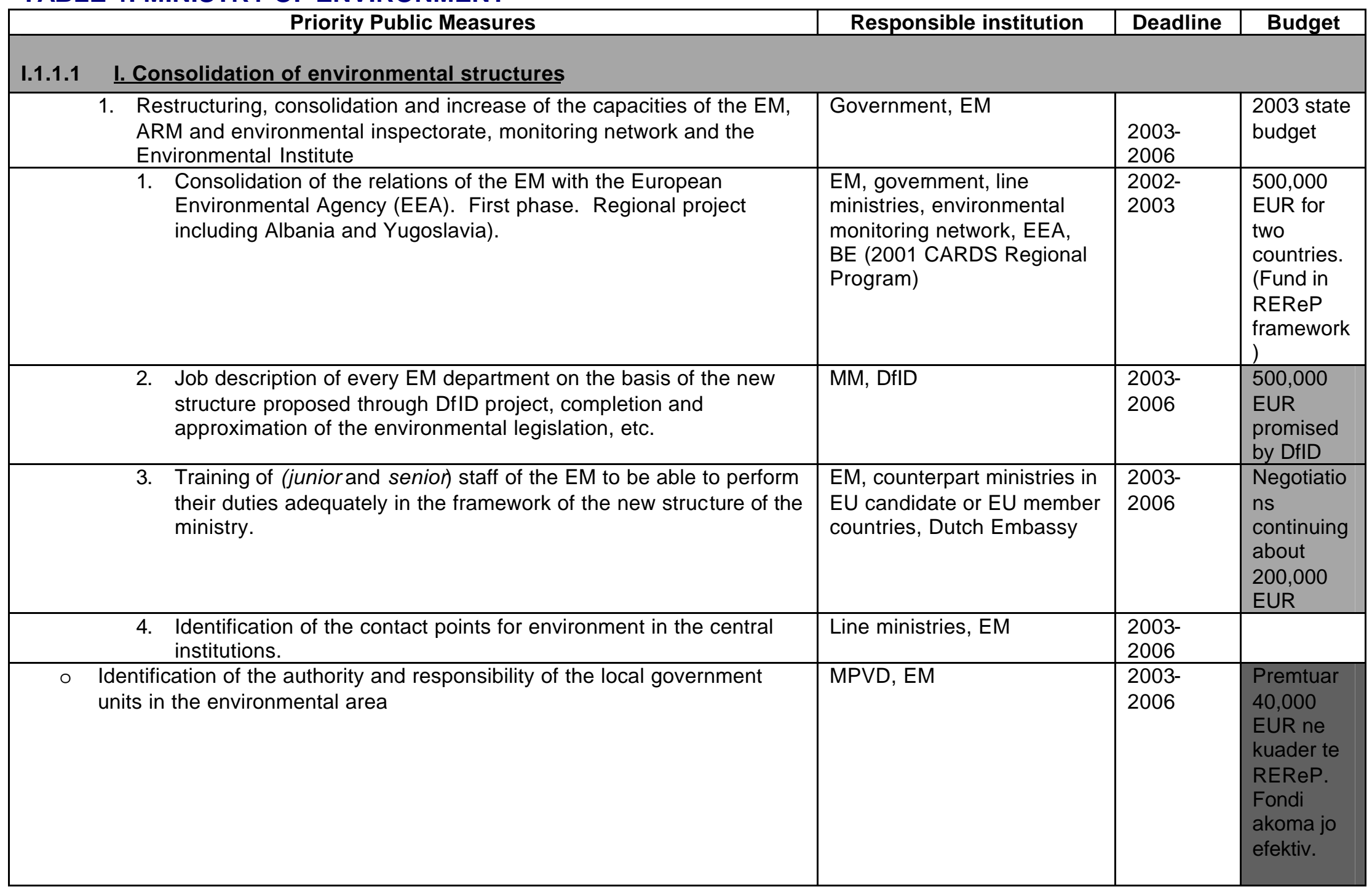




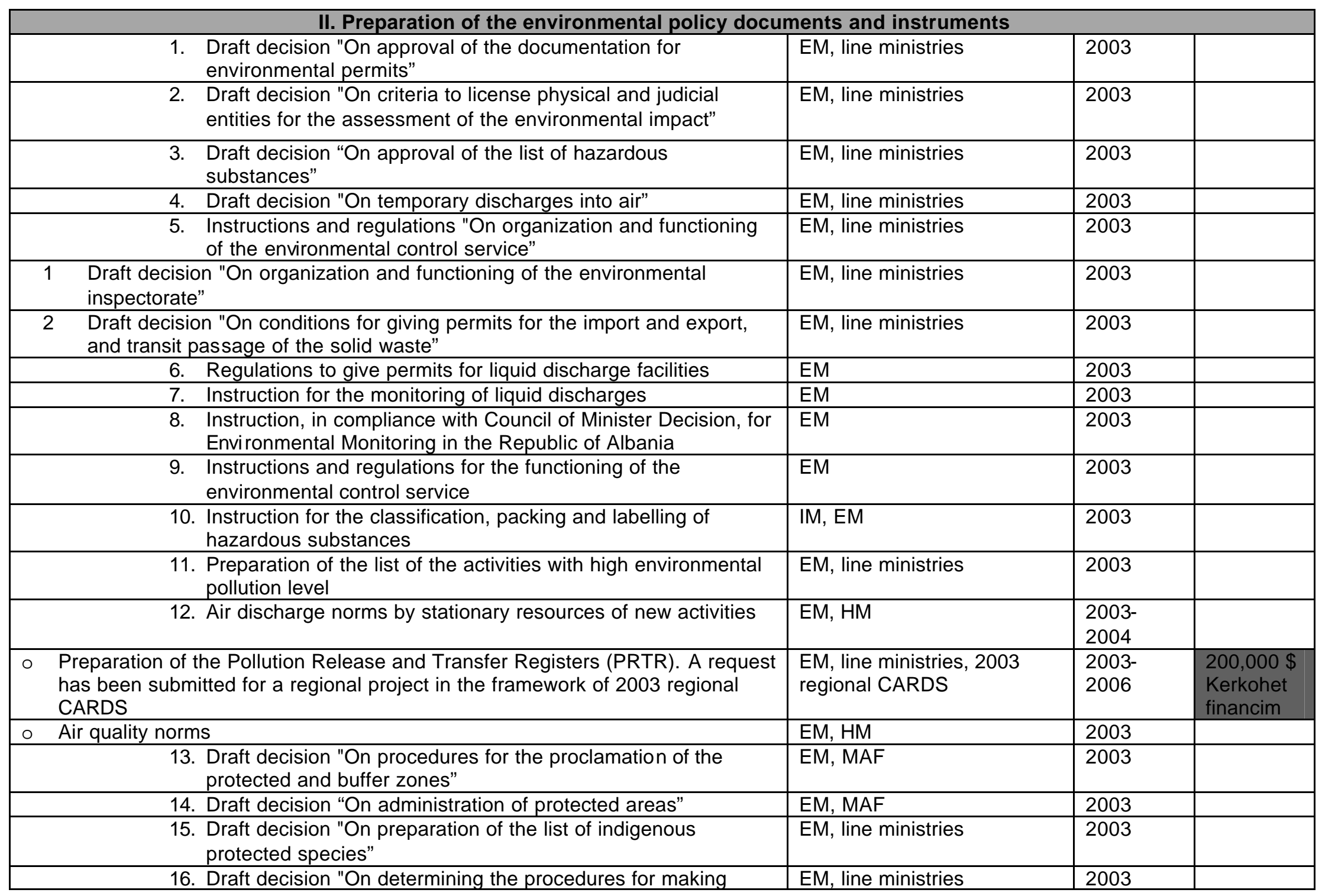


ANNEX 2 PROGRAM OF PRIORITY ACTION PLAN 2003

\begin{tabular}{|c|c|c|c|}
\hline caves available for eco-tourist use" & & & \\
\hline \multicolumn{4}{|l|}{$\bullet$} \\
\hline $\begin{array}{l}\text { - Documents and action plans for the implementation of the international } \\
\text { environmental conventions }\end{array}$ & EM, line ministries & $\begin{array}{l}2003- \\
2006\end{array}$ & \\
\hline$\circ \quad$ Publication of "Report on 1999-2000 Environmental Situation" & EM & 2003 & $5,000 \$$ \\
\hline $\begin{array}{ll}\text { Preparation and publication of "Report on 2001-2002 Environmental } \\
\text { Situation" }\end{array}$ & EM & 2003 & $15,000 \$$ \\
\hline$\circ \quad$ Launching EM page on the Internet & EM & 2003 & $10,000 \$$ \\
\hline $\begin{array}{l}\text { Preparation, contracting, and implementation of the project for the } \\
\text { approximation with the European environmental legislation, practices, and } \\
\text { mentality. }\end{array}$ & $\begin{array}{l}\text { EM, civil society, EU (2002 } \\
\text { National CARDS program) }\end{array}$ & $\begin{array}{l}2003- \\
2006\end{array}$ & $\begin{array}{l}\text { Premtuar } \\
\text { ne parim } \\
\text { per tu } \\
\text { financuar } \\
2,5 \mathrm{mln} \\
\text { EUR. } \\
\text { Pritet qe } \\
\text { fondi te } \\
\text { behet } \\
\text { operativ } \\
\text { gjate } \\
2003 \text {. }\end{array}$ \\
\hline$\circ \quad$ Public awareness activities in cooperation with the media & $\begin{array}{l}\text { Media, EM, line ministries, } \\
\text { monitoring institutions, } \\
\text { environmental NGOs, donor } \\
\text { community }\end{array}$ & $\begin{array}{l}2003- \\
2006\end{array}$ & $\begin{array}{l}\text { Kerkohet } \\
\text { financim }\end{array}$ \\
\hline $\begin{array}{l}\text { Raising the awareness and inclusion of the public in decision-making } \\
\text { process on environment }\end{array}$ & EM, NGOs & $\begin{array}{l}2003- \\
2006\end{array}$ & $\begin{array}{l}\text { In the } \\
\text { framework } \\
\text { of } 2002 \\
\text { CARDS } \\
\text { project }\end{array}$ \\
\hline \multicolumn{4}{|c|}{ III. Reduction of existing pollution } \\
\hline - Elemination of the arsenic solution in Nitrogenous Plant in Fier & $\begin{array}{l}\text { EM, MIE, MRTT, Fier } \\
\text { Prefecture, EU (PHARE } \\
\text { program) in REReP } \\
\text { framework }\end{array}$ & $\begin{array}{l}2003- \\
2004\end{array}$ & $\begin{array}{l}\text { Premtuar } \\
\text { ne parim } \\
1,000,000 \\
\text { EUR }\end{array}$ \\
\hline $\begin{array}{l}\text { Preparation of the feasibility study on the rehabilitation of the hotbed in Porto } \\
\text { Romano in Durres }\end{array}$ & EM, MEPP, World Bank & $\begin{array}{l}2002- \\
2004\end{array}$ & $\begin{array}{l}250,020 \\
\text { USD }\end{array}$ \\
\hline
\end{tabular}

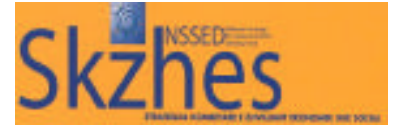


ANNEX 2 PROGRAM OF PRIORITY ACTION PLAN 2003

\begin{tabular}{|c|c|c|c|c|}
\hline & & & & $\begin{array}{l}\text { (received } \\
\text { fund) }\end{array}$ \\
\hline & $\begin{array}{l}\text { Preparation of the pre-investment study on the rehabilitation of the } \\
\text { hotbet in Vlore }\end{array}$ & $\begin{array}{l}\text { EM, MEPP, local } \\
\text { government, UNEP MAP }\end{array}$ & $\begin{array}{l}2003- \\
2004\end{array}$ & $\begin{array}{l}300,000 \\
\text { USD } \\
\text { (received } \\
\text { fund) }\end{array}$ \\
\hline & $\begin{array}{l}\text { Establishment of the water treatment facility in the Oil Refinery in } \\
\text { Ballsh. }\end{array}$ & $\begin{array}{l}\text { EM, MIE, EU (2002 National } \\
\text { CARDS program) }\end{array}$ & $\begin{array}{l}2003- \\
2006\end{array}$ & $\begin{array}{l}0.7 \text { MEUR } \\
\text { promised } \\
\text { in } \\
\text { principle. } \\
\text { The fund } \\
\text { expected } \\
\text { to become } \\
\text { operationa } \\
\text { I during } \\
2003 \text {. }\end{array}$ \\
\hline & $\begin{array}{l}\text { Feasibility study and implementation project on a landfill for the } \\
\text { hazardous waste. }\end{array}$ & $\begin{array}{l}\text { EM, MIE, EU (2002 National } \\
\text { CARDS program) }\end{array}$ & $\begin{array}{l}2003- \\
2006\end{array}$ & $\begin{array}{l}0.8 \text { MEUR } \\
\text { promised } \\
\text { in } \\
\text { principle. } \\
\text { The fund } \\
\text { expected } \\
\text { to become } \\
\text { operationa } \\
\text { I during } \\
2003\end{array}$ \\
\hline & $\begin{array}{l}\text { Implementation of an action plan on bringing ozon-thinning substances } \\
\text { out of use }\end{array}$ & $\begin{array}{l}\text { EM, line ministries and } \\
\text { institutions, UNEP DTIE }\end{array}$ & $\begin{array}{l}2003- \\
2005\end{array}$ & $\begin{array}{l}18.500 \\
\text { USD } \\
\text { (received } \\
\text { fund) }\end{array}$ \\
\hline & Implementation of the action plan on weather changes & EM, AKE, MIE, MSH, UNDP & $\begin{array}{l}2003- \\
2005\end{array}$ & $\begin{array}{l}100,000 \\
\text { USD } \\
\text { (received } \\
\text { fund) }\end{array}$ \\
\hline & $\begin{array}{l}\text { Completion of the feasibility studies for sewage treatment facilities in } \\
\text { three towns }\end{array}$ & MRTT, EM, World Bank & 2003 & $\begin{array}{l}250,000 \\
\text { USD } \\
\text { (received }\end{array}$ \\
\hline
\end{tabular}


ANNEX 2 PROGRAM OF PRIORITY ACTION PLAN 2003

\begin{tabular}{|c|c|c|c|c|}
\hline \multirow{2}{*}{\multicolumn{5}{|c|}{ IV. Sustainable use of resources }} \\
\hline & & & & \\
\hline & The project for "Protection of Ohrid Lake". & $\begin{array}{l}\text { EM, Pogradec municipality, } \\
\text { World Bank }\end{array}$ & 2003 & $\begin{array}{l}1.7 \mathrm{mln} \\
\text { USD } \\
\text { (received } \\
\text { fund) }\end{array}$ \\
\hline & $\begin{array}{l}\text { The project for "Protection of coastal and everglade eco-system of the } \\
\text { Mediterranean" }\end{array}$ & $\begin{array}{l}\text { EM, Vlore municipality, } \\
\text { UNDP }\end{array}$ & $\begin{array}{l}2003- \\
2005\end{array}$ & $\begin{array}{l}1.7 \mathrm{mln} \\
\text { USD } \\
\text { (received } \\
\text { fund) }\end{array}$ \\
\hline & $\circ$ Increase of the area of protected zones & MAF, EM, & $\begin{array}{l}2003- \\
2006\end{array}$ & \\
\hline
\end{tabular}


ANNEX 2 PROGRAM OF PRIORITY ACTION PLAN 2003

TABLE 5: MINISTRY OF PUBLIC ORDER 
ANNEX 2 PROGRAM OF PRIORITY ACTION PLAN 2003

TABLE 5: MINISTRY OF PUBLIC ORDER

\begin{tabular}{|c|c|c|c|c|}
\hline Objectives & Planned measures & Current status & $\begin{array}{c}\text { Responsible } \\
\text { institution }\end{array}$ & Deadline \\
\hline \multirow[t]{5}{*}{$\begin{array}{l}\text { Fight against corruption } \\
\text { and abuses with tasks } \\
\text { in the ranks of the State } \\
\text { police employees. }\end{array}$} & $\begin{array}{l}\text { Order for information } \\
\text { sources. }\end{array}$ & $\begin{array}{l}\text { Law } 8749 \text { dated } \\
01.03 .2001 \text { article } 15 .\end{array}$ & $\begin{array}{c}\text { Ministry } \\
\text { Judicial } \\
\text { Department } \\
\text { SHKB Department }\end{array}$ & $\begin{array}{l}\text { Until 15 } \\
\text { February } \\
2003\end{array}$ \\
\hline & $\begin{array}{l}\text { Order of the Public Order } \\
\text { Minister for the } \\
\text { information process. }\end{array}$ & $\begin{array}{lcr}\text { Law } & 8749 & \text { dated } \\
01.03 .2001 \text { article } 15 .\end{array}$ & $\begin{array}{c}\text { Ministry } \\
\text { SHKB Department }\end{array}$ & $\begin{array}{l}\text { Until } 28 \\
\text { February } \\
2003\end{array}$ \\
\hline & $\begin{array}{l}\text { Study, analysis, and } \\
\text { assessment of the } \\
\text { operational evidence, } \\
\text { which has been } \\
\text { administered in the } \\
\text { process. }\end{array}$ & $\begin{array}{l}\text { Law } 8749 \text { dated } \\
01.03 .2001 \text { article } 15 .\end{array}$ & $\begin{array}{c}\text { Ministry } \\
\text { SHKB Department }\end{array}$ & $\begin{array}{c}\text { Until } 25 \\
\text { March } 2003\end{array}$ \\
\hline & $\begin{array}{l}\text { Planning of the } \\
\text { verification activity of the } \\
\text { service for entities within } \\
\text { the deadlines specified in } \\
\text { the Regulations of the } \\
\text { operational evidence. }\end{array}$ & $\begin{array}{l}\text { Law } 8749 \text { dated } \\
\text { 01.03.2001 article } 15 .\end{array}$ & $\begin{array}{c}\text { Ministry } \\
\text { SHKB Department }\end{array}$ & $\begin{array}{l}\text { Until May } \\
2003\end{array}$ \\
\hline & $\begin{array}{l}\text { Analysis to study and } \\
\text { draw conclusions about } \\
\text { the phenomenon of } \\
\text { corruption in the POM } \\
\text { structures and the } \\
\text { measures for enhanced } \\
\text { effectiveness of the fight } \\
\text { against this phenomenon. }\end{array}$ & $\begin{array}{l}\text { Law } 8749 \text { dated } \\
01.03 .2001 \text { article } 15 .\end{array}$ & $\begin{array}{c}\text { Ministry } \\
\text { SHKB Department }\end{array}$ & 18 June 2003 \\
\hline $\begin{array}{l}\text { Higher detective and } \\
\text { operational capacity of } \\
\text { the Criminal Police } \\
\text { structures }\end{array}$ & $\begin{array}{l}\text { Identification of all } \\
\text { people, who commit } \\
\text { blood feud and revenge } \\
\text { murders, and the place }\end{array}$ & $\begin{array}{l}\text { There are many } \\
\text { persons in wanted } \\
\text { lists for such motives }\end{array}$ & $\begin{array}{l}\text { General Police } \\
\text { Department } \\
\text { Criminal } \\
\text { Department }\end{array}$ & 15 June 2003 \\
\hline
\end{tabular}


ANNEX 2 PROGRAM OF PRIORITY ACTION PLAN 2003

\begin{tabular}{|c|c|c|c|c|}
\hline & $\begin{array}{l}\text { where they hide with the } \\
\text { aim of organizing } \\
\text { operations to catch them. } \\
\text { Priority to the Sub- } \\
\text { Department of the Fight } \\
\text { Against Organized Crime, } \\
\text { and its component units, } \\
\text { which operate directly, } \\
\text { such as: } \\
\text { - Unit of the Fight } \\
\text { Against Economic- } \\
\text { Financial Crime -Central } \\
\text { Service of the Fight } \\
\text { Against Drugs } \\
\text { - Unit of the Fight } \\
\text { Against Illegal Trafficking. }\end{array}$ & $\begin{array}{l}\text { As a newly } \\
\text { established structure, } \\
\text { with units and offices } \\
\text { engaged directly in } \\
\text { the fight against } \\
\text { organized forms of } \\
\text { crime, ensuring } \\
\text { coordinated } \\
\text { organization with } \\
\text { Regional offices }\end{array}$ & $\begin{array}{l}\text { Person Property L. } \\
\text { K.K.Unit }\end{array}$ & \\
\hline $\begin{array}{l}\text { Higher effectiveness in } \\
\text { the fight against illegal } \\
\text { trafficking. }\end{array}$ & $\begin{array}{l}\text { Based on "National } \\
\text { Strategy of the Fight } \\
\text { Against Trafficking of } \\
\text { Human Beings " of the } \\
\text { Council of Ministers, this } \\
\text { unit will carry out the } \\
\text { following tasks : } \\
\text { - Providing the necessary } \\
\text { material means to all } \\
\text { police units (Regional } \\
\text { Offices of the Fight } \\
\text { Against Traffic) so that } \\
\text { they are able to do their } \\
\text { duty. } \\
\text { - Providing the necessary } \\
\text { material means to the } \\
\text { special unit (Delta) so }\end{array}$ & $\begin{array}{l}\text { There are tangible } \\
\text { results, with } \\
\text { increasing indicators, } \\
\text { but which have not } \\
\text { led to the elimination } \\
\text { of the illegal traffic } \\
\text { networks. }\end{array}$ & $\begin{array}{l}\text { Police General } \\
\text { Department } \\
\text { Polici General } \\
\text { Department } \\
\text { TIIAP Section } \\
\text { Anti-Traffic Sk.L.A. }\end{array}$ & $\begin{array}{l}\text { During } 2003 \\
\text { First half of } \\
2003 \\
\\
\text { During the } \\
\text { year untill } \\
\text { December } \\
2003\end{array}$ \\
\hline
\end{tabular}


ANNEX 2 PROGRAM OF PRIORITY ACTION PLAN 2003

\begin{tabular}{|c|c|c|c|c|}
\hline & $\begin{array}{l}\text { that it is capable of } \\
\text { preventing and fighting } \\
\text { illegal trafficking through } \\
\text { naval means. }\end{array}$ & & & \\
\hline $\begin{array}{l}\text { Accomplishment of the } \\
\text { national operation in } \\
\text { the fight against drugs } \\
\text { based on approved } \\
\text { action plans. }\end{array}$ & $\begin{array}{l}\text { Normative acts will be } \\
\text { completed and required } \\
\text { staff will be provided for } \\
\text { the Inter Ministerial } \\
\text { activity for the Fight } \\
\text { Against Drugs, on basis } \\
\text { of Law } 875 \text {, date } \\
27.3 .2001 \text { (article 30). } \\
\text { Collection of criminal } \\
\text { information about drug } \\
\text { trafficking groups, to } \\
\text { identify the people, the } \\
\text { organization, the means, } \\
\text { resources for funding this } \\
\text { activity. } \\
\text { Identification of the areas, } \\
\text { in which narcotic plants } \\
\text { are cultivated, with the } \\
\text { aim of preventing the } \\
\text { planting of these } \\
\text { substances. } \\
\text { - The cooperation with } \\
\text { the foreign counterpart } \\
\text { services, mainly with } \\
\text { those of the neighboring } \\
\text { countries, will be } \\
\text { intensified and become } \\
\text { more specific for a more } \\
\text { effective fight against } \\
\text { drug trafficking } \\
\text { - Strengthening of the }\end{array}$ & $\begin{array}{l}\text { Some groups have } \\
\text { been identified, but } \\
\text { there is no sufficient } \\
\text { information for the } \\
\text { legal documentation } \\
\text { of this activity. } \\
\text { Some of the areas } \\
\text { have been identified } \\
\text { in cooperation with } \\
\text { the local government, } \\
\text { but there is still no } \\
\text { comprehensive map } \\
\text { of this activity. }\end{array}$ & $\begin{array}{l}\text { POM } \\
\text { Police General } \\
\text { Department } \\
\text { Drug L.K.Section } \\
\text { Criminal D.Q.P. } \\
\text { Section of Fight } \\
\text { Against Drugs } \\
\\
\\
\text { POM, Local MP } \\
\text { Polici General } \\
\text { Department } \\
\text { Public Relations } \\
\text { Department } \\
\text { Police General } \\
\text { Department }\end{array}$ & $\begin{array}{l}\text { February - } \\
\text { March } 2003 \\
\text { January - } \\
\text { March } 2003 \\
\text { Continuing } \\
\text { During } 2003 \\
\text { June } 2003\end{array}$ \\
\hline
\end{tabular}


ANNEX 2 PROGRAM OF PRIORITY ACTION PLAN 2003

\begin{tabular}{|c|c|c|c|c|}
\hline $\begin{array}{l}\text { Accomplishmet of } \\
\text { operations for } \\
\text { elimination of narcotic } \\
\text { plants }\end{array}$ & $\begin{array}{l}\text { cooperation with the } \\
\text { prosecution offices and } \\
\text { the customs in joint } \\
\text { activities to investigate } \\
\text { cases of drug trafficking. } \\
\text { - Proposal to National } \\
\text { Commitee of the Fight } \\
\text { Against Drugs for the } \\
\text { preparation of the } \\
\text { Strategy on the } \\
\text { prevention and Fight } \\
\text { Against Drugs. } \\
\text { - In all areas identified } \\
\text { with narcotic plants. }\end{array}$ & & $\begin{array}{l}\text { Criminal Police } \\
\text { Department }\end{array}$ & $\begin{array}{l}\text { April and } \\
\text { continuing } \\
\text { during } 2003\end{array}$ \\
\hline $\begin{array}{l}\text { Improvement of the } \\
\text { cooperation with other } \\
\text { law enforcement } \\
\text { structures }\end{array}$ & $\begin{array}{l}\text { Partial changes in Law } \\
\text { "On Municipal Police". } \\
\text { Joint normative acts } \\
\text { should be revised. } \\
\text { Transfer of the detention } \\
\text { system under the } \\
\text { responsibility of the } \\
\text { Justice Ministry. Transfer } \\
\text { of the convicted people to } \\
\text { the prison facilities to } \\
\text { serve their sentences. }\end{array}$ & $\begin{array}{l}\text { With establishment of } \\
\text { Municipal and } \\
\text { Communal Police } \\
\text { there is a clash of } \\
\text { concrete } \\
\text { competencies of this } \\
\text { Police with those of } \\
\text { the State Police } \\
\text { In violation to the } \\
\text { criminal procedural } \\
\text { law, the State Police } \\
\text { have still, in its } \\
\text { structures, the } \\
\text { service for the } \\
\text { custody of the } \\
\text { convicted people, } \\
\text { including those who } \\
\text { have received final } \\
\text { conviction. }\end{array}$ & $\begin{array}{l}\text { POM (Public Order } \\
\text { D.Q.P) } \\
\text { Ministry of Local } \\
\text { Government and } \\
\text { Dencetralization } \\
\\
\\
\text { POM } \\
\text { Justice Ministry } \\
\text { (Public Order } \\
\text { Dr.Q.P.) } \\
\text { Public Order } \\
\text { Section }\end{array}$ & $\begin{array}{l}\text { December } \\
2003 \\
\text { Until June } \\
2003\end{array}$ \\
\hline Guarantee security for & Legal regulation of the & The procedures for & & \\
\hline
\end{tabular}


ANNEX 2 PROGRAM OF PRIORITY ACTION PLAN 2003

\begin{tabular}{|c|c|c|c|c|}
\hline $\begin{array}{l}\text { the activity of foreign } \\
\text { physical and judicial } \\
\text { entities }\end{array}$ & $\begin{array}{l}\text { procedures for the } \\
\text { foreigners engaged in } \\
\text { activities in Albania. } \\
\text { Additional amendment in } \\
\text { the law "On foreigners" } \\
\text { regarding the powers of } \\
\text { the Border Police Central } \\
\text { Department with the aim } \\
\text { of setting up a single } \\
\text { institutional register for } \\
\text { the foreigners. }\end{array}$ & $\begin{array}{l}\text { the foreigners, } \\
\text { regarding their visas, } \\
\text { entry, and residence, } \\
\text { are different from } \\
\text { those of the Western } \\
\text { countries. }\end{array}$ & $\begin{array}{l}\text { POM, Foreign } \\
\text { Affairs Ministry, } \\
\text { Public Order } \\
\text { D.Q.P. } \\
\text { Foreign Pas } \\
\text { Section }\end{array}$ & $\begin{array}{l}\text { March - June } \\
2003\end{array}$ \\
\hline $\begin{array}{l}\text { Redistribution of the } \\
\text { police forces in } \\
\text { concurrence with the } \\
\text { tasks, interruption of } \\
\text { services, which do not } \\
\text { belong to the State } \\
\text { Police }\end{array}$ & $\begin{array}{l}\text { Increased police } \\
\text { presence. Cooperation } \\
\text { with the citizens. } \\
\text { Effectiveness in the } \\
\text { services in uniform, } \\
\text { enhanced mobility. } \\
\text { Preparation of the } \\
\text { instructions for alternative } \\
\text { and dynamic plans on the } \\
\text { organization of services } \\
\text { in uniform, including both } \\
\text { normal situations and } \\
\text { incidents and activities } \\
\text { related to public order. } \\
\text { Preparation of the plans } \\
\text { for the deployment of the } \\
\text { police forces for all } \\
\text { structures, by level. }\end{array}$ & $\begin{array}{l}\text { Territorial control } \\
\text { service to cover all } \\
\text { the regions of the } \\
\text { country, preparing a } \\
\text { new scheme for the } \\
\text { territorial coverage. }\end{array}$ & $\begin{array}{l}\text { General Police } \\
\text { Department } \\
\text { Public Order } \\
\text { D.Q.P. }\end{array}$ & June 2003 \\
\hline
\end{tabular}


ANNEX 2 PROGRAM OF PRIORITY ACTION PLAN 2003

\begin{tabular}{|c|c|c|c|c|}
\hline $\begin{array}{l}\text { Strengthening of } \\
\text { measures for the } \\
\text { protection, control, and } \\
\text { management of } \\
\text { borders. }\end{array}$ & $\begin{array}{l}\text { Preparation of the } \\
\text { additional amendments } \\
\text { for changes in the law } \\
\text { "On Border Police". } \\
\text { Preparation of the draft } \\
\text { regulations "On } \\
\text { functioning of Border } \\
\text { Police services". }\end{array}$ & $\begin{array}{l}\text { Proposals have been } \\
\text { made, a draft law will } \\
\text { be prepared and } \\
\text { submitted for } \\
\text { approval }\end{array}$ & $\begin{array}{l}\text { POM. } \\
\text { Border D.Q.P. } \\
\text { Analyses Office } \\
\text { POM. } \\
\text { Border D.Q.P. } \\
\text { Analyses Office }\end{array}$ & $\begin{array}{l}\text { May } 2003 \\
\text { June } 2003\end{array}$ \\
\hline $\begin{array}{l}\text { Improvements in the } \\
\text { current structure of the } \\
\text { Border Police to adjust } \\
\text { it to the new integration } \\
\text { conditions in the border } \\
\text { service. }\end{array}$ & $\begin{array}{l}\text { Preparation of the new } \\
\text { Border Police structure } \\
\text { and proposal for its } \\
\text { approval. In accordance } \\
\text { with the strategy on } \\
\text { border protection and } \\
\text { control. } \\
\text { Preparation of draft } \\
\text { structures for the new } \\
\text { border crossing points, } \\
\text { and those, which will be } \\
\text { opened in the future. }\end{array}$ & $\begin{array}{l}\text { The new structure of } \\
\text { the Border Police will } \\
\text { be prepared on the } \\
\text { basis of the new } \\
\text { regulations, which will } \\
\text { be prepared, and the } \\
\text { needs. } \\
\text { Continuous } \\
\text { integration has raised } \\
\text { need for the opening } \\
\text { of new border } \\
\text { crossings time after } \\
\text { time }\end{array}$ & $\begin{array}{l}\text { POM } \\
\text { Border D.Q.P. } \\
\\
\text { POM } \\
\text { Border D.Q.P. } \\
\text { Border Section }\end{array}$ & $\begin{array}{l}\text { September } \\
2003 \\
\text { April } 2003\end{array}$ \\
\hline $\begin{array}{l}\text { Increased effectiveness } \\
\text { of the border protection } \\
\text { and control services, } \\
\text { particularly for the fight } \\
\text { against trafficking, } \\
\text { improvement of the } \\
\text { border infrastructure. }\end{array}$ & $\begin{array}{l}\text { Improvement of the } \\
\text { organization of the border } \\
\text { police services to close } \\
\text { possible routes of } \\
\text { crossborder trafficking } \\
\text { and crime. } \\
\text { Implementation of the }\end{array}$ & $\begin{array}{l}\text { Intensification and } \\
\text { sophistication of } \\
\text { illegal actions } \\
\text { dictates need for } \\
\text { establishment of } \\
\text { Border Police special } \\
\text { services to fight } \\
\text { them. In view of }\end{array}$ & $\begin{array}{l}\text { POM } \\
\text { Border D.Q.P. }\end{array}$ & $\begin{array}{l}\text { During the } \\
\text { year } 2003\end{array}$ \\
\hline
\end{tabular}


ANNEX 2 PROGRAM OF PRIORITY ACTION PLAN 2003

\begin{tabular}{|c|c|c|c|c|}
\hline & $\begin{array}{l}\text { projects prepared in } \\
\text { cooperation with the } \\
\text { international } \\
\text { organizations and foreign } \\
\text { donors for the } \\
\text { improvement of current } \\
\text { infrastructure with } \\
\text { contemporary elements. }\end{array}$ & $\begin{array}{l}\text { current infrastructure } \\
\text { with significant } \\
\text { shortcomings in both } \\
\text { living and service } \\
\text { conditions, several } \\
\text { projects for the } \\
\text { improvement of the } \\
\text { entire infrastructure } \\
\text { have been submitted. }\end{array}$ & Border D.Q.P. & $\begin{array}{l}\text { During the } \\
\text { year } 2003\end{array}$ \\
\hline $\begin{array}{l}\text { Revision of the } \\
\text { Agreements, Protocols } \\
\text { of cooperation with the } \\
\text { counterpart bodies of } \\
\text { other countries in the } \\
\text { framework of further } \\
\text { integration. }\end{array}$ & $\begin{array}{l}\text { Preparation and } \\
\text { improvement of the draft } \\
\text { agreement with } \\
\text { neighboring countries, } \\
\text { Macedonia, Kosova } \\
\text { (KFOR), Yugoslavia and } \\
\text { Montenegro on border } \\
\text { issues. } \\
\text { Conclusion of repatriation } \\
\text { agreements, which are } \\
\text { being prepared with the } \\
\text { neighboring countries and } \\
\text { the third countries. } \\
\text { Continued work to clean } \\
\text { the border and the border } \\
\text { markings and support for } \\
\text { the resumption of work in } \\
\text { other border sectors with } \\
\text { Macedonia. }\end{array}$ & $\begin{array}{l}\text { The agreements with } \\
\text { neighboring } \\
\text { countries, with the } \\
\text { exception of KFOR } \\
\text { and Macedonia, have } \\
\text { become outdated. } \\
\text { It is necessary to } \\
\text { achieve the } \\
\text { conclusion, as soon } \\
\text { as possible, of } \\
\text { repatriation } \\
\text { agreements with third } \\
\text { countries, Croatia, } \\
\text { Great Britain, and } \\
\text { Belgium. } \\
\text { With the exception of } \\
\text { Greece, the } \\
\text { borderline with other } \\
\text { countries has not } \\
\text { been cleaned for } \\
\text { many years. }\end{array}$ & $\begin{array}{l}\text { D.P.P } \\
\text { Economic } \\
\text { Department } \\
\text { Border D.Q.P } \\
\\
\text { POM. } \\
\text { Judicial.Perf.Legal } \\
\text { Department } \\
\text { Integ Internat. } \\
\text { Cooperat. } \\
\text { Department. } \\
\text { Foreign Affairs } \\
\text { Ministry } \\
\text { Border D.Q.P. } \\
\\
\text { POM, } \\
\text { Foreign Affairs } \\
\text { Ministry }\end{array}$ & $\begin{array}{l}\text { During the } \\
\text { year } 2003\end{array}$ \\
\hline $\begin{array}{l}\text { Improvement of the } \\
\text { legal framework. }\end{array}$ & $\begin{array}{l}\text { Studies for the } \\
\text { development of the } \\
\text { standard procedures of }\end{array}$ & $\begin{array}{l}\text { Road Code } \\
\text {-State Police Law } \\
\text {-Code of Ethics }\end{array}$ & $\begin{array}{l}\text { Road D.Q.P. } \\
\text { Traffic Office }\end{array}$ & October 2003 \\
\hline
\end{tabular}


ANNEX 2 PROGRAM OF PRIORITY ACTION PLAN 2003

\begin{tabular}{|c|c|c|c|c|}
\hline & $\begin{array}{l}\text { the service at a strategic } \\
\text { and operational level, in } \\
\text { accordance with the West } \\
\text { European standards. }\end{array}$ & $\begin{array}{l}\text {-Regulations of Road } \\
\text { Police service }\end{array}$ & & \\
\hline & $\begin{array}{l}\text { Draft decision of the } \\
\text { Council of Ministers on } \\
\text { some changes in the } \\
\text { system of plates used for } \\
\text { the vehicles of the } \\
\text { Diplomatic and Consular } \\
\text { Representations } \\
\text { accredited to the } \\
\text { Republic of Albania and } \\
\text { the High Personalities of } \\
\text { the country. }\end{array}$ & $\begin{array}{l}\text { Decisions made by } \\
\text { Transport Ministry }\end{array}$ & $\begin{array}{l}\text { POM } \\
\text { Transport Ministry } \\
\text { Road Q.S.Section }\end{array}$ & January 2003 \\
\hline & $\begin{array}{l}\text { Preparation of the manual } \\
\text { for the violations and the } \\
\text { relevant administrative } \\
\text { measures, in compliance } \\
\text { with the Traffic Code. } \\
\text { Order of the Public Order } \\
\text { Minister for the issuance } \\
\text { of special ability } \\
\text { certificate to the police } \\
\text { employees, who use } \\
\text { State Police vehicles. }\end{array}$ & $\begin{array}{l}\text { Does not exist } \\
\text { Does not exist }\end{array}$ & $\begin{array}{l}\text { Road Q.S.Section } \\
\text { Traffic Office } \\
\\
\text { Traffic Office } \\
\text { Sections }\end{array}$ & $\begin{array}{l}\text { March } 2003 \\
\text { October } 2003\end{array}$ \\
\hline $\begin{array}{l}\text { Higher level of } \\
\text { cooperation with the } \\
\text { Road Ownership Entity } \\
\text { for the improvement of } \\
\text { the road infrastructure. }\end{array}$ & $\begin{array}{l}\text { Higher role and } \\
\text { responsibilities of the } \\
\text { Traffic Police service in } \\
\text { increasing the } \\
\text { cooperation with the road } \\
\text { ownership entity for the } \\
\text { improvement of the road } \\
\text { infrastructure. The road } \\
\text { infrastructure and its } \\
\text { elements are among }\end{array}$ & $\begin{array}{l}\text { Interventions to } \\
\text { improve situation, as } \\
\text { soon as possible, in } \\
\text { aeras with high risk of } \\
\text { accidents (black } \\
\text { holes), both for the } \\
\text { national, and local } \\
\text { and urban roads are } \\
\text { being identified. } \\
\text { Relevant map at the }\end{array}$ & $\begin{array}{l}\text { POM } \\
\text { Minis. of Local Gov. } \\
\text { and Decent } \\
\text { Transport Ministry } \\
\text { Road Police } \\
\text { Department }\end{array}$ & $\begin{array}{l}\text { February } \\
2003\end{array}$ \\
\hline
\end{tabular}


ANNEX 2 PROGRAM OF PRIORITY ACTION PLAN 2003

\begin{tabular}{|c|c|c|c|c|}
\hline & $\begin{array}{l}\text { basic elements affecting } \\
\text { road safety. } \\
\text { Identification of the } \\
\text { selected areas, branches } \\
\text { and crossroads, } \\
\text { application of the traffic } \\
\text { islands to discipline and } \\
\text { separate traffic flows, } \\
\text { closure of the branches, } \\
\text { which are not envisioned } \\
\text { in the project, regulations } \\
\text { for the stoppage and } \\
\text { parking lots, more } \\
\text { effective road transport } \\
\text { methods for the reduction } \\
\text { of the flow of vehicles and } \\
\text { for environmental } \\
\text { improvements, the } \\
\text { improvement of the } \\
\text { technical condition of the } \\
\text { vehicles and ban on the } \\
\text { outdated and unsuitable } \\
\text { vehicles for circulation, in } \\
\text { cooperation with the } \\
\text { Department of the Road } \\
\text { Transport Services. } \\
\text { Higher awareness of the } \\
\text { Traffic Police employees } \\
\text { about their role and tasks, } \\
\text { by increasing their } \\
\text { professional presence in } \\
\text { the inspection of roads } \\
\text { and their users. }\end{array}$ & $\begin{array}{l}\text { national level should } \\
\text { be studied and } \\
\text { compiled }\end{array}$ & $\begin{array}{l}\text { Road D.Q.P. } \\
\text { Road Q.S.Section }\end{array}$ & August 2003 \\
\hline Higher level of Traffic & Study on the organization & Requalification of the & Road D.Q.P. & June 2003 \\
\hline
\end{tabular}


ANNEX 2 PROGRAM OF PRIORITY ACTION PLAN 2003

\begin{tabular}{|c|c|c|c|c|}
\hline Police service. & $\begin{array}{l}\text { of the structure of the } \\
\text { Traffic Police services to } \\
\text { increase their operational } \\
\text { efficiency; } \\
\text {-Organization of the } \\
\text { seminars and explanatory } \\
\text { classes, familiarization } \\
\text { with studies, descriptions, } \\
\text { or conclusions related to } \\
\text { our and foreign } \\
\text { experience, preparation } \\
\text { of the curricula for } \\
\text { professional training and } \\
\text { the testing of the Traffic } \\
\text { Police forces. } \\
\text {-Training of the units } \\
\text { through courses in and } \\
\text { outside the country. } \\
\text {-Organization of the } \\
\text { qualifying test } \\
\text { commission in the Central } \\
\text { Traffic Police Department } \\
\text { to test and issue special } \\
\text { certificate for driving } \\
\text { State Police vehicles. }\end{array}$ & $\begin{array}{l}\text { traffic police } \\
\text { personnel is going } \\
\text { through at testing } \\
\text { process, also through } \\
\text { the assistance of } \\
\text { foreign missions, in } \\
\text { cooperation with the } \\
\text { Police Academy. } \\
\text { Guiding standards for } \\
\text { studies, which will be } \\
\text { followed in the future, } \\
\text { have been prepared. }\end{array}$ & Road D.Q.P. & Annual 2003 \\
\hline $\begin{array}{l}\text { Organizational } \\
\text { improvement of the } \\
\text { Intervention and } \\
\text { Special structures. }\end{array}$ & $\begin{array}{l}\text { Final deployment of the } \\
\text { basic operational units in } \\
\text { the whole territory of the } \\
\text { country and the Special } \\
\text { units of the Rapid } \\
\text { Intervention Forces on } \\
\text { the basis of the objectives } \\
\text { specified in the Strategy } \\
\text { of the State Police. }\end{array}$ & $\begin{array}{l}\text { Organization of Rapid } \\
\text { Intervention Force } \\
\text { into nine units and } \\
\text { the grouping of the } \\
\text { Special Units, } \\
\text { including RENEA, } \\
\text { Helicopter Group, } \\
\text { Anti-Explosive Unit, } \\
\text { and negotiators. }\end{array}$ & $\begin{array}{l}\text { General Police } \\
\text { Department } \\
\text { FSH\&NSH } \\
\text { Department }\end{array}$ & $\begin{array}{l}\text { March } 2003 \\
\text { Continuing }\end{array}$ \\
\hline
\end{tabular}


ANNEX 2 PROGRAM OF PRIORITY ACTION PLAN 2003

\begin{tabular}{|c|c|c|c|c|}
\hline & $\begin{array}{l}\text { Modernization of the } \\
\text { armaments and special } \\
\text { self-protection equipment } \\
\text { in the Special units of the } \\
\text { Rapid Intervention Forces } \\
\text { and the readiness } \\
\text { groups. } \\
\text { Verification of the } \\
\text { measures to enhance the } \\
\text { level of readiness. }\end{array}$ & & $\begin{array}{l}\text { General Police } \\
\text { Department } \\
\text { FSH\&NSH } \\
\text { Department }\end{array}$ & 2003 \\
\hline $\begin{array}{l}\text { Intensification of the } \\
\text { work on the } \\
\text { familiarization with and } \\
\text { implementation of } \\
\text { human rights by the } \\
\text { State Police } \\
\text { employees. }\end{array}$ & $\begin{array}{l}\text { Annual training activities } \\
\text { will be planned, on basis } \\
\text { of a specific calendar, for } \\
\text { the State Police } \\
\text { employees in and outside } \\
\text { the country. } \\
\text { Supply of the libraries } \\
\text { with literature on issures } \\
\text { related to human rights } \\
\text { protection. } \\
\\
\text { Organization of } \\
\text { continuous inspections to } \\
\text { check the application of } \\
\text { laws by the local police } \\
\text { structures. }\end{array}$ & $\begin{array}{l}\text { Agenda of } \\
\text { professional work of } \\
\text { the General } \\
\text { Department. } \\
\text { There are } \\
\text { cooperation } \\
\text { programs with the } \\
\text { NGOs and } \\
\text { international } \\
\text { institutions in the field } \\
\text { of police legal } \\
\text { education. } \\
\text { Some manuals and } \\
\text { other publicity } \\
\text { material on protection } \\
\text { and respect for } \\
\text { citizens' rights have } \\
\text { been published. } \\
\text { Some roundtable } \\
\text { meetings have been } \\
\text { organized and the } \\
\text { opinions of the Ngos, }\end{array}$ & $\begin{array}{l}\text { General Police } \\
\text { Department } \\
\text { Emergency Center } \\
\text { Training Personnel } \\
\text { Unit } \\
\\
\text { Public Relations } \\
\text { Department } \\
\\
\text { General Police } \\
\text { Department } \\
\text { Public Relations } \\
\text { Department }\end{array}$ & $\begin{array}{l}\text { January } 2003 \\
\text { And } \\
\text { continuing } \\
\text { Continuing } \\
2003 \\
\text { June- } \\
\text { December } \\
2003\end{array}$ \\
\hline
\end{tabular}


ANNEX 2 PROGRAM OF PRIORITY ACTION PLAN 2003

\begin{tabular}{|c|c|c|c|c|}
\hline & $\begin{array}{l}\text { Programs will be } \\
\text { prepared and } \\
\text { implemented, in } \\
\text { cooperation with NGOs } \\
\text { and international } \\
\text { institutions, for the legal } \\
\text { education of the police at } \\
\text { the central and local } \\
\text { level. }\end{array}$ & $\begin{array}{l}\text { foreign police } \\
\text { missions and } \\
\text { international } \\
\text { institutions have been } \\
\text { drawn in the } \\
\text { framework of the } \\
\text { work on the } \\
\text { preparation of various } \\
\text { laws on state police. }\end{array}$ & & $\begin{array}{l}\text { January- } \\
\text { March } 2003\end{array}$ \\
\hline & $\begin{array}{l}\text { Preparation and } \\
\text { publication of guides, } \\
\text { regulations and other } \\
\text { publicity material. }\end{array}$ & & & $\begin{array}{l}\text { September - } \\
2003,\end{array}$ \\
\hline $\begin{array}{l}\text { Greater cooperation } \\
\text { between police and } \\
\text { community on crime } \\
\text { prevention. }\end{array}$ & $\begin{array}{l}\text { Information of the public } \\
\text { about the activity of the } \\
\text { police in the fight against } \\
\text { crime and the periodical } \\
\text { publication of the police } \\
\text { wanted lists. } \\
\text { Implementation of } \\
\text { projects in schools on } \\
\text { crime prevention. The } \\
\text { identification of the police } \\
\text { employees for permanent } \\
\text { contacts with the schools. }\end{array}$ & $\begin{array}{l}\text { Police vision is } \\
\text { founded on } \\
\text { community policing } \\
\text { and crime prevention. } \\
\text { There are } \\
\text { cooperation } \\
\text { programs with NGO } \\
\text { specialized in crime } \\
\text { prevention in schools, } \\
\text { cooperation with the } \\
\text { local government etc. } \\
\text { In the Institute for } \\
\text { Democracy and } \\
\text { Mediation Albanian } \\
\text { Human Rights Center } \\
\text { etc. }\end{array}$ & $\begin{array}{l}\text { POM } \\
\text { General Police } \\
\text { Department } \\
\text { Public Relations } \\
\text { Department } \\
\\
\text { General Police } \\
\text { Department } \\
\text { Criminal D.Q.P. } \\
\text { Person K.K.Section } \\
\text { Public Relations } \\
\text { Department }\end{array}$ & $\begin{array}{l}\text { Quarterly } \\
\text { periodical } \\
\text { publications }\end{array}$ \\
\hline
\end{tabular}


ANNEX 2 PROGRAM OF PRIORITY ACTION PLAN 2003

\begin{tabular}{|c|c|c|c|c|}
\hline & $\begin{array}{l}\text { Continued cooperation } \\
\text { with the local government } \\
\text { bodies, particularly on } \\
\text { crime prevention } \\
\text { Preparation of the guides } \\
\text { with practical advice for } \\
\text { Albanian and foreign } \\
\text { citizens on how to guard } \\
\text { themselves against } \\
\text { becoming crime victims. } \\
\text { Expansion of the feature } \\
\text { "Information for the } \\
\text { citizens" on the Internet } \\
\text { page of the Public Order } \\
\text { Ministry, as part of crime } \\
\text { prevention effort. }\end{array}$ & & & $\begin{array}{l}\text { During } 2003 \\
\text { During } 2003 \\
\text { During } 2003\end{array}$ \\
\hline $\begin{array}{l}\text { Higher police } \\
\text { transparency to the } \\
\text { media and the public. }\end{array}$ & $\begin{array}{l}\text { Training and logistics } \\
\text { supply to the structures, } \\
\text { which are responsible for } \\
\text { communication with the } \\
\text { media. } \\
\text { Preparation of a guide for } \\
\text { police employees in } \\
\text { leading posts on } \\
\text { principles and ways for } \\
\text { the communication of the } \\
\text { police with the media. } \\
\text { Organization of the } \\
\text { seminars on police }\end{array}$ & $\begin{array}{l}\text { There is a normative } \\
\text { act of POM for the } \\
\text { communication of the } \\
\text { police with the media } \\
\text { There are bodies at } \\
\text { central and local level } \\
\text { responsible for the } \\
\text { communication with } \\
\text { th emedia. } \\
\text { Training seminars } \\
\text { have been organized } \\
\text { with the police } \\
\text { bodies, which are } \\
\text { responsiible for the } \\
\text { communication with }\end{array}$ & $\begin{array}{l}\text { POM } \\
\text { Public Relations } \\
\text { Department } \\
\text { "A.Zylyftari" Police } \\
\text { Academy }\end{array}$ & $\begin{array}{l}\text { January - } \\
\text { June } 2003 \\
\text { June - } \\
\text { December } \\
2003\end{array}$ \\
\hline
\end{tabular}


ANNEX 2 PROGRAM OF PRIORITY ACTION PLAN 2003

\begin{tabular}{|c|c|c|c|c|}
\hline & $\begin{array}{l}\text { communication with the } \\
\text { media. }\end{array}$ & the media. & & $\begin{array}{l}\text { December } \\
2003\end{array}$ \\
\hline \multirow[t]{2}{*}{$\begin{array}{l}\text { Area for the protection } \\
\text { of the classified } \\
\text { information }\end{array}$} & $\begin{array}{l}\text { The list and the relevant } \\
\text { documents of the people, } \\
\text { who will have access to } \\
\text { classified information, } \\
\text { should be submitted to } \\
\text { DSIK in the Council of } \\
\text { Ministers to obtain } \\
\text { "Security certificate" }\end{array}$ & & & March 2003 \\
\hline & $\begin{array}{l}\text { The list of the documents } \\
\text { classified by their } \\
\text { classification level and } \\
\text { the deadlines for their } \\
\text { protection should be } \\
\text { prepared and submitted } \\
\text { to the DSIK in the Council } \\
\text { of Ministers. }\end{array}$ & & & March 2003 \\
\hline $\begin{array}{l}\text { Registration of } \\
\text { immovable property. }\end{array}$ & $\begin{array}{l}\text { Structural } \\
\text { This process will be } \\
\text { carried out with the } \\
\text { existing structures. } \\
\text { Cooperation will take } \\
\text { place with AIPP and } \\
\text { ZRPP. The Council of } \\
\text { Ministers will prepare the } \\
\text { list of the facilities under } \\
\text { the ownership of the } \\
\text { Public Order Ministry. }\end{array}$ & $\begin{array}{l}\text { POM has prepared } \\
\text { the POM Order and } \\
\text { Instruction }\end{array}$ & $\begin{array}{l}\text { Economic } \\
\text { Department }\end{array}$ & Year 2003 \\
\hline $\begin{array}{l}\text { - Follow, monitor and } \\
\text { planning of aid received } \\
\text { from various sources } \\
\text { and donations PHARE, } \\
\text { CARDS DANIDA } \\
\text { programs, ECPA, } \\
\text { Italian Z.N.P, ICITAP }\end{array}$ & $\begin{array}{l}\text { Collection, examination of } \\
\text { the requests received } \\
\text { from various branches of } \\
\text { the Public Order Ministry, } \\
\text { giving priority to the State } \\
\text { Police. }\end{array}$ & & $\begin{array}{l}\text { General Police } \\
\text { Department } \\
\text { Econ. Department } \\
\text { "A.Zylyftari" Police } \\
\text { Academy }\end{array}$ & Year 2003 \\
\hline
\end{tabular}


ANNEX 2 PROGRAM OF PRIORITY ACTION PLAN 2003

\begin{tabular}{|c|c|c|c|c|}
\hline $\begin{array}{l}\text { missions, Stability Pact } \\
\text { etc. }\end{array}$ & $\begin{array}{l}\text { Cooperation with the } \\
\text { Economy Mnistry and } \\
\text { various domestic and } \\
\text { foreign Agencies. } \\
\text { Agreements, protocols } \\
\text { Council of Minister } \\
\text { decisions, some ratified } \\
\text { by the parliament; } \\
\text { training of the personnel } \\
\text { on project drafting. }\end{array}$ & & & \\
\hline $\begin{array}{l}\text { Monitor implementation } \\
\text { of investment } \\
\text { programs of the Public } \\
\text { Order Ministry, in } \\
\text { accordance with the } \\
\text { specified priorities and } \\
\text { policies. }\end{array}$ & $\begin{array}{l}\text { Consistent monitoring of } \\
\text { the use of the funds, in } \\
\text { cooperation with the } \\
\text { Finance Department. } \\
\text { Establishment of a } \\
\text { Technical Office. } \\
\text { End to the operation of } \\
\text { two parallel structures. } \\
\text { Law on State Budget. } \\
\text { Training of personnel with } \\
\text { methods and instructions. }\end{array}$ & $\begin{array}{l}\text { POM Order on } \\
\text { dealing with } \\
\text { investments. }\end{array}$ & $\begin{array}{l}\text { Economic } \\
\text { Department }\end{array}$ & $\begin{array}{l}\text { Every } 4 \\
\text { months } \\
\text { January } 2003 \\
\text { During } 2003\end{array}$ \\
\hline $\begin{array}{l}\text { The platform for the } \\
\text { privatization of free } \\
\text { facilities. }\end{array}$ & $\begin{array}{l}\text { Identification of the } \\
\text { facilities, which result to } \\
\text { be free, and the } \\
\text { identification of the } \\
\text { possibilities to use them } \\
\text { for renting, housing, } \\
\text { capital transfer } \\
\text { privatization } \\
\text { Law } 7512 \\
\text { date10.08.2001 } \\
\text { Council of Minister } \\
\text { Decision } 192 \text { date } \\
\text { 02.04.1998 }\end{array}$ & $\begin{array}{l}\text { Preparation of the the } \\
\text { minister's order }\end{array}$ & $\begin{array}{l}\text { Economic } \\
\text { Department } \\
\text { TIIAP Sector }\end{array}$ & $\begin{array}{l}\text { Every } 6 \\
\text { months } 2003\end{array}$ \\
\hline
\end{tabular}


ANNEX 2 PROGRAM OF PRIORITY ACTION PLAN 2003

\begin{tabular}{|c|c|c|c|c|}
\hline & $\begin{array}{l}\text { Council of Minister } \\
\text { Decision } 81 \\
\text { date.28.02.1994 } \\
\text { Discussion of the } \\
\text { problems in the } \\
\text { Commission of Public } \\
\text { Order Ministry } \\
\text { Personnel training. }\end{array}$ & & & \\
\hline $\begin{array}{l}\text { Contemporary concept } \\
\text { about economic } \\
\text { elements and increase } \\
\text { of the professional } \\
\text { level. }\end{array}$ & $\begin{array}{l}\text { Privatization of the food } \\
\text { service } \\
\text { Increase of the } \\
\text { decentralization and } \\
\text { computerization } \\
\text { elements. } \\
\text { Law and Council of } \\
\text { Minister Decision on } \\
\text { administration and } \\
\text { circulation of material and } \\
\text { monetary values. } \\
\text { Identification of the } \\
\text { procedures to be followed } \\
\text { for these changes. } \\
\text { Pilot project } \\
\text { Personnel training. }\end{array}$ & & $\begin{array}{l}\text { POM } \\
\text { Economic } \\
\text { Department } \\
\text { Project Office } \\
\text { TIIAP Sector } \\
\text { Food Service } \\
\\
\text { Economic } \\
\text { Department } \\
\text { Budget-Finance } \\
\text { Department }\end{array}$ & $\begin{array}{l}\text { December } \\
2003 \\
\\
\text { December } \\
2003\end{array}$ \\
\hline $\begin{array}{l}\text { Monitoring and } \\
\text { improvement of the } \\
\text { activities of the } \\
\text { enterprises and } \\
\text { institutions of the Public } \\
\text { Order Ministry. }\end{array}$ & $\begin{array}{l}\text { Riorganization, giving } \\
\text { them a cultural, } \\
\text { educational, and training } \\
\text { character, too. } \\
\text { Law on enterprises and } \\
\text { the Law on State Budget. } \\
\text { Approval of the criteria. }\end{array}$ & & $\begin{array}{l}\text { POM } \\
\text { Economic } \\
\text { Department }\end{array}$ & $\begin{array}{l}\text { September } \\
2003\end{array}$ \\
\hline $\begin{array}{l}\text { Improvement of the } \\
\text { information system } \\
\text { through the }\end{array}$ & $\begin{array}{l}\text { New structure of the } \\
\text { Information Unit, in } \\
\text { accordance with the }\end{array}$ & $\begin{array}{l}\text { Strategy on } \\
\text { computarization in } \\
\text { the Public Order }\end{array}$ & $\begin{array}{l}\text { General } \\
\text { Department } \\
\text { Economic }\end{array}$ & $\begin{array}{l}\text { February - } \\
\text { March } 2003\end{array}$ \\
\hline
\end{tabular}


ANNEX 2 PROGRAM OF PRIORITY ACTION PLAN 2003

\begin{tabular}{|c|c|c|c|c|}
\hline $\begin{array}{l}\text { computerization in the } \\
\text { Public Order Ministry } \\
\text { and the General Police } \\
\text { Department. }\end{array}$ & $\begin{array}{l}\text { recommendations for } \\
\text { SI/TI by ICITAP Mission. } \\
\text { Preparation of the Master } \\
\text { plan on computerization } \\
\text { in the Public Order } \\
\text { Ministry } \\
\text { Phase I Computerization } \\
\text { of Police Departments in } \\
\text { Dr. Pol. Tirane,Durres, } \\
\text { Phase II Computerization } \\
\text { of Police Departments } \\
\text { Kukes,Korce, Shkoder, } \\
\text { Diber } \\
\text { Phase III Computerization } \\
\text { of Police Departments } \\
\text { Elbasan, Gjirokaster,Fier, } \\
\text { Lezhe, Berat Year 2004 } \\
\text { Minister's Order on } \\
\text { operation of SI/TI in } \\
\text { Public Order Ministry. } \\
\text { Minister's Order on the } \\
\text { criteria and use of the } \\
\text { information. } \\
\text { Identification of the } \\
\text { criteria for the evaluation } \\
\text { of the Si/Ti personnel and } \\
\text { measures for new } \\
\text { recruitments. } \\
\text { Training of the existing } \\
\text { SI/TI personnel and the } \\
\text { information processing } \\
\text { personnel, operator, } \\
\text { technitian, officers etc. }\end{array}$ & $\begin{array}{l}\text { Ministry and its } \\
\text { subordinate } \\
\text { structures has been } \\
\text { prepared } \\
\text { Work has begun on } \\
\text { the installation of the } \\
\text { infrastructure s. } \\
\\
\text { The working group } \\
\text { chaired by chief of } \\
\text { Information Unit has } \\
\text { been set up. } \\
\text { The joint consortium } \\
\text { led by CITAP and } \\
\text { including ECPA, } \\
\text { Z.N.P.Italy, MAPE, } \\
\text { PHARE. Program } \\
\text { operates }\end{array}$ & $\begin{array}{l}\text { Department } \\
\text { Telecommunication } \\
\text { and information } \\
\text { Section } \\
\\
\text { Phase I } \\
\text { Computerization of } \\
\text { Police Depart. } \\
\text { Tirana,Durres, } \\
\text { second phase } \\
\text { computerization of } \\
\text { police depart. of. } \\
\text { Kukes, Korce, } \\
\text { Shkoder, Diber } \\
\text { Phase III Regional } \\
\text { Drejt.Police of } \\
\text { Elbasan, } \\
\text { Gjirokaster, } \\
\text { Fier, Lezhe. }\end{array}$ & $\begin{array}{l}\text { April-May } \\
2003 \\
\text { Faza I } \\
\text { Computerizat } \\
\text { ion of Police } \\
\text { Deprt. } \\
\text { Tirana,Durres } \\
\text {, Vlore } \\
\\
\text { End of } 2003 \\
\text { General } \\
\text { Department } \\
\text { Economic } \\
\text { Department } \\
\\
\text { General } \\
\text { Department } \\
\text { Telecom. and } \\
\text { computeriz. } \\
\text { Unit }\end{array}$ \\
\hline
\end{tabular}


ANNEX 2 PROGRAM OF PRIORITY ACTION PLAN 2003

\begin{tabular}{|c|c|c|c|c|}
\hline $\begin{array}{l}\text { Establishment of the } \\
\text { telecommunication } \\
\text { systems toward } \\
\text { development and } \\
\text { modernization. }\end{array}$ & $\begin{array}{l}\text { Establishment of the } \\
\text { Radio-Relay System for } \\
\text { Southern and Eastern } \\
\text { parts. } \\
\text { Establishment of the } \\
\text { Radio Communication } \\
\text { System in HF frequency } \\
\text { band. } \\
\text { Establishment of mini- } \\
\text { systems of Radio } \\
\text { Communication in UHF. }\end{array}$ & $\begin{array}{l}\text { Project idea about } \\
\text { this system } \\
\text { Project idea about } \\
\text { this system } \\
\text { Project idea about } \\
\text { this system }\end{array}$ & $\begin{array}{l}\text { Intependent } \\
\text { telephone and data } \\
\text { transmission for } \\
\text { Police departments } \\
\text { will be provided in } \\
\text { the Southern and } \\
\text { Eastern part. } \\
\text { Phono-Fax-Data } \\
\text { communication will } \\
\text { be provided among } \\
\text { Regional Police } \\
\text { Departments. } \\
\text { Area of coverage } \\
\text { with radio- } \\
\text { communication is } \\
\text { increased } \\
\text { Coordination of } \\
\text { work among police } \\
\text { stations of the } \\
\text { same department is } \\
\text { achieved }\end{array}$ & $\begin{array}{l}\text { Telecom. } \\
\text { Unit } \\
2003 \text { and } \\
\text { continuing } \\
\\
\text { Computeriz. } \\
\text { Unit June } \\
2003 \\
\text { Telecom. } \\
\text { Unit } \\
\text { 2003 and } \\
\text { continuing }\end{array}$ \\
\hline $\begin{array}{l}\text { Establishment of the } \\
\text { automative site } \\
\text { observation and } \\
\text { recording systems. }\end{array}$ & $\begin{array}{l}\text { Automatic observation } \\
\text { and recording system in } \\
\text { border crossing points. } \\
\text { Automatic observation } \\
\text { and recording system in } \\
\text { border crossing points. }\end{array}$ & $\begin{array}{l}\text { Project idea about } \\
\text { this system }\end{array}$ & POM & 2003 \\
\hline $\begin{array}{l}\text { Organization, } \\
\text { supervision, and } \\
\text { monitoring of the } \\
\text { preparation and } \\
\text { implementation process } \\
\text { of the Ministry's budget }\end{array}$ & $\begin{array}{l}\text { Improvement of the } \\
\text { orders and instructions } \\
\text { related to the preparation } \\
\text { and implementation of the } \\
\text { budget and property } \\
\text { administration. }\end{array}$ & & $\begin{array}{l}\text { POM } \\
\text { Budget Finance } \\
\text { Department }\end{array}$ & January 2003 \\
\hline
\end{tabular}


ANNEX 2 PROGRAM OF PRIORITY ACTION PLAN 2003

\begin{tabular}{|c|c|c|c|c|}
\hline \multicolumn{5}{|l|}{$\begin{array}{l}\text { and the process of } \\
\text { keeping and } \\
\text { implementing the } \\
\text { standard accounting } \\
\text { plan. }\end{array}$} \\
\hline & $\begin{array}{l}\text { Preparation of the basic } \\
\text { Instruction "On } \\
\text { implementation of the } \\
\text { budget in the system of } \\
\text { the Public Order Ministry. }\end{array}$ & & $\begin{array}{l}\text { POM } \\
\text { Budget Finance } \\
\text { Department }\end{array}$ & January 2003 \\
\hline & $\begin{array}{l}\text { Preparation of the } \\
\text { instruction "on the free-of- } \\
\text { charge circulation of the } \\
\text { goods in the system of } \\
\text { the Ministry ". }\end{array}$ & $\begin{array}{l}\text { Invalidation of } \\
\text { existing instructure }\end{array}$ & $\begin{array}{l}\text { POM } \\
\text { Budget Finance } \\
\text { Department }\end{array}$ & March 2003 \\
\hline & $\begin{array}{l}\text { Submission of reports on } \\
\text { the progress in the } \\
\text { attainment of the budget } \\
\text { indicators. }\end{array}$ & & $\begin{array}{l}\text { Budget Finance } \\
\text { Department }\end{array}$ & $\begin{array}{l}\text { Every 4- } \\
\text { month period } \\
2003\end{array}$ \\
\hline & $\begin{array}{l}\text { Preparation of the } \\
\text { instruction on the } \\
\text { preparation of the draft } \\
\text { budget. }\end{array}$ & & $\begin{array}{l}\text { Budget Finance } \\
\text { Department }\end{array}$ & January 2003 \\
\hline & $\begin{array}{l}\text { Training of the budget } \\
\text { and finance personnel. }\end{array}$ & & $\begin{array}{l}\text { Public Order } \\
\text { Ministry }\end{array}$ & January 2003 \\
\hline & $\begin{array}{l}\text { Introduction of the } \\
\text { information technology in } \\
\text { the financial audit system. }\end{array}$ & & $\begin{array}{l}\text { POM } \\
\text { Budget Finance } \\
\text { Department }\end{array}$ & 2003 \\
\hline & $\begin{array}{l}\text { Implementation of the } \\
\text { annual programs } \\
\text { approved by the Public } \\
\text { Order Ministry. }\end{array}$ & & $\begin{array}{l}\text { Budget Finance } \\
\text { Department. }\end{array}$ & $\begin{array}{l}\text { During entire } \\
\text { period } 2003\end{array}$ \\
\hline $\begin{array}{l}\text { Reorganization of the } \\
\text { structure of the Guard } \\
\text { on the basis of the New } \\
\text { law. }\end{array}$ & $\begin{array}{l}\text { - Establishment of the } \\
\text { working groups } \\
\text { - Task assisgnment }\end{array}$ & $\begin{array}{l}\text { Required working } \\
\text { procedures have } \\
\text { been prepared }\end{array}$ & $\begin{array}{l}\text { POM } \\
\text { Guard Command } \\
\text { Judicial } \\
\text { Department }\end{array}$ & $\begin{array}{l}\text { After } \\
\text { approval of } \\
\text { the law } 2003\end{array}$ \\
\hline
\end{tabular}


ANNEX 2 PROGRAM OF PRIORITY ACTION PLAN 2003

\begin{tabular}{|c|c|c|c|c|}
\hline $\begin{array}{l}\text { Preparation of the sub- } \\
\text { legal acts stemming } \\
\text { from the New law "On } \\
\text { the Guard of the } \\
\text { Republic". }\end{array}$ & $\begin{array}{l}\text { - Issuance of sub-legal } \\
\text { acts } \\
\text { - Division of working } \\
\text { groups }\end{array}$ & $\begin{array}{l}\text {-Work programs and } \\
\text { responsible persons } \\
\text { have been prepared }\end{array}$ & $\begin{array}{l}\text { POM } \\
\text { Guard Command } \\
\text { Judicial } \\
\text { Department }\end{array}$ & $\begin{array}{l}\text { Second half } \\
\text { of } 2003\end{array}$ \\
\hline $\begin{array}{l}\text { Increase of the security } \\
\text { elements in the ORV } \\
\text { and Protection of the } \\
\text { PLSH through } \\
\text { application of } \\
\text { contemporary visual } \\
\text { equipment. }\end{array}$ & $\begin{array}{l}\text { Studies and the } \\
\text { calculation of the costs } \\
\text { for the installation of the } \\
\text { equipment have been } \\
\text { made. }\end{array}$ & $\begin{array}{l}\text { - Control bridges } \\
\text { have been set up in } \\
\text { some ORV. }\end{array}$ & $\begin{array}{l}\text { POM } \\
\text { Guard Command }\end{array}$ & $\begin{array}{l}\text { Begins in } \\
2003 \text { and } \\
\text { continuing }\end{array}$ \\
\hline $\begin{array}{l}\text { Preparation of the draft } \\
\text { regulations for the } \\
\text { ceremonial service. }\end{array}$ & $\begin{array}{l}\text { - Establishment of the } \\
\text { working group } \\
\text { - Preparation of the } \\
\text { program. }\end{array}$ & $\begin{array}{l}\text { Regulations of } \\
\text { internal life in the } \\
\text { army. }\end{array}$ & $\begin{array}{l}\text { POM } \\
\text { Guard Command } \\
\text { Judicial } \\
\text { Department }\end{array}$ & $\begin{array}{l}\text { Second half } \\
\text { of } 2003\end{array}$ \\
\hline $\begin{array}{l}\text { Supply of technology, } \\
\text { armaments, and other } \\
\text { contemporary } \\
\text { equipment, through the } \\
\text { gradual substitution of } \\
\text { the existing technology. }\end{array}$ & $\begin{array}{l}\text { - Partial substitution of } \\
\text { the armaments and } \\
\text { equipment has been } \\
\text { made. }\end{array}$ & $\begin{array}{l}\text { - A small technical } \\
\text { amount of } \\
\text { armaments has been } \\
\text { replaced }\end{array}$ & $\begin{array}{l}\text { POM } \\
\text { Guard Command }\end{array}$ & $\begin{array}{l}2003 \text { and } \\
\text { continuing }\end{array}$ \\
\hline
\end{tabular}


ANNEX 2 PROGRAM OF PRIORITY ACTION PLAN 2003

TABLE 6: MINISTRY OF LABOR AND SOCIAL AFFAIRS 
ANNEX 2 PROGRAM OF PRIORITY ACTION PLAN 2003

TABLE 6: MINISTRY OF LABOR AND SOCIAL AFFAIRS

\begin{tabular}{|c|c|c|c|c|c|}
\hline Field/Sector & Objectives & Priority Public Measures & $\begin{array}{l}\text { Responsible } \\
\text { institutions }\end{array}$ & Deadline & $\begin{array}{l}\text { Budgetory } \\
\text { effects } \\
\text { (thousand } \\
\text { leks) } \\
\end{array}$ \\
\hline \multirow[t]{3}{*}{ Labor market } & $\begin{array}{l}\text { 1.1 Institucionalization } \\
\text { and formalization of } \\
\text { the labor market. }\end{array}$ & $\begin{array}{l}\text { Improvement of law No.7995 date.20.09.1995 } \\
\text { "On promotion of employment" } \\
\text { Preparation of draft Council of Minister decision on company } \\
\text { factory doctor } \\
\text { Accomplishment of the study on short and medium-term } \\
\text { development of the labor market. } \\
\text { Training, qualification, and specialization of the staff of the } \\
\text { employment services ( } 80 \text { specialists) } \\
\text { Establishment of standard and contemporary facilities in the } \\
\text { employment offices, suitable for the services they provide. }\end{array}$ & $\begin{array}{l}\text { MPCS } \\
\text { ISHP,MPCS } \\
\text { SHKP } \\
\text { SHKP }\end{array}$ & $\begin{array}{l}\text { November } \\
2003 \\
2003 \\
\text { During } 2003 \\
\text { December } \\
2003 \\
\text { During } 2003\end{array}$ & 35000 \\
\hline & $\begin{array}{l}\text { 22. Expansion and } \\
\text { improvement of the } \\
\text { quality of the } \\
\text { employment services }\end{array}$ & $\begin{array}{l}\text { Assessment of the quantitative and qualitative indicators of the } \\
\text { results of the employment services. } \\
\text { Accomplishment of } 7,000 \text { mediations in the Employment } \\
\text { Offices. } \\
\text { Computerization of the employment service system in the } \\
\text { regional and local offices. } \\
\text { Pilot project on the basis of the French employment service } \\
\text { experience and its extension to other regions. } \\
\text { Establishment of the trainer group for the qualification of the } \\
\text { employment service specialists. }\end{array}$ & $\begin{array}{l}\text { SHKP } \\
\text { SHKP } \\
\text { SHKP }\end{array}$ & $\begin{array}{l}\text { During } 2003 \\
\text { Second half } \\
2003 \\
\text { December } \\
2003 \\
\text { " }\end{array}$ & 2700 \\
\hline & $\begin{array}{l}33 \text { Quantative and } \\
\text { qualitative system of } \\
\text { the professional } \\
\text { training system, in } \\
\text { concurrence with the } \\
\text { labor market needs. }\end{array}$ & $\begin{array}{l}\text { Increase of the number of the professional training centers } \\
\text { (establishment of six new training centers) } \\
\text { Identification of the standards for the development of the } \\
\text { professional training curricula (preparation of the sub-legal } \\
\text { acts) } \\
\text { Promotion of the Professional Training Centers to open } \\
\text { professional training courses demanded by the market ( } 66 \% \\
\text { more people than in 2001) } \\
\text { Increase of the number of the private companies offering }\end{array}$ & $\begin{array}{l}\text { SHKP } \\
\text { MPCS,DPP } \\
\text { MPCS,SHKP }\end{array}$ & $\begin{array}{l}\text { December } \\
2003 \\
\text { May } 2003 \\
\text { December } \\
2003\end{array}$ & 54000 \\
\hline
\end{tabular}


ANNEX 2 PROGRAM OF PRIORITY ACTION PLAN 2003

\begin{tabular}{|c|c|c|c|c|c|}
\hline & & $\begin{array}{l}\text { professional training } \\
\text { Accomplishment of a study for the establishment of the } \\
\text { National Center of the AFP. } \\
\text { Preparation of the draft decision "On estabishment of the } \\
\text { National Center of the AFP" }\end{array}$ & $\begin{array}{l}\text { MPCS,SHKP } \\
\text { MPCS,SHKP } \\
\text { SHKP }\end{array}$ & $\begin{array}{l}\text { During } 2003 \\
\text { November } \\
2003 \\
\text { December } \\
2003\end{array}$ & 5000 \\
\hline & $\begin{array}{l}44 \text { Development of } \\
\text { incentive measures for } \\
\text { employment growth }\end{array}$ & $\begin{array}{l}\text { Approval of the statute of the National Employment Fund } \\
\text { Continued implementation of the Job Promotion Program }\end{array}$ & MPCS & $\begin{array}{l}\text { December } \\
2003\end{array}$ & 150000 \\
\hline $\begin{array}{l}\text { Social } \\
\text { insurances }\end{array}$ & $\begin{array}{l}\text { 1. Enhanced financial } \\
\text { sustainability of the } \\
\text { social insurance } \\
\text { scheme }\end{array}$ & $\begin{array}{l}\text { Increase of the number of the contributors to the social } \\
\text { insurance scheme by } 160,000 \text { people, } 32,000 \text { in the urban } \\
\text { areas and } 128,000 \text { in the rural areas. } \\
\text { Inclusion of the people employed in emigration in the social } \\
\text { insurance scheme, } 5,000 \text { people } \\
\text { Increase of the revenues at faster pace than the expenditures } \\
\text { for the scheme, at an average rate of } 6-8 \% \\
\text { The reduction of the evasion in the contribution to a minimum } \\
\text { level, through reduced activity of the informal sector and the } \\
\text { management of the debts. } \\
\text { Reduction of the state subsidies by } 33 \% \\
\text { Completion of the legal framework for the establishment of of } \\
\text { supplementary, professional schemes of social insurances. }\end{array}$ & $\begin{array}{l}\text { ISSH } \\
\text { ISSH } \\
\text { ISSH } \\
\text { ISSH } \\
\text { ISSH } \\
\text { MPCS, ISSH }\end{array}$ & $\begin{array}{l}2003 \\
2003 \\
2003 \\
2003 \\
2003 \\
2003 \\
\end{array}$ & \\
\hline & $\begin{array}{l}\text { Higher benefitting level } \\
\text { from social insurances }\end{array}$ & $\begin{array}{l}\text { Increase of the town pensions by } 10 \% \text { and village pensions by } \\
20-25 \%\end{array}$ & MPCS, ISSH & July 2003 & \\
\hline
\end{tabular}


ANNEX 2 PROGRAM OF PRIORITY ACTION PLAN 2003

\begin{tabular}{|c|c|c|c|c|}
\hline & & $\begin{array}{l}\text { Completion of the process for narrowing the differences } \\
\text { between pensions set with law before } 1996 \text { and the pensions } \\
\text { set in the subsequent years. } \\
\text { Completion of the study and identification of the methodology } \\
\text { for the indexation of the pensions }\end{array}$ & $\begin{array}{l}\text { MPCS, ISSH } \\
\text { MPCS,ISSH }\end{array}$ & $\begin{array}{l}\text { September } \\
2003 \\
2003\end{array}$ \\
\hline & $\begin{array}{l}\text { Development of the } \\
\text { institutional capacities }\end{array}$ & $\begin{array}{l}\text { Application of a computerized information system for the social } \\
\text { insurances. Computerization of the system of contributions and } \\
\text { benefits from the supplementary insurance scheme. } \\
\text { Bids and application of technical assistance, analysis of } \\
\text { information and proposals for solution. } \\
\text { Improvement of the services through the expansion of the } \\
\text { network of the local social insurance agencies, by setting up } 10 \\
\text { new agencies. } \\
\text { Institutionalization, with legal and by-legal acts, of the } \\
\text { procedures for the cooperation between Taxes and Social } \\
\text { Insurance Institute } \\
\text { Bid for assistance "Analysis of work flow in DRSSH" } \\
\text { Structural improvements and improvement of the process for } \\
\text { the collection and monitoring of the contributions } \\
\text { Preparation of the model of the contract for the management } \\
\text { and attainment of the indicators, which are monitored }\end{array}$ & $\begin{array}{l}\text { ISSH } \\
\text { ISSH } \\
\text { ISSH } \\
\text { MPCS, ISSH } \\
\text { ISSH } \\
\text { ISSH } \\
\text { ISSH }\end{array}$ & $\begin{array}{l}\text { April } 2003 \\
\text { February } \\
2003 \\
2003 \\
2003 \\
\text { April } 2003 \\
2003 \\
\text { April } 2003 \\
\end{array}$ \\
\hline
\end{tabular}


ANNEX 2 PROGRAM OF PRIORITY ACTION PLAN 2003

\begin{tabular}{|c|c|c|c|c|c|}
\hline & & $\begin{array}{l}\text { Assistance at the central, regional, and local level. } \\
\text { Training of the social administrators. } \\
\text { Preparation and periodical updating of the Poverty Map. } \\
\text { Preparation of the Regional Maps }\end{array}$ & SHSSH,MPCS & 2003-04 & 80000 \\
\hline & $\begin{array}{l}\text { Implementation of } \\
\text { effective programs for } \\
\text { the reintegration of the } \\
\text { poor people into the } \\
\text { social and economic } \\
\text { life }\end{array}$ & $\begin{array}{l}\text { Preparation of the model for the inclusion of the poor people } \\
\text { (beneficaries of Economic Assistance) into employment } \\
\text { promotion programs and private initiatives. }\end{array}$ & $\begin{array}{l}\text { MPCS } \\
\text { SHSSH } \\
\text { SHKP }\end{array}$ & 2003-04 & \\
\hline & $\begin{array}{l}\text { Coverage of the } \\
\text { categories of disabled } \\
\text { people with social } \\
\text { assistance (cash) }\end{array}$ & $\begin{array}{l}\text { Improvement of the legal bsis for persons with the disability } \\
\text { status and the paraplegic and tetraplegic people. } \\
\text { Preparation of the draft for changes in the Council of Minister } \\
\text { Decision } \\
\text { Re-commissioning of the persons, who have acquired the } \\
\text { disability status, by KMCAP to SHSSH. } \\
\text { Continued re-commissioning of the blind people. } \\
\end{array}$ & $\begin{array}{l}\text { MPCS } \\
\text { SHSSH }\end{array}$ & & \\
\hline & & $\begin{array}{l}\text { Preparation of the integral law on social services. } \\
\text { Establishment of the working group with experts of } \\
\text { MPCS,SHSSH,NGOs etc } \\
\text { Preparation of the draft } \\
\text { Institutionalization of the structures for planning community } \\
\text { services at regional level (Community Care Planning } \\
\text { Commitees) } \\
\text { Status and regulations for the operation of the KPPK } \\
\text { Structural improvement and enhanced capacities of Regional } \\
\text { Offices (pilot regions) to plan community-based services } \\
\text { Establishment of the social sectors in the pilot Regional } \\
\text { Offices. }\end{array}$ & $\begin{array}{l}\text { MPCS } \\
\text { SHSSH }\end{array}$ & & \\
\hline
\end{tabular}


ANNEX 2 PROGRAM OF PRIORITY ACTION PLAN 2003

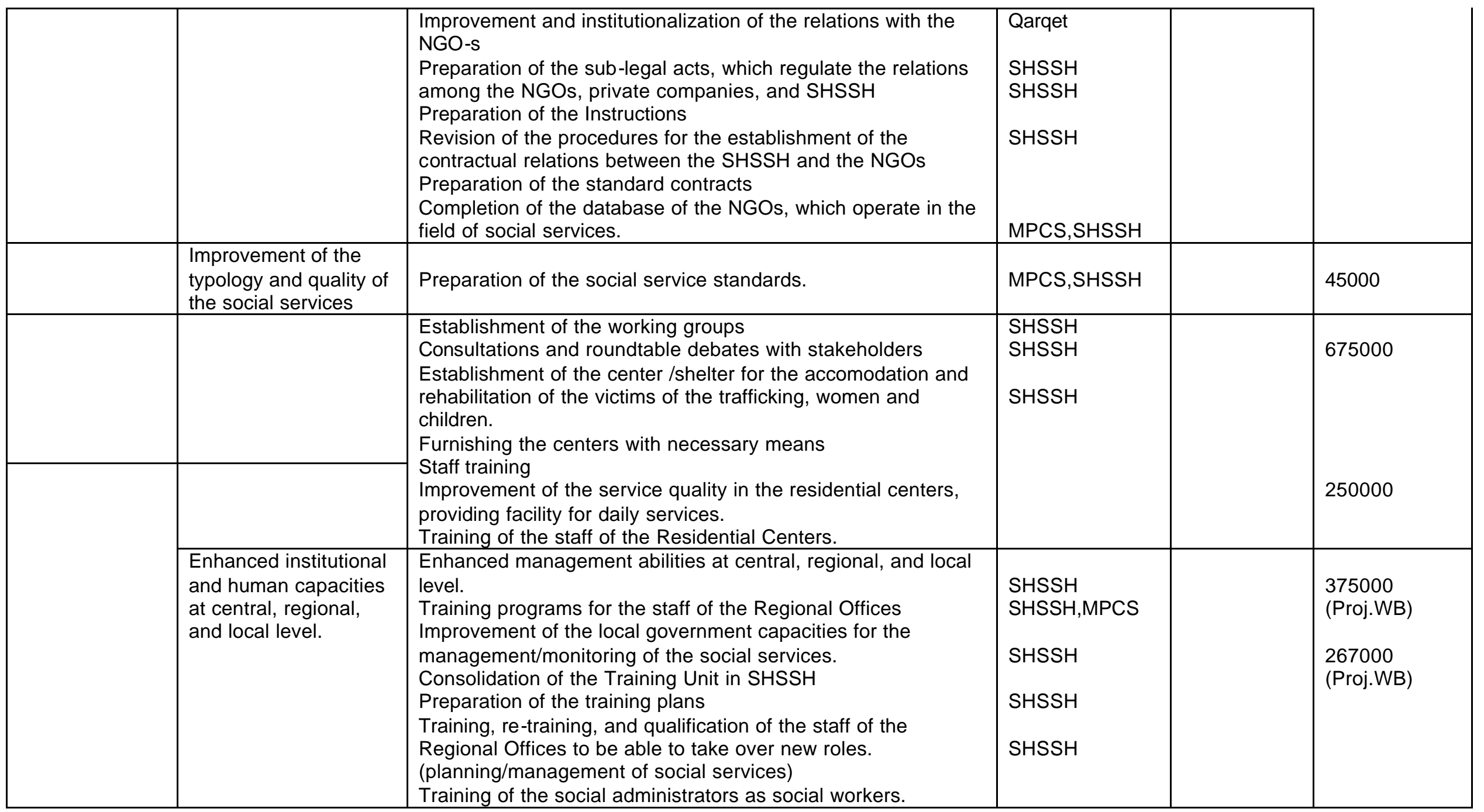


ANNEX 2 PROGRAM OF PRIORITY ACTION PLAN 2003

TABLE 7: MINISTRY OF INDUSTRY AND ENERGY 
ANNEX 2 PROGRAM OF PRIORITY ACTION PLAN 2003

TABLE 7: MINISTRY OF INDUSTRY AND ENERGY

\section{ELECTRO-ENERGY SECTOR}

\begin{tabular}{|c|c|c|c|c|c|}
\hline No & Objectives & Planned actions & $\begin{array}{l}\text { Responsible } \\
\text { Institution }\end{array}$ & Deadline & $\begin{array}{c}\text { Budgetory } \\
\text { effects }\end{array}$ \\
\hline \multirow[t]{7}{*}{1} & $\begin{array}{l}\text { Establishment of a } \\
\text { financially and } \\
\text { technically strong } \\
\text { power industry }\end{array}$ & & & & \\
\hline & 1.1 & Implementation of 2003-2004 Action Plan & $\mathrm{KESH}$ & 2003 & \\
\hline & 1.2 & $\begin{array}{l}\text { Forecasts for the electric power needs in the } \\
\text { framework of the National Energy Srategy }\end{array}$ & KESH & $\begin{array}{l}\text { 31 March } \\
2003\end{array}$ & \\
\hline & 1.3 & $\begin{array}{l}\text { Preparation of the Plan for Expansion of } \\
\text { Albanian Electro-Energy System, (LCEP) in } \\
\text { the framework of the National Energy Srategy. }\end{array}$ & KESH, & $\begin{array}{l}\text { 31 March } \\
2003\end{array}$ & \\
\hline & 1.4 & $\begin{array}{l}\text { Preparation of a detailed plan of actions for full } \\
\text { cost recovery and for enhanced effectiveness } \\
\text { of distribution tariffs until mid- } 2005\end{array}$ & KESH & $\begin{array}{l}30 \text { June } \\
2003\end{array}$ & \\
\hline & 1.5 & $\begin{array}{l}\text { Updating of the Action Plan for Electro-Energy } \\
\text { sector during the next two years 2004-2005 }\end{array}$ & $\mathrm{KESH}$ & $\begin{array}{l}30 \text { November } \\
2003\end{array}$ & \\
\hline & 1.6 & $\begin{array}{l}\text { Continued enhancement of the effectiveness } \\
\text { of the tariffs }\end{array}$ & ERE & Continuing & \\
\hline \multirow[t]{3}{*}{2} & $\begin{array}{l}\text { Establishment of an } \\
\text { effective and } \\
\text { transparent legal and } \\
\text { regulatory framework }\end{array}$ & & & & \\
\hline & 2.1 & $\begin{array}{l}\text { Preparation, presentation, and approval of the } \\
\text { Law on Electro-Energy System }\end{array}$ & MIE, ERE & $\begin{array}{l}\text { 2002-March } \\
2003\end{array}$ & \\
\hline & 2.2 & $\begin{array}{l}\text { Preparation and approval of the legislation } \\
\text { authorizing Ministry of Labor and Socal Affairs, } \\
\text { in cooperation with the Ministry of Industry and } \\
\text { Energy and the Ministry of Finances, to } \\
\text { develop the mechanism for facilitating the } \\
\text { impact of higher electric power tariffs on a } \\
\text { group of consumers with low revenues and to } \\
\text { stabilize a minimum level of the service to }\end{array}$ & MPCS & $2002-2003$ & \\
\hline
\end{tabular}


ANNEX 2 PROGRAM OF PRIORITY ACTION PLAN 2003

\begin{tabular}{|c|c|c|c|c|c|}
\hline No & Objectives & Planned actions & $\begin{array}{l}\text { Responsible } \\
\text { Institution }\end{array}$ & Deadline & $\begin{array}{l}\text { Budgetory } \\
\text { effects }\end{array}$ \\
\hline & & meet the most necessary needs & & & \\
\hline & 2.3 & $\begin{array}{l}\text { Adoption and approval of the Energy Code of } \\
\text { Building }\end{array}$ & MI\&E & $\begin{array}{l}\text { 31 March } \\
2003\end{array}$ & \\
\hline & 2.4 & $\begin{array}{l}\text { Preparation of the National Strategy on Electric } \\
\text { Power - PHASE } 1\end{array}$ & MI\&E & 1 April, 2003 & \\
\hline & 2.5 & $\begin{array}{l}\text { Preparation of the Energy Conservation Plan } \\
\text { as part of the National Energy Strategy }\end{array}$ & MI\&E & $\begin{array}{l}30 \text { April, } \\
2003\end{array}$ & \\
\hline & 2.6 & $\begin{array}{l}\text { Preparation of the methodology for the } \\
\text { establishment of the Regional and National } \\
\text { System of Energy Data }\end{array}$ & $\mathrm{MI} \& \mathrm{E}$ & $\begin{array}{l}30 \text { June, } \\
2003\end{array}$ & \\
\hline & 2.7 & $\begin{array}{l}\text { Preparation of a program for the } \\
\text { implementation of the National Strategy and its } \\
\text { approval by the Government }\end{array}$ & MI\&E & $\begin{array}{l}30 \text { June, } \\
2003\end{array}$ & \\
\hline & 2.8 & $\begin{array}{l}\text { Selection of the Transmission Model of Electric } \\
\text { Power Market and the signing of the proposed } \\
\text { model by the Government }\end{array}$ & MI\&E & $\begin{array}{c}31 \text { December } \\
2003\end{array}$ & \\
\hline \multirow[t]{2}{*}{3} & $\begin{array}{l}\text { Division of KESH Lmt. } \\
\text { into legally separate } \\
\text { units }\end{array}$ & & & & \\
\hline & 3.1 & $\begin{array}{l}\text { Accomplishment of a study, in cooperation with } \\
\text { KESH-in, to determine the most adequate } \\
\text { number of the distribution enterprises for the } \\
\text { division of KESH. }\end{array}$ & MI\&E & $\begin{array}{l}\text { 31 March } \\
2003\end{array}$ & \\
\hline \multirow[t]{2}{*}{4} & $\begin{array}{l}\text { Attraction of private } \\
\text { capital and foreign } \\
\text { investments }\end{array}$ & & & & \\
\hline & 4.1 & $\begin{array}{l}\text { Preparation of the policies for privatization and } \\
\text { investments in the distribution and generation } \\
\text { sectors }\end{array}$ & $\mathrm{ME}$ & $\begin{array}{c}31 \text { December } \\
2003\end{array}$ & \\
\hline 5 & $\begin{array}{l}\text { Establishment } \text { of a } \\
\text { competitive } \\
\text { market in comergy } \\
\text { with } \quad \text { the } \quad \text { EU }\end{array}$ & & & & \\
\hline
\end{tabular}

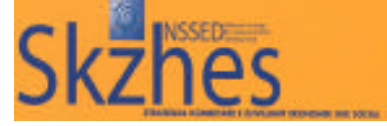


ANNEX 2 PROGRAM OF PRIORITY ACTION PLAN 2003

\begin{tabular}{|l|l|l|l|l|l|}
\hline No & \multicolumn{1}{|c|}{ Objectives } & $\begin{array}{c}\text { Responsible } \\
\text { Institution }\end{array}$ & Deadline & $\begin{array}{c}\text { Budgetory } \\
\text { effects }\end{array}$ \\
\hline & $\begin{array}{l}\text { requirements for reform } \\
\text { in the power sector } \\
(96 / 92 \text { EU Directive) and } \\
\text { Albania's obligations } \\
\text { under Thessaloniki } \\
\text { Agreement to support } \\
\text { Albania's integration } \\
\text { into the South East } \\
\text { European Regional } \\
\text { Market (REM) and inter } \\
\text { connections with the } \\
\text { UCTE system. }\end{array}$ & & & \\
& 5.1 & $\begin{array}{l} \\
\text { Marticipation in the meetings of the Power } \\
\text { Market Management Committee (REM). }\end{array}$ & MI\&E & Continuing & \\
\hline
\end{tabular}


ANNEX 2 PROGRAM OF PRIORITY ACTION PLAN 2003

FUEL SECTOR

\begin{tabular}{|c|c|c|c|c|c|}
\hline No & Objectives & Planned actions & $\begin{array}{l}\text { Responsible } \\
\text { Institution }\end{array}$ & Deadline & Budgetory effects \\
\hline 1 & $\begin{array}{l}\text { Full reconstruction of } \\
\text { the publicly-owned } \\
\text { companies in the fuel } \\
\text { sector }\end{array}$ & $\begin{array}{l}\text { All measures will be taken for the } \\
\text { implementation of Council of Minister Decision } \\
\text { No } 28 \text { date } 16.01 .2003 \text { on the liquidation of } \\
\text { APC. } \\
\text { The decisions of the supervisory council of the } \\
\text { sector companies for their organizational } \\
\text { restructuring will be implemented }\end{array}$ & $\begin{array}{l}\text { ME } \\
\text { MIE } \\
\text { Companies }\end{array}$ & $\begin{array}{l}\text { Until May } \\
2003\end{array}$ & \\
\hline \multirow[t]{6}{*}{2} & $\begin{array}{l}\text { Privatization of publicly- } \\
\text { owned oil companies }\end{array}$ & & & & \\
\hline & 2.1 & $\begin{array}{l}\text { Bringing "SERVCOM SH.A" company to the } \\
\text { point of sale }\end{array}$ & $\begin{array}{l}\text { ME } \\
\text { MIE } \\
\text { SERVCOM }\end{array}$ & 2003 & \\
\hline & 2.2 & $\begin{array}{l}\text { Bringing "TRANSNAFTA" Sh.p.k Patos } \\
\text { company to the point of sale, in compliance of } \\
\text { Council of Minister Decision } 30 \text { date } 16.1 .2003\end{array}$ & $\begin{array}{l}\text { ME } \\
\text { MIE } \\
\text { TRANSNAFTA }\end{array}$ & 2003 & \\
\hline & 2.3 & $\begin{array}{l}\text { Bringing "Mechanical Plant" Sh.p.k Patos } \\
\text { company to the point of sale, in compliance of } \\
\text { Council of Minister Decision } 29 \text { date 16.1.2003 }\end{array}$ & $\begin{array}{l}\text { ME } \\
\text { MIE } \\
\text { Patos Plant }\end{array}$ & 2003 & \\
\hline & 2.4 & $\begin{array}{l}\text { Bringing } 51 \% \text { of the state shares in } \\
\text { "Petrolimpex" sh.a. Tirane company to the } \\
\text { point of sale }\end{array}$ & $\begin{array}{l}\text { ME } \\
\text { MIE } \\
\text { Petrolimpex }\end{array}$ & 2003 & \\
\hline & 2.5 & $\begin{array}{l}\text { Preparation for the privatization of "ARMO" } \\
\text { SH.A. Fier company. Following the } \\
\text { procedures from the preparation of the draft } \\
\text { law and other judicial acts up to the point of } \\
\text { sale of this company. }\end{array}$ & $\begin{array}{l}\text { ME } \\
\text { MIE } \\
\text { ARMO }\end{array}$ & 2003 & \\
\hline 3 & $\begin{array}{l}\text { Strengthening of } \\
\text { producing, processing, } \\
\text { and importing } \\
\text { capacities for oil, gas } \\
\text { and by-products }\end{array}$ & & & & \\
\hline & 3.1 & $\begin{array}{l}\text { Increase of the oil and gas production by } \\
\text { Albpetrol sh.a., as well as in the framework of }\end{array}$ & $\begin{array}{l}\text { MIE } \\
\text { ALBPETROL }\end{array}$ & $\begin{array}{l}2003 \text { and } \\
\text { continuing }\end{array}$ & \\
\hline
\end{tabular}


ANNEX 2 PROGRAM OF PRIORITY ACTION PLAN 2003

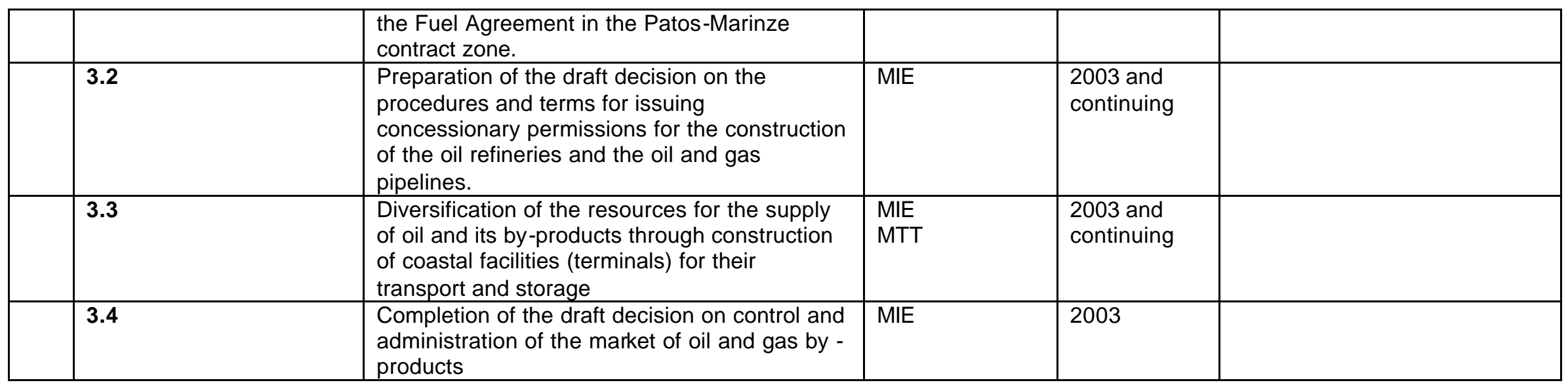


ANNEX 2 PROGRAM OF PRIORITY ACTION PLAN 2003

\section{MINING SECTOR}

\begin{tabular}{|c|c|c|c|c|c|}
\hline No & Objectives & Planned actions & $\begin{array}{c}\text { Responsible } \\
\text { Institution }\end{array}$ & Deadline & $\begin{array}{c}\text { Budgetory } \\
\text { effects }\end{array}$ \\
\hline \multirow[t]{7}{*}{1} & $\begin{array}{l}\text { MONITORING AND } \\
\text { IMPLEMENTATION OF } \\
\text { CHROME } \\
\text { CONCESSIONARY } \\
\text { AGREEMENTS }\end{array}$ & & $\begin{array}{l}\text { MINING D.P. } \\
\text { O.SH.A } \\
\text { (Authorized } \\
\text { state entity) }\end{array}$ & 2002- June 2004 & \\
\hline & 1.1 & $\begin{array}{l}\text { Follow the completion of the investments } \\
\text { amounting to } 6.0 \text { million USD, on the third } \\
\text { furnace and the gas cleaning facility of UFK } \\
\text { Elbasan, law No } 8590 \text { date } 23.03 .2000 \text { and } \\
\text { achieving a production of } 40000 \text { tons of FeCr a } \\
\text { year. }\end{array}$ & & $\begin{array}{l}\text { JANUARY DECEMBER } \\
2003\end{array}$ & \\
\hline & 1.2 & $\begin{array}{l}\text { Follow the implementation of the agreement by } \\
\text { OSHA, on investments the accomplishment of } \\
\text { works in the Mines, Enrichment Factory and } \\
\text { UFK Elbasan and Burrel. }\end{array}$ & & CONTINUING & \\
\hline & 1.3 & $\begin{array}{l}\text { Application of the penalizations, according to } \\
\text { the contract, on all shortfalls }\end{array}$ & & CONTINUING & \\
\hline & 1.4 & $\begin{array}{l}\text { Making the investmens of the agreement by } \\
\text { year }\end{array}$ & & CONTINUING & \\
\hline & 1.5 & $\begin{array}{l}\text { Achieving production of the mineral } \\
\text { Concentrate and Ferro-chrome }\end{array}$ & & CONTINUING & \\
\hline & 1.6 & $\begin{array}{l}\text { Follow the implementation of the agreement by } \\
\text { OSHA, on investments the accomplishment of } \\
\text { works in the Mines, Enrichment Factory and } \\
\text { UFK Elbasan and Burrel. }\end{array}$ & & CONTINUING & \\
\hline 2 & $\begin{array}{l}\text { Monitoring of the } \\
\text { implementation of } \\
\text { copper concessionary } \\
\text { agreement, law No } 8761 \\
\text { date } 02.04 .2001 \text {. }\end{array}$ & & & & \\
\hline & 2.1 & Identification of the facilities, which will be & MINING D.P & JANUARY MARCH & \\
\hline
\end{tabular}


ANNEX 2 PROGRAM OF PRIORITY ACTION PLAN 2003

\begin{tabular}{|c|c|c|c|c|c|}
\hline No & Objectives & Planned actions & $\begin{array}{l}\text { Responsible } \\
\text { Institution }\end{array}$ & Deadline & $\begin{array}{l}\text { Budgetory } \\
\text { effects }\end{array}$ \\
\hline & & $\begin{array}{l}\text { taken over, on the basis of the Protocol } \\
\text { Agreement }\end{array}$ & $\begin{array}{l}\text { O.SH.A } \\
\text { (Authorized } \\
\text { state entity) }\end{array}$ & 2003 & \\
\hline & 2.2 & $\begin{array}{l}\text { Making the investments in the facilities, which } \\
\text { will be taken over (their total value is } 20.6 \\
\text { million USD). }\end{array}$ & & CONTINUING & \\
\hline & 2.3 & $\begin{array}{l}\text { Preparation of the study, preparation of the } \\
\text { agreement, and the realization of the } \\
\text { technological test in UB Rubik to determine the } \\
\text { technical-economic standards for the } \\
\text { production of blister copper }\end{array}$ & & $\begin{array}{l}\text { JANUARY OCTOBER } \\
2003\end{array}$ & \\
\hline & 2.4 & $\begin{array}{l}\text { Implementation of the protocol agreements on } \\
\text { the identification of the facilities and their } \\
\text { handover }\end{array}$ & & JANUARY APRIL 2003 & \\
\hline 3 & $\begin{array}{l}\text { Determination of the } \\
\text { new status of Albkrom } \\
\text { Lmt., and Albbaker Lmt., } \\
\text { with adjustment to new } \\
\text { conditions, after the } \\
\text { facilities are subjected } \\
\text { to concessionary and } \\
\text { privatization processes }\end{array}$ & & & & \\
\hline & 3.1 & $\begin{array}{l}\text { Implementation of the tasks specified in the } \\
\text { study. }\end{array}$ & $\begin{array}{l}\text { D.P.M, D.P.ZH, } \\
\text { JUDICIAL } \\
\text { DEPART. }\end{array}$ & JANUARY JULY 2003 & \\
\hline & 3.2 & Un-registration of the companies. & $\begin{array}{l}\text { D.P.M, D.P.ZH, } \\
\text { JUDICIAL } \\
\text { DEPART. }\end{array}$ & $\begin{array}{l}\text { AUGUST DECEMBER } \\
2003\end{array}$ & \\
\hline 4 & $\begin{array}{l}\text { Closure of chrome, } \\
\text { copper, coal, and iron- } \\
\text { nickel mines (which are } \\
\text { closed in compliance } \\
\text { with approved Council } \\
\end{array}$ & & MINING D.P. & & \\
\hline
\end{tabular}


ANNEX 2 PROGRAM OF PRIORITY ACTION PLAN 2003

\begin{tabular}{|c|c|c|c|c|c|}
\hline No & Objectives & Planned actions & $\begin{array}{l}\text { Responsible } \\
\text { Institution }\end{array}$ & Deadline & $\begin{array}{l}\text { Budgetory } \\
\text { effects }\end{array}$ \\
\hline & $\begin{array}{l}\text { of Minister decisions; } \\
\text { which are not subjected } \\
\text { to a concessionary } \\
\text { takeover). Privatization } \\
\text { of their assets or their } \\
\text { liquidation. }\end{array}$ & & & & \\
\hline & 4.1 & $\begin{array}{l}\text { Preparation of the necessary documents for } \\
\text { privatization and liquidation. }\end{array}$ & & $\begin{array}{l}\text { JANUARY DECEMBER } \\
2003\end{array}$ & \\
\hline & 4.2 & $\begin{array}{l}\text { Preparation of the Council of Ministers } \\
\text { Decision on the closure of the miners, which } \\
\text { will not be taken over on basis of a } \\
\text { concessionary agreement }\end{array}$ & & JANUARY JUNE 2003 & \\
\hline & 4.3 & $\begin{array}{l}\text { Follow continuously the implementation of the } \\
\text { program on the closure of the mines and the } \\
\text { implementation of the relevant Council of } \\
\text { Ministers Decisions }\end{array}$ & & $\begin{array}{l}\text { DURING THE YEAR } \\
2003\end{array}$ & \\
\hline 5 & $\begin{array}{l}\text { Engagement of the } \\
\text { Albanian Geological } \\
\text { Service in important } \\
\text { studies for the national } \\
\text { economy }\end{array}$ & & $\begin{array}{l}\text { MINING D.P., } \\
\text { SH.GJ.SH. }\end{array}$ & 2003-2005 & \\
\hline & 5.1 & $\begin{array}{l}\text { Evaluation and management of the } \\
\text { underground water in the main water basins, } \\
\text { with priority given to those in the urban and } \\
\text { tourist areas. } \\
\text { Study of Elbasan-Korçe dhe Vlore -Butrint } \\
\text { basins. }\end{array}$ & & $\begin{array}{l}\text { JANUARY DECEMBER } \\
2003\end{array}$ & \\
\hline & 5.2 & $\begin{array}{l}\text { Complex study regarding the administration of } \\
\text { the territory and the natural resources, at a } \\
\text { national and local level } \\
\text { a. Completion of the study of the Tirane- } \\
\text { Durres-Kavaje region and Shkoder-Vlore- }\end{array}$ & & & \\
\hline
\end{tabular}


ANNEX 2 PROGRAM OF PRIORITY ACTION PLAN 2003

\begin{tabular}{|c|c|c|c|c|c|}
\hline No & Objectives & Planned actions & $\begin{array}{c}\text { Responsible } \\
\text { Institution }\end{array}$ & Deadline & $\begin{array}{l}\text { Budgetory } \\
\text { effects }\end{array}$ \\
\hline & & Korçe-Gjirakoster-Kukes-Diber-Lezhe regions & & $\begin{array}{l}\text { JANUARY DECEMBER } \\
2003\end{array}$ & \\
\hline & 5.3 & $\begin{array}{l}\text { Civil geological study related to problems of } \\
\text { the infrastructure in our country. } \\
\text { a.Monitoring of the deformations and landslide } \\
\text { for the dams of Boville and Dallake. }\end{array}$ & & $\begin{array}{l}\text { JANUARY DECEMBER } \\
2003\end{array}$ & \\
\hline & 5.4 & $\begin{array}{l}\text { Studies to identify adequate sites for urban } \\
\text { waste, mainly for urban areas. } \\
\text { a.Studies for Lac-Kruje-Rreshen-Rrogozhine- } \\
\text { Cerrik-Peqin regions. }\end{array}$ & & $\begin{array}{l}\text { JANUARY DECEMBER } \\
2003\end{array}$ & \\
\hline 6 & $\begin{array}{l}\text { Revision of the main } \\
\text { laws, on which the } \\
\text { development of the } \\
\text { mining industry and } \\
\text { SHGJSH is based }\end{array}$ & & $\begin{array}{l}\text { D.P.M, } \\
\text { I.T.N.P.M, D.J. } \\
\text { SHGJSH }\end{array}$ & & \\
\hline & 6.1 & $\begin{array}{l}\text { Preparation of the draft for the Amendment of } \\
\text { the Albanian Mining Law No. } 7796 \text { date } \\
17.02 .1994\end{array}$ & & $\begin{array}{l}\text { JANUARY DECEMBER } \\
2003\end{array}$ & \\
\hline & 6.2 & $\begin{array}{l}\text { Preparation of the draft for the Amendment of } \\
\text { the Law on SHGJSH }\end{array}$ & & $\begin{array}{l}\text { JANUARY DECEMBER } \\
2003\end{array}$ & \\
\hline
\end{tabular}


ANNEX 2 PROGRAM OF PRIORITY ACTION PLAN 2003

INDUSTRY SECTOR

\begin{tabular}{|c|c|c|c|c|c|}
\hline No & Objectives & Planned actions & $\begin{array}{l}\text { Responsible } \\
\text { Institution }\end{array}$ & Deadline & $\begin{array}{l}\text { Budgetory } \\
\text { effects }\end{array}$ \\
\hline \multirow[t]{4}{*}{11} & $\begin{array}{l}\text { The possibility for the } \\
\text { establishment of the } \\
\text { industrial parks and } \\
\text { ways for their } \\
\text { development should } \\
\text { be explored }\end{array}$ & & M.I.E. & 2003 & \\
\hline & 1.1 & $\begin{array}{l}\text { The facilities and the free areas should be } \\
\text { identified for the proposed establishment of the } \\
\text { industrial park in the region of former } \\
\text { Metallurgical Plant Elbasan }\end{array}$ & $\begin{array}{l}\text { M.I.E. } \\
\text { I.S.P. Metallurgy }\end{array}$ & 2003 & \\
\hline & 1.2 & $\begin{array}{l}\text { The infrastructure in the former Metallurgical } \\
\text { Plant Elbasan should be studied and } \\
\text { measures should be identified for its } \\
\text { consolidation so that it can be used for the } \\
\text { establishment of the industrial park. }\end{array}$ & $\begin{array}{l}\text { M.I.E. } \\
\text { I.S.P. Metallurgy } \\
\text { Elbasan }\end{array}$ & 2003 & \\
\hline & 1.3 & $\begin{array}{l}\text { Preparation of the draft project on the industrial } \\
\text { park in the Metallurgical Plant Elbasan. }\end{array}$ & $\begin{array}{l}\text { M.I.E. } \\
\text { I.S.P. Metallurgy } \\
\text { Elbasan }\end{array}$ & 2003 & \\
\hline
\end{tabular}


ANNEX 2 PROGRAM OF PRIORITY ACTION PLAN 2003

TABLE 8: HEALTH CARE INSURANCE INSTITUTE 
ANNEX 2 PROGRAM OF PRIORITY ACTION PLAN 2003

TABLE 8: HEALTH CARE INSURANCE INSTITUTE

\begin{tabular}{|c|c|c|c|c|c|}
\hline $\begin{array}{l}\text { Field/ } \\
\text { Sector }\end{array}$ & Objectives & Priority Public Measures & $\begin{array}{c}\text { Responsible } \\
\text { Institution }\end{array}$ & Deadline & $\begin{array}{l}\text { Budgetory } \\
\text { Effects } \\
\text { millions leks) }\end{array}$ \\
\hline 1 & 2 & 3 & 4 & 5 & 6 \\
\hline $\begin{array}{l}\text { Health Care } \\
\text { Insurance } \\
\text { Institute }\end{array}$ & $\begin{array}{l}\text { - Legal preparation for the } \\
\text { introduction of new } \\
\text { services into the Health } \\
\text { Insurance scheme. } \\
\text { Institutional development } \\
\text { in compliance with the } \\
\text { legal changes }\end{array}$ & $\begin{array}{l}\text { 1. Overall restructuring of the ISKSH in accordance with } \\
\text { the expansion and consolidation of the scheme. } \\
\text { 2. Preparation of the Law on Health Insurance } \\
\text { 3. Preparation of the Law on Health Care Financing } \\
\text { 4. Preparation of the Law on Supplementary and Voluntary } \\
\text { Insurance Scheme. } \\
\text { 5. Preparation of the Law on Coverage of Expensive Check- } \\
\text { Ups by ISKSH } \\
\text { 6. Preparation of the legal and sub-legal acts for the } \\
\text { implementation of the laws. } \\
\text { 7. Change of the regulations for internal operation. } \\
\text { 1. Job description for every new working place } \\
\text { 2. Establishment of new bodies in ISKSH and Regional } \\
\text { Departments. } \\
\text { 3. Reorganization of the operation of the Regional } \\
\text { Departments and Agencies } \\
\text { 4. Training of the staff. }\end{array}$ & $\begin{array}{l}\text { ISKSH, Health } \\
\text { Ministry, Finance } \\
\text { Ministry }\end{array}$ & $\begin{array}{l}\text { September- } \\
\text { December } \\
\text { September } \\
\text { September } \\
\text { June } \\
\text { June } \\
\text { April- } \\
\text { September } \\
\text { During the year }\end{array}$ & 10 \\
\hline
\end{tabular}


ANNEX 2 PROGRAM OF PRIORITY ACTION PLAN 2003

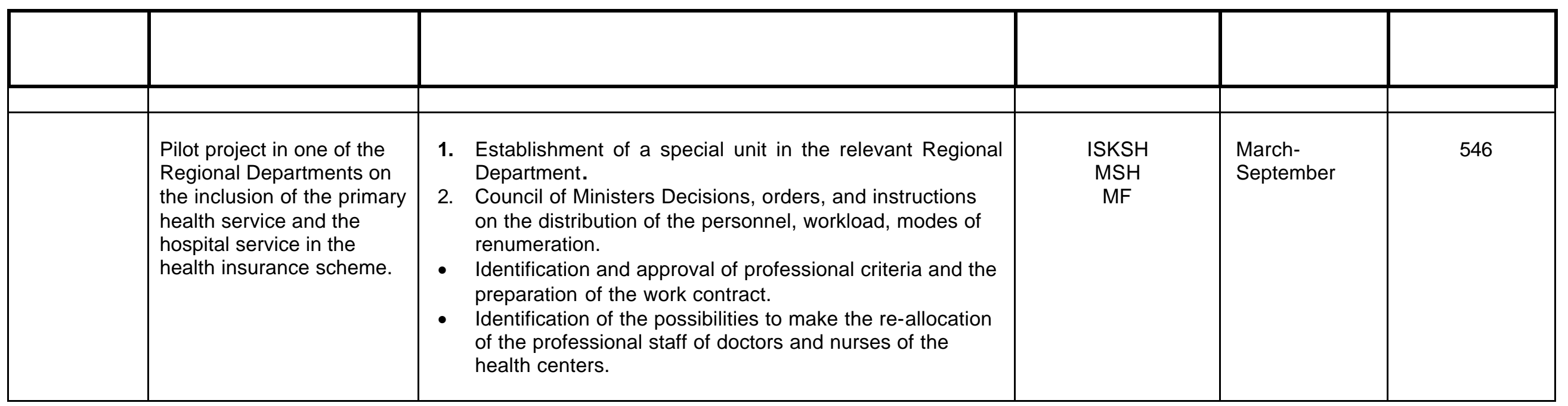


ANNEX 2 PROGRAM OF PRIORITY ACTION PLAN 2003

\begin{tabular}{|c|c|c|c|c|c|}
\hline & $\begin{array}{l}\text { Re-registration of the } \\
\text { population and its } \\
\text { provision with the } \\
\text { insurance card } \\
\text { Qualitative identification of } \\
\text { the level of coverage of } \\
\text { the drugs' price based on } \\
\text { the cost-efficiency } \\
\text { concept. }\end{array}$ & $\begin{array}{l}\text { 3. Establishment of the relevant unit in the ISKSH to monitor } \\
\text { the process. } \\
\text { 4. Establishment of the relevant units in every Prefecture for } \\
\text { the implementation of the Re-registration project. } \\
\text { a. Preparation and approval of the Council of } \\
\text { - Ministers Decision on this project. } \\
\text { Organization of the relevant bodies in the ISKSH and in } \\
\text { its subordinate bodies. } \\
\text { - Identification of the methodology for the implementation } \\
\text { of this project. } \\
\text { - Establishment of the unit, which will calculate the } \\
\text { extent of the coverage. } \\
\text { The Council of Ministers Decision on determining the } \\
\text { level at which the drugs' prices will be covered. } \\
\text { Qualification of the specialists, who will work on } \\
\text { achieving cost efficiency. } \\
\text { Establishment of a broad working group, in which the } \\
\text { QSUT clinics will be of primary } \\
\text { cooperation with the } \\
\text { importance for the implementation of this project. }\end{array}$ & $\begin{array}{l} \\
\text { ISKSH in } \\
\text { cooperation with } \\
\text { QSUT. }\end{array}$ & $\begin{array}{l}\text { April- } \\
\text { September } \\
\text { April- } \\
\text { September } \\
\text { September- } \\
\text { December }\end{array}$ & 59 \\
\hline \multirow[t]{2}{*}{1} & 2 & 3 & 4 & 5 & 6 \\
\hline & $\begin{array}{l}\text { Improvement of the list of } \\
\text { drugs reimbursed by the } \\
\text { ISKSH }\end{array}$ & $\begin{array}{l}\text { - The Council of Ministers Decision on the approval of } \\
\text { the list of the drugs, which are reimbursed. } \\
\text { - Changes in the Council of Minsters Decision on the } \\
\text { prices of the drugs, which are reimbursed by the } \\
\text { ISKSH }\end{array}$ & $\begin{array}{l}\text { ISKSH, MSH, } \\
\text { Commission of the } \\
\text { Drug List, } \\
\text { Commission of the } \\
\text { Drug Price }\end{array}$ & & \\
\hline
\end{tabular}


ANNEX 2 PROGRAM OF PRIORITY ACTION PLAN 2003

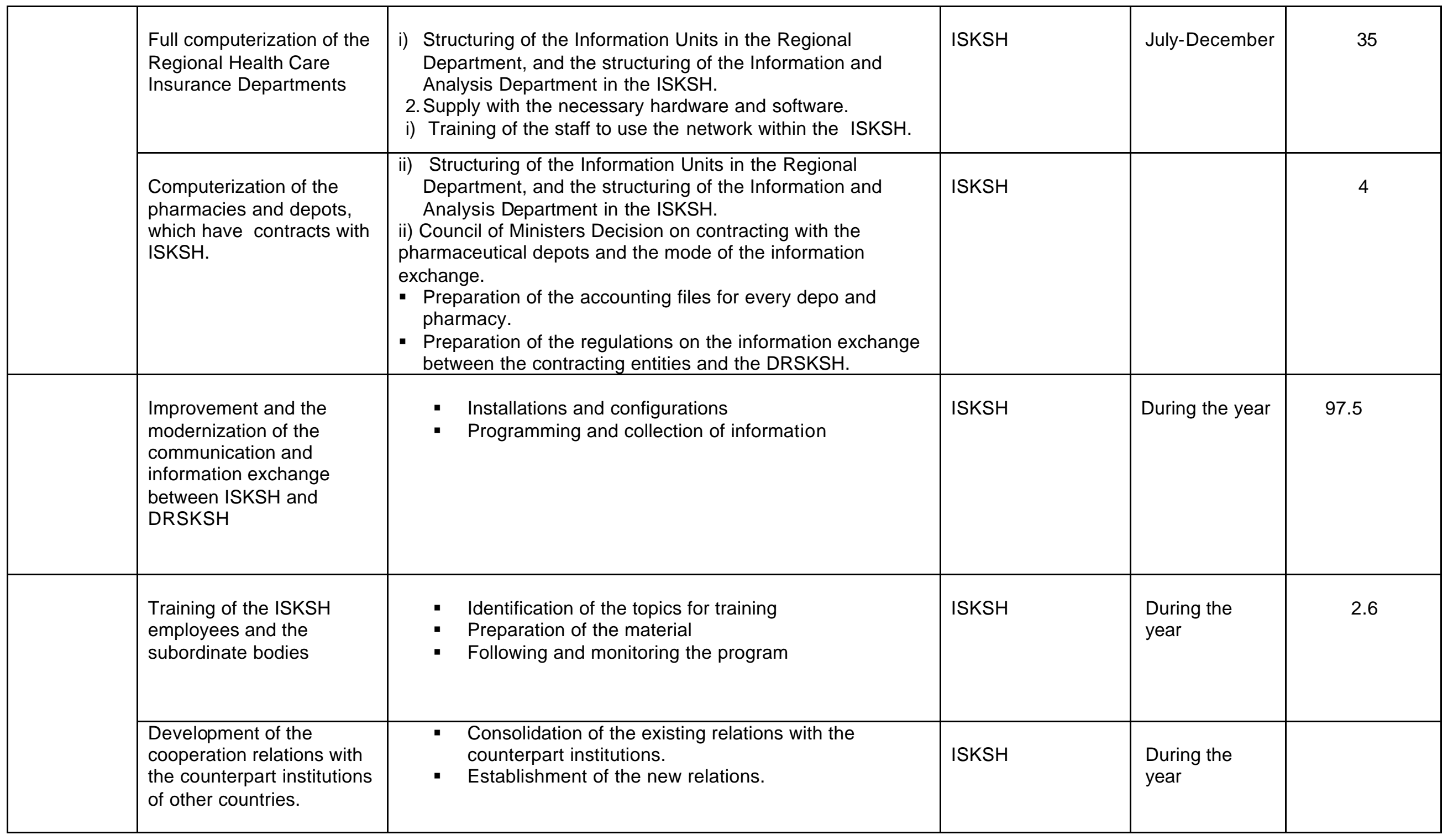


ANNEX 2 PROGRAM OF PRIORITY ACTION PLAN 2003

TABLE 9: MINISTRY OF AGRICULTURE AND FOOD 
ANNEX 2 PROGRAM OF PRIORITY ACTION PLAN 2003

TABLE 9: MINISTRY OF AGRICULTURE AND FOOD

DETAILED PROGRAM OF PRIORITY ACTIONS FOR 2003

\begin{tabular}{|c|c|c|c|c|c|}
\hline $\begin{array}{l}\text { Field/ } \\
\text { Sector }\end{array}$ & Objectives & Public Priority measures & $\begin{array}{l}\text { Responsible } \\
\text { Institution }\end{array}$ & Deadline & $\begin{array}{l}\text { Budgetory } \\
\text { Effects } \\
\text { (mln/lek) }\end{array}$ \\
\hline $\begin{array}{l}\text { Agriculture } \\
\text { and Food }\end{array}$ & $\begin{array}{l}\text { 1. Maintaining the } \\
\text { growth rate of the } \\
\text { agricultural, } \\
\text { livestock, agro-food } \\
\text { and fishery } \\
\text { production }\end{array}$ & $\begin{array}{l}\text { Development of the land market and the } \\
\text { consolidation of ownership: } \\
\text { 1.1.1 Consolidation of the land administration } \\
\text { offices in all districts; } \\
\text { - Compilation and supply of documentation to all land } \\
\text { administration bodies } \\
\text { - Approval of the draft decision of the Council of Ministers } \\
\text { on the number of employees } \\
\text { 1.1.2 Completion of the registration of land, forests, } \\
\quad \text { and pastures and its publication (Draft for } \\
\text { Immoveable Property Registration etc); } \\
\text { - Registration of the agricultural land and pastures in } 445 \mathrm{ZK} \\
\text { and submission to the registration offices } \\
\text { - Distribution of the ownership documents in the northern area } \\
\text { - Settlement of the disputes in various districts } \\
\text { - Development of the land market in the pilot communes } \\
\text { - Publication of a brochure on the application of the } \\
\text { procedures of transactions } \\
\text { - Preparation of a documentary on the effectiveness of land } \\
\text { consolidation } \\
\text { - Making an inventory of the registration and transfer of state- } \\
\text { owned immoveable property } \\
\text { a. Filling and submission of the forms } \\
\text { b. Approval of the public property documentation } \\
\text { c. Preparation and organization of the consultations on } \\
\text { unified documentation } \\
\text { d. Approval of the unified documentation } \\
\text { - Draft Council of Ministers Decision on change of the } \\
\text { registration of transactions on agricultural land } \\
\text { 1.1.3 Establishment of the information system on }\end{array}$ & $\begin{array}{l}\text { MBU, PSHB, } \\
\text { SRPP } \\
\text { KOM.KK Prones }\end{array}$ & $\begin{array}{l}2003 \text { - } 2006 \\
\text { January- } \\
\text { November } \\
\text { January } \\
\\
\\
\text { February } \\
\text { December } \\
\text { January- } \\
\text { October } \\
\text { January- } \\
\text { October } \\
2003 \\
\text { March-April, } \\
\text { June } 2003 \\
\text { December } \\
2003 \\
\text { January- } \\
\text { March } 2003 \\
\text { December } \\
2003 \\
\text { January-May } \\
\text { July } 2003 \\
\text { January-June }\end{array}$ & 366 \\
\hline
\end{tabular}




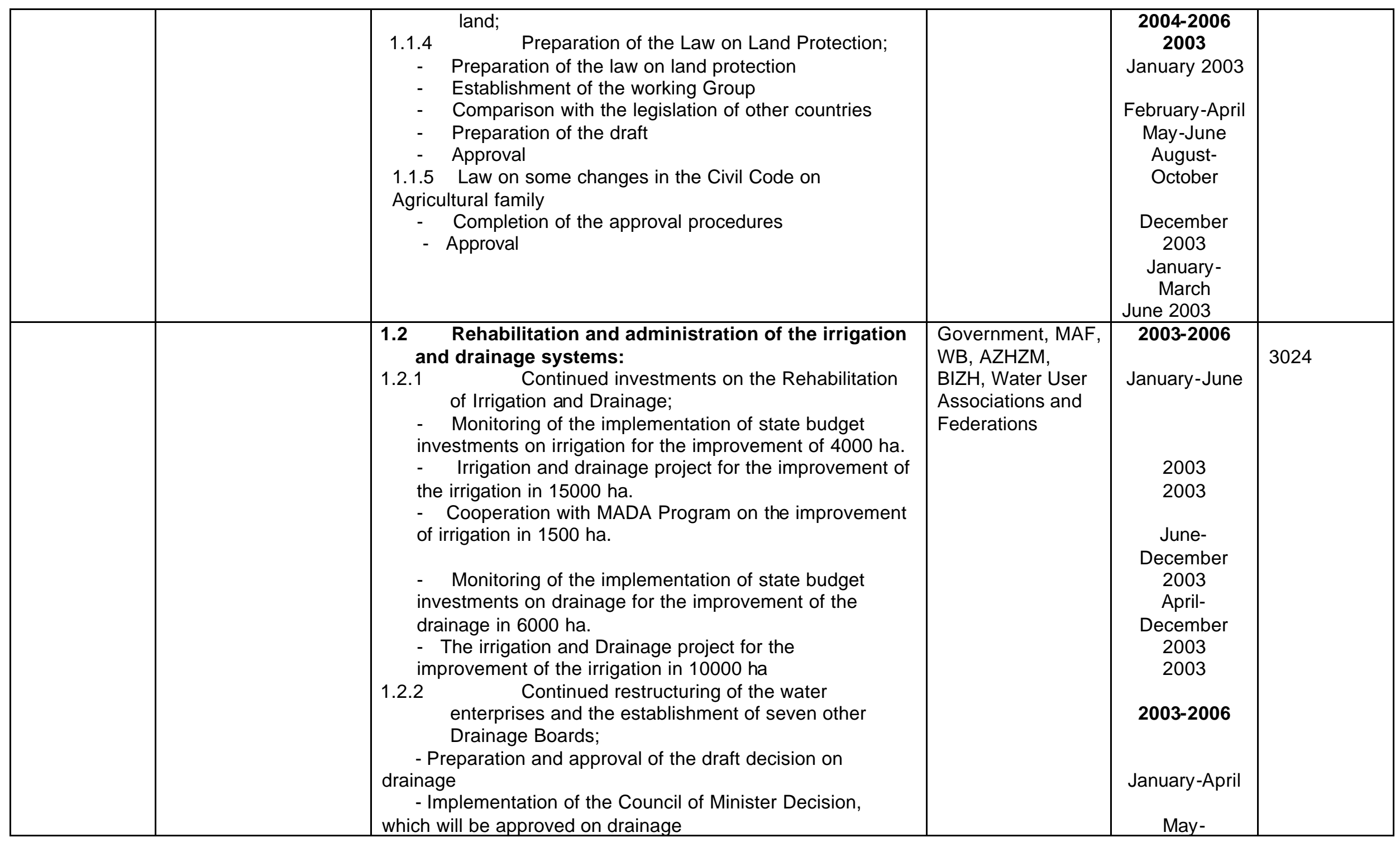




\begin{tabular}{|c|c|c|c|c|c|}
\hline & & 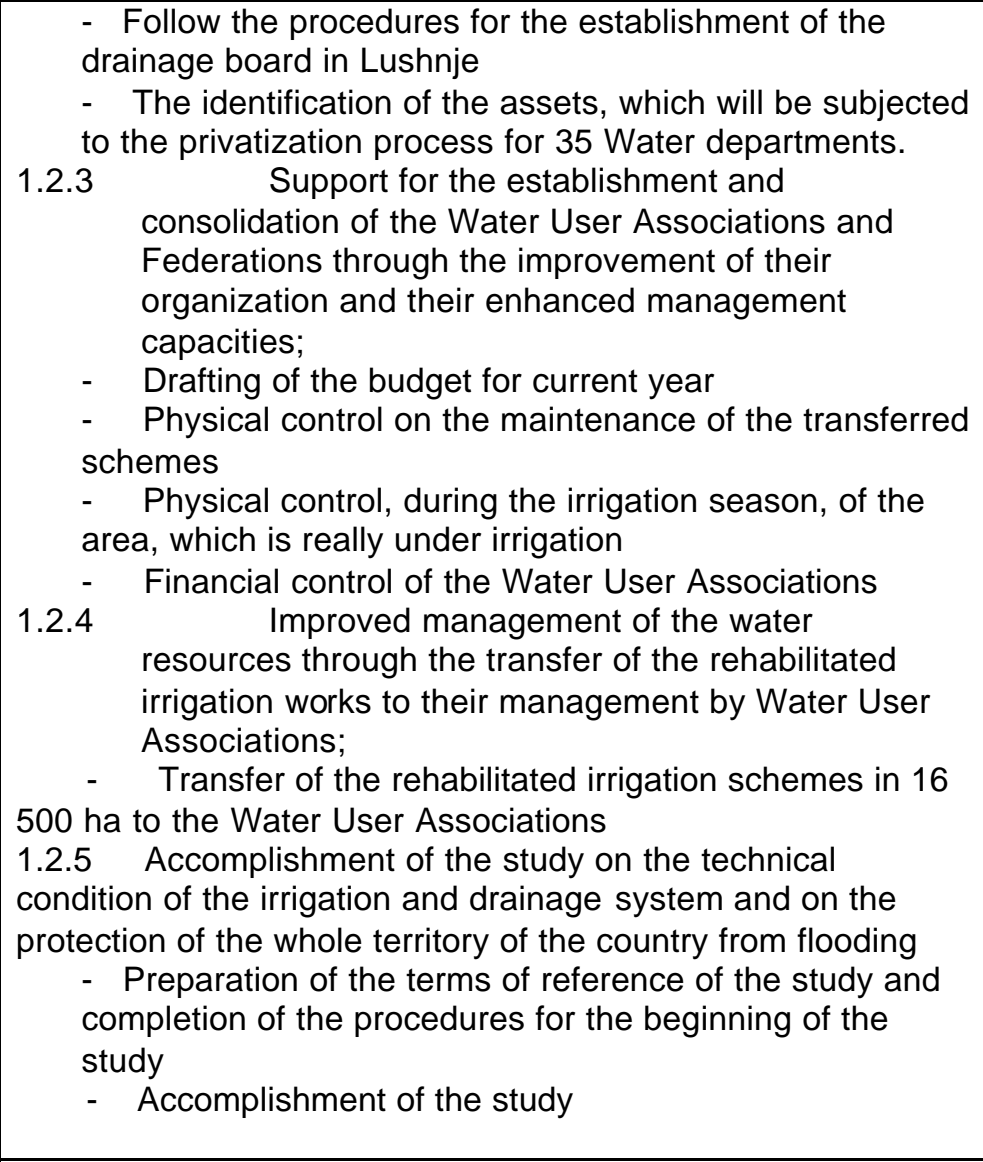 & & $\begin{array}{l}\text { December } \\
2003 \\
2003 \\
\\
\text { 2003-2006 } \\
\\
\\
\text { January- } \\
\text { March } \\
\text { April-May } \\
2003 \\
\text { June- } \\
\text { September } \\
\text { September- } \\
\text { December } \\
\text { January- } \\
\text { December } \\
\text { 2003-2006 } \\
\text { January- } \\
\text { March } \\
\text { April- } \\
\text { December } \\
\end{array}$ & \\
\hline & & $\begin{array}{l}\text { 1.3 Promotion of the mechanization and application } \\
\text { of new technologies, and the improvement of the } \\
\text { quality of inputs: } \\
\text { Promotion of the investments for the } \\
\text { i.3.1 } \\
\text { mprovement of the technologies and the level of the } \\
\text { such as Agricultural Production Growth Project (2KR), } \\
\text { Agricultural Service Project (Scheme of Competitive }\end{array}$ & $\begin{array}{l}\text { Government, MAF, } \\
\text { PSHB, 2KR } \\
\text { ESHFF, } \\
\text { IKB, PSHB, } \\
\text { Various } \\
\text { organizations }\end{array}$ & & 643 \\
\hline
\end{tabular}




\begin{tabular}{|c|c|c|c|c|c|}
\hline & . & $\begin{array}{l}\text { Grants), etc, and the improvement of the legislation; } \\
\text { - In the framework of 2KR project, new machineries and } \\
\text { technologies for the processing of the agricultural } \\
\text { products will be brought } \\
\text { - } \begin{array}{l}\text { About } 30 \text { grants for the improvement of the technology will } \\
\text { be approved }\end{array} \\
\text { Enhanced level of the glasshouse } \\
\text { 1.3.2 mechanization and production through cost reduction } \\
\text { of the inputs (through fuel price differentiation); } \\
\text { Restructuring and consolidation of the } \\
\text { 1.3.3 institutions and laboratories for the control and } \\
\text { certification of the chemical fertilizers, seeds, } \\
\text { saplings, livestock feed, products for crop protection } \\
\text { PMB (2004); } \\
\text { Financial support for the sector of the } \\
\text { production of high-quality seeds through projects with } \\
\text { various donors and associations; } \\
\text { 1.3.4 Continued activities in the framework of the two projects } \\
\text { of World Bank IFAD } \\
\text { Establishment of breed improvement centers } \\
\text { 1.3.5 for larger and smaller livestock; } \\
\text { - } \begin{array}{l}\text { establishment of breed herds for the production of } \\
\text { livestock breeding material } \\
\text { opening of } 20 \text { centers of IA for larger and smaller livestock }\end{array} \\
\text { - }\end{array}$ & & $\begin{array}{l}\text { October- } \\
\text { December } \\
2006 \\
2006 \\
\\
\text { June and } \\
\text { November } \\
2003 \\
\text { January - } \\
\text { December }\end{array}$ & \\
\hline & & $\begin{array}{l}\text { 1.4 Various agricultural services (Advisory, fito-sanitary, } \\
\text { veterinary, zoo-technical) } \\
\text { 1.4.1 Consolidation of the agricultural research and advisory } \\
\text { network } \\
\text { - Consolidation of the public advisory bodies in the } \\
\text { regional agricultural and food departments. } \\
\text { - Delivery of the services contracted for the farmers (up } \\
\text { to } 45 \text { contracts by 2006); } \\
\text { - Support for the development of an effective private } \\
\text { advisory service in the areas with the highest } \\
\text { production potential in the country; }\end{array}$ & MAF, & 2003-2006 & 70 \\
\hline
\end{tabular}




\begin{tabular}{|c|c|c|c|}
\hline & 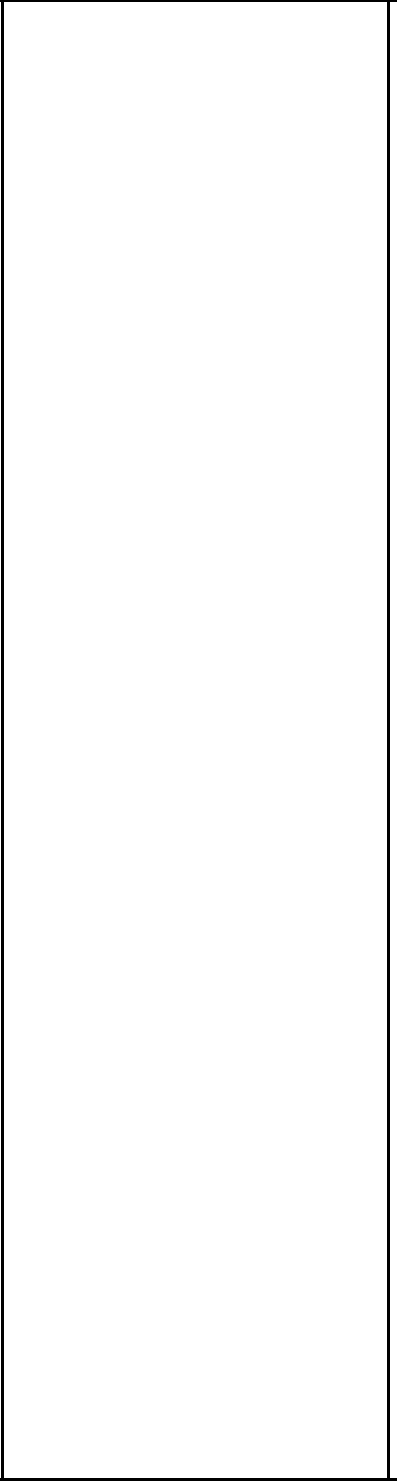 & $\begin{array}{ll}- & \text { Restructuring of the agricultural research } \\
\text { - } & \text { Consolidation of IKBA, product of the first phase of } \\
\text { the restructuring of four Agricultural Research } \\
\text { Institutes } \\
\text { - } \quad \text { Study and planning of further phases in the } \\
\text { restructuring of IKB-s; } \\
\text { - } \quad \text { Increased contribution to the growth of production and } \\
\text { improvement of the quality; } \\
\text { - } \quad \text { Preparation of a draft on research policies with } \\
\text { foreign technical assistance } \\
\text { 1.4.2 } \quad \text { Consolidation of the fito-sanitary and crop protection } \\
\text { services; } \\
\text { Keeping the crop diseases and pests under control; } \\
\text { - Control over products for the protection of crops and } \\
\text { fito-pharmacies; } \\
\text { Enhanced inter-institutional cooperation on prevention } \\
\text { of epidemics; } \\
\text { Increased awareness of the producers to apply crop } \\
\text { integrated protection and support for the organic } \\
\text { agriculture initiatives; } \\
\text { Continuity and extension of the projects on the } \\
\text { improvement of the veterinary prophylaxis and the } \\
\text { livestock health (various projects in cooperation with } \\
\text { the Veterinary Research Institute); } \\
\text { Keeping the zoonotic diseases under control and } \\
\text { cooperation with the Health Ministry and the reduction } \\
\text { of the level of animal and human disease contraction; } \\
\text { Adoption of the measures related to signaling and } \\
\text { prevention of the diseases of A List and other } \\
\text { diseases; } \\
\text { Improvement of the policies on the use of the human } \\
\text { and financial resources at all levels of veterinary } \\
\text { service; } \\
\text { Consolidation of the zoo-technical service } \\
\text { Restructuring of the zoo-technical service in the } \\
\text { framework of the establishment of the Regional } \\
\text { Agricultural Departments; }\end{array}$ & $\begin{array}{l}\text { January - } \\
\text { December } \\
\text { January - } \\
\text { December } \\
\text { 2003-2006 } \\
\text { 2003-2006 } \\
2003-2006\end{array}$ \\
\hline
\end{tabular}




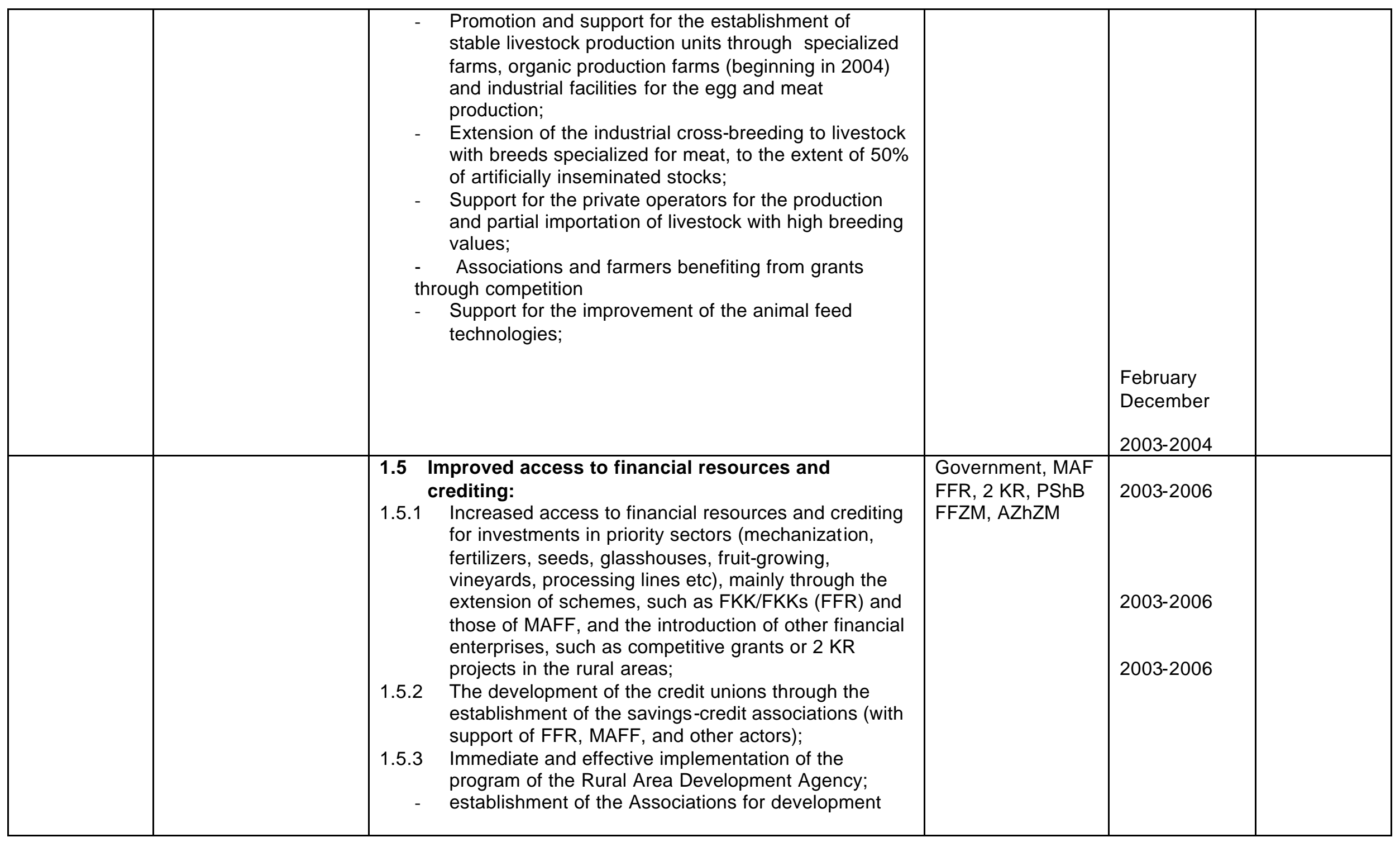




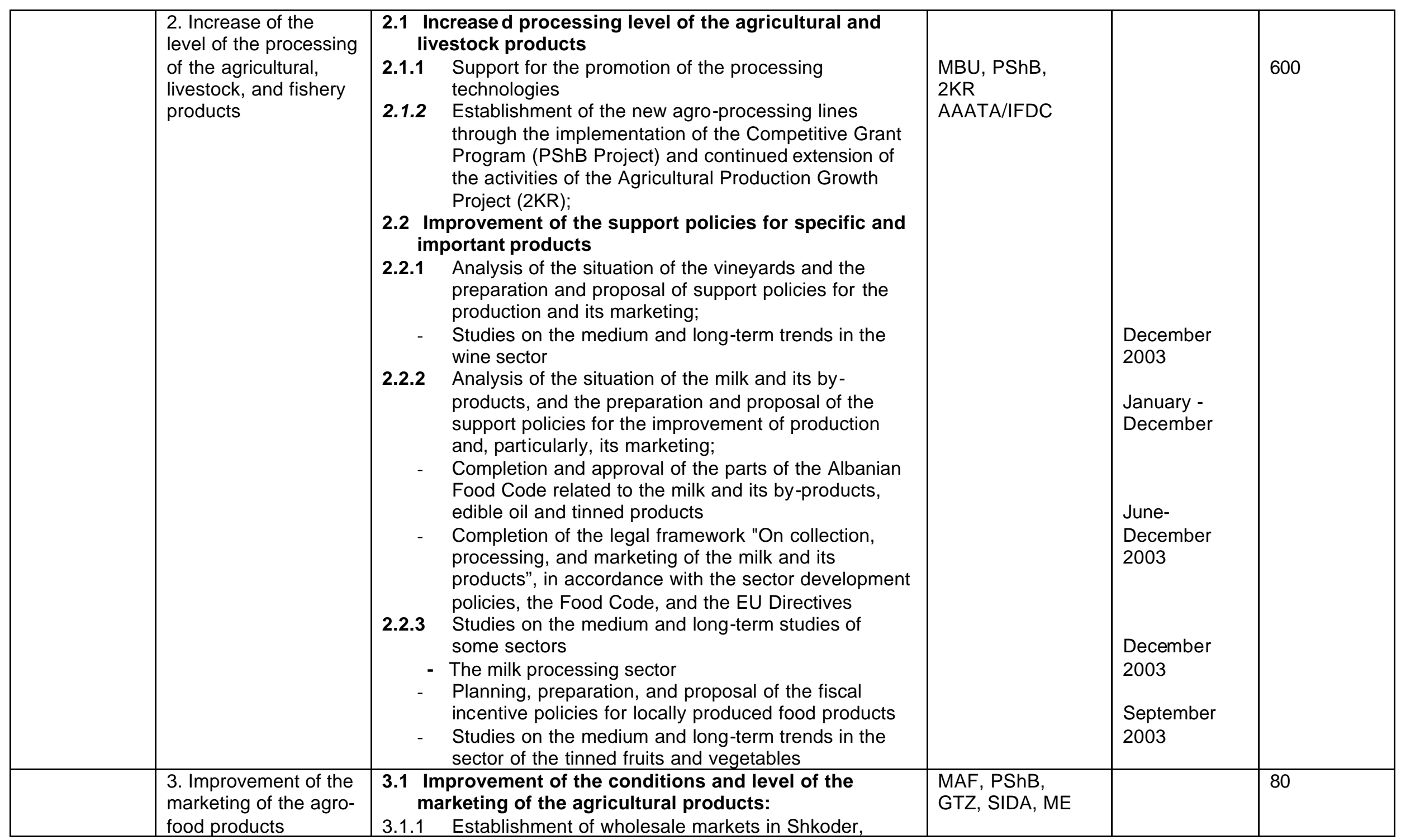




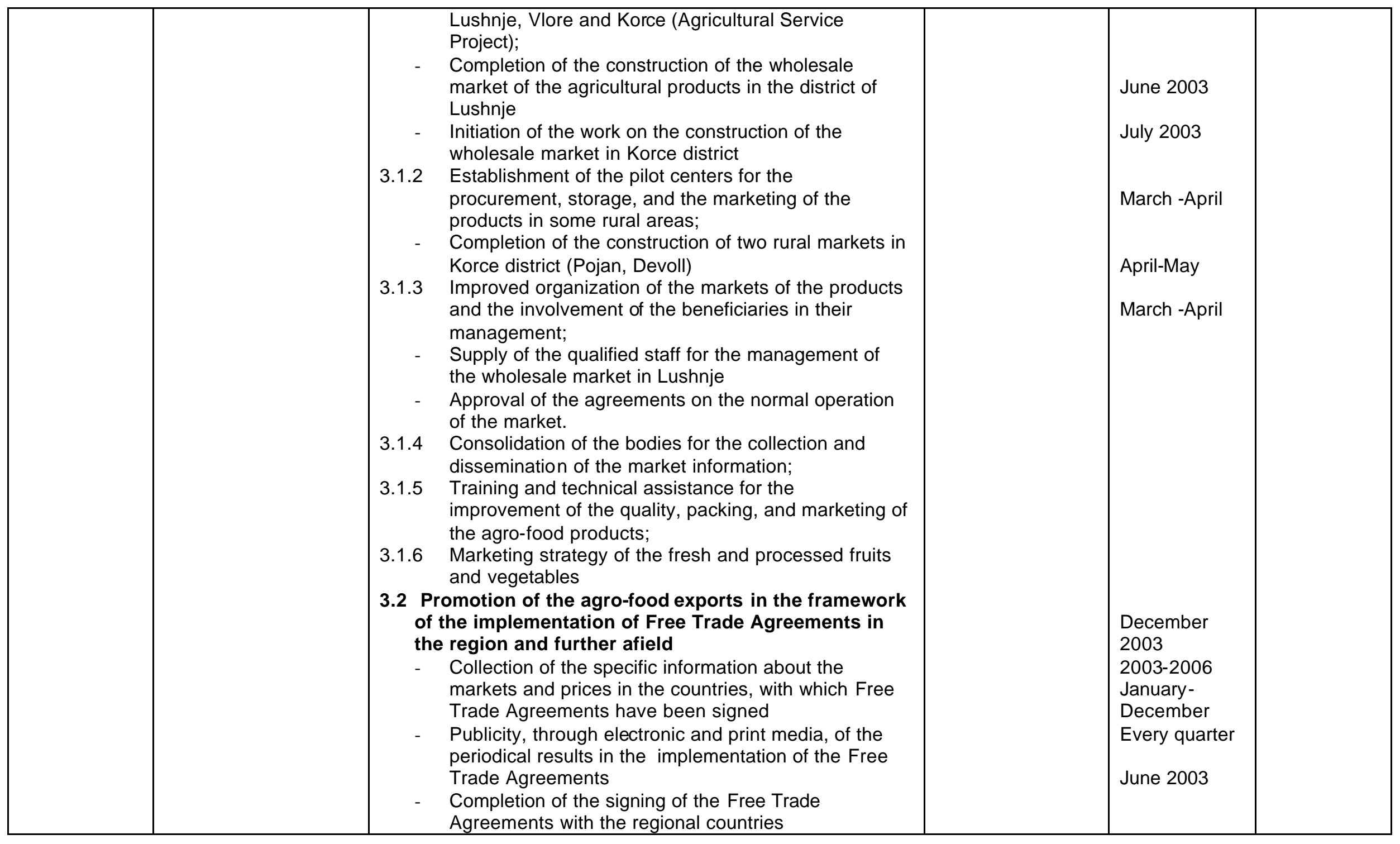




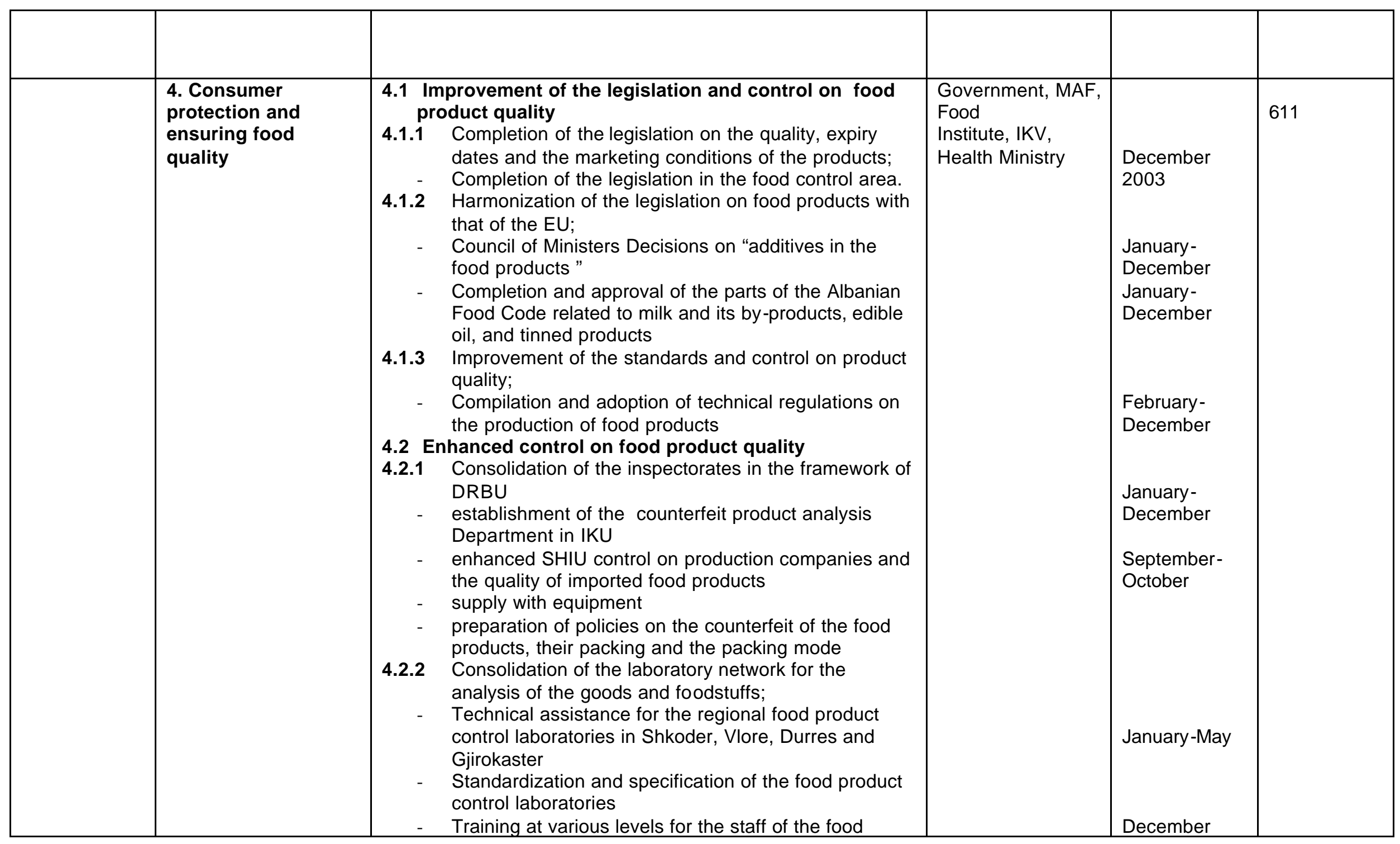


ANNEX 2 PROGRAM OF PRIORITY ACTION PLAN 2003

\begin{tabular}{|l|l|l|l|l|l|}
\hline & 4.2.3 & $\begin{array}{l}\text { product control laboratory } \\
\text { Consolidation of the veterinary, fito-sanitary, and food } \\
\text { product quality control at the border crossing points; } \\
\text { Improvement of the cooperation with the stakeholder } \\
\text { institutes and consumer associations }\end{array}$ & $\begin{array}{l}2003 \\
\text { January- } \\
\text { December }\end{array}$ & \\
\hline
\end{tabular}




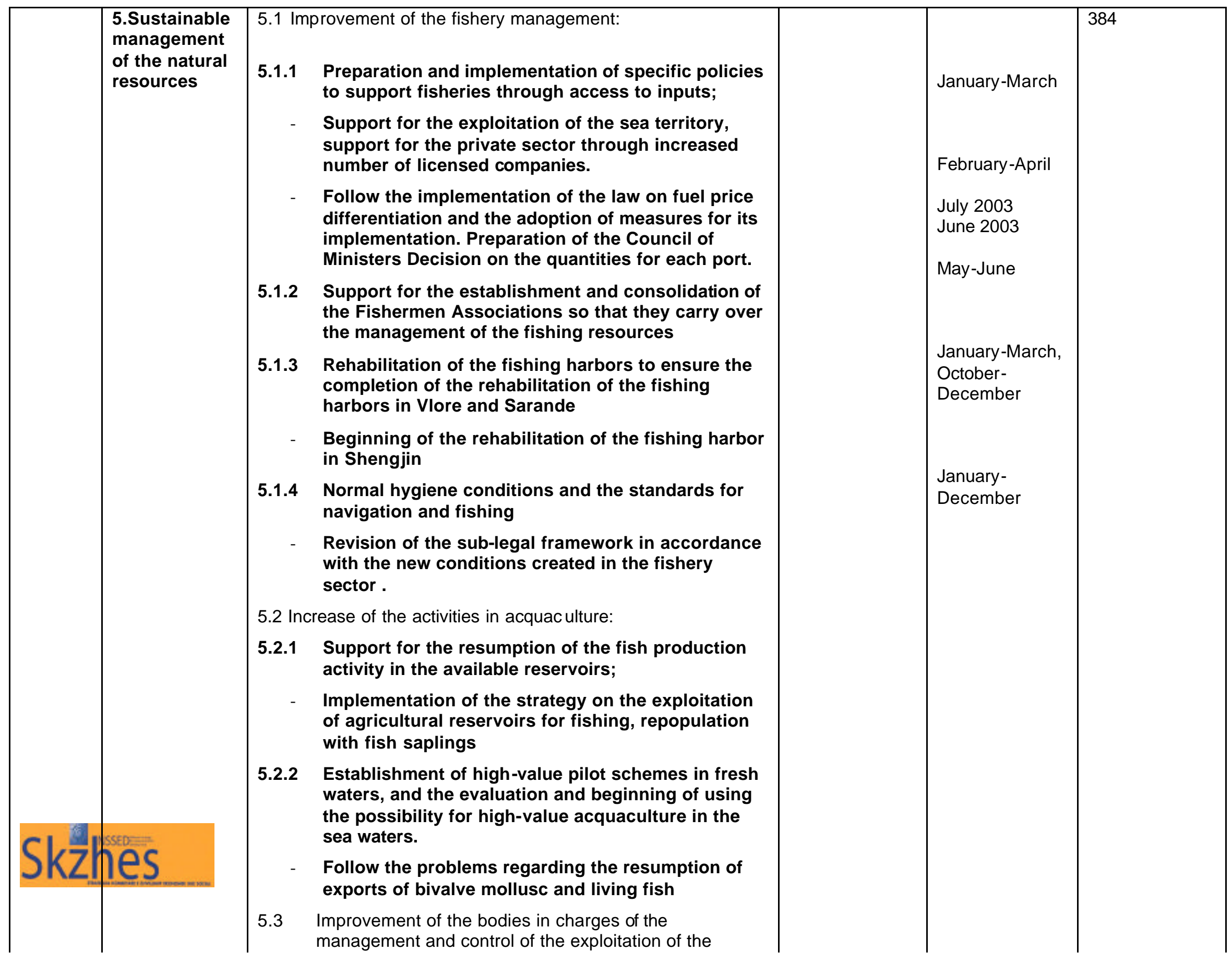




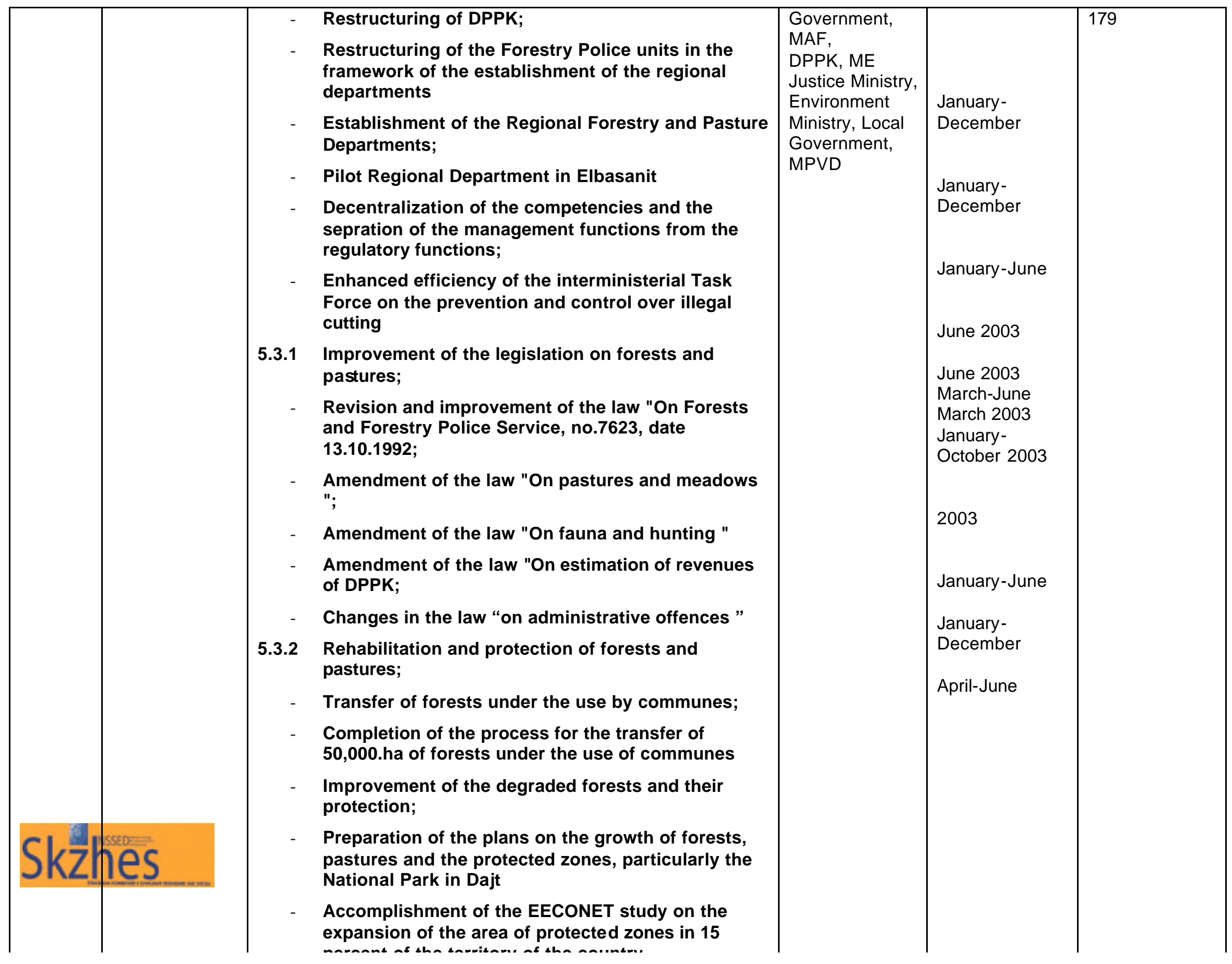




\begin{tabular}{|c|c|c|c|c|}
\hline $\begin{array}{l}\text { Non- } \\
\text { agricultural } \\
\text { activity }\end{array}$ & $\begin{array}{l}\text { 1. Promotion } \\
\text { of the } \\
\text { employment } \\
\text { and the } \\
\text { increase of } \\
\text { revenues } \\
\text { from non- } \\
\text { agricultural } \\
\text { activities in } \\
\text { the rural } \\
\text { areas }\end{array}$ & $\begin{array}{l}\text { * Promotion of the establishment of micro-enterprises } \\
\text { through micro-financing projects and the offer of } \\
\text { advisory services; } \\
\text { * Increased possibilities for employment through public } \\
\text { works programs; } \\
\text { * Consolidation and extension of the credit } \\
\text { cooperatives through establishment of the savings- } \\
\text { credit associations; } \\
\text { * Establishment of the marketing and information } \\
\text { centers as rural-urban linking points; } \\
\text { * Promotion of the activities of agro-tourism, } \\
\text { procurement, and processing of the medical herbs, } \\
\text { handicraft etc. }\end{array}$ & $\begin{array}{l}\text { Government, } \\
\text { MAF, } \\
\text { Min.of Labor } \\
\text { and Social } \\
\text { Affairs } \\
\text { FZHSH, } \\
\text { FFR, MAFF, } \\
\text { Local } \\
\text { Government }\end{array}$ & $\begin{array}{l}2003- \\
2004 \text { - } \\
\text { continuing } \\
2003 \text { - } \\
2006 \\
2003-2004 \\
- \\
\text { continuing } \\
2003 \text { - } \\
2004 \text { - } \\
\text { continuing } \\
2003 \text { - } \\
2004 \text { - } \\
\text { continuing }\end{array}$ \\
\hline \multirow[t]{2}{*}{$\begin{array}{l}\text { Rural } \\
\text { infrastructure }\end{array}$} & $\begin{array}{l}1 . \\
\text { Improvement } \\
\text { of the } \\
\text { potable } \\
\text { water and } \\
\text { sewages, } \\
\text { infrastructure } \\
\text { of the rural } \\
\text { transport }\end{array}$ & $\begin{array}{l}\text { 6 Improvement of the access and quality of } \\
\text { potable water and sewages; } \\
\text { - Approval of the strategy on potable water supply and } \\
\text { sewages in the rural areas; } \\
\text { - Establishment of the Sanitary and Potable Water } \\
\text { Agency for the rural areas; } \\
\text { - Construction of the water supply systems and } \\
\text { sewages in the most critical rural areas to meet the } \\
\text { needs for potable water and improve the hygiene in } \\
\text { these areas; } \\
\text { - Support for the participation of the community in the } \\
\text { projects on water supply and improvement of the } \\
\text { sewage system; }\end{array}$ & $\begin{array}{l}\text { Government, } \\
\text { MAF } \\
\text { Public } \\
\text { Works Minis, } \\
\text { MPVD, } \\
\text { FZHSH, } \\
\text { Local } \\
\text { Government }\end{array}$ & $\begin{array}{l}2003 \\
2003-2006 \\
2003-2006 \\
2003 \text { - } \\
2006 \text { - } \\
\text { continuing }\end{array}$ \\
\hline & & $\begin{array}{ll}7 & \text { Rehabilitation and improvement of the main } \\
\text { roads. power supply systems and the }\end{array}$ & & \\
\hline
\end{tabular}


ANNEX 2 PROGRAM OF PRIORITY ACTION PLAN 2003

\begin{tabular}{|c|c|c|c|}
\hline & & $\begin{array}{l}\text { telecommunications: } \\
\text { - Rehabilitation of the main roads linking the centers of } \\
\text { the communes with the closest towns, and the } \\
\text { communes and villages with one another ( } 920 \text { road } \\
\text { rehabilitation projects or about } 1800 \mathrm{~km} \text { of roads); } \\
\text { - Reorganization and improvement of the maintenance } \\
\text { of the secondary and tertiary road network; } \\
\text { - Improvement of the power supply for the rural } \\
\text { population, mainly through the improvement of the } \\
\text { overall condition of the supply network; } \\
\text { - Increased level of the penetration of the telephone } \\
\text { service through private operators; }\end{array}$ & $\begin{array}{l}2003-2006 \\
2003-2006 \\
2003-2006 \\
2003-2006\end{array}$ \\
\hline
\end{tabular}


ANNEX 3: MONITORING INDICATORS IDENTIFIED BY THE MINISTRIES

J. ANNEX 3: MONITORING INDICATORS IDENTIFIED BY THE MINISTRIES

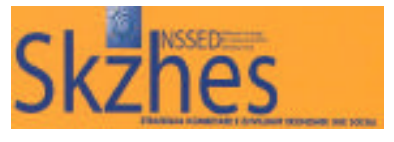


ANNEX 3: MONITORING INDICATORS IDENTIFIED BY THE MINISTRIES

TABLE 1: MINISTRY OF TERRITORIAL ADJUSTMENT AND TOURISM 
ANNEX 3: MONITORING INDICATORS IDENTIFIED BY THE MINISTRIES

\section{TABLE 1: MINISTRY OF TERRITORIAL ADJUSTMENT AND TOURISM}

\begin{tabular}{|c|c|c|c|c|c|c|c|c|c|c|}
\hline \multirow{2}{*}{ No. } & \multirow{2}{*}{ Objectives } & \multirow{2}{*}{ Housing Indicators } & \multicolumn{3}{|c|}{ Indicators of } & \multicolumn{5}{|c|}{ Time Period } \\
\hline & & & NSSED & PRSC & MDG & $\begin{array}{l}\text { Baseline } \\
2000\end{array}$ & 2001 & 2002 & 2003 & 2004 \\
\hline 1 & & No. of homeless families & & & & 26000 & & & & \\
\hline 2 & & $\begin{array}{l}\text { No. of homeless families in } \\
\text { the former p.p }\end{array}$ & & & & 4274 & & & & \\
\hline 3 & & $\begin{array}{l}\text { No. of families owning } \\
\text { their own homes }\end{array}$ & & & & 9227 & & & & \\
\hline 4 & & $\begin{array}{l}\text { No. of families renting their } \\
\text { own homes in the former } \\
\text { p.p }\end{array}$ & & & & 1300 & & & & \\
\hline 5 & & $\begin{array}{l}\text { No. of apartments } \\
\text { constructed }\end{array}$ & & & & 10379 & & & & \\
\hline 6 & & Total no. of apartments sold & & & & & & 888 & & \\
\hline 7 & & $\begin{array}{l}\text { No. of families having lost } \\
\text { their homes in the pyramid } \\
\text { schemes }\end{array}$ & & & & & & & & \\
\hline 8 & & $\begin{array}{l}\text { No. of families benefiting } \\
\text { from the } \\
\text { first phase of the Greek } \\
\text { credit Explain }\end{array}$ & & & & & & 125 & & \\
\hline 9 & & $\begin{array}{l}\text { No. of fa milies benefiting } \\
\text { from the first phase of the } \\
\text { Greek credit }\end{array}$ & & & & & & & & 900 \\
\hline 10 & & $\begin{array}{l}\text { Average construction cost } \\
\text { by } \mathbf{E K B}\end{array}$ & & & & & & & & \\
\hline 11 & & $\begin{array}{l}\text { Investments in housing } \\
\text { compared to the total of the } \\
\text { budgetary investments }\end{array}$ & & & & & & & & \\
\hline 12 & & $\begin{array}{l}\text { No. of houses constructed } \\
\text { annually per } / 1000\end{array}$ & & & & & & & & \\
\hline
\end{tabular}


ANNEX 3: MONITORING INDICATORS IDENTIFIED BY THE MINISTRIES

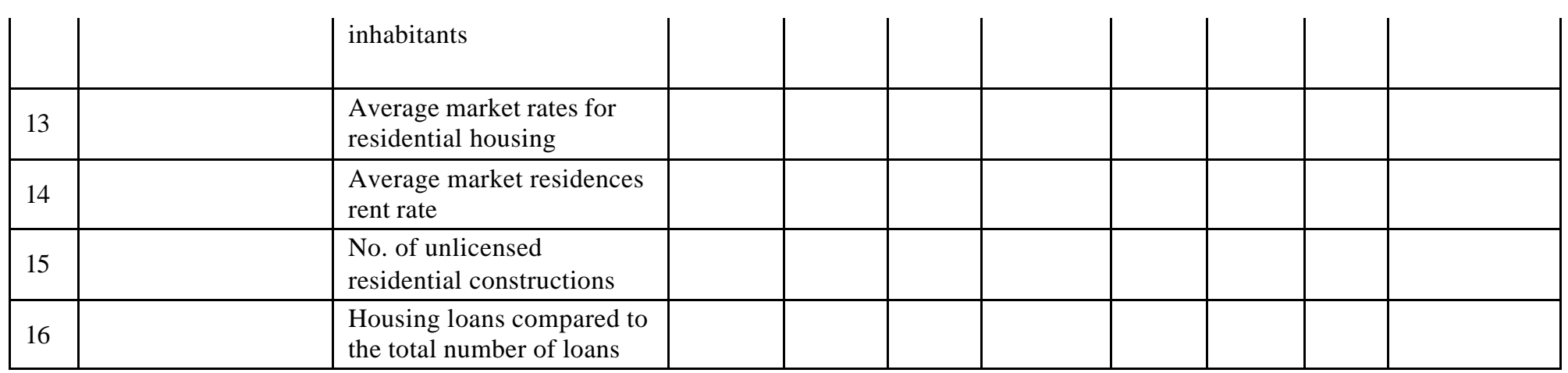


ANNEX 3: MONITORING INDICATORS IDENTIFIED BY THE MINISTRIES

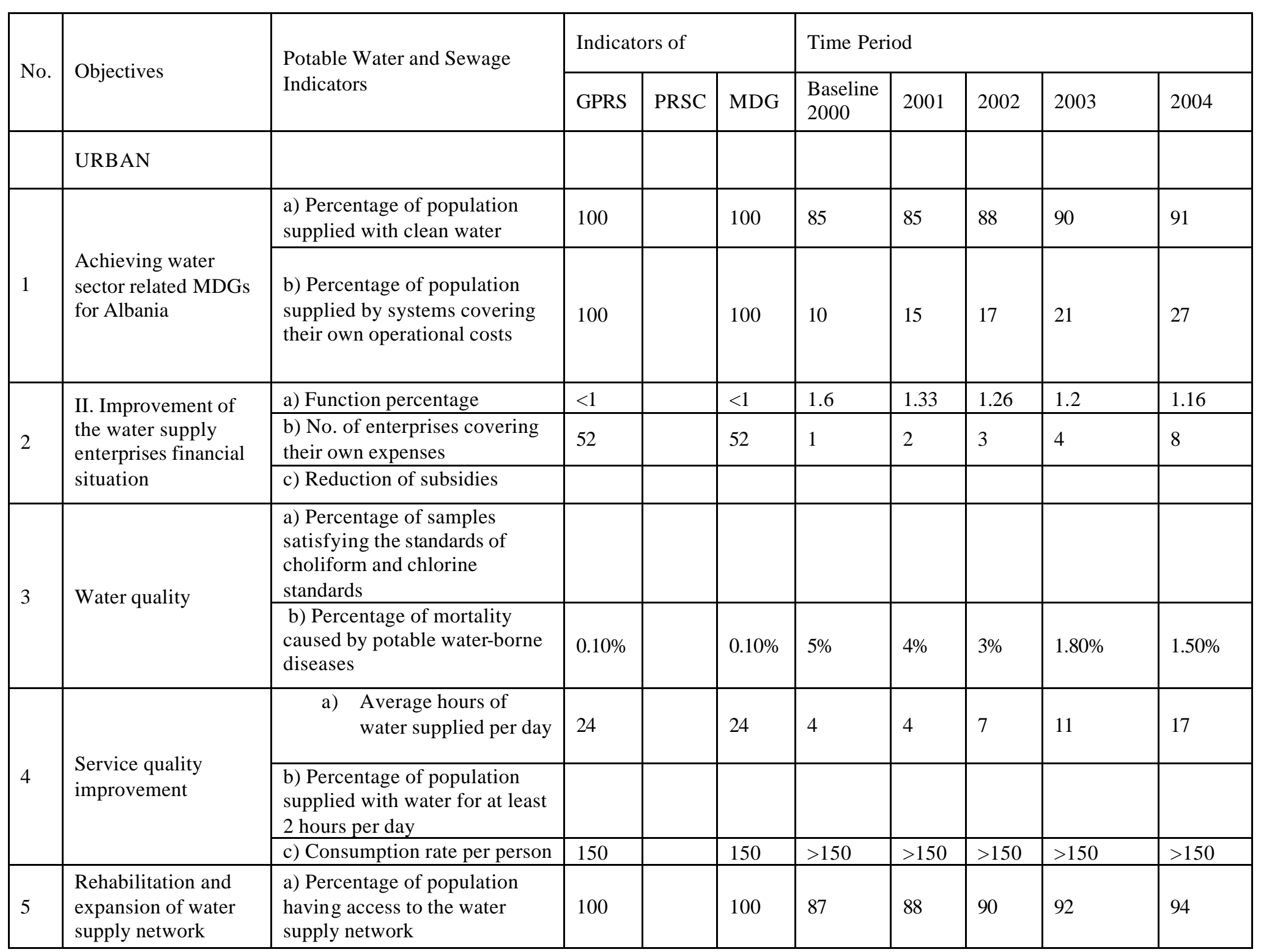


ANNEX 3: MONITORING INDICATORS IDENTIFIED BY THE MINISTRIES

Rehabilitation and

expansion of sewage a) Percentage of the population

$\begin{array}{lll}\text { network } & \text { linked to the sewage network }\end{array}$

100

$100 \quad 67$

\begin{tabular}{|l|l|l}
68 & 72 & 75
\end{tabular}

\begin{tabular}{l|l}
75 & 77
\end{tabular} 
ANNEX 3: MONITORING INDICATORS IDENTIFIED BY THE MINISTRIES

\begin{tabular}{|c|c|c|c|c|c|c|c|c|c|c|}
\hline \multirow{2}{*}{ No. } & \multirow{2}{*}{ Objectives } & \multirow{2}{*}{$\begin{array}{l}\text { Potable Water and } \\
\text { Sewage Indicators }\end{array}$} & \multicolumn{3}{|c|}{ Indicators of } & \multicolumn{5}{|c|}{ Time Period } \\
\hline & & & GPRS & PRSC & MDG & $\begin{array}{l}\text { Baseline } \\
2000\end{array}$ & 2001 & 2002 & 2003 & 2004 \\
\hline & RURAL & & & & & & & & & \\
\hline \multirow[b]{2}{*}{1} & \multirow{2}{*}{$\begin{array}{l}\text { Achieving water } \\
\text { sector related } \\
\text { MDGs for } \\
\text { Albania }\end{array}$} & $\begin{array}{l}\text { a) percentage of } \\
\text { population supplied } \\
\text { with clean water }\end{array}$ & 100 & & 100 & 60 & 65 & 67 & 72 & 80 \\
\hline & & $\begin{array}{l}\text { b) percentage of } \\
\text { population supplied } \\
\text { by systems covering } \\
\text { their own operational } \\
\text { costs }\end{array}$ & 100 & & 100 & 0 & 0 & 0 & 2 & 7 \\
\hline \multirow[b]{3}{*}{2} & \multirow{3}{*}{$\begin{array}{l}\text { II. Improvement } \\
\text { of the water } \\
\text { supply } \\
\text { enterprises' } \\
\text { financial } \\
\text { situation }\end{array}$} & $\begin{array}{l}\text { a) function } \\
\text { percentage }\end{array}$ & $<1$ & & $<1$ & $>1$ & $>1$ & $>1$ & $>1$ & $>1$ \\
\hline & & $\begin{array}{l}\text { b) no. of enterprises } \\
\text { covering their own } \\
\text { expenses }\end{array}$ & $\begin{array}{l}\text { All of } \\
\text { them }\end{array}$ & & $\begin{array}{l}\text { All of } \\
\text { them }\end{array}$ & 0 & 0 & 0 & 0 & \\
\hline & & $\begin{array}{l}\text { c) reduction of } \\
\text { subsidies }\end{array}$ & $\begin{array}{l}\text { Under } \\
\text { way }\end{array}$ & & $\begin{array}{l}\text { Under } \\
\text { way }\end{array}$ & & & & Under way & $\begin{array}{l}\text { in } \\
\text { continuation }\end{array}$ \\
\hline \multirow[t]{2}{*}{3} & \multirow{2}{*}{ Water quality } & $\begin{array}{l}\text { a) percentage of } \\
\text { samples satisfying } \\
\text { choliform and } \\
\text { chlorine standards } \\
\end{array}$ & & & & & & & & \\
\hline & & $\begin{array}{l}\text { b) mortality rate by } \\
\text { water-borne } \\
\text { diseases }\end{array}$ & & & & & & & & \\
\hline
\end{tabular}


ANNEX 3: MONITORING INDICATORS IDENTIFIED BY THE MINISTRIES

\begin{tabular}{|c|c|c|c|c|c|c|c|c|c|}
\hline \multirow{3}{*}{4} & \multirow{3}{*}{$\begin{array}{l}\text { Service quality } \\
\text { improvement }\end{array}$} & $\begin{array}{l}\text { a) average hours of } \\
\text { water supplied per } \\
\text { day }\end{array}$ & 24 & 24 & 2 & 3 & 5 & 7 & 10 \\
\hline & & $\begin{array}{l}\text { b) percentage of } \\
\text { population supplied } \\
\text { with water at least } 2 \\
\text { hours per day }\end{array}$ & 0 & 0 & 38 & 36 & 35 & 30 & 19 \\
\hline & & $\begin{array}{l}\text { c) per capita } \\
\text { consumption }\end{array}$ & 100 & 100 & 100 & 100 & 100 & 100 & 100 \\
\hline 5 & $\begin{array}{l}\text { Rehabilitation } \\
\text { and expansion of } \\
\text { water supply } \\
\text { network }\end{array}$ & $\begin{array}{ll}\text { a) } & \text { percentage } \\
\text { of } \\
\text { population } \\
\text { having } \\
\text { access to } \\
\text { b) the water } \\
\text { c) } & \text { supply } \\
& \text { network }\end{array}$ & 100 & 100 & 60 & 62 & 62 & 65 & 70 \\
\hline 6 & $\begin{array}{l}\text { Rehabilitation } \\
\text { and expansion of } \\
\text { sewage network }\end{array}$ & $\begin{array}{l}\text { a) percentage of } \\
\text { population linked to } \\
\text { the sewage and } \\
\text { septic system }\end{array}$ & 100 & 100 & 35 & 37 & 38 & 40 & 47 \\
\hline
\end{tabular}

Note: $\quad$ The Albanian standard for choliform and chlorine is used as a standard for the safe water. The percentage of users supplied by the system covering the operational and service costs is considered as a standard for the sustainable water.

\begin{tabular}{|c|c|c|c|c|c|c|c|c|c|c|}
\hline \multirow[b]{2}{*}{ No. } & \multirow[b]{2}{*}{ Objectives } & \multirow[b]{2}{*}{ Urban Development Indicators } & \multicolumn{3}{|c|}{ Indicators of } & \multicolumn{5}{|c|}{ Time Period } \\
\hline & & & NSSED & $\begin{array}{l}\text { PRS } \\
\text { C } \\
\end{array}$ & MDG & $\begin{array}{l}\text { Baselin } \\
\text { e } 2000\end{array}$ & 2001 & 2002 & 2003 & 2004 \\
\hline 1 & & Regional Strategies & & & & & & & & \\
\hline 2 & & Regional studies and Master plans & & & & & & & & \\
\hline 3 & & Inter-communal regulatory Plans & & & & & & & & \\
\hline
\end{tabular}


ANNEX 3: MONITORING INDICATORS IDENTIFIED BY THE MINISTRIES

\begin{tabular}{|l|l|l|l|l|l|l|l|l|} 
& \\
\hline & & $\begin{array}{l}\text { Construction sites and permits } \\
\text { outside the construction boundaries } \\
\text { lines for villages and cities [the } \\
\text { rural and urban areas] }\end{array}$
\end{tabular}

\begin{tabular}{|c|c|c|c|c|c|c|c|c|c|c|}
\hline \multirow[b]{2}{*}{ No. } & \multirow[b]{2}{*}{ Objectives } & \multirow[b]{2}{*}{ Urban Development Indicators } & \multicolumn{3}{|c|}{ Indicators of } & \multicolumn{5}{|c|}{ Time Period } \\
\hline & & & NSSED & PRSC & $\begin{array}{l}\text { MD } \\
\text { G }\end{array}$ & $\begin{array}{l}\text { Baselin } \\
\text { e } 2000\end{array}$ & 2001 & 2002 & 2003 & 2004 \\
\hline 1 & & $\begin{array}{l}\text { Studies conducted within the } \\
\text { boundary lines of the } \\
\text { construction zone }\end{array}$ & & & & & & & & \\
\hline 2 & & $\begin{array}{l}\text { Expansion of boundary lines } \\
\text { for cities and villages [urban } \\
\text { and rural areas]. }\end{array}$ & & & & & & & & \\
\hline 3 & & $\begin{array}{l}\text { Construction sites and permits } \\
\text { issued locally }\end{array}$ & & & & & & & & \\
\hline 4 & & $\begin{array}{l}\text { Revenues acquired by levying } \\
2 \% \text { of the value of approved } \\
\text { construction permits }\end{array}$ & & & & & & & & \\
\hline
\end{tabular}


ANNEX 3: MONITORING INDICATORS IDENTIFIED BY THE MINISTRIES

TABLE 2: MINISTRY OF ECONOMY 
ANNEX 3: MONITORING INDICATORS IDENTIFIED BY THE MINISTRIES

\section{TABLE 2: MINISTRY OF ECONOMY}

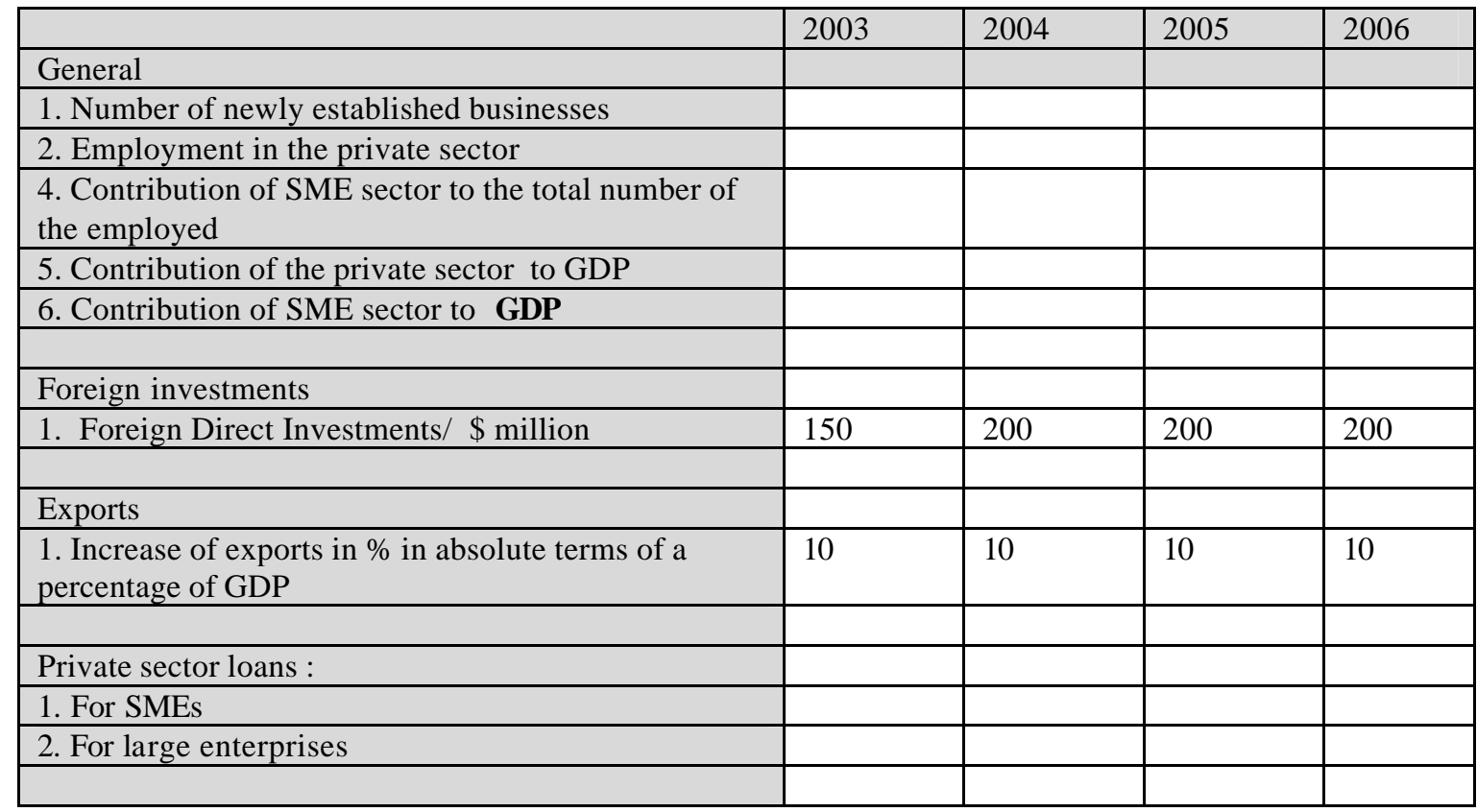


ANNEX 3: MONITORING INDICATORS IDENTIFIED BY THE MINISTRIES

TABLE 3: MINISTRY OF LOCAL GOVERNMENT AND DECENTRALIZATION 
ANNEX 3: MONITORING INDICATORS IDENTIFIED BY THE MINISTRIES

\section{TABLE 3: MINISTRY OF LOCAL GOVERNMENT AND DECENTRALIZATION}

\begin{tabular}{|c|c|c|c|c|}
\hline \multirow[t]{2}{*}{ No. } & Indicators & $\begin{array}{l}\text { Sources of } \\
\text { Information }\end{array}$ & $\begin{array}{l}\text { Type of } \\
\text { Indicators }\end{array}$ & NSSED Objectives \\
\hline & $\begin{array}{l}\text { Indexes of the Decentralization reform } \\
\text { I. Transfer of functions (competences) }\end{array}$ & & & \\
\hline & $\begin{array}{l}\text { Potable water supply service } \\
\text { a) Inventory of the system for every local } \\
\text { unit } \\
\text { b) plan preparation for transfer to these } \\
\text { units } \\
\text { c) transfer of the budgetary funds in } \\
\text { compliance with the transfer of assets } \\
\text { d) number of local structures } \\
\text { Community participation in water supply and } \\
\text { sewage system and rural infrastructure } \\
\text { projects } \\
\text { Number of beneficiary units } \\
\text { Number of rehabilitated water supply } \\
\text { systems } \\
\text { Total Fund } \\
\text { Benefit Fund }\end{array}$ & $\begin{array}{l}\text { MoTA/ MoF/ } \\
\text { MoLGD/ADF }\end{array}$ & Input & $\begin{array}{l}\text { Improvement of the } \\
\text { system through the } \\
\text { transfer of the potable } \\
\text { water function } \\
\text { (competence) to the } \\
\text { local units }\end{array}$ \\
\hline & $\begin{array}{l}\text { Urban Planning } \\
\text { a) Establishment of local government units } \\
\text { a. } 1 \text { Number of civil servants employed in } \\
\text { offices or sections in compliance with the law } \\
\text { "On City Planning" } \\
\text { b) number of approved regulatory plans } \\
\text { (complete or partial) } \\
\text { c) number of approved urban studies } \\
\text { (complete or partial) } \\
\text { d) number annually approved construction }\end{array}$ & MoTA/ MoLGD & Input & $\begin{array}{l}\text { Increase in access to } \\
\text { infrastructure through } \\
\text { the transfer of the } \\
\text { urban planning } \\
\text { function to the local } \\
\text { units }\end{array}$ \\
\hline
\end{tabular}


ANNEX 3: MONITORING INDICATORS IDENTIFIED BY THE MINISTRIES

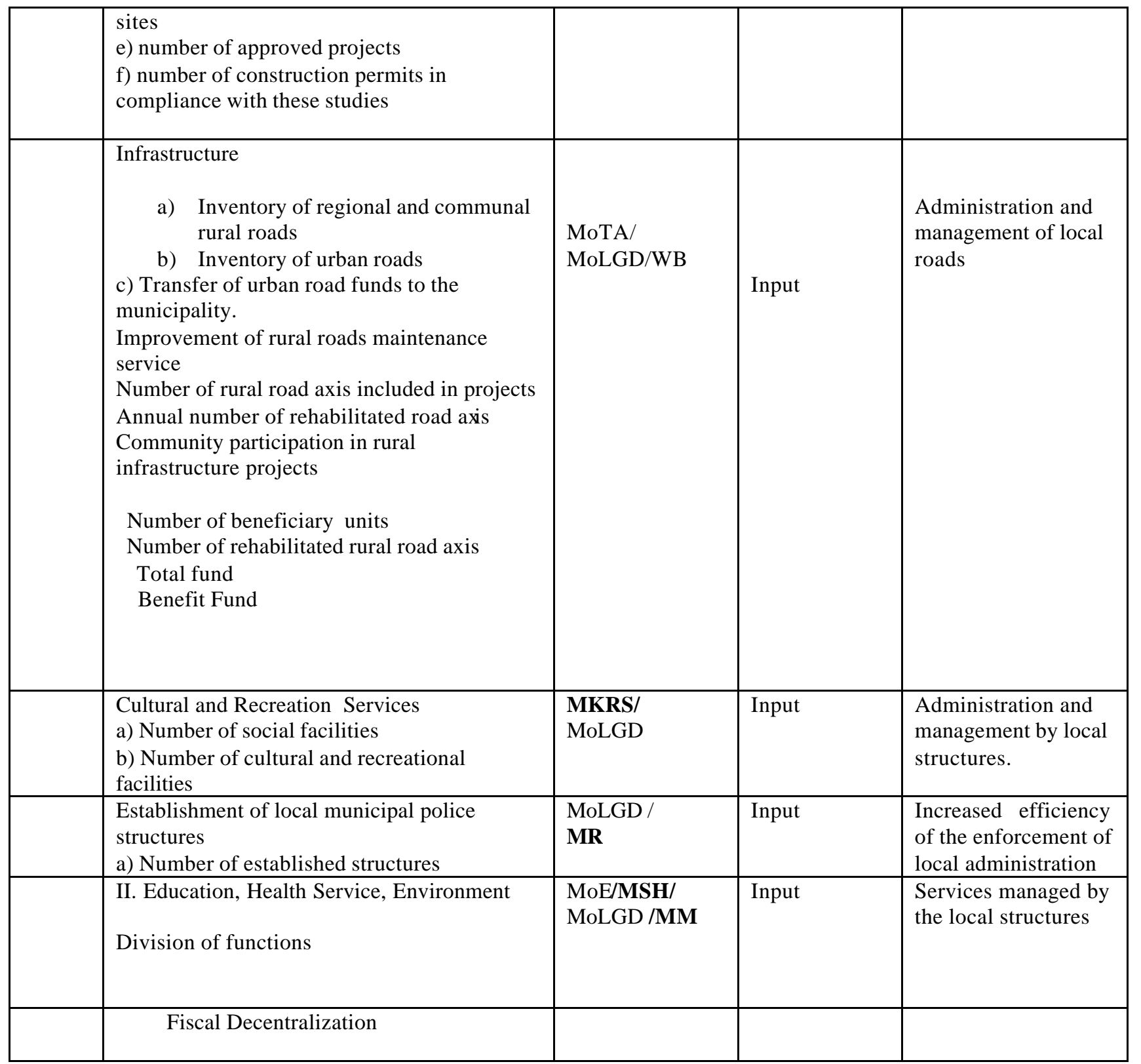


ANNEX 3: MONITORING INDICATORS IDENTIFIED BY THE MINISTRIES

\begin{tabular}{|c|c|c|c|}
\hline $\begin{array}{l}\text { a) Local incomes } \\
\text { Conditional grant } \\
\text { Unconditional grant } \\
\text { Formula application } \\
\text { Distribution of funds according to the } \\
\text { budget criteria } \\
\text { b) revenues collected from local taxes and } \\
\text { duties on: } \\
\text {-Agricultural land } \\
\text {-Buildings } \\
\text {-Small businesses } \\
\text {-Hotel stays } \\
\text {-Impacts on infrastructure } \\
\text {-Vehicle registrations } \\
\text {-Immovable property transactions } \\
\text {-Occupation of public areas } \\
\text {-Tables (Boards) } \\
\text { c) Strengthening of local capacities } \\
\text { c.1 Number of local structures } \\
\text { c.2 Education level of the local structure } \\
\text { personnel } \\
\text { c.3 Number of local units using the software } \\
\text { to administer local taxes }\end{array}$ & MoLGD /MoF & Input & $\begin{array}{l}\text { Increase of local } \\
\text { revenues and } \\
\text { effective funds } \\
\text { management utilized } \\
\text { to exercise new } \\
\text { functions. }\end{array}$ \\
\hline $\begin{array}{l}\text { Inventory and transfer of public assets } \\
\text { a) Establishment of local structures } \\
\text { b) Preparation of assets inventory and } \\
\text { transfer schedule } \\
\text { c) No. and type of assets to be transferred to } \\
\text { the LGO }\end{array}$ & MoLGD & Input & $\begin{array}{l}\text { Increase of local } \\
\text { autonomy through } \\
\text { transfer of ownership } \\
\text { rights }\end{array}$ \\
\hline III Delegated functions & & & \\
\hline $\begin{array}{l}\text { Civil Registry Service } \\
\text { a) Computerization of the Civil Registry } \\
\text { Service } \\
\text { b) Strengthening of the capacity of Civil } \\
\text { Registry Service personnel }\end{array}$ & MoLGD & Input & $\begin{array}{l}\text { Improvement of } \\
\text { services through } \\
\text { modernization }\end{array}$ \\
\hline Improvement of natural resources use & & & \\
\hline
\end{tabular}


ANNEX 3: MONITORING INDICATORS IDENTIFIED BY THE MINISTRIES

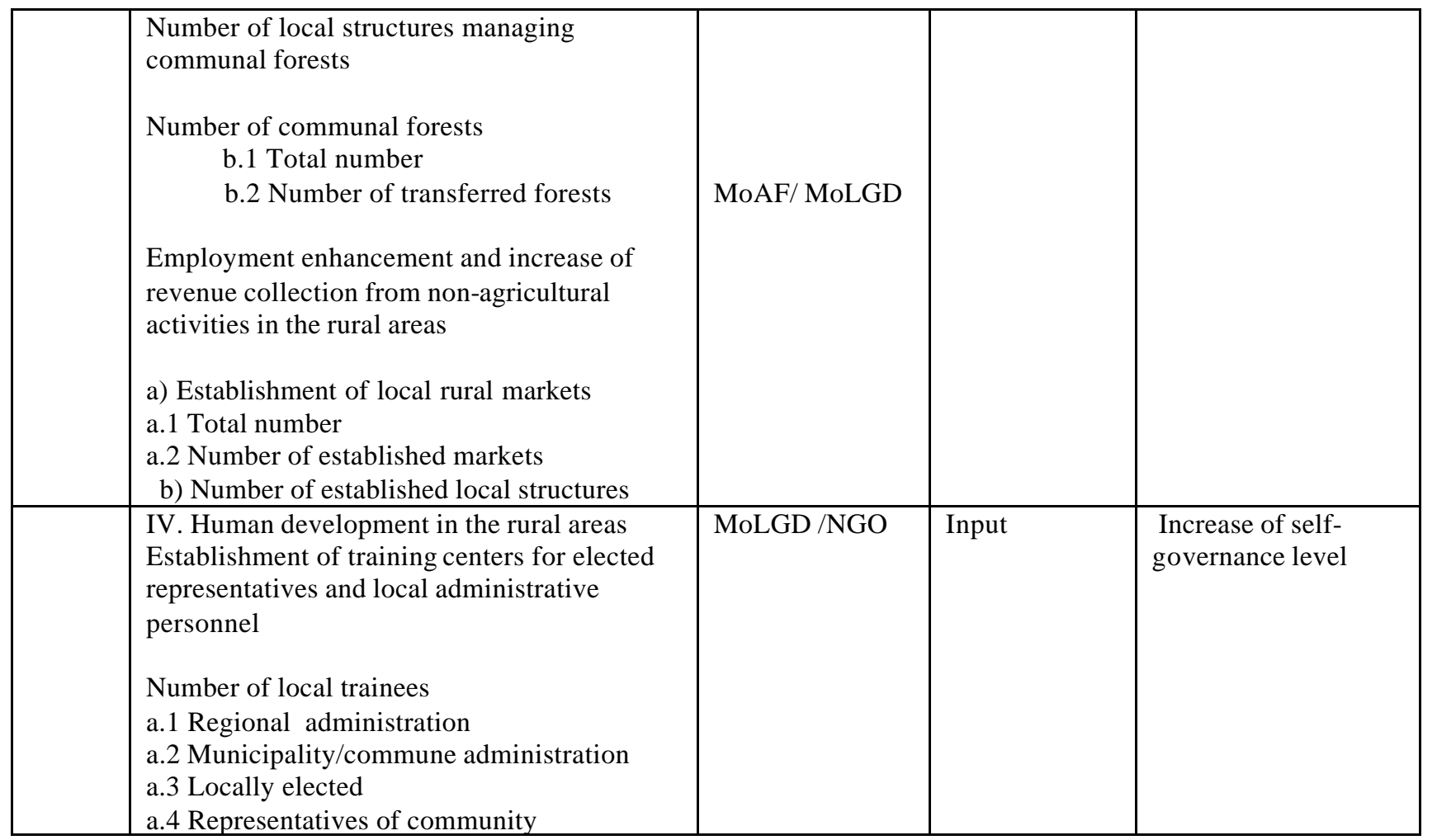


ANNEX 3: MONITORING INDICATORS IDENTIFIED BY THE MINISTRIES

\begin{tabular}{|c|c|c|c|c|c|c|c|}
\hline & & & & 2000 & 2002 & 2003 & 2004 \\
\hline 1 & Input Indicators & Inventory of water supply systems for every local unit & MoTAT & & & 50 SHA & \\
\hline 2 & Input Indicators & Transfer draft plan to the local units & MoTAT/MOLGD & & & & \\
\hline 3 & Input Indicators & Transfer of water supply systems to the local units & MoTAT/MoLGD/MoE/MoF & & & & \\
\hline 4 & Process Indicators & $\begin{array}{l}\text { Number of legal \& sub-legal acts prepared and } \\
\text { Adopted to enable exercising of functions }\end{array}$ & MoLGD/MoTAT & & 35 & & \\
\hline 5 & Process Indicators & $\begin{array}{l}\text { Number of established inter-ministerial structures } \\
\text { serving to process progress }\end{array}$ & MoLGD/Line Mins. & & 5 & 11 & \\
\hline 6 & Process Indicators & $\begin{array}{l}\text { Number of policy documents prepared in } \\
\text { cooperation with NGO }\end{array}$ & MoLGD/MoTAT /OJQ & & 1 & 3 & \\
\hline 7 & Process Indicators & $\begin{array}{l}\text { Number of activities carried out in cooperation with the } \\
\text { media media }\end{array}$ & MoLGD & 25 & 40 & 80 & \\
\hline 8 & Input Indicators & Number of rural roads (regional and local) & MoLGD & 4139 & 4139 & 9451 & \\
\hline 9 & Input Indicators & Number of regional rural roads & MoLGD & 4139 & 4139 & 4471 & \\
\hline 10 & Input Indicators & Number of local rural roads & MoLGD & & & 4980 & \\
\hline 11 & Process Indicators & Number of Minister's instructions & MoLGD & 10 & 14 & & \\
\hline 12 & Input Indicators & Establishment of the Civil Registry Office in the Ministry & MoLGD & & 3 & 13 & \\
\hline $\begin{array}{l}13 \\
14\end{array}$ & $\begin{array}{l}\text { Input Indicators } \\
\text { Input Indicators }\end{array}$ & $\begin{array}{l}\text { Computerization of the Civil Registry Office } \\
\text { Training of Civil Registry servants }\end{array}$ & $\begin{array}{l}\text { MoLGD } \\
\text { MoLGD }\end{array}$ & & & $\begin{array}{c}14 \\
544\end{array}$ & 50 \\
\hline 15 & Process Indicators & State budget & MoLGD & & 9500000 & 6300000 & \\
\hline 16 & Input Indicators & Donors' funds & MoLGD & & & & \\
\hline 17 & Input Indicators & Local revenues & MoLGD & & 3020635 & 8000000 & \\
\hline 18 & Input Indicators & Small businesses tax revenues & MoLGD & & & 3045000 & \\
\hline 19 & Process Indicators & $\begin{array}{l}\text { Number of legal/sub-legal acts on } \\
\text { fiscal decentralization }\end{array}$ & MoLGD & & 3 & & \\
\hline 20 & Input Indicators & Conditional grant & MoLGD & & 227900 & 239000 & \\
\hline 21 & Input Indicators & $\begin{array}{l}\text { Investment funds from the unconditional grant } 2002 \\
\text { (for } 2003 \text { conditional transfers). }\end{array}$ & MoLGD & & 505000 & 380000 & \\
\hline 22 & Input Indicators & Unconditional grant (formulae application) & MoLGD & & 9500000 & 14354000 & \\
\hline 23 & Input Indicators & Distribution of equalizing funds & MoLGD & & 1399110 & 644000 & \\
\hline 24 & Input Indicators & Number of established local structures & MoLGD & & 386 & 386 & \\
\hline 25 & Input Indicators & Established local structures & MoLGD & & 7 & 374 & 260 \\
\hline 26 & Input Indicators & $\begin{array}{l}\text { Preparation of assets inventory } \\
\text { and transfer schedule }\end{array}$ & MoLGD & & 7 & 110 & 260 \\
\hline 27 & Input Indicators & Number of AITTP guidelines & MoLGD & & 3 & & \\
\hline 28 & Input Indicators & $\begin{array}{l}\text { Number of public assets transferred to the local } \\
\text { units }\end{array}$ & MoLGD & & & $30 \%$ & $70 \%$ \\
\hline 29 & Input Indicators & Local administrative structures & MoLGD/ loc.expand.associat. & 410 & 386 & 386 & \\
\hline 30 & Input Indicators & Local control structures & MoLGD/local units & & 200 & 250 & \\
\hline 31 & Input Indicators & Number of local units with civil servant status & MoLGD/ local units & 0 & 77 & & \\
\hline
\end{tabular}


ANNEX 3: MONITORING INDICATORS IDENTIFIED BY THE MINISTRIES

TABLE 4: BANK OF ALBANIA

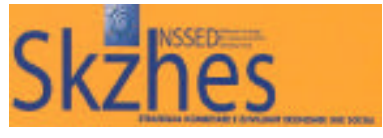


ANNEX 3: MONITORING INDICATORS IDENTIFIED BY THE MINISTRIES

\section{TABLE 4: BANK OF ALBANIA}

First objective: Maintain economic stability

\begin{tabular}{|l|l|}
\hline Type & Indicators \\
\hline Product & - achieving macroeconomic indicators \\
\hline & - annual inflation rate \\
\hline $\begin{array}{l}\text { Input and } \\
\text { process }\end{array}$ & -preserving sustainability of the exchange market \\
\hline
\end{tabular}

Second objective: Enhancement of free market

\begin{tabular}{|l|l|}
\hline Type & Indicators \\
\hline $\begin{array}{l}\text { Input and } \\
\text { process }\end{array}$ & - strengthening of accounting and auditing legislation \\
\hline & - strengthening of legislation on collateral \\
\hline & $\begin{array}{l}\text { - development of institutional mechanisms on borrowing and technical } \\
\text { assistance (establishment of Credit Information Office) }\end{array}$ \\
\hline Product & $-\mathrm{H}$ index on loans and deposits (measures the level of competitiveness) \\
\hline
\end{tabular}

Third objective: Restructuring and strengthening of the financial market

\begin{tabular}{|l|l|}
\hline Type & Indicators \\
\hline $\begin{array}{l}\text { Input and } \\
\text { process }\end{array}$ & - privatization of the Savings Bank \\
\hline & - strengthening of supervisory capacities \\
\hline & - establishment of Deposit Insurance Agency \\
\hline
\end{tabular}

Fourth objective: Strengthening banking system reforms

\begin{tabular}{|l|l|}
\hline Type & Indicator \\
\hline Outcome & - number of licensed businesses \\
\hline $\begin{array}{l}\text { Input and } \\
\text { process }\end{array}$ & $\begin{array}{l}\text { - preparation and implementation of RTGS. Enhancement and diversification } \\
\text { of banking products and services. }\end{array}$ \\
\hline & - enhancement of the territorial expansion of the banking network \\
\hline
\end{tabular}


ANNEX 3: MONITORING INDICATORS IDENTIFIED BY THE MINISTRIES

TABLE 5: MINISTRY OF EDUCATION 
ANNEX 3: MONITORING INDICATORS IDENTIFIED BY THE MINISTRIES

\section{TABLE 2: MINISTRY OF EDUCATION}

\begin{tabular}{|c|c|c|c|c|}
\hline No. & Education Indicators & Baseline 2000 & 2002 & Comments \\
\hline 1. & $\begin{array}{l}\text { Teachers` remuneration in: } \\
\text { Urban areas } \\
\text { Rural areas }\end{array}$ & $\begin{array}{l}17400 \\
21350\end{array}$ & $\begin{array}{l}20170 \\
24470\end{array}$ & \\
\hline 2. & Percentage of GDP for education & $3.2 \%$ & $3.4 \%$ & \\
\hline 3. & $\begin{array}{l}\text { Teachers`remuneration as percentage of per } \\
\text { capita GDP }\end{array}$ & $142.3 \%$ & $147.8 \%$ & \\
\hline 4. & $\begin{array}{l}\text { Percentage of vertical compression of } \\
\text { teachers` remuneration }\end{array}$ & 133.4 & 132.3 & \\
\hline 5. & $\begin{array}{l}\text { School text subsidization as a percentage of } \\
\text { the MoES budget }\end{array}$ & $2.06 \%$ & $1,86 \%$ & \\
\hline 6. & $\begin{array}{l}\text { Percentage of qualified teachers possessing } \\
8^{\text {th }} \text { grade education }\end{array}$ & 74.3 & 81.2 & \\
\hline 7. & $\begin{array}{l}\text { Percentage of teachers satisfying relevant } \\
\text { standards required by the MoES }\end{array}$ & 74.3 & 81.2 & \\
\hline 8. & Quality of published text books & Unsatisfactory & Improved & \\
\hline 9. & $\begin{array}{l}\text { Percentage of students in primary schools } \\
\text { without textbooks }\end{array}$ & $20 \%$ & $20 \%$ & \\
\hline 10. & $\begin{array}{l}\text { Attendance: } \\
\text { Primary education } \\
\text { Tertiary education } \\
\text { High school education }\end{array}$ & $\begin{array}{l}98 \% \\
97 \% \\
93 \% \\
\end{array}$ & $\begin{array}{l}98 \% \\
97 \% \\
95 \% \\
\end{array}$ & \\
\hline 11. & $\begin{array}{l}\text { Quantity and value of textbooks published } \\
\text { through a tendering process }\end{array}$ & $\begin{array}{l}4.86 \mathrm{mln} \\
601.7 \mathrm{mln} \text { ALL }\end{array}$ & $\begin{array}{l}4.1 \mathrm{mln} \\
645 \mathrm{mln} \text { ALL }\end{array}$ & \\
\hline 12 . & $\begin{array}{l}\text { Ratio students/teachers: } \\
\text { Primary education } \\
\text { Tertiary education } \\
\text { High school education }\end{array}$ & $\begin{array}{l}22.4 \\
16.2 \\
17 \\
\end{array}$ & $\begin{array}{l}22 \\
16.3 \\
18.9 \\
\end{array}$ & \\
\hline 13. & $\begin{array}{l}\text { Quantity and the value of textbook contracts } \\
\text { over the threshold for international tendering } \\
\text { process }\end{array}$ & $\begin{array}{l}1.5 \mathrm{mln} \text { pieces } \\
114.6 \mathrm{mln} \text { ALL }\end{array}$ & $\begin{array}{l}0.7 \mathrm{mln} \text { pieces } \\
66.8 \mathrm{mln} \text { ALL }\end{array}$ & \\
\hline 14. & $\begin{array}{l}\text { Class size student/class: } \\
\text { Primary education } \\
\text { Tertiary education } \\
\end{array}$ & $\begin{array}{l}22.5 \\
26 \\
\end{array}$ & $\begin{array}{l}22.5 \\
26 \\
\end{array}$ & \\
\hline 15 . & $\begin{array}{l}\text { Current inequality in access to textbooks and } \\
\text { teaching materials in the rural and urban }\end{array}$ & & & \\
\hline
\end{tabular}


ANNEX 3: MONITORING INDICATORS IDENTIFIED BY THE MINISTRIES

\begin{tabular}{|c|c|c|c|c|c|}
\hline & $\begin{array}{l}\text { areas: } \\
\text { Primary education } \\
\text { Tertiary education }\end{array}$ & $\begin{array}{l}\text { None } \\
\text { None }\end{array}$ & & $\begin{array}{l}\text { None } \\
\text { None }\end{array}$ & \\
\hline 16. & $\begin{array}{l}\text { Gross enrollment percentage, rural areas and } \\
\text { poor families } \\
\text { Elementary } \\
\text { Tertiary } \\
\text { Primary } \\
\text { High school }\end{array}$ & $\begin{array}{l}86 \% \\
88 \% \\
87 \% \\
42 \% \\
\end{array}$ & & $\begin{array}{lr}\text { Tot. } & \text { Village } \\
& \\
105 \% & 100 \% \\
99 \% & 93 \% \\
102 \% & 96 \% \\
48 \% & 24 \% \\
\end{array}$ & \\
\hline 17. & $\begin{array}{l}\text { Approximate percentage of completion of } \\
\text { primary school education of } \\
\text { girls } \\
\text { boys }\end{array}$ & $\begin{array}{l}97 \% \\
95 \% \\
\end{array}$ & & $\begin{array}{l}97 \% \\
96 \% \\
\end{array}$ & \\
\hline 18. & $\begin{array}{l}\text { Net enrollment percentage: } \\
\text { Elementary } \\
\text { Tertiary } \\
\text { Primary } \\
\text { High school } \\
\text { General education } \\
\end{array}$ & $\begin{array}{l}76 \% \\
86 \% \\
81 \% \\
38 \%\end{array}$ & & $\begin{array}{ll}\text { Tot. } & \text { Village } \\
96 \% & 93 \% \\
93 \% & 91 \% \\
94 \% & 92 \% \\
42 \% & 22 \%\end{array}$ & \\
\hline 19. & $\begin{array}{l}\text { Total percentage of school education } \\
\text { completion for the rural areas and poor } \\
\text { families } \\
\text { Elementary } \\
\text { Tertiary } \\
\text { Primary } \\
\text { General education } \\
\end{array}$ & $\begin{array}{l}\text { Tot. } \\
96 \% \\
90 \% \\
93 \% \\
79 \%\end{array}$ & $\begin{array}{l}\text { Village } \\
96 \% \\
89 \% \\
93 \% \\
79 \%\end{array}$ & $\begin{array}{ll}\text { Tot. } & \text { Village } \\
96 \% & 95 \% \\
94 \% & 95 \% \\
96 \% & 96 \% \\
95 \% & 96 \%\end{array}$ & \\
\hline 20. & Enrollment percentage in high schools rural & $63 \%$ & & $66 \%$ & \\
\hline 21. & $\begin{array}{l}\text { Ratio of general post-secondary education } \\
\text { and vocational education }\end{array}$ & $84 / 16$ & & $84 / 16$ & \\
\hline
\end{tabular}


ANNEX 3: MONITORING INDICATORS IDENTIFIED BY THE MINISTRIES

TABLE 6: MINISTRY OF INDUSTRY AND ENERGY 
ANNEX 3: MONITORING INDICATORS IDENTIFIED BY THE MINISTRIES

TABLE 6: MINISTRY OF INDUSTRY AND ENERGY

\begin{tabular}{|c|c|c|c|c|c|c|c|c|c|c|}
\hline \multirow[t]{2}{*}{ No. } & \multirow[t]{2}{*}{ Energy Indicators } & \multirow{2}{*}{$\begin{array}{l}\text { Indicators of } \\
\text { NSSED PRSC }\end{array}$} & \multirow[b]{2}{*}{ MDG } & \multirow{2}{*}{$\begin{array}{l}\text { Unit } \\
\text { KTOE }\end{array}$} & \multirow{2}{*}{$\begin{array}{l}\text { Executing } \\
\text { Agency }\end{array}$} & \multicolumn{5}{|c|}{$\begin{array}{l}\text { Time } \\
\text { Period }\end{array}$} \\
\hline & & & & & & 2000 & 2001 & 2002 & 2003 & 2004 \\
\hline \multirow[b]{2}{*}{1.1} & $\begin{array}{l}\text { Public investments in the } \\
\text { energy sector }(\mathbf{a}+\mathbf{b}+\mathbf{c}) \\
(\mathbf{m i l l i o n} \text { lek) } \\
\text { a) transmission network } \\
\text { rehabilitation } \\
\text { b) energy distribution } \\
\text { c) generation }\end{array}$ & & & & & 2.283 & 4.818 & 6.332 & 14.254 & 20.865 \\
\hline & $\begin{array}{l}\text { Public investment in the } \\
\text { electr alenergy sector (\% } \\
\text { GDP) }\end{array}$ & & & & & & & & & \\
\hline \multirow{3}{*}{2.2} & $\begin{array}{l}\text { Energy sources (Prod): } \\
\text { Hydro energy } \\
\text { Oil - } 1 \text { sub-product } \\
\text { Gas - natural } \\
\text { Coal } \\
\text { Wood } \\
\text { Solar energy } \\
\text { Total }\end{array}$ & & & $\begin{array}{l}\text { KTOE } \\
\text { KTOE } \\
\text { KTOE } \\
\text { KTOE } \\
\text { KTOE } \\
\text { KTOE } \\
\text { KTOE } \\
\end{array}$ & & $\begin{array}{r}394.58 \\
314.3 \\
10.00 \\
7.14 \\
258.00 \\
1.10 \\
\mathbf{9 8 5 . 1 3} \\
\end{array}$ & $\begin{array}{r}355.21 \\
329.36 \\
7.80 \\
8.57 \\
256.00 \\
1.90 \\
\mathbf{9 5 8 . 8 4} \\
\end{array}$ & $\begin{array}{r}296.27 \\
352 \\
7.66 \\
9.00 \\
251.00 \\
2.33 \\
\mathbf{9 1 8 . 2 6} \\
\end{array}$ & $\begin{array}{r}371.52 \\
370 \\
12.33 \\
9.43 \\
244.00 \\
3.11 \\
\mathbf{1 0 1 0 . 3 9} \\
\end{array}$ & $\begin{array}{r}398.01 \\
400 \\
13.77 \\
10.00 \\
241.11 \\
3.56 \\
\mathbf{1 0 6 6 . 4 5} \\
\end{array}$ \\
\hline & $\begin{array}{l}\text { Energy sources } \\
\text { (Imported): } \\
\text { Hydro energy } \\
\text { Oil - sub-product } \\
\text { Liquid gas } \\
\text { Coal } \\
\text { Wood } \\
\text { Solar energy }\end{array}$ & & & $\begin{array}{l}\text { KTOE } \\
\text { KTOE } \\
\text { KTOE } \\
\text { KTOE } \\
\text { KTOE } \\
\text { KTOE }\end{array}$ & & $\begin{array}{r}86.62 \\
150.00 \\
15.00 \\
9.86 \\
0.00 \\
0.00\end{array}$ & $\begin{array}{r}112.17 \\
268.00 \\
23.00 \\
12.03 \\
0.00 \\
0.00\end{array}$ & $\begin{array}{r}159.53 \\
251.00 \\
40.00 \\
15.33 \\
0.00 \\
0.00\end{array}$ & $\begin{array}{r}144.48 \\
270.00 \\
50.00 \\
19.01 \\
0.00 \\
0.00\end{array}$ & $\begin{array}{r}99.50 \\
280.00 \\
65.00 \\
23.12 \\
0.00 \\
0.00\end{array}$ \\
\hline & Total & & & \multicolumn{2}{|l|}{ KTOE } & 838.80 & 902.18 & 980.91 & 1002.25 & 982.09 \\
\hline 2 & $\begin{array}{l}\text { Energy sources } \\
\text { (Prod.+Imp): }\end{array}$ & & & & & & & & & \\
\hline
\end{tabular}


ANNEX 3: MONITORING INDICATORS IDENTIFIED BY THE MINISTRIES

\begin{tabular}{|c|c|c|c|c|c|c|c|}
\hline & Hydro energy & KTOE & 481.20 & 467.38 & 455.80 & 516.00 & 497.51 \\
\hline & Oil & KTOE & 1056.63 & 1107.34 & 1158.05 & 1208.76 & 1259.47 \\
\hline & Gas & KTOE & 10.00 & 7.80 & 7.66 & 12.33 & 13.77 \\
\hline & Coal & KTOE & 17.00 & 20.60 & 24.33 & 28.44 & 33.12 \\
\hline & Wood & KTOE & 258.00 & 256.00 & 251.00 & 244.00 & 241.11 \\
\hline & Solar energy & KTOE & 1.10 & 1.90 & 2.33 & 3.11 & 3.56 \\
\hline & Total & KTOE & 1823.93 & 1861.02 & 1899.17 & 2012.64 & 2048.54 \\
\hline 3 & $\begin{array}{l}\text { Per Capita Energy } \\
\text { produced }\end{array}$ & $\begin{array}{l}\text { KTOE/ } \\
\text { persons }\end{array}$ & 592.12 & 604.28 & 614.95 & 647.29 & 652.44 \\
\hline \multirow[t]{4}{*}{4} & $\begin{array}{l}\text { Sources of electrical } \\
\text { energy: }\end{array}$ & & & & & & \\
\hline & HEC/TEC & KTOE & 459.02 & 390.51 & 331.22 & 340.16 & 390.43 \\
\hline & Import & KTOE & 105.26 & 156.45 & 177.45 & 215.00 & 154.80 \\
\hline & Total & KTOE & 564.27 & 546.96 & 508.67 & 555.16 & 545.23 \\
\hline \multirow[t]{8}{*}{5} & Energy consumed by sector: & & & & & & \\
\hline & Population & KTOE & 373.02 & 374.87 & 375.22 & 388.33 & 392.20 \\
\hline & Services & KTOE & 334.71 & 332.86 & 336.22 & 345.55 & 351.22 \\
\hline & Industry & KTOE & 290.23 & 324.50 & 335.33 & 354.22 & 376.23 \\
\hline & Agriculture & KTOE & 192.17 & 194.75 & 196.22 & 205.33 & 218.23 \\
\hline & Transport & KTOE & 570.09 & 595.85 & 602.44 & 633.22 & 654.33 \\
\hline & Others & KTOE & 25.57 & 25.17 & 25.33 & 26.33 & 25.66 \\
\hline & Total & KTOE & 1785.79 & 1848.01 & 1870.76 & 1952.98 & 2017.87 \\
\hline 6 & Per Capita Energy Consumption: & & & & & & \\
\hline \multirow[t]{6}{*}{7} & $\begin{array}{l}\text { Energy consumed by sectors: } \\
\text { Population }\end{array}$ & KTOE & 211.82 & 211.24 & 205.22 & 200.32 & 196.44 \\
\hline & Services & KTOE & 53.75 & 47.03 & 43.22 & 50.33 & 56.44 \\
\hline & Industry & KTOE & 78.26 & 74.61 & 80.12 & 85.45 & 90.21 \\
\hline & Agriculture & KTOE & 16.68 & 14.90 & 13.22 & 17.89 & 25.33 \\
\hline & Transport & KTOE & 2.44 & 3.19 & 4.33 & 5.78 & 6.34 \\
\hline & Others & KTOE & 362.95 & 350.98 & 346.11 & 359.77 & 374.76 \\
\hline 8 & Total & $\begin{array}{l}\text { KTOE/ } \\
\text { persons }\end{array}$ & 183.18 & 177.60 & 164.70 & $\mathbf{1 7 8 . 5 5}$ & $\mathbf{1 7 3 . 6 5}$ \\
\hline 9 & Energy Consumption revenue amounts & & 61.6 & 76.3 & 89.9 & 90.3 & 92.4 \\
\hline 10 & $\begin{array}{l}\text { Level of losses in the } \\
\text { network in \% }\end{array}$ & & 53.8 & 44.8 & 41.7 & 39.2 & 35.8 \\
\hline
\end{tabular}


ANNEX 3: MONITORING INDICATORS IDENTIFIED BY THE MINISTRIES

TABLE 7: MINISTRY OF ENVIRONMENT 
ANNEX 3: MONITORING INDICATORS IDENTIFIED BY THE MINISTRIES

\section{TABLE 7: MINISTRY OF ENVIRONMENT}

\begin{tabular}{|c|c|c|c|c|c|c|c|c|c|c|c|}
\hline \multirow[t]{2}{*}{ No } & \multirow{2}{*}{$\begin{array}{l}\text { Types of } \\
\text { Indicators }\end{array}$} & \multirow{2}{*}{ Environment Indicators } & \multicolumn{3}{|c|}{ Indicators of } & \multirow{2}{*}{$\begin{array}{l}\text { Executing } \\
\text { Agency }\end{array}$} & \multicolumn{5}{|c|}{ Time Period } \\
\hline & & & $\begin{array}{l}\text { NSSE } \\
\text { D }\end{array}$ & $\begin{array}{l}\text { PRS } \\
\text { C }\end{array}$ & MDG & & 2000 & 2001 & 2002 & 2003 & 2004 \\
\hline \multicolumn{12}{|c|}{ I. Establishment of environmental structures } \\
\hline & Process indicators & $\begin{array}{l}\text { State budget allocated to the MoEn } \\
\text { in lek }\end{array}$ & & & & MoEn, MoF & 58954 & 69026 & 203379 & 236967 & 273000 \\
\hline 4 & Input indicators & Ministry personnel & & & & MoEn, PAD & 70 & 83 & 83 & 110 & 120 \\
\hline 6 & Process indicators & $\begin{array}{l}\text { Personnel with access to } \\
\text { communications tools }\end{array}$ & & & & MoEn & 25 & 25 & 25 & 40 & 50 \\
\hline 10 & Process indicators & $\begin{array}{l}\text { Personnel trained by the Ministry } \\
\text { and the Environment Inspectorate }\end{array}$ & & & & MoEn & & & & & $80 \%$ \\
\hline 12 & Process indicators & $\begin{array}{l}\text { Contact person for environment in } \\
\text { other ministries }\end{array}$ & & & & $\begin{array}{l}\text { MoEn, line } \\
\text { ministries }\end{array}$ & & & & & \\
\hline 13 & Process indicators & $\begin{array}{l}\text { Number of central inter-sectorial } \\
\text { environmental structures }\end{array}$ & & & & $\mathrm{CoM}$ & - & - & - & 12 & 12 \\
\hline \multicolumn{12}{|c|}{ II. Preparation of the environmental documents and policy instruments } \\
\hline & Process indicators & $\begin{array}{l}\text { Number of legal and sub-legal acts } \\
\text { prepared and approved }\end{array}$ & & & & MoEn & & & & 20 & \\
\hline & Product indicators & $\begin{array}{l}\text { Number of policy documents and } \\
\text { sectorial sub-legal acts prepared in } \\
\text { cooperation with the MoEn }\end{array}$ & & & & $\begin{array}{l}\text { Line ministries, } \\
\text { MoEn }\end{array}$ & - & - & - & & \\
\hline & Product indicators & $\begin{array}{l}\text { Number of legal and sub-legal acts } \\
\text { and policy documents prepared in } \\
\text { cooperation with NGOs }\end{array}$ & & & & $\begin{array}{l}\text { MoEn, line } \\
\text { ministries }\end{array}$ & - & - & & & \\
\hline & Process indicators & $\begin{array}{l}\text { Total number of awareness-raising } \\
\text { activities organized by MoEn in } \\
\text { cooperation with NGOs }\end{array}$ & & & & MoEn, NGO & 15 & 18 & 32 & 40 & 45 \\
\hline & Process indicators & $\begin{array}{l}\text { Number of activities organized by } \\
\text { the MoEn in cooperation with the } \\
\text { media }\end{array}$ & & & & $\mathrm{MoE}$ & - & - & 40 & 60 & 80 \\
\hline
\end{tabular}


ANNEX 3: MONITORING INDICATORS IDENTIFIED BY THE MINISTRIES

\begin{tabular}{|c|c|c|c|c|c|c|c|c|c|c|c|}
\hline \multirow[t]{2}{*}{ No } & \multirow{2}{*}{$\begin{array}{l}\text { Types of } \\
\text { Indicators }\end{array}$} & \multirow{2}{*}{ Environment Indicators } & \multicolumn{3}{|c|}{ Indicators of } & \multirow{2}{*}{$\begin{array}{l}\text { Executing } \\
\text { Agency }\end{array}$} & \multicolumn{5}{|c|}{ Time Period } \\
\hline & & & $\begin{array}{l}\text { NSSE } \\
\text { D }\end{array}$ & $\begin{array}{l}\text { PRS } \\
\text { C }\end{array}$ & MDG & & 2000 & 2001 & 2002 & 2003 & 2004 \\
\hline & Product indicators & $\begin{array}{l}\text { Availability of MoEn web-page on } \\
\text { the internet }\end{array}$ & & & & & & & & & \\
\hline & Product indicators & $\begin{array}{l}\text { Publish environment summary } \\
\text { report } 1999-2000\end{array}$ & & & & & & & & & \\
\hline & Product indicators & $\begin{array}{l}\text { Prepare and publish environment } \\
\text { summary report } 1999-2000\end{array}$ & & & & & & & & & \\
\hline \multicolumn{12}{|c|}{ III. Reduction of Existing Pollution } \\
\hline & Input indicators & $\begin{array}{l}\text { Available funds for studies and } \\
\text { environmental rehabilitation } \\
\text { projects }\end{array}$ & & & & & & & & & \\
\hline & Process indicators & $\begin{array}{l}\text { Number of feasibility studies } \\
\text { addressing contaminated areas }\end{array}$ & & & & & 1 & 7 & 1 & 2 & 2 \\
\hline & Product indicators & Number of rehabilitated hot spots & & & & MoEn, MoIE & - & 0 & 0 & 1 & \\
\hline & Process indicators & $\begin{array}{l}\text { Feasibility studies addressing } \\
\text { sewage issues in the urban plans }\end{array}$ & & & & MoTA, MoEn & 1 & 1 & - & 3 & \\
\hline \multicolumn{12}{|c|}{ IV. Sustainable Use of Sources } \\
\hline & Input indicators & $\begin{array}{l}\text { Funds allocated for protected areas } \\
\text { (in 000/lek) }\end{array}$ & & & & $\begin{array}{l}\text { MoAF, MoEn, } \\
\text { MoF }\end{array}$ & 7800 & 8500 & & & \\
\hline & Process indicators & $\begin{array}{l}\text { Transfer of resources } \\
\text { administration to the community: } \\
\text { forests, land, waters (ha) }\end{array}$ & & & & & & $\begin{array}{l}145000 \\
\text { ha } \\
\text { forests } \\
40000 \\
\text { ha } \\
\text { pastures }\end{array}$ & $\begin{array}{l}200000 \\
\text { ha forests } \\
55000 \\
\text { ha } \\
\text { pastures }\end{array}$ & $\begin{array}{l}250000 \\
\text { ha } \\
\text { forests } \\
60000 \\
\text { ha } \\
\text { pastures }\end{array}$ & $\begin{array}{l}360000 \\
\text { ha forests } \\
66000 \\
\text { ha } \\
\text { pastures }\end{array}$ \\
\hline & Product indicators & $\begin{array}{l}\text { Total surface of protected areas } \\
\text { (ha) }\end{array}$ & & & & MoAF, MoEn & 164000 & 164000 & 189000 & 190000 & 200000 \\
\hline & Product indicators & Total reforested area (in ha) & & & & MoEn & 337 & 580 & & & \\
\hline & Process indicators & $\begin{array}{l}\text { Number of protected areas with } \\
\text { approved management plans }\end{array}$ & & & & $\begin{array}{l}\text { MoAF, } \\
\text { MoLGD, MoEn }\end{array}$ & 2 & 2 & 2 & 5 & 6 \\
\hline
\end{tabular}


ANNEX 3: MONITORING INDICATORS IDENTIFIED BY THE MINISTRIES

TABLE 8: MINISTRY OF LABOUR AND SOCIAL AFFAIRS 
ANNEX 3: MONITORING INDICATORS IDENTIFIED BY THE MINISTRIES

TABLE 8: MINISTRY OF LABOUR AND SOCIAL AFFAIRS

\begin{tabular}{|c|c|c|c|c|c|c|}
\hline \multirow[t]{2}{*}{ Area/Sector } & \multirow[t]{2}{*}{ Selected indicators } & \multirow[t]{2}{*}{ Baseline 2000} & \multirow[t]{2}{*}{2001} & \multicolumn{2}{|c|}{2002} & \multirow[t]{2}{*}{ Informative data base } \\
\hline & & & & Objective & Realization & \\
\hline \multirow[t]{11}{*}{ Labor Market } & A. Input and Process Indicators & & & & & \\
\hline & - number of employment enhancement projects & 417 & 187 & & 163 & \\
\hline & $\begin{array}{l}\text { - employment enhancement projects funds / in } \\
\text { millions }\end{array}$ & 546 & 388 & 310 & 303 & \\
\hline & $\begin{array}{l}\text { - number of jobs identified by the Employment } \\
\text { Offices }\end{array}$ & 2464 & 3793 & & 5233 & \\
\hline & - number of persons trained & 7277 & 10528 & 8100 & 12358 & \\
\hline & - unemployment benefit funds in '000 lek & 1373356 & 1890854 & 1500000 & 1130328 & \\
\hline & B. Product indicators & & & & & \\
\hline & $\begin{array}{l}\text {-Number of employed in the non-agricultural sector } \\
\text { (public and private) }\end{array}$ & 405825 & 394276 & & 395278 & \\
\hline & $\begin{array}{l}\text { - total number of employed through employment } \\
\text { enhancement programs } \\
\text { - employment enhancement programs }\end{array}$ & 11773 & 4769 & & 4167 & \\
\hline & $\begin{array}{l}\text { - number of persons from the beneficiary groups } \\
\text { receiving unemployment benefits employed by the } \\
\text { employment enhancement programs }\end{array}$ & & & & $2760(36 \%)$ & \\
\hline & - Number of registered unemployed & 215085 & 180513 & 174000 & 172385 & \\
\hline
\end{tabular}


ANNEX 3: MONITORING INDICATORS IDENTIFIED BY THE MINISTRIES

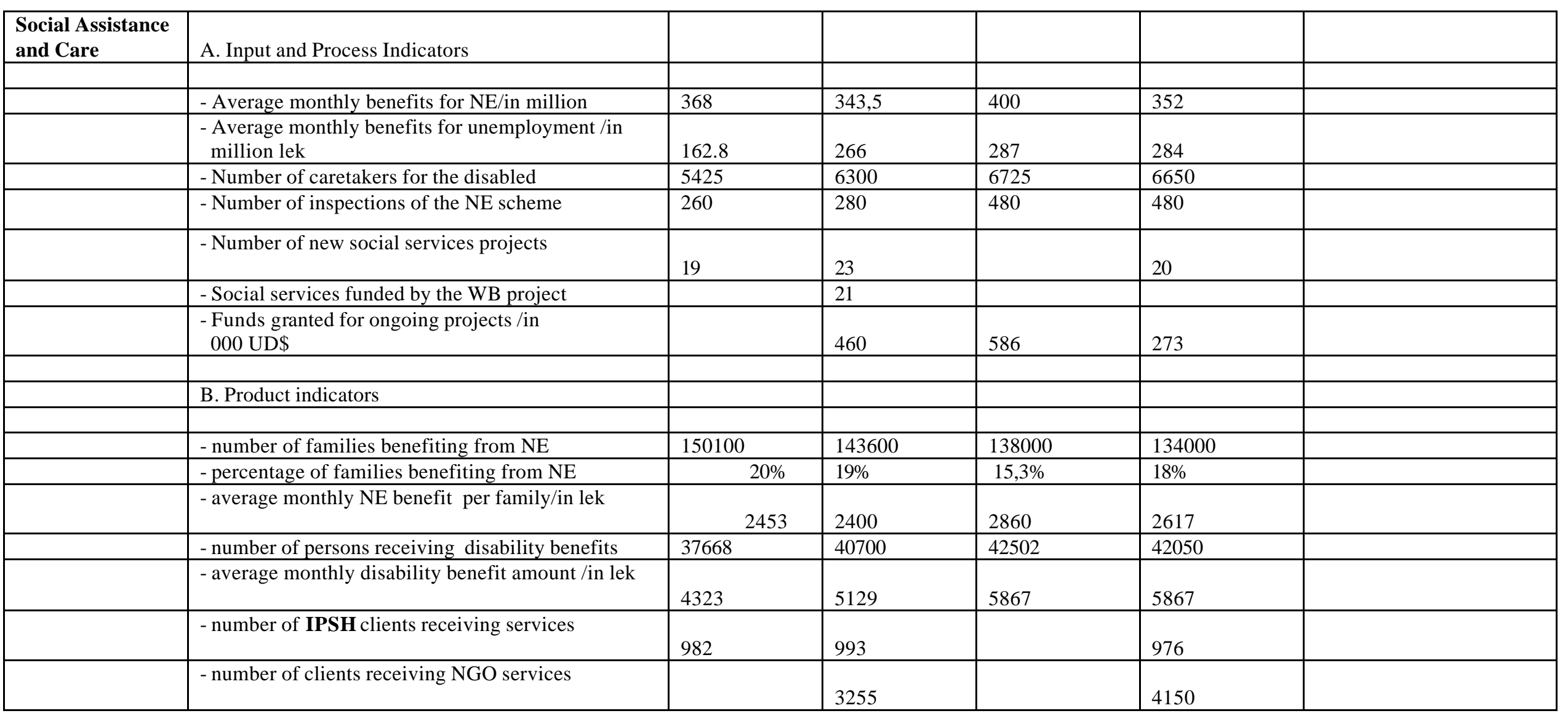

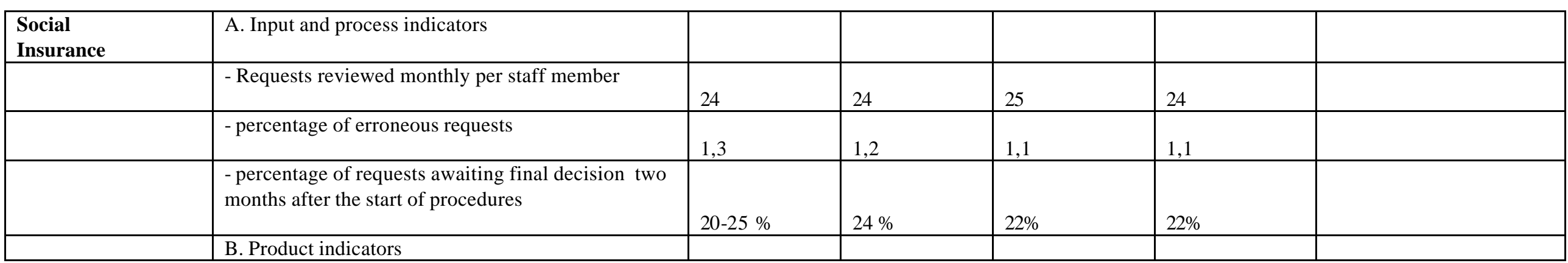


ANNEX 3: MONITORING INDICATORS IDENTIFIED BY THE MINISTRIES

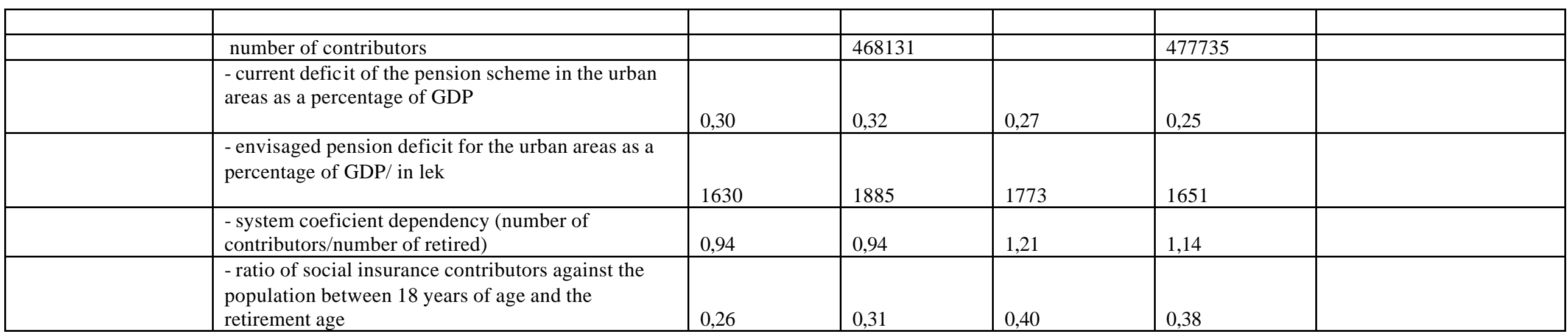


ANNEX 3: MONITORING INDICATORS IDENTIFIED BY THE MINISTRIES

TABLE 9: MINISTRY OF HEALTH 
ANNEX 3: MONITORING INDICATORS IDENTIFIED BY THE MINISTRIES

\section{TABLE 9: MINISTRY OF HEALTH}

\begin{tabular}{|c|c|c|c|c|c|c|}
\hline Indicators & Baseline 2000 & 2001 & Year 2002 & $\begin{array}{l}\text { Objectives for } \\
2004\end{array}$ & $\begin{array}{l}\text { Objectives for } \\
2015\end{array}$ & $\begin{array}{l}\text { Source of } \\
\text { Information }\end{array}$ \\
\hline \multicolumn{7}{|l|}{ Input indicators } \\
\hline $\begin{array}{l}\text { Health expenditures as a percentage } \\
\text { of GDP }\end{array}$ & 1.3 & 2.0 & 2.7 & 3.0 & & E.D/ MoH \\
\hline $\begin{array}{l}\text { Amount and percentage of the state } \\
\text { budget allocated for the health } \\
\text { sector (including the local } \\
\text { government grant and the transfer } \\
\text { for IHSI) }\end{array}$ & $\begin{array}{l}12.334 \\
7.2 \%\end{array}$ & $\begin{array}{l}12.027 \\
6.47 \%\end{array}$ & $\begin{array}{l}18.044 \\
8.49 \%\end{array}$ & & & E.D/ MoH \\
\hline $\begin{array}{l}\text { Percentage of the health service } \\
\text { funding coming through the } \\
\text { advisory health insurance scheme }\end{array}$ & 732 & 1.286 & 1.907 & & & E.D/ MoH \\
\hline $\begin{array}{l}\text { Investments funded by the state } \\
\text { budget }\end{array}$ & 1.114 & 1.350 & 1.475 & & & E.D/ MoH \\
\hline Investments for regional hospitals & 512 & 824 & 710 & & & E.D/ MoH \\
\hline $\begin{array}{l}\text { Investments in health centers } \\
\text { (budget) in what lek }\end{array}$ & 190 & 76 & 52.7 & & & NKP/ MoH \\
\hline Investments in public health labs & 11.1 & 11.3 & 24 & & & E.D/ MoH \\
\hline $\begin{array}{l}\text { Investments in the maternity and } \\
\text { pediatric health clinics network }\end{array}$ & N/a & N/a & 8 & & & E.D/ MoH \\
\hline Investments in information systems & & & $\$ 464.811 \mathrm{US}$ & & & $\begin{array}{l}\text { Donors' Conference } \\
22 / 01 / 2002\end{array}$ \\
\hline \multicolumn{7}{|l|}{ Indicators } \\
\hline Process Indicators & & & & & & $\begin{array}{l}\text { Source of } \\
\text { Information } \\
\end{array}$ \\
\hline
\end{tabular}


ANNEX 3: MONITORING INDICATORS IDENTIFIED BY THE MINISTRIES

\begin{tabular}{|c|c|c|c|c|c|c|c|}
\hline $\begin{array}{l}\text { Legal and sub-legal acts } \\
\text { aiming at improving the } \\
\text { health legislation }\end{array}$ & \multicolumn{6}{|c|}{$\begin{array}{l}\text { 1. Order of the Minister "On patients' reference system at all levels." } \\
\text { 2. Decision No.306, dated 26.6.2002 on applying a new remuneration system for the first-level } \\
\text { specialists in the Health sector } \\
\text { 3. Guideline No.39, dated } 15.2 .2002 \text { "On additional bonuses [supplements] for physicians working } \\
\text { away from their place of residence". } \\
\text { 4. Guideline No.24, dated } 29.01 .2002 \text { "On additional supplements to the specialists' wages". } \\
\text { 5. Summary Guideline No.316, dated } 05.02 .2002 \text { to the subordinate institutions "On sector legislation } \\
\text { and wage regulatory system" }\end{array}$} & $\mathrm{MoH}$ \\
\hline $\begin{array}{l}\text { Policy and strategic } \\
\text { documents }\end{array}$ & \multicolumn{6}{|c|}{$\begin{array}{l}\text { 1. Albanian Health System } 10 \text { year Strategy draft } \\
\text { 2. Public Health Strategy, } \\
\text { 3. Tobacco Control Strategy } \\
\text { 4. HIV/AIDS Control Strategy } \\
\text { 5. Alcohol Control Strategy, } \\
\text { 6. Mental Health Strategy } \\
\text { 7. Draft Food and Nutrition Action Plan }\end{array}$} & $\mathrm{MoH}$ \\
\hline Training activities & \multicolumn{6}{|c|}{$\begin{array}{l}\text { 1. A series of courses offered to assist nurses and midwives in the district of Durres, Korce, Gjirokaster, } \\
\text { Kavaje, } \\
\text { 2. Continuous training course offered at prefecture level in the framework of Primary Health Care }\end{array}$} & $\mathrm{MoH}$ \\
\hline $\begin{array}{l}\text { Seminars, Workshops and } \\
\text { Conferences }\end{array}$ & \multicolumn{6}{|c|}{$\begin{array}{l}\text { 1. International Conference on Health in Albania } \\
\text { 2. Workshops held in the MoH on Monitoring and Evaluation process } \\
\text { 3. Workshop with the district PHD Directors on introducing MoH concepts } \\
\text { 4. } 1^{\text {st }} \text { Albanian national conference on Thyroid ... } \\
\text { 5. Conference on safe parenting }\end{array}$} & \\
\hline \multicolumn{2}{|l|}{ Indicators } & $\begin{array}{l}\text { Baseline Year } \\
2000\end{array}$ & 2001 & 2002 & $\begin{array}{l}\text { Objectives for } \\
2004\end{array}$ & $\begin{array}{l}\text { Objectives for } \\
2015\end{array}$ & $\begin{array}{l}\text { Source of } \\
\text { Information }\end{array}$ \\
\hline \multicolumn{8}{|l|}{ Product Indicators } \\
\hline \multicolumn{2}{|c|}{$\begin{array}{l}\text { Number of administrative personnel } \\
\text { trained }\end{array}$} & 110 & 145 & 200 & & & DoHR /MoH \\
\hline \multicolumn{2}{|c|}{ Number of medical personnel trained: } & 135 & 210 & 320 & & & DoHR /MoH \\
\hline \multicolumn{2}{|l|}{ Nurses } & 1930 & 1140 & 2146 & & & DoHR /MoH \\
\hline \multicolumn{2}{|c|}{$\begin{array}{l}\text { Number of fully constructed or } \\
\text { rehabilitated health centers }\end{array}$} & 28 & 17 & 15 & & & E.D/MoH \\
\hline
\end{tabular}

rehabilitated health centers

1. Order of the Minister "On patients' reference system at all levels."

Decision No.306, dated 26.6.2002 on applying a new remuneration system for the first-level

sector

Summary Guideline No.316, dated 05.02.2002 to the subordinate institutions "On sector legislation and wage regulatory system"

1. Albanian Health System 10 year Strategy draft

. Public Health Strategy,

Alcohol Control Strategy,

. Kavaje,

1. International Conference on Health in Albania

2. Workshops held in the $\mathrm{MoH}$ on Monitoring and Evaluation process

Workshop with the district PHD Directors on introducing MoH concepts

4. $1^{\text {st }}$ Albanian national conference on Thyroid ... 
ANNEX 3: MONITORING INDICATORS IDENTIFIED BY THE MINISTRIES

\begin{tabular}{|c|c|c|c|c|c|c|}
\hline & & & $16(\mathrm{BB})$ & & & \\
\hline $\begin{array}{l}\text { Number of fully constructed or } \\
\text { rehabilitated out-patients clinics }\end{array}$ & - & 7 & 33 & & & DoHR /MoH \\
\hline $\begin{array}{l}\text { Percentage of mandatory vaccines } \\
\text { provided }\end{array}$ & $100 \%$ & $100 \%$ & $100 \%$ & $100 \%$ & $100 \%$ & $\mathrm{DoHR} / \mathrm{MoH}$ \\
\hline $\begin{array}{l}\text { Population covered by mandatory } \\
\text { vaccines }\end{array}$ & $97 \%$ & $97 \%$ & $97 \%$ & $97 \%$ & $97 \%$ & $\mathrm{DoPHC} / \mathrm{MoH}$ \\
\hline Number of new cases of HIV/AIDS & 10 & 20 & 17 & & & PHI \\
\hline $\begin{array}{l}\text { Number of mental health community } \\
\text { centers }\end{array}$ & - & 6 & - & & & DoPHC/ MoH \\
\hline Indicators & $\begin{array}{l}\text { Baseline Year } \\
2000\end{array}$ & 2001 & 2002 & $\begin{array}{l}\text { Objectives for } \\
2004\end{array}$ & $\begin{array}{l}\text { Objectives for } \\
2015\end{array}$ & $\begin{array}{l}\text { Source of } \\
\text { Information }\end{array}$ \\
\hline \multicolumn{7}{|l|}{ Effect Indicators } \\
\hline Average life expectancy & 74,6 & - & - & & & INSTAT \\
\hline Infant mortality rate per 1000 births & 22,8 & 17,5 & & & 10 & INSTAT \\
\hline $\begin{array}{l}\text { Maternal mortality per } 100 \text { 000live } \\
\text { birth }\end{array}$ & 22,6 & 22,7 & & & 10 & INSTAT \\
\hline $\begin{array}{l}\text { Incidence of diarrea per } 100.000 \\
\text { inhabitants }\end{array}$ & 142 & 146 & & & & INSTAT \\
\hline
\end{tabular}


ANNEX 3: MONITORING INDICATORS IDENTIFIED BY THE MINISTRIES

TABLE 10: DEPARTMENT OF PUBLIC ADMINISTRATION - COUNCIL OF MINISTERS

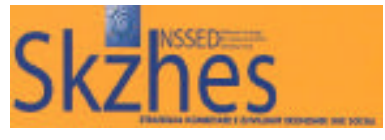


ANNEX 3: MONITORING INDICATORS IDENTIFIED BY THE MINISTRIES

TABLE 10: DEPARTMENT OF PUBLIC ADMINISTRATION - COUNCIL OF MINISTERS

\begin{tabular}{|c|c|c|c|c|c|c|}
\hline \multirow[t]{2}{*}{ No } & \multirow[t]{2}{*}{ Ref. } & \multirow[t]{2}{*}{ Indicators } & \multicolumn{4}{|c|}{ Indicators Progress } \\
\hline & & & Unit & 2000 & 2001 & 2002 \\
\hline 1 & $2 / 4$ & $\begin{array}{l}\begin{array}{l}\text { Number of } \\
\text { evaluated }\end{array} \\
\text { civil servants }\end{array}$ & Individuals & & & 624 \\
\hline 2 & $2 / 4$ & $\begin{array}{l}\text { Percentage of evaluations } \\
\text { according to the evaluation } \\
\text { categories }(1-4)\end{array}$ & $\%$ & & & $\begin{array}{l}\text { by } 1-61.3 \% \\
\text { by } 2-34.6 \% \\
\text { by } 3-3.8 \% \\
\text { by } 4-0.3 \%\end{array}$ \\
\hline 3 & $2 / 5$ & $\begin{array}{l}\text { Number of confirmed civil } \\
\text { servants }\end{array}$ & & & & \\
\hline 4 & $2 / 6$ & $\begin{array}{l}\text { Average number of } \\
\text { applicants/vacancy }\end{array}$ & Individuals & & 5.4 & 7 \\
\hline 5 & $3 / 2$ & $\begin{array}{l}\text { Number of training courses } \\
\text { offered for DoPA experts }\end{array}$ & Training & & & 8 \\
\hline 6 & $3 / 3$ & $\begin{array}{l}\text { Number of training courses } \\
\text { offered for the personnel } \\
\text { managers within line ministries }\end{array}$ & Training & & & 6 \\
\hline 7 & $3 / 4$ & $\begin{array}{l}\text { Number of training courses } \\
\text { offered for Secretaries General }\end{array}$ & Training & & & 3 \\
\hline 8 & $4 / 2$ & $\begin{array}{l}\text { Number of training courses } \\
\text { conducted by the Public } \\
\text { Administration Training Institute }\end{array}$ & Training & & & 4 \\
\hline
\end{tabular}


ANNEX 3: MONITORING INDICATORS IDENTIFIED BY THE MINISTRIES

TABLE 11: MINISTRY OF TRANSPORT 
ANNEX 3: MONITORING INDICATORS IDENTIFIED BY THE MINISTRIES

TABLE 11: MINISTRY OF TRANSPORT

1/a Input Indicators

total

INVESTMENTS IN TRANSPORT ACCORDING TO THE SECTORS

\begin{tabular}{|c|c|c|c|c|c|c|c|}
\hline No & Sectors & 98 & 99 & 2000 & 2001 & $\begin{array}{c}\text { Operational } \\
2002 \\
\end{array}$ & \\
\hline \multirow[t]{3}{*}{ I } & Total Road infrastructure & $4,676,693$ & $10,978,410$ & $14,366,663$ & $13,819,135$ & $8,524,642$ & \\
\hline & - Budget Inv. & $1,929,395$ & $3,617,657$ & $5,307,729$ & $6,041,335$ & $4,626,986$ & \\
\hline & -Foreign Inv. & $2,747,298$ & $7,360,753$ & $9,058,934$ & $7,777,800$ & $3,897,656$ & \\
\hline \multirow[t]{3}{*}{ II } & Total Automobile Transport & $2,765,496$ & 54,284 & 40,428 & 21,379 & 0 & \\
\hline & - Budget Inv. & 215,976 & 54,284 & 40,428 & 21,379 & 0 & \\
\hline & - Foreign Inv. & $2,549,520$ & 0 & 0 & 0 & 0 & \\
\hline \multirow[t]{3}{*}{ III } & Total Railway Transport & 87,000 & 161,605 & 636,107 & 648,827 & 489,760 & \\
\hline & - Budget Inv. & 87,000 & 161,605 & 270,607 & 254,166 & 489,760 & \\
\hline & - Foreign Inv. & 0 & 0 & 365,500 & 394,661 & 0 & \\
\hline \multirow[t]{3}{*}{ IV } & Total Sea and Water Transport & 138,382 & 610,796 & 763,728 & $1,061,233$ & $1,690,022$ & \\
\hline & - Budget Inv. & 18,500 & 64,074 & 168,121 & 227,933 & 436,460 & \\
\hline & - Foreign Inv. & 119,882 & 546,722 & 595,607 & 833,300 & $1,253,562$ & \\
\hline \multirow[t]{6}{*}{$\mathbf{V}$} & Total Air Transport & $1,551,600$ & 155,000 & 180,990 & 290,208 & 0 & \\
\hline & - Budget Inv. & 0 & 155,000 & 180,990 & 65,108 & 0 & \\
\hline & - Foreign Inv. & $1,551,600$ & 0 & 0 & 225,100 & 0 & \\
\hline & Total Investments & $9,219,171$ & $11,960,095$ & $15,987,916$ & $15,840,782$ & $10,704,424$ & \\
\hline & - Budget Inv. & $2,250,871$ & $4,052,620$ & $5,967,875$ & $6,609,921$ & $5,553,206$ & \\
\hline & - Foreign Inv. & $6,968,300$ & $7,907,475$ & $10,020,041$ & $9,230,861$ & $5,151,218$ & \\
\hline
\end{tabular}


ANNEX 3: MONITORING INDICATORS IDENTIFIED BY THE MINISTRIES

b. Water transport

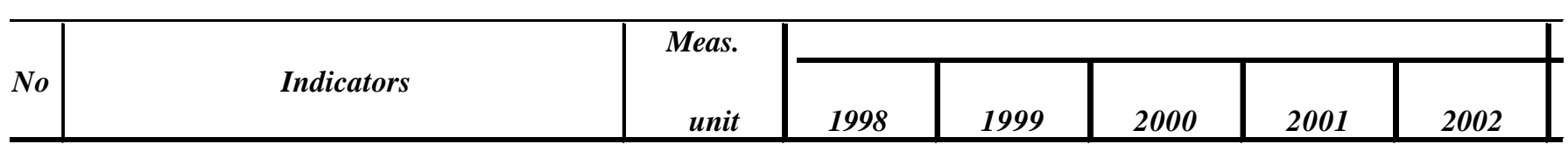

\begin{tabular}{|c|c|c|c|c|c|c|}
\hline 1|Total loading-and-unloading volume & & 1656.3 & 2149.6 & 2702.2 & 2994.9 & 3091.97| \\
\hline - Durres harbor & thou ton phys & 1168.4 & 1556.9 & 1882.9 & 1989.1 & 2181.07 \\
\hline -Vlore harbor & thou ton phys & 339.5 & 366.9 & 526.7 & 591.8 & 503.47 \\
\hline - Sarande harbor & thou ton ohvs & 31.6 & 42.7 & 60.4 & 51.6 & 60.63 \\
\hline - Shengjin harbor & hou te & 116.8 & 183.1 & 232.2 & 362.4 & 346.8 \\
\hline \multicolumn{7}{|l|}{$\begin{array}{l}2 \text { Total number of incoming \& outgoing } \\
\text { travelers }\end{array}$} \\
\hline $\begin{array}{l}\text { travelers } \\
\text { - Durres harbor }\end{array}$ & no & 320536 & 620027 & 566470 & 605040 & (5915039 \\
\hline -Vlore harbor & & 45955 & 65157 & $\overline{63416}$ & $\overline{72046}$ & 83802 \\
\hline - Sarande harbor & no & 29500 & 37001 & 44588 & 46756 & 72344 \\
\hline - Shengiin harbor & & & & 6766 & & \\
\hline
\end{tabular}

3 Total number of processed containers

\begin{tabular}{|c|c|c|c|c|c|c|}
\hline - Durres harbor & no & & & & & \\
\hline -Vlore harbor & no & & & & & \\
\hline -Sarande harbor & no & & & & & \\
\hline - Shengjin harbor & no & & & & & \\
\hline 4 Total number of in & & 1297 & 1531 & 1750 & 2888 & 0 \\
\hline - Durres harbor & no & 844 & 1071 & 1142 & 2231 & \\
\hline -Vlore harbor & no & 286 & 248 & 331 & 378 & \\
\hline - Sarande harbor & no & 39 & 37 & 54 & 36 & \\
\hline - Shengjin harbor & no & 128 & 175 & 223 & 243 & \\
\hline
\end{tabular}


ANNEX 3: MONITORING INDICATORS IDENTIFIED BY THE MINISTRIES

c Railway transport

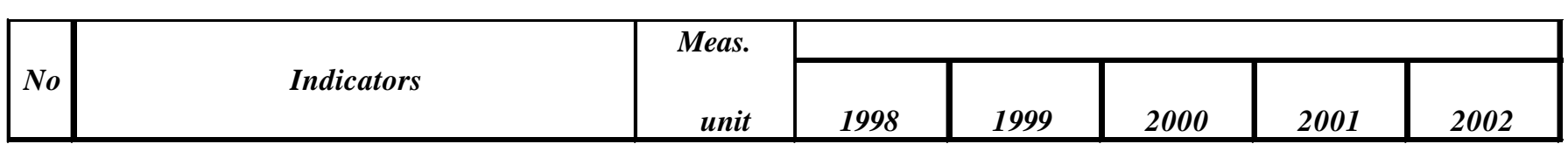

\begin{tabular}{|c|c|c|c|c|c|c|c|}
\hline 1 & Inventory of transport means & & & & & & \\
\hline & Engines & piece & 68 & 68 & 68 & 68 & 58 \\
\hline & & $000 \mathrm{HP}$ & 93.75 & 93.75 & 93.75 & 93.75 & 73.377 \\
\hline & Traveler cars & piece & 79 & 99 & 99 & 95 & 66 \\
\hline & " & 000 seats & 4.5 & 6 & 6 & 5.757 & 4814 \\
\hline & Freight cars & piece & 1648 & 840 & 840 & 834 & 834 \\
\hline & 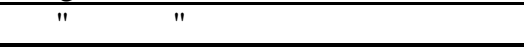 & 000 ton & 63.782 & 35.225 & 35.225 & 39.387 & 39.387 \\
\hline 2 & Loading \& unloading work volume & 000 ton physic & 139 & 295.8 & 334.5 & 189.7 & 269.64 \\
\hline 3 & Goods transport work volume & & & & & & \\
\hline & -Ton & 000 ton & 304.6 & 360.8 & 411.9 & 258.8 & 348.65 \\
\hline & International transport & 000 ton & & & & & \\
\hline & -Ton-km & 000 tonkm & 25428 & 25843 & 28157 & 19060 & 20944.5 \\
\hline & International transport & 000 tonkm & & & & & \\
\hline \multicolumn{8}{|c|}{4 Passengers transport work load } \\
\hline & -Passengers & 000 pass & 2268.6 & 2268.7 & 2381.4 & 2676 & 2279.78 \\
\hline & -Travel-km & $000 \mathrm{tkm}$ & 115635 & 120726.5 & 124730 & 138170.4 & 122996.9 \\
\hline
\end{tabular}


ANNEX 3: MONITORING INDICATORS IDENTIFIED BY THE MINISTRIES

d Air transport

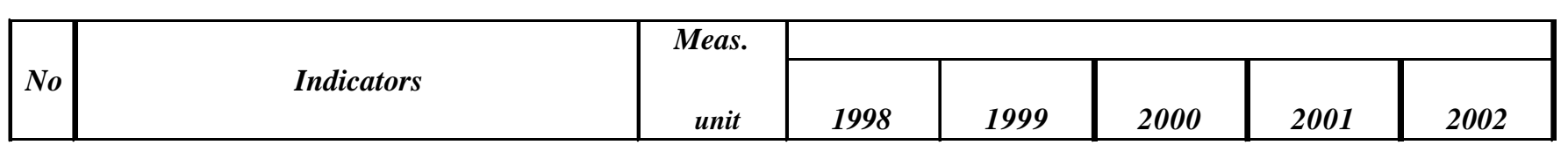

\begin{tabular}{|r|l|r|r|r|r|r|r|}
\hline 1 & Number of planes landing and taking off & no & 4304 & $\mathbf{8 2 4}$ & 5302 & 5307 & 5200 \\
\hline & Number of overflys & & & & & & \\
\hline 2 & & 23106 & 13387 & 65166 & $\mathbf{7 4 9 6 5}$ & $\mathbf{8 7 9 8 0}$ \\
\hline 3 & Number of incoming \& outgoing passengers & pass & 295308 & 356823 & 408334 & 460020 & 495102 \\
\hline & & & & & & & \\
\hline 4 & Number of operating airline companies & no & 13 & 12 & 10 & 11 & 12 \\
\hline
\end{tabular}

e Telecommunication Sector

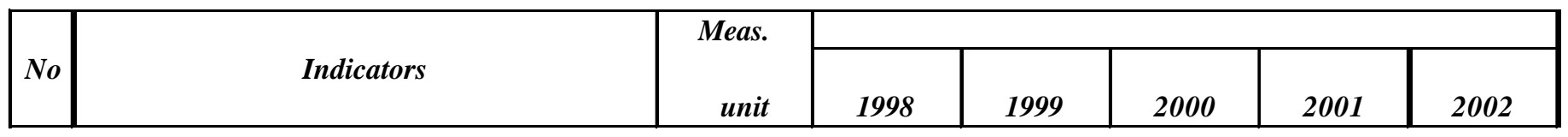

\begin{tabular}{|r|l|r|r|r|r|r|r|}
\hline $\mathbf{1}$ & Outspread of fixed telephony & $\mathbf{\%}$ & $\mathbf{3 . 0 5}$ & $\mathbf{4 . 1 6}$ & $\mathbf{4 . 4 9}$ & $\mathbf{6 . 4}$ & $\mathbf{7}$ \\
\hline & -outspread of fixed telephony in rural areas & $\%$ & 0.12 & 0.16 & 0.17 & 0.08 & 0.1 \\
\hline $\mathbf{2}$ & Outspread of mobile telephony & $\mathbf{\%}$ & $\mathbf{0 . 1 5}$ & $\mathbf{0 . 2 9}$ & $\mathbf{0 . 7 6}$ & $\mathbf{1 2}$ & $\mathbf{2 2 . 6}$ \\
\hline $\mathbf{3}$ & Coverage of mobile telephony & & & & & & \\
\hline & -territory & $\%$ & 35 & 42 & 42 & 63 & 80 \\
\hline & -population & $\%$ & 40 & 48 & 48 & 84 & 90 \\
\hline $\mathbf{4}$ & Internet & & & & & & \\
\hline & - ISP number & No & 3 & 6 & 10 & 17 & 22 \\
\hline & -users number & No & & & & 5000 & 10000 \\
\hline $\mathbf{5}$ & Number of licensed subjects [businesses] & No & 175 & 215 & 320 & 358 & 414 \\
\hline
\end{tabular}


ANNEX 3: MONITORING INDICATORS IDENTIFIED BY THE MINISTRIES

f. Mail-service

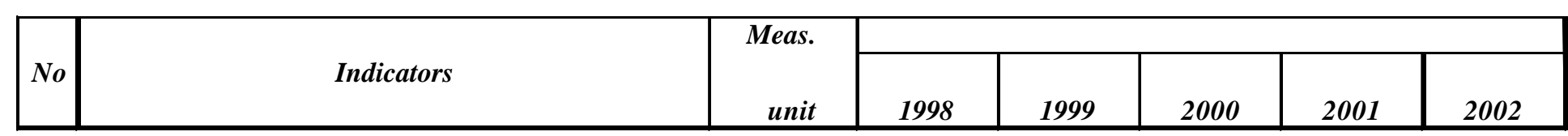

\begin{tabular}{|r|l|r|r|r|r|r|r|}
\hline 1 & Public postal operator (Posta Shqiptare Sh.a) & & & & & \\
\hline & Letters accepted & no & 301300 & 2640880 & 2756270 & 1690906 & 1636207 \\
\hline & b. total number of postal objects & no & 338593 & 2791104 & 3010866 & 3539265 & 4418838 \\
\hline & c. number of postal offices & no & 504 & 446 & 494 & 541 & 535 \\
\hline & d. number of general counters & no & 150 & 200 & 350 & 430 & 650 \\
\hline e. number of financial services provided & no & 5 & 8 & 8 & 12 & 19 \\
\hline & f. number of objects accepted & no & 57510 & 193377 & 247201 & 266421 & 1088720 \\
\hline & g. number of payments & no & 322 & 213631 & 528357 & 1475103 & 2466086 \\
\hline & & & & & & \\
\hline 2 & All the other providers & & & & & & \\
\hline & a. Letters accepted & no & & & & 93900 & \\
\hline & b. Goods accepted & no & & & & & \\
\hline & c. Number of licenses for liberalized services & no & & & & & 6 \\
\hline
\end{tabular}


ANNEX 3: MONITORING INDICATORS IDENTIFIED BY THE MINISTRIES

TABLE 12: MINISTRY OF AGRICULTURE AND FOOD 
ANNEX 3: MONITORING INDICATORS IDENTIFIED BY THE MINISTRIES

TABLE 12: MINISTRY OF AGRICULTURE AND FOOD

\begin{tabular}{|c|c|c|c|c|c|c|}
\hline \multirow{2}{*}{ No. } & \multirow{2}{*}{ Ref. } & \multirow{2}{*}{ Indicators } & \multicolumn{4}{|c|}{ Indicators Progress } \\
\hline & & & Unit & 2000 & 2001 & 2002 \\
\hline 1 & 2.A & Investments in irrigation and drainage rehabilitation & USD & 4.698 .537 & 5.788 .303 & 8.744 .786 \\
\hline 2 & $3.1 \mathrm{~A}$ & Mechanization level (number of tractors) & number & 7187 & 6947 & 8250 \\
\hline 3 & $3.1 \mathrm{~A}$ & $\begin{array}{l}\text { Quantity of inputs used (in tons) } \\
\text { Fertiliser } \\
\text { Pesticides }\end{array}$ & $\begin{array}{l}\text { ton } \\
\text { ton } \\
\text { ton }\end{array}$ & $\begin{array}{l}118010 \\
117900 \\
110\end{array}$ & $\begin{array}{l}113498 \\
113400 \\
98\end{array}$ & $\begin{array}{l}184232 \\
184126 \\
106\end{array}$ \\
\hline 4 & $3.4 \mathrm{~A}$ & Number of licensed subjects cultivating saplings & number & 45 & 50 & 61 \\
\hline 5 & $4.1 \mathrm{~A}$ & Number of Artificial Livestock Insemination Centers & number & 370 & 420 & 440 \\
\hline 6 & $4.1 \mathrm{~A}$ & Increase in quantity of animal products & ton & 19000 & 25000 & 40000 \\
\hline 7 & $4.1 \mathrm{~A}$ & Live-stock farms (more than 5 heads) & number & 584 & 722 & 850 \\
\hline 8 & $4.2 \mathrm{~A}$ & Number of information centers & number & 0 & 0 & 32 \\
\hline 9 & $5.2 \mathrm{~A}$ & Number of Credit- Savings Associations & number & - & 59 & 88 \\
\hline 10 & $1.1 \mathrm{~B}$ & Number of new technology lines & number & 13 & 24 & 22 \\
\hline 11 & $1.3 \mathrm{~B}$ & Number of grants for technology lines (PSHB) & number & 0 & 0 & 4 \\
\hline 12 & $1.4 \mathrm{~B}$ & Total investments in the agricultural industry & thousand ALL & 897960 & 1020532 & 1020800 \\
\hline
\end{tabular}


ANNEX 3: MONITORING INDICATORS IDENTIFIED BY THE MINISTRIES

TABLE 2 A PROCESS INDICATORS PROGRESS 
ANNEX 3: MONITORING INDICATORS IDENTIFIED BY THE MINISTRIES

TABLE 2 A PROCESS INDICATORS PROGRESS

\begin{tabular}{|c|c|c|c|c|c|c|}
\hline \multirow{2}{*}{ No. } & \multirow{2}{*}{ Ref. } & \multirow{2}{*}{ Indicators } & \multicolumn{4}{|c|}{ Indicators Progress } \\
\hline & & & Unit & 2000 & 2001 & 2002 \\
\hline 1 & $2.5 \mathrm{~A}$ & $\begin{array}{l}\text { Surface Area to Irrigation Utilization Associations \& Irrigation } \\
\text { Utilization Federations }\end{array}$ & ha & 127893 & 130073 & 166214 \\
\hline 2 & $3.3 \mathrm{~A}$ & Quantity of saplings tested and equipped with warranty certificates & thousand plants & 300 & 330 & 420 \\
\hline 3 & $3.8 \mathrm{~A}$ & $\begin{array}{l}\text { Number of identified veterinary diseases } \\
\text { Mad Cow } \\
\text { Tuberculosis } \\
\text { Brucellosis }\end{array}$ & $\begin{array}{l}\text { heads (cattle) } \\
\text { number } \\
\text { number } \\
\text { number }\end{array}$ & $\begin{array}{l}11134 \\
248 \\
598 \\
10288 \\
\end{array}$ & $\begin{array}{l}5358 \\
161 \\
523 \\
4674 \\
\end{array}$ & $\begin{array}{l}8177 \\
158 \\
391 \\
7628 \\
\end{array}$ \\
\hline 4 & $3.8 \mathrm{~A}$ & $\begin{array}{l}\text { Number of tracked animals } \\
\text { Tuberculosis } \\
\text { Brucellosis }\end{array}$ & $\begin{array}{l}\text { heads (cattle ) } \\
\text { number } \\
\text { number }\end{array}$ & $\begin{array}{l}1720603 \\
232603 \\
1488000\end{array}$ & $\begin{array}{l}1184500 \\
220000 \\
964500\end{array}$ & $\begin{array}{l}1195193 \\
174585 \\
1020608\end{array}$ \\
\hline 5 & $3.8 \mathrm{~A}$ & $\begin{array}{l}\text { Number of vaccinated animals } \\
\text { Mad Cow }\end{array}$ & $\begin{array}{l}\text { heads (cattle } \\
\text { \&sheep) } \\
\text { number }\end{array}$ & 1785085 & 1584000 & 1650529 \\
\hline 6 & $3.8 \mathrm{~A}$ & $\begin{array}{l}\text { Number of destroyed animals } \\
\text { Tuberculosis } \\
\text { Brucellosis }\end{array}$ & $\begin{array}{l}\text { heads (cattle) } \\
\text { number } \\
\text { number }\end{array}$ & $\begin{array}{l}7748 \\
234 \\
7514\end{array}$ & $\begin{array}{l}3892 \\
192 \\
3700\end{array}$ & $\begin{array}{l}6609 \\
190 \\
6419\end{array}$ \\
\hline 7 & $6.7 \mathrm{~A}$ & Number of ports under rehabilitation & number & 0 & 0 & 2 \\
\hline 8 & $1.4 \mathrm{C}$ & Number of observed markets & number & 3 & 3 & 5 \\
\hline 9 & $2.1 \mathrm{C}$ & Number of tests carried out in the regional test labs & number & 32117 & 33237 & 35094 \\
\hline 11 & $1 . \mathrm{A}$ & Number of purchase transactions & number & 3542 & 3167 & 3500 \\
\hline 12 & $1.1 \mathrm{~A}$ & Number of land administration offices established at the regional level & number & 0 & 0 & 12 \\
\hline 13 & $6.3 \mathrm{~A}$ & Number of licenses issued for reservoir utilization & number & 68 & 80 & 106 \\
\hline
\end{tabular}

